\title{
REPTILIAN FAUNAS OF THE TORREJON, PUERCO, AND UNDERLYING UPPER CRETACEOUS FORMATIONS OF SAN JUAN COUNTY, NEW MEXICO
} \\ BY \\ CHARLES W. GILMORE
}

WASHINGTON

GOVERNMENT PRINTING OFFICE 



\section{DEPARTMENT OF THE INTERIOR}

FrankLin K. LANE, Secretary

United States Geological SuRvey

George Otis Smith, Director

\section{Professional Paper 119}

\section{REPTILIAN FAUNAS OF THE TORREJON, PUERCO, AND UNDERLYING UPPER CRETACEOUS FORMATIONS OF SAN JUAN COUNTY, NEW NEXICO}

- CHARLES W. GILMORE

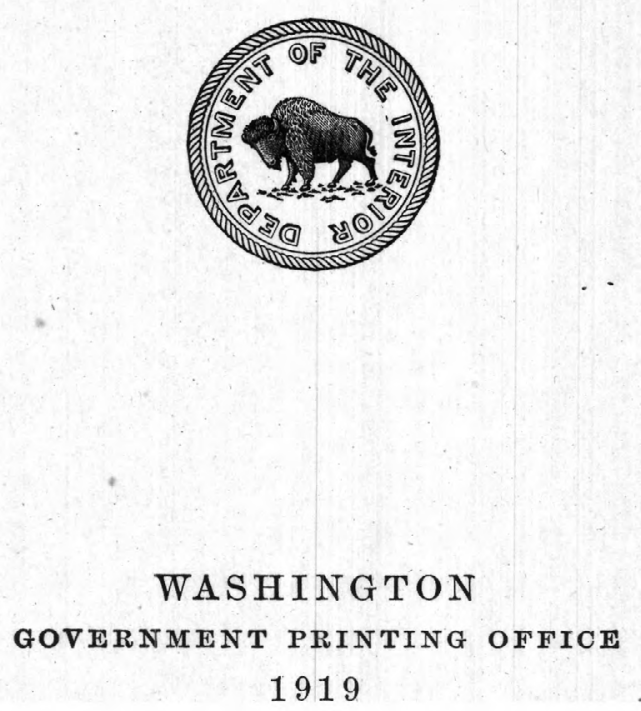


ADDITIONAL COPIES

OF THIS PUBLICATION MAY BE PROCURED FROM

THE SUPERINTENDENT OF DOCUMENTS

GOVERNMENT PRINTING OFFICE

WASHINGTON, D. C.

40 CENTS PER COPY 


\section{CONTENTS.}

The reptilian faunas of the Upper Cretaceous and basal Eocene formations of the San Juan Basin........... 7

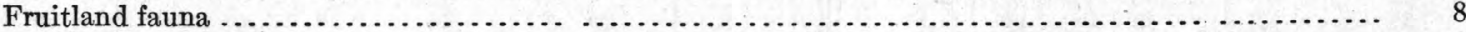

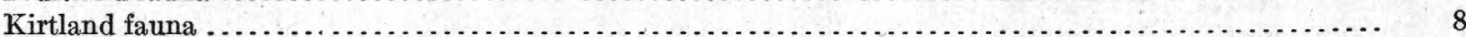

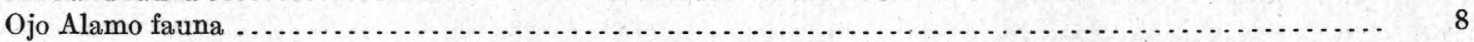

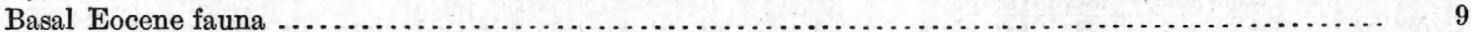

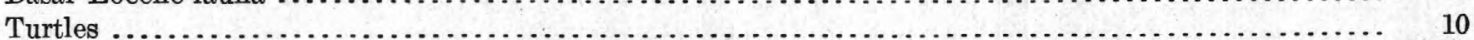

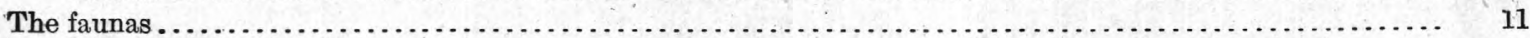

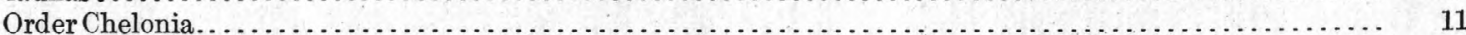

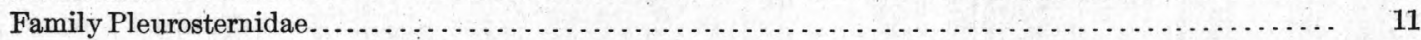

Genus Neurankylus Lambe ..................................................... 11

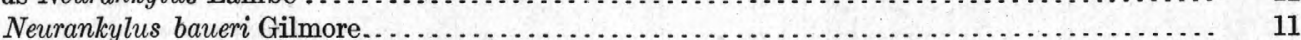

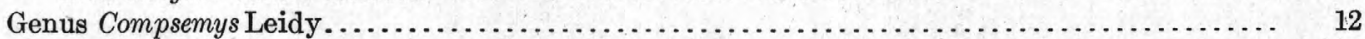

Compsemys parva Hay. .................................................. 13

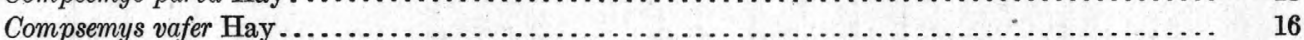

Compsemys puercensis Gilmore, n. sp..................................... 19

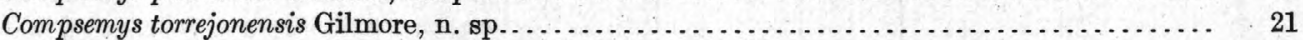

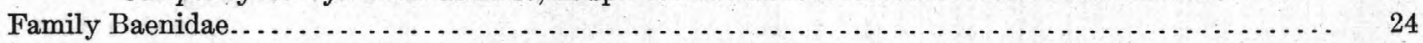

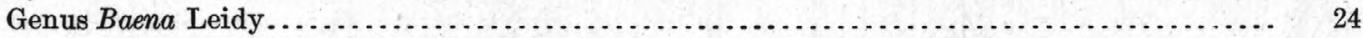

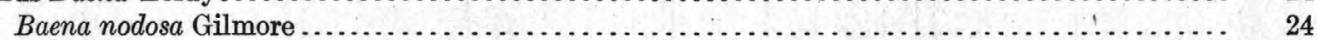

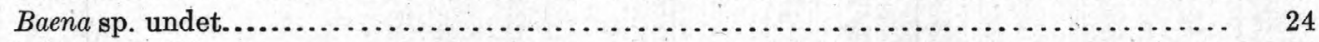

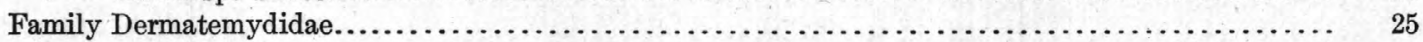

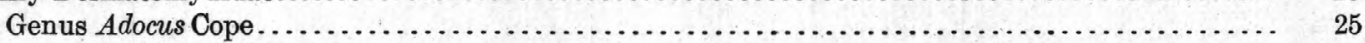

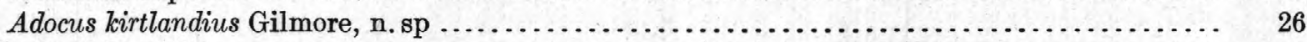

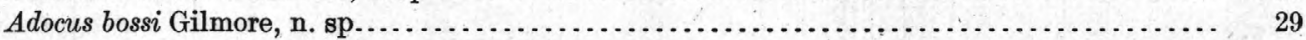

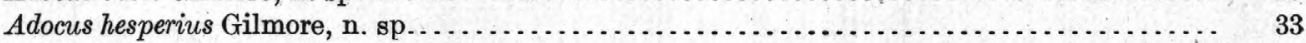

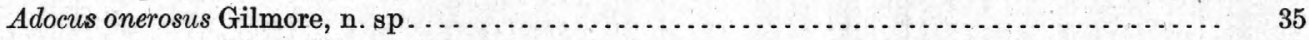

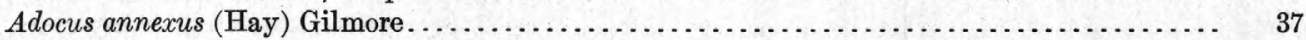

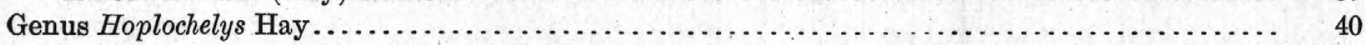

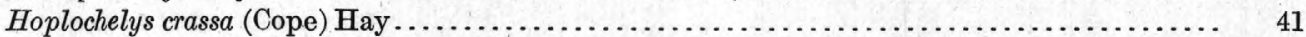

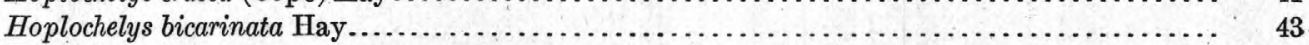

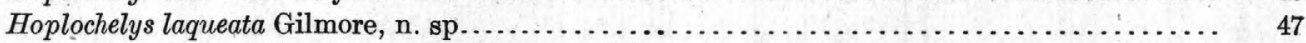

Hoplochelys saliens Hay .............................................. 49

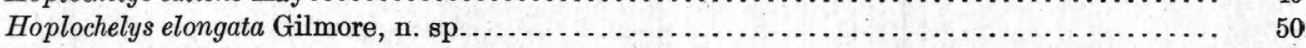

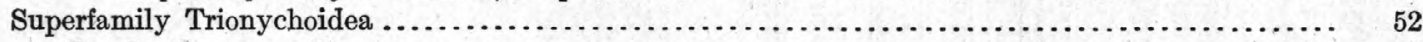

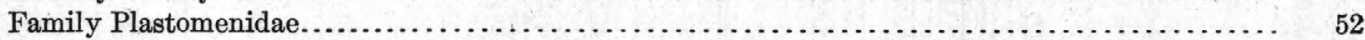

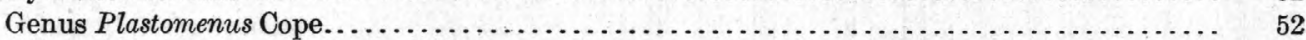

Plastomenus robustus Gilmore, n. sp ................................. 53

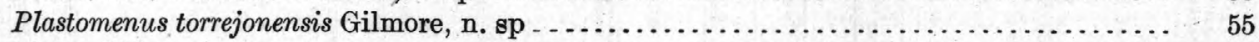

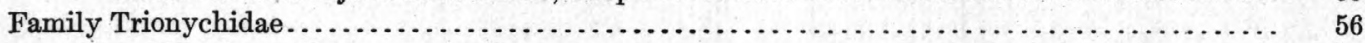

Genus Aspideretes Hay . . . . . . . . . . . . . . . . . .

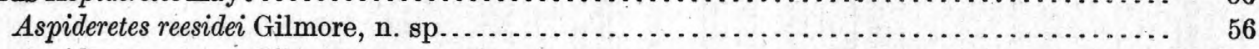

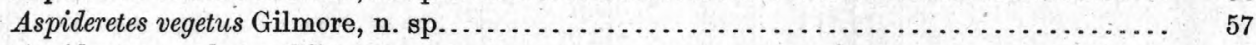

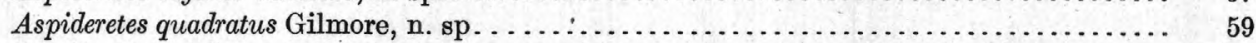

Aspideretes perplexus Gilmore, n. sp................................... 60

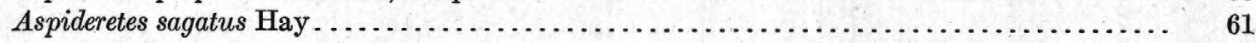

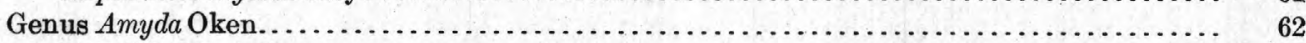

Amyda eloisae Gilmore, n. sp......................................... 63 
The faunas-Continued. Page.

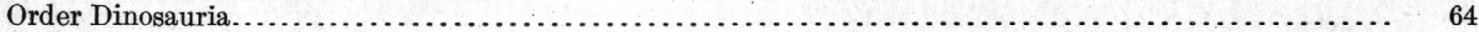

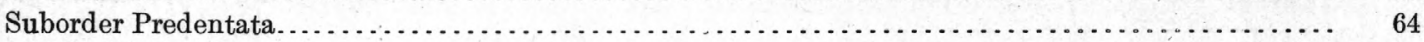

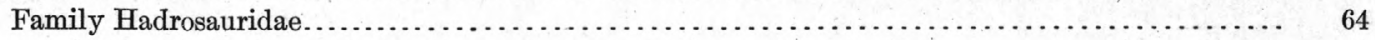

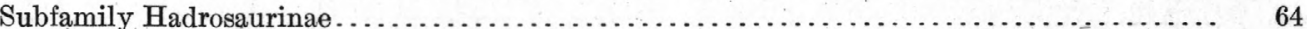

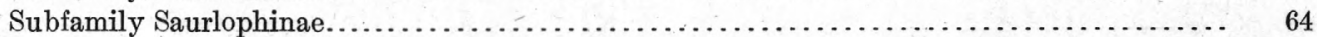

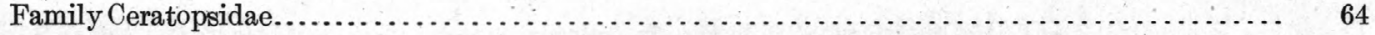

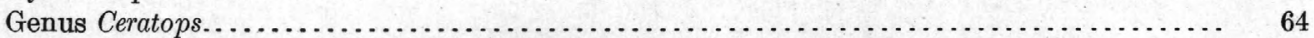

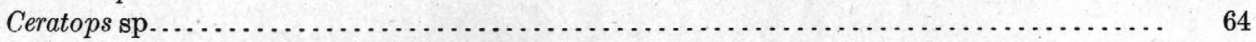

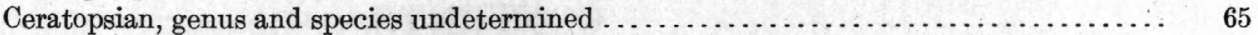

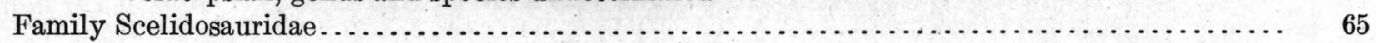

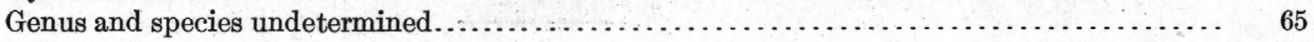

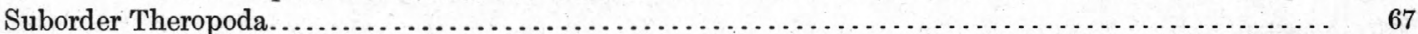

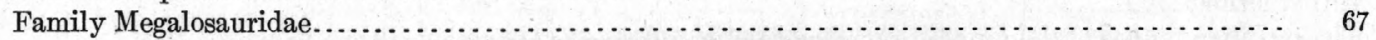

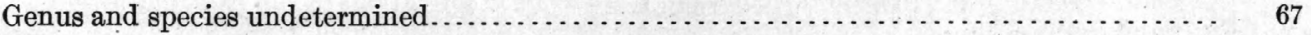

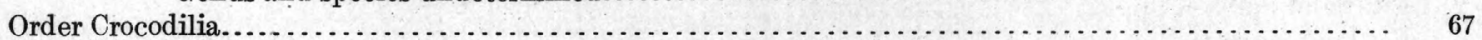

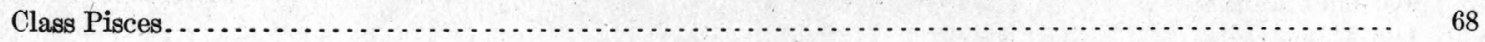

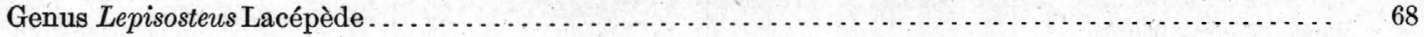

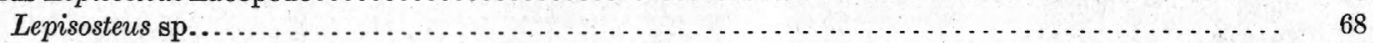

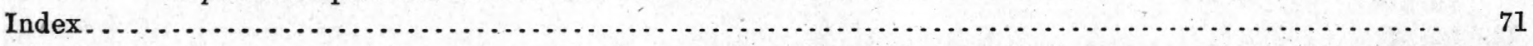




\section{ILLUSTRATIONS.}

Plates I-XXVI. Fossil reptiles from San Juan County, N. Mex

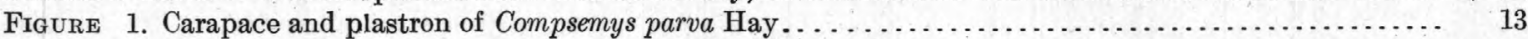

2. Carapace and plastron of Compsemys vafer Hay................................... 17

3. Carapace and plastron of Compsemys puercensis Gilmore, n. sp........................ 19

4. Comparative view of plastra: A, Compsemys torrejonensis; B, Compsemys puercensis; C, Compsemys

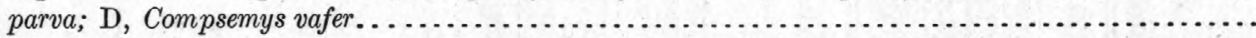

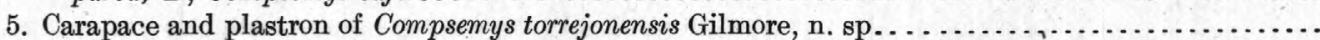

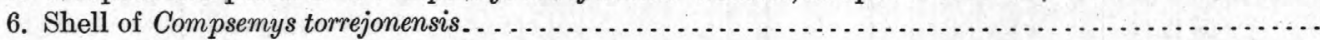

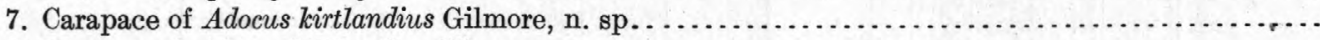

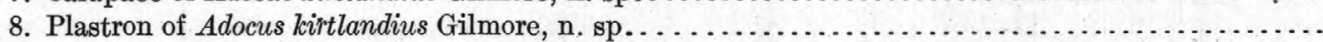

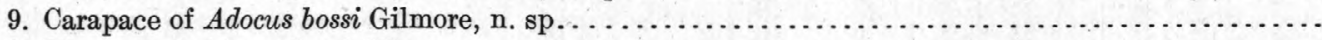

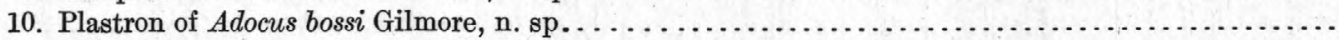

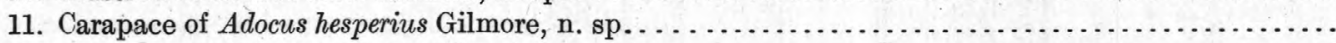

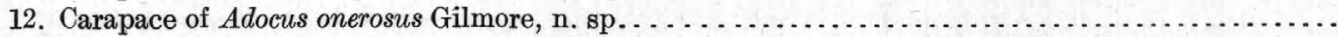

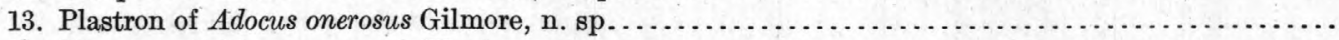

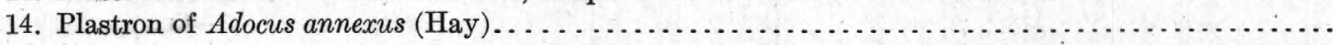

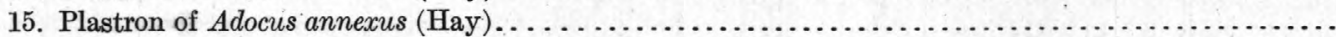

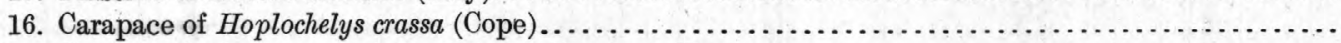

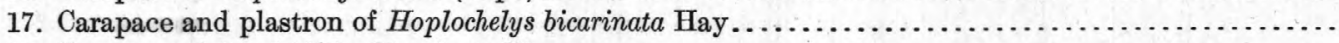

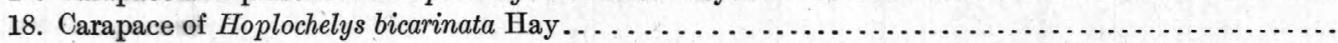

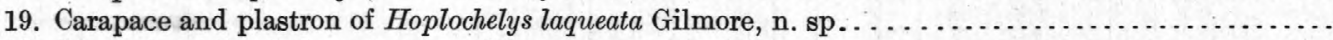

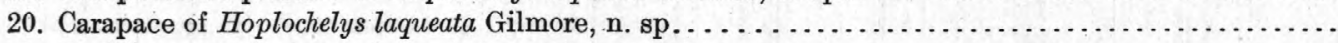

21. Carapace and plastron of Hoplochelys elongata Gilmore, n. sp. . . . . . . . . . . . . . . . . .

22. Carapace of Hoplochelys elongata Gilmore, n. sp. . . . . . . . . . . . . . . . . . . . . . . . .

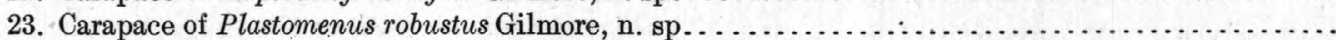

24. Plastral bones of Plastomenys robustus Gilmore, n. sp. . . . . . . . . . . . . . . . . . . . . . . . . .

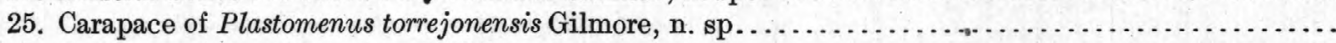

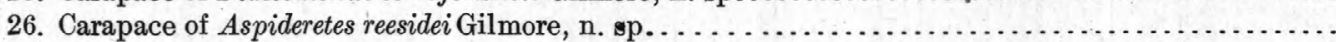

27. Carapace of Aspideretes vegetus Gilmore, n. sp. . . . . . . . . . . . . . . . . . . . . . . .

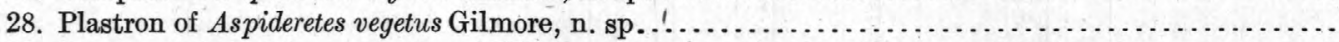

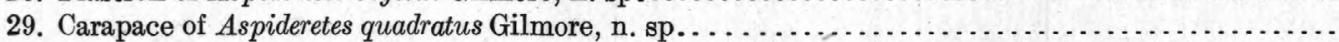

30. Carapace of Aspideretes perplexus Gilmore, n. sp. . . . . . . . . . . . . . . . . . . . . . . . . . .

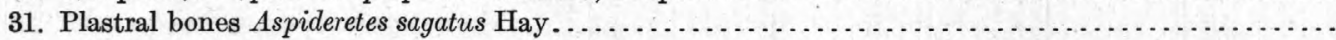

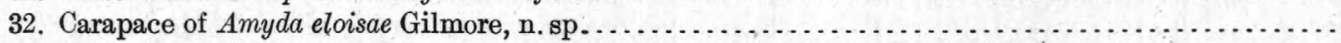

33. Skin plates of an armored dinosaur. . . . . . . . . . . . . . . . 



\title{
REPTILIAN FAUNAS OF THE TORREJON, PUERC0, AND UNDERLYING UPPEK CRETACEOUS FORMATIONS OF SAN JUAN COUNTY, NEW MEXICO.
}

\author{
By Charles W. Gilmore. ${ }^{1}$
}

\section{INTRODUCTION:}

The present paper, which in some respects is supplementary to another recent one on the same region, ${ }^{2}$ is based on a series of vertebrate remains collected during the field season of 1916 for the United States Geological Survey by J. B. Reeside, jr., and F. R. Clark. Specimens were collected at several horizons in the Puerco, Torrejon, Ojo Alamo, Kirtland, and Fruitland formations at many localities in San Juan County, N. Mex. This collection is especially rich in turtle remains. In the number of specimens and the excellent state of their preservation it forms the best single collection of fossil turtles that has ever been made in the southwestern United States, and Mr. Reeside and Mr. Clark are to be highly commended for the industry and skill they displayed in bringing it together.

The recovery of nearly perfect individuals pertaining to Compsemys, Hoplochelys, and Adocus-genera which, prior to this time, were known only from very fragmentary materialsforms a distinct contribution to our knowledge of the skeletal anatomy of these extinct turtles. Furthermore, the presence in the collection of good specimens representing species of the same genera from successive geologic formations is of the greatest interest for study of the structural changes that may have taken place in a genus over considerable periods of time.

Sixteen new species of extinct turtles are described in the present paper, the greater number of which pertain to the Puerco and Torrejon formations. The faunas of the San Juan area are yet but imperfectly known, and

\footnotetext{
${ }^{1}$ Associate curator of the division of paleontology, U. S. National Museum.

2 Gilmore, C. W., Vertebrate faunas of the Ojo Alamo, Kirtland, and Fruitland formations: U. S. Geol. Survey Prof. Paper 98, pp. 279-308 1916.
}

the region is by no means exhausted. Careful collecting is certain to yield many new forms and more perfect specimens of others now imperfectly known.

The recovery of additional though incomplete dinosaur specimens from the Upper Cretaceous formations is of interest as showing the presence of forms other than those reported in my paper of $1916 .^{3}$ Some of these specimens give corroborative evidence bearing on the earlier conclusion that the formations from which they came is of Montana age.

I take this opportunity to acknowledge my indebtedness to Dr. W. D. Matthew, of the American Museum of Natural History, New York, for the loan of type specimens. I am especially under obligations to Dr. O. P. Hay for invaluable advice and assistance on numerous occasions, and to Messrs. N. H. Boss and Louis Goldberg, preparator and assistant preparator in the section of vertebrate paleontology, United States National Museum, for their efficient work in preparing for study the specimens forming this collection.

\section{THE REPTILIAN FAUNAS OF THE UPPER CRE- TACEOUS AND BASAL EOCENE FORMATIONS OF THE SAN JUAN BASIN.}

The vertebrate faunas of the Ojo Alamo, Kirtland, and Fruitland formations were so fully reviewed in the paper already cited that at present it seems necessary only to record the additional information obtained from a study of the specimens procured by the Reeside expedition during the summer of 1916.

The reptilian faunas of the Puerco and Torrejon formations, however, are reviewed at somewhat greater length, not only on account of their apparent neglect for many years, but 3 Gilmore, C. W., op. cit., p. 280. 
also because of the notable contribution to our knowledge of those faunas furnished by specimens in this collection.

Beginning with the Fruitland, the oldest formation from which vertebrate fossils were obtained in this area, these faunas are discussed successively below in the order in which they occur in the geologic section.

\section{FRUITLAND FAUNA.}

The list of extinct turtles in the Fruitland formation is increased by the discovery of a member of the family Baenidae, provisionally identified as Baena nodosa? Gilmore, a species founded on a specimen from the Kirtland formation. In the published ${ }^{1}$ faunal list of the Fruitland formation, ${ }^{1}$ Adocus? Tineolatus Cope was included. The identification of this species rested on a peripheral bone having a sculpture indistinguishable from the type of the species. Materials in the present collection show that the character of the sculpture can not be depended on for specific determinations in the genus Adocus, and in the revised list below the species name is dropped. Likewise the interrogation mark following the generic name is no longer used, for the discovery of well-preserved specimens shows that the genus is present in this formation.

\section{Fruitland formation: \\ Dinosauria:}

Monoclonius?

Carnivorous dinosaur.

Chelonia:

Adocus sp.

Aspideretes sp.

Pisces: Baena nodosa? Gilmore.

Lepisosteus sp.

\section{KIRTLAND FAUNA.}

Vertebrate fossils appear to occur most abundantly in the upper part of the Kirtland formation and sparsely in and below the Farmington sandstone member.

In the present collection there are three new species of turtles from this formation, though the genera to which they pertain have all been previously recognized. Fragmentary specimens show the presence of other unrecognized and probably undescribed species.

The dinosaurian remains, though incomplete specimens, are of importance because they

\footnotetext{
${ }_{1}^{1}$ Gilmore, C. W., op. eit., p. 280.
}

furnish cerroborative evidence in support of the former contention that the Kirtland formation is of Montana age. This evidence consists in the presence of individuals of the horned Dinosauria or Ceratopsia provisionally identified as belonging to the genus Ceratops, for, regardless of the uncertainty of the generic identification, these specimens show a stage of development reached only in the Judith River and Belly River ceratopsians.

Additional evidence along the same line is afforded by the duck-billed or trachodont specimens in the collection-for example, the trachodont ischia of the footed and nonfooted kinds, which indicate the crested and noncrested types of skulls. The crested trachodonts, a type of development not known to occur in beds later than the Edmonton, are now first recognized in this formation. Trachodont dentaries in the collection showing a reduced number of rows of teeth as compared with those from the Lance formation also indicate a greater antiquity for these forms. The revised faunal list as known at this time is given below.

Kirtland formation:

Dinosauria:

Kritosaurus navajovius Brown.

Crested trachodonts.

Carnivorous dinosaurs.

Ceratops? sp.

Armored dinosaur (Scelidosauridae).

Chelonia:

Baena nodosa Gilmore.

Baena sp.

Neurankylus baueri Gilmore.

Adocus bossi Gilmore, n. sp.

Adocus kirtlandius Gilmore, n. sp.

Plastomenus robustus Gilmore, n. sp.

Plastomenus sp.

Aspideretes sp.

Crocodilia:

Crocodylus sp.

Brachychampsa ep.

Pisces:

Lepisosteus sp.

Myledaphus sp.

OJO ALAMO FAUNA.

The faunal list of the Ojo Alamo formation is increased by the discovery of a few bones of an armored dinosaur, the first to be recorded from this formation. Although the remains are too scanty for close identification, their nearest affinities are unquestionably with those members of this group found in the 
more ancient formations rather than with Ankylosaurus of the Lance formation.

Ojo Alamo formation:

Dinosauria:

Kritosaurus navajovius Brown.

Monoclonius sp.

Armored dinosaur.

Deinodon?

Chelonia:

Basilemys nobilis Hay.

Adocus vigoratus Hay.

Aspideretes vorax Hay.

Aspideretes fontanus Hay.

Aspideretes austerus Hay.

Thescelus rapiens Hay.

Compsemys sp.

Crocodilia:

Pisces:

Crocodylus sp.

Lepisosteus sp.

\section{BASAL EOCENE FAUNA.}

All the described reptiles of the Puerco and Torrejon formations have been made known by the work of two paleontologists. Prof. E. D. Cope described the first materials, founding several species of the aquatic lizard Champsosaurus and one species each of a turtle, a snake, and a crocodile. Unfortunately all the species were founded on scanty and in part inadequate materials. In recent years Dr. O. P. Hay has added a considerable number to the known species of turtles.

The present collection of reptile remains furnishes the most important single contribution ever made to our knowledge of these reptilian faunas. No less than 11 new species of turtles are recognized, in addition to the several described forms represented by specimens so well preserved that now all the important features of the shells can be fully determined. Representatives of two families, the Pleurosternidae and Plastomenidae, each represented by two or more species, are recognized for the first time in these faunas.

W. D. Matthew, ${ }^{1}$ who has published the only complete faunal list of recent years, sums up the reptilian part of the basal Eocene fauna as follows:

The reptiles are chiefly Chelonia, Crocodilia, and Choristodera. One snake has been recorded; lizards were

1 Matthew, W. D., Evidence of the Paleocene vertebrate fauna on the Cretaceous-Tertiary problem: Geol. Soc. America Bull., vol. 25, p. 383, 1914. present. *** The reptiles all belong to families that originated in the Cretaceous (Belly River) or earlier. Three of the families still survive; one disappeared with the Eocene, another with the Paleocene.

The mammalian faunas of the Puerco and Torrejon have been studied from large collections, and the distinctness of the two faunas has been clearly demonstrated through the excellent work of Dr. Matthew and his associates in the American Museum of Natural History, New York.

In recent years the reptilian part of these faunas has been almost entirely neglected by paleontologists, so that the excellent materials in the present collection, which add greatly to the knowledge of described forms based on fragmentary specimens and furnish a considerable number of new species, lay the foundation of faunal lists that will eventually be valuable adjuncts to the mammalian evidence as horizon indicators.

So far as known at present, while all the reptilian families and most of the genera passed through from the Puerco to the Torrejon, very few species survived from one to the other, and the few occurrences recorded may be due to incorrect identification.

The large aquatic lizard Champsosaurus, the many turtles, all of which are marsh and river varieties, and the single snake, which Osborn ${ }^{2}$ says " is unspecialized in character and of about the size of the common black snake," all indicate the lowland nature of their habitat.

The complete faunal list of the known reptiles of the Puerco and Torrejon formations is given below:

Puerco forniation:

Chelonia:

Family Pleurosternidae: Compsemys parva Hay. Compsemys vafer Hay. Compsemys puercensis Gilmore, $\mathbf{n}$. sp.

Family Baenidae: Baena sp.

Family Dermatemydidae: Adocus hesperius Gilmore, n. sp. Hoplochelys crassa (Cope). Hoplochelys bicarinata Hay. Hoplochelys laqueata Gilmore, n. sp.

Family Plastomenidae: Plastomenus sp.

2 Osborn, H. F., The age of mammals, p. 106, 1910. 
Puerco formation-Continued.

Chelonia-Continued.

Family Trionychidae:

Aspideretes ragatus Hay.

Aspideretes puercensis Hay.

Aspideretes reesidei Gilmore, $\mathbf{n}$. sp.

Aspideretes vegetus Gilmore, n. sp.

Aspideretes quadratus Gilmore, n. sp.

Aspideretes perplexus Gilmore, n. sp.

Conchochelys admirabilis Hay.

Rhynchocephalia:

Family Champsosauridae:

Champsosaurus australis Cope.

Loricata:

Champsosaurus saponensis Cope.

Family Crocodylidae: Pisces:

Crocodylus stavelianus Cope.

Family Lepisosteidae:

Lepisosteus sp.

Torrejon formation:

Chelonia:

Family Pleurosternidae: Compsemys torrejonensis Gilmore, n. sp. Compsemys parva? Hay.

Family Baenidae:

Baena escavada Hay.

Baena sp.

Family Dermatemydidae:

Adocus substrictus (Hay).

Adocus onerosus Gilmore, n. sp.

Adocus annexus (Hay).

Hoplochelys saliens Hay.

Hoplocheleys paludosa Hay.

Hoplochelys elongata Gilmore, n. sp.

Family Plastomenidae:

Plastomenus acupictus Hay.

Plastomenus n. sp.?

Plastomenus sp. undet.

Family Trionychidae:

Aspideretes singularis Hay.

Aspideretes sp.

Platypeltis antiqua Hay.

Amyda eloisae Gilmore, n. sp.

Serpentes:

Helagras prisciformis Cope.

Rhynchocephalia:

Family Champsosauridae:

Champsosaurus puercensis Cope.

Champsosaurus saponensis Cope.

Loricata:

Family Crocodylidae: Crocodylus ep.

Pisces:

Family Lepisosteidae:

Lepisosteus sp.
TURTLES.

Identified turtle specimens collected by $J . B$. Reeside in San Juan County, N. Mex., 1916.

\begin{tabular}{|c|c|c|}
\hline $\begin{array}{c}\text { U. S. } \\
\text { N. M. } \\
\text { cata- } \\
\text { logue } \\
\text { No. }\end{array}$ & Name. & Formation. \\
\hline 8621 & Neurankylus baueri Gilmore....... & Kirtland. \\
\hline 8531 & 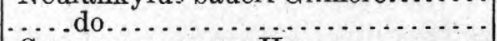 & Do. \\
\hline 8528 & Compsemys parva Hay.......... & Puerco. \\
\hline 8598 & Compsemys parva? Hay........... & Torrejon. \\
\hline 8529 & Compsemys vafer Hay............... & Puerco. \\
\hline 8530 & 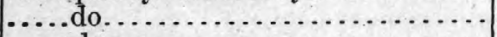 & Do. \\
\hline 8600 & 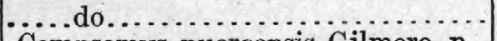 & Do. \\
\hline 8544 & $\begin{array}{l}\text { Compsemys puercensis Gilmore, } \mathbf{n} \text {. } \\
\text { sp. }\end{array}$ & Do. \\
\hline 8549 & $\begin{array}{l}\text { Compsemys torrejonensis Gilmore, } \\
\text { n. sp. }\end{array}$ & Torrejon. \\
\hline 8597 & $\ldots \ldots$ do $\ldots \ldots \ldots \ldots \ldots \ldots \ldots \ldots \ldots$ & Do. \\
\hline 8599 & 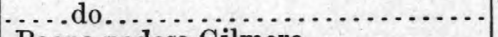 & Do. \\
\hline 8603 & Baena nodosa Gilmore. ........... & Kirtland. \\
\hline 8622 & ....do.................... & Do. - \\
\hline 8614 & . do.......................... & Do. \\
\hline 8840 & Baena escavada? Hay............ & Torrejon. \\
\hline 8623 & 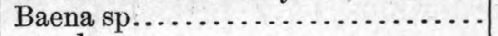 & Kirtland. \\
\hline 8624 & . do do. $_{\text {. }}$ & Do. \\
\hline 8577 & Adocus bossi Gilmore, n. sp........ & Do. \\
\hline 8613 & 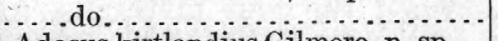 & Do. \\
\hline 8593 & Adocus kirtlandius Gilmore, n. sp... & Do. \\
\hline 8596 & Adocus hesperius Gilmore, n. sp..... & Puerco. \\
\hline 8594 & Adocus onerosus Gilmore, n. sp...... & Torrejon. \\
\hline 8649 & 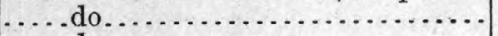 & Do. \\
\hline 8650 & 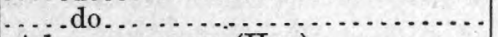 & Do. \\
\hline 8606 & Adocus annexus (Hay) ............ & Do. \\
\hline 8651 & 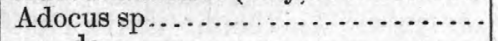 & Do. \\
\hline 8654 & 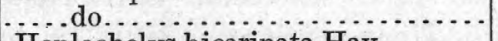 & Kirtland: \\
\hline 8524 & Hoplochelys bicarinata Hay........ & Puerco. \\
\hline 8526 & $\ldots$ do $\ldots \ldots$. . . . & Do. \\
\hline 8525 & Hoplochelys crassa (Cope)........ & Do. \\
\hline 8641 & 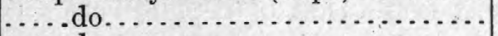 & Do. \\
\hline 8643 & 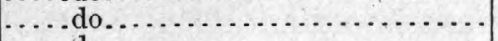 & Do. \\
\hline 8607 & 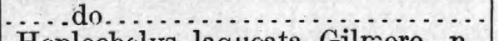 & Do. \\
\hline 8527 & Hoplochelys laqueata Gilmore, n. & Do. \\
\hline 8553 & Hoplechelys elongata Gilmore, n. sp. & Torrejon. \\
\hline 8608 & 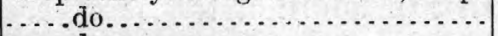 & Do. \\
\hline 8609 & 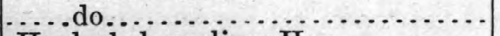 & Do. \\
\hline 8605 & Hoplochelys saliens Hay.......... & $D_{0}$ \\
\hline 8646 & 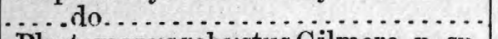 & \\
\hline 8538 & Plastomenus robustus Gilmore, $\mathrm{n} . \mathrm{sp}$. & Kirtland. \\
\hline 8543 & $\begin{array}{l}\text { Plastomenus torrjennensis Gilmore, } \\
\text { n. sp. }\end{array}$ & Torrejon. \\
\hline 8653 & Plastomenus sp. . . . . . . . . . . . & Do. \\
\hline 8532 & $\begin{array}{l}\text { Aspideretes perplexus Gilmore, } n \text {. } \\
\text { sp. }\end{array}$ & Puerco. \\
\hline 8537 & Aspideretes reesidei Gilmore, n. sp. . & Do. \\
\hline 8539 & Aspideretes vegetus Gilmore, n. sp. . & Do. \\
\hline 8545 & Aspideretes quadratus Gilmore, n. sp & $\pi 7^{8}$ \\
\hline 8554 & Aspideretes sagatus Hay........... & Torrejon. \\
\hline 8652 & Aspideretes sagatus? Hay.......... & Do. \\
\hline 8555 & 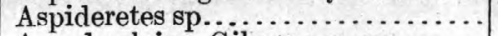 & Do. \\
\hline 8540 & Amyda eloisea Gilmore, и. вр...... & Puerco. \\
\hline
\end{tabular}


THE FAUNAS.

Order CHELONIA.

Turtle remains belonging to five familiesthe Pleurosternidae, Baenidae, Dermatemydidae, Plastomenidae, and Trionychidae-have been recognized in the present collection. These specimens pertain to 8 genera and 24 species. Sixteen of these are described as new, 11 of which come from the basal Eocene deposits of the San Juan Basin. That there are other undescribed forms is indicated by fragmentary specimens in this collection, but these are regarded as inadequate type material on which to found new species.

In studying this collection of extinct turtles, much difficulty has been experienced in determining the exact characters which distinguish certain described species. For most species it has entailed a considerable search through the descriptive text and long study and comparison. At the present time more than 300 species of extinct turtles from North America have been described, and rarely has the describer of any particular species given or attempted to give a concise synopsis of the specific characters which distinguish that species. In order to correct this deficiency I have noted at the end of the description of each species in the present paper the group of characters which in my judgment indicates its specific distinctness. I am satisfied that when more and better materials are available, many of the characters thus selected will be found to represent individual rather than specific differences. However that may be, this plan has the very great advantage of making immediately available to later students the characters on which the author founded the species, and it establishes a definition which may, as our knowledge grows, be revised from time to time, so that ultimately it will become an accurate specific diagnosis.

\section{Family PLEUROSTERNIDAE Cope.}

The family Pleurosternidae at the time Hay published his "Fossil turtles of North America," in 1908, contained the single American genus Glyptops. In 1916 the study of excellent material showed the Upper Cretaceous genus $\mathrm{Neu}$ rankylus to be a member of this family. ${ }^{1}$

1 Gilmore, C. W., Vertebrate faunas of the Ojo Alamo, Kirtland, and Fruitland formations: U. S. Geol. Survey Prof. Paper 98, p. 290, 1916.
After a study of several well-preserved specimens in the present collection pertaining to the genus Compsemys I conclude that its affinities also, are with the Pleurosternidae rather than with the Baenidae as proposed by Hay. ${ }^{2}$ The Pleurosternidae therefore now include the three genera Glyptops, Neurankylus, and Compsemys.

\section{Genus NEURANKYLUS Lambe, 1902.}

\section{Neurankylus baueri Gilmore.}

Neurankylus baueri Gilmore, Vertebrate faunas of the Ojo Alamo, Kirtland, and Fruitland formations: U. S. Geol. Survey Prof. Paper 98, pp. 290-293, pls. 74 and 75 , text figs. $32,33,1916$.

A very large individual in the present collection, consisting of the greater part of the carapace and plastron (catalogue No. 8531, U.S. N. M.), is identified as belonging to Neurankylus baueri. The specimen was collected $2 \frac{3}{4}$ miles south of west of Kimbetoh, in sec. 3, T. 22 N., R. 10 W., San Juan County, N. Mex., 330 feet above the base of the Kirtland formation.

The chief importance of this specimen lies in its being the second individual of the species to be found and that it records a new geographic occurrence of this species. Its geologic position appears to be about the same as that of the type. It is considerably larger than the type specimen and has a relatively wider posterior lobe at its extremity with a broader truncated end and five costal scutes (the fourth divided), but it closely resembles the type in most other particulars. Some of the principal measurements as compared with those of the type specimen are given below.

Dimensions of Neurankylus baueri, in millimeters.

\begin{tabular}{|c|c|c|}
\hline & $\begin{array}{l}\text { No. } \\
8531 .\end{array}$ & $\begin{array}{c}\text { No. } \\
8344 \\
\text { (type). }\end{array}$ \\
\hline Greatest length of carapace. & 635 & 560 \\
\hline Greatest width of carapace. & 530 & 480 \\
\hline Greatest length of plastron. . & 449 & 416 \\
\hline Length of anterior lobe........ & 119 & 111 \\
\hline Width of anterior lobe at base.. & 182 & 168 \\
\hline Length of posterior lobe..... . & 126 & 122 \\
\hline Width of posterior lobe at base............. & 203 & 185 \\
\hline Width of posterior lobe at anal-femoral sulcus. & 142 & 113 \\
\hline Width of bridge. $\ldots \ldots \ldots \ldots \ldots \ldots \ldots \ldots$ & 208 & 195 \\
\hline
\end{tabular}

2 Hay, O. P., Descriptions of eight new species of fossil turtles from west of the one hundredth meridian: U. S. Nat. Mus. Proc., vol. 38, p. 308, 1910. 
A second specimen (No. 8621, U. S. N. M.), consisting of a portion of the posterior end of the carapace, is identified as belonging to this genus, but I am uncertain as to its specific identification. On the median posterior margin the edge is rounded and broadly emarginated, as contrasted with the acute rim and broadly rounded contour of this end in Neurankylus baueri Gilmore. It may be that these peculiarities are due to an injury received in life, though the character of the bone appears to be normal. The fragmentary nature of the specimen renders it a poor subject for further speculation, and its principal interest at this time lies in the fact that it somewhat extends the known geologic and geographic range of the genus. The specimen was collected $3 \frac{1}{2}$ miles south of west of Kimbetoh, San Juan County, N. Mex., near the south side of sec. 4, T. 22 N., R. 10 W., 75 feet above the base of the Kirtland formation.

\section{Genus COMPSEMYS Leidy, 1856.}

Until the acquisition of the specimens here described the genus Compsemys has been known only from very fragmentary materials. The genus was founded by Leidy in 1856 to receive the scanty remains which he named Compsemys victus. In later years many species have been referred to this genus and subsequently removed from it, so that at this time it comprises but six recognized species, and the generic assignment of one of these, C. obscura, is queried by Hay. ${ }^{1}$ In the order in which they were described, the species are Compsemys victa Leidy, C.? obscura (Leidy), C. parva Hay, $C$. vafer Hay, C. torrejonensis Gilmore, and $C$. puercensis Gilmore.

In 1908, from the study of scanty materials, $\mathrm{Hay}^{2}$ was led to believe that a mesoplastron was not present in Compsemys, and on that account he provisionally assigned the genus to the family Dermatemydidae, but in $1911^{3}$ the study of new material showed the presence of that bone, whereupon Hay transferred Compsemys to the superfamily Amphichelydia,

1 Hay, O. P., The fossil turtles of North America: Carnegie Inst. Washington Pub. 75, p. 235, 1908.

2 Idem, p. 233.

3 Hay, O. P., Descriptions of eight new species of fossil turtles from west of the one hundredth meridian: U. S. Nat. Mus. Proc., vol. 38, p. 308, 1911. making it a member of the family Baenidae. The genus was defined as follows:

A genus of Baenidae. Plastron relatively small, with broad mesoplastra which meet at the midline. Axillary and inguinal buttresses rising above the lower ends of the costals; buttresses wide transversely to the body and shutting off ample sternal chambers. Peripheral bones united to costals by jagged sutures. Neural bones with the broader end forward. External surface of all the bones ornamented with small circular pustular elevations.

The short and broadly rounded anterior lobe of the plastron; the wide entoplastron; the broad mesoplastra, joining extensively at the midline; the broadly rounded posterior end of carapace without scalloped borders; vertebrals broad as compared to their lengths; and costoperipheral sutures above costo-marginal sulcus are all characters wherein Compsemys resembles Glyptops and Neurankylus, of the Pleurosternidx more nearly than any members of the Baenidae, and I therefore now refer the genus Compsemys to the Pleurosternidae. The following definition of the genus is proposed:

A genus of Pleurosternidae. External surfaces of the shell ornamented with small, closeset enameled tubercles; first peripherals meet on midline and exclude the nuchal from reaching the anterior margin of the carapace; vertebrals broader than long; first suprapygal absent; inguinal buttresses uniting exclusively with the fifth costals; mesoplastrals joining broad at midline, often narrowing toward outer extremities; costo-marginal sulcus entirely below costo-peripheral sutures; gulars reduced; humerals meeting narrow at midline; entoplastron wider than long; posterior lobe of plastron deeply notched; inframarginals only partially on plastron.

The exclusion of the nuchal from the anterior border of the carapace is an important structural feature not before observed, so far as I have been able to discover, in any turtle living or extinct. This feature, taken in conjunction with the articulation of the inguinal buttress exclusively with the fifth costal and the absence of the first suprapygal, may by some students be considered of more than generic value, so that a new subfamily should be erected for the reception of this genus. At this time, however, I do not subscribe to such a view, preferring to consider these features as 
of generic importance, definitely separating Compsemys from the other members of the family.

The following table shows the geologic range of the genus and the position of the several species:

Geologic distribution of species of the genus Compsemys.

\begin{tabular}{|c|c|c|}
\hline \multirow{3}{*}{ Basal Eocene. } & Fort Union. & Compsemys sp. \\
\hline & Torrejon. & $\begin{array}{l}\text { Compsemys torrejonensis } \\
\text { Gilmore, n. sp. } \\
\text { Compsemys parva? Hay. }\end{array}$ \\
\hline & Puerco. & $\begin{array}{l}\text { Compsemys parva Hay. } \\
\text { Compsemys vafer Hay. } \\
\text { Compsemys puercensis Gil- } \\
\text { more, n. sp. }\end{array}$ \\
\hline \multirow{4}{*}{$\begin{array}{l}\text { Upper Creta- } \\
\text { ceous. }\end{array}$} & Lance. & $\begin{array}{l}\text { Compsemys? obscura } \\
\text { (Leidy). } \\
\text { Compsemys victa Leidy. }\end{array}$ \\
\hline & Arapahoe. & Compsemys victa Leidy. \\
\hline & Ojo Alamo. & Compsemys sp. \\
\hline & Judith River. & Compsemys sp. \\
\hline
\end{tabular}

Compsemys parva Hay.

Plate I, figures 1 and 2; Plate XIX, figure 3.

Compsemys parva Hay, U. S. Nat. Mus. Proc., vol. 38, pp. 308-310, text fig. 1, pl. 10, figs. 1, 2, 3, 1910.

In the collection made by J. B. Reeside, jr., and party in the San Juan Basin, N. Mex., 4 miles east of Kimbetoh, in sec. 35, T. 23 N., R. $9 \mathrm{~W}$., at a horizon 50 feet above the base of the Puerco formation, during the summer of 1916, was the greater portion of the carapace and plastron of a small turtle, here identified as pertaining to Compsemys parva Hay, a species founded on a fragmentary specimen (No. 6548, U. S. N. M.) consisting chiefly of portions of the plastron. The discovery of the present specimen, the most perfect individual of the species yet found, now makes it possible to give an adequate diagnosis and description of this species. At the time the species was established some doubt was expressed as to the exact geologic age of the type, but the discovery of this specimen in undoubted Pureco deposits appears to establish its geologic position.
The specimen (No. 8528 , U. S. N. M.) represents an individual that is slightly larger than the type specimen, the length of the plastron at
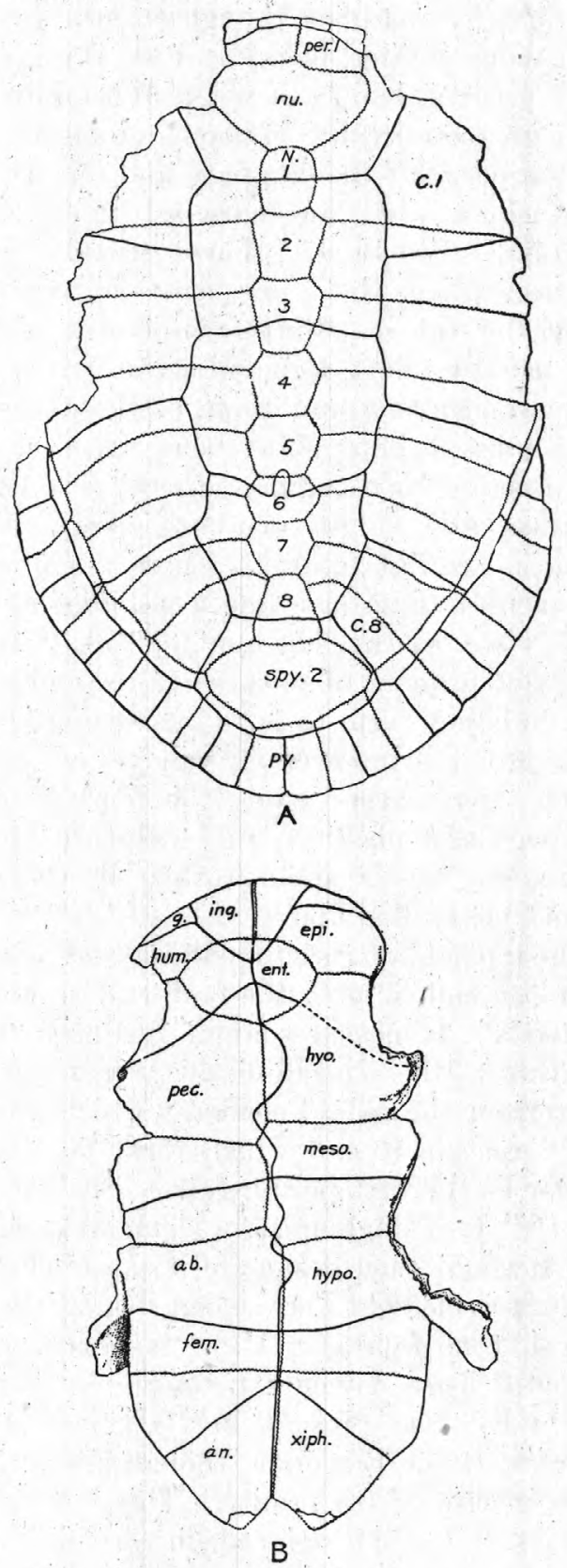

FIGURE 1.-Compsemys parva Hay (No. 8528, U. S. N. M.). A, Carapace: $C 1, C 8$, Costal bones 1 and $8 ; N 1,2,3,4,5,6,7,8$, neural bones 1 to 8; $n u$, nuchal; per 1, first peripheral; py, pygal; spy 2, suprapygal. B, Plastron: $a b$, abdominal scute; $a n$, anal scute; ent, entoplastron; epi, epiplastron; fem , femoral scute; $g$, gular scute; $h u m$, humeral scute; hyo, hyoplastron; hypo, hypoplastron; ing, intergular scute; meso, mesoplastron; pec, pectoral scute; xiph, xiphiplastron. One-half naturalsize.

the center being about 130 millimeters, whereas Hay estimated the plastron of the type as probably not exceeding 120 millimeters. The 
carapace appears to have been comparatively low and broadly arched, probably following the general outlines of the shell as expressed by the type of $C$.torrejonensis, though it appears to have been more pointed behind. (See Pl. IV.) It has a greatest length of about 165 millimeters and a greatest breadth of about 120 millimeters. All the bones of the carapace and plastron are ornamented with low, close-set elevations or pustules. (See Pl. I.) These pustules on the plastron merge into one another, especially along the sutures, thus forming short ridges that usually take a fore, and aft direction. On the carapace two and three of these pustules often join, forming short bent ridges that do not assume any regular direction. All the pustules and ridges on both carapace and plastron are flat topped. There are from six to seven of these in a line 5 millimeters long. In C. victa, as Hay has pointed out, "there is the same number of pustules in a 5-millimeter line, but they seem to have more pointed summits, and the intervening valleys are wider." In C. vafer, except along the borders of the carapace and plastron, the sculpture appears to be less clearly defined than in the other species mentioned above.

The nuchal bone is subquadrilateral, with the broadest side joining the first and second peripherals. It measures about 34 millimeters in greatest width. In calling this bone the nuchal I interpret the paired elements which immediately precede it and which form the median border as the first peripherals. (See fig. 1, A, per 1.) If a single median element were present, I would then designate it the nuchal and the larger element here called nuchal the preneural, thus following Hay ${ }^{1}$ in this interpretation of these elements in Chisternon. A preneural is also present in Boremys, another member of the Baenidae, though absent in all other genera of the family. This bone is also present, but much reduced, in Aspideretes and Plastomenus.

The first neural is oval; the six following are hexagonal, with the wider end forward; the eighth has the wider end posterior. All except the first are wider than long. The anterior ends of the second and third are concave; all others join by straight transverse sutures.

1 Hay, O. P., The fossil turtles of North America: Carnegie Inst. Washington Pub. 75, p. 57, 1908.
Measurements of the neurals of Compsemys parva (No. 8528, U.S. N. M.), in millimeters.

\begin{tabular}{|c|c|l|}
\hline No. & Length. & Width. \\
\cline { 1 - 1 } $1 \ldots \ldots$ & 15 & 11.5 \\
$2 \ldots \ldots$ & 13 & 15 \\
$3 \ldots \ldots$. & 14.5 & 15 \\
$4 \ldots \ldots$ & 12.5 & 15 \\
$6 \ldots \ldots$ & 12.5 & 15 \\
$7 \ldots \ldots$ & 9 & 15 \\
$8 \ldots \ldots$ & 13.5 & 13 \\
\hline
\end{tabular}

The pygal is missing.

The peripherals in this specimen are represented by the first, seventh, eighth, and tenth of the right side, the seventh, eleventh, and part of the first of the left side, and fragmentary parts of others whose exact position in the series has not been recognized. The first peripherals of opposite sides meet on the median line. The first is 14 millimeters long on the free border and has a greatest height of 11.5 millimeters; the seventh is 22 millimeters long; the eighth 21 millimeters; the eleventh is $\mathbf{1 6}$ millimeters long and has a depth of 21 millimeters. The free borders of the peripherals are subacute.

The costals grow successively narrower from the front toward the back. Their distal ends articulate with the peripherals by means of dentated sutures. On the inferior surface of the first costal is a rounded ridge produced by the strongly developed rib, which forms an articulation with the axillary buttress. The buttress, as in the type, rises about 10 millimeters above the lower border of this costal. The articulation for the inguinal buttress is entirely on the fifth costal and rises about 5 millimeters above the lower border of that bone. The costals of this specimen are relatively thinner than those of the few preserved with the type specimen.

The nuchal scute, as in C.vafer Hay, is small, narrow anteroposteriorly, and elongated transversely, being about 10 millimeters wide and 2 millimeters long at the center.

The vertebrals, except the first, are wider than long. In this specimen the fourth vertebral has a decided loop extending forward into the third vertebral on the midline. All these scutes are broader in front than behind. There is only slight expansion on the sides where the 
costal sulci are given off. The fourth is urnshaped.

Measurements of vertebrals of Compsemys parva (No. 8528, U.S.N.M.), in millimeters.

\begin{tabular}{|r|r|r|}
\hline \multicolumn{1}{|c|}{ No. } & Length. & Width. \\
\cline { 1 - 1 } & & \\
\cline { 1 - 2 } & 36 & 50 \\
$3 . \ldots$. & 29 & 41 \\
$4 . \ldots$. & 29 & 43 \\
& 30 & 36 \\
\hline
\end{tabular}

The costal scutes are of moderate size. The second is the widest; the third has a length of 30 millimeters and a height of 40 millimeters. All extend slightly below the costo-peripheral suture.

The posterior marginals in Compsemys parva extend high on the peripherals as compared with those of the other species of the genus; for example, the eleventh peripheral shows the sulcus within 4 millimeters of the costoperipheral suture, whereas in the type of $C$. torrejonensis it is 19 millimeters from the top of the same bone; or, in other words, in $C$. torrejonensis and apparently also in $G$. vafer the costomarginal sulcus crosses the peripherals at about their centers or below. The great height of the posterior marginals therefore appears to be one of the distinctive characters of this species.

The plastron has a length at the center of about 30 millimeters, and a greatest length of about 135 millimeters; the difference between these measurements ( 5 millimeters) represents the depth of the posterior notch. The plastron is relatively thinner than in the type of the species, and the sulci, though plain, are not so deeply impressed. Only a small portion of the border of the anterior lobe on the right and left sides is preserved, but this shows it to be without thickening and rather obtusely rounded. There does not appear to have been an epiplastral lip.

The entoplastron is about 28 millimeters wide and, as in Compsemys vafer Hay (No. 8529 , U. S. N. M.), appears to have been wider than long. It is estimated that the bridge had a width of about 60 millimeters, being therefore nearly one-half the entire length of the plastron.

The posterior lobe has a length of about 42 millimeters and a width of 63 millimeters. It is sharply notched at the center. The borders are thin and present sharp edges-in fact, the entire posterior two-thirds of this lobe is unusually thin.

The axillary and inguinal buttresses are of moderate development, are wide apart, and unite with the carapace by strongly developed sutures. The right hyoplastron is somewhat longer (antero-posteriorly) than the left, the former measuring 26 millimeters on the midline and the latter only 20 millimeters. The right hyoplastron thus came into contact with the inner end of the left mesoplastron. The mesoplastra, likewise, differ considerably in length at the center (see fig. 1, B, meso), the left being 27 millimeters long and the right 19 millimeters. The left mesoplastron is in contact with the inner ends of 'both the hyoplastron and hypoplastron of the right side. Hay considered that the same conditions prevailed in the plastron of the type. The mesoplastron at the center has a thickness of 6.5 millimeters, as compared with 6 millimeters in the type, a smaller specimen. The hypoplastra also differ in length at the center, the right measuring 29 millimeters and the left 26 millimeters. The xiphiplastrals are of equal length, measuring 26 millimeters long on the midline.

The sulci bounding the epidermal scutes are very distinct and consist of threadlike grooves on the level of the general surface. The median sulcus runs an irregular course, being first on one side of the midline and then on the other. The intergulars overlap the anterior end of the entoplastron, and it is estimated that they met on the midline for a distance of at least 17 millimeters. The gulars, as in Compsemys vafer, are small and are excluded from meeting on the midline by the intervening intergulars, The humero-pectoral sulcus starts from the axillary notch strongly forward to cross the entoplastron 8 millimeters anterior to its median posterior extremity, and in this respect Compsemys parva differs from all other members of the Baenidae as well as all Pleurosternidae. The humerals join on the midline for a distance of only 5 millimeters, but, as in Basilemys sinuosa Riggs, they expand rapidly toward their outer ends. The pectoral scutes are exceedingly broad at the midline and are 41 millimeters long; their outer ends measure less than 30 millimeters; the abdominals join 
on the midline, a distance of 31 millimeters; the femorals are narrow at the center, meeting for only 10 millimeters, but they expand rapidly toward their outer ends, there reach= ing a greatest length of 30 millimeters. The anals meet for 24 millimeters on the midline. On account of the damaged condition of the bridges the number of inframarginal scutes can not be determined.

A. second specimen in this collection (No. 8598 , U. S. N. M.) is provisionally identified as belonging to the present species. It consists of a considerable part of the plastron, neurals 2 and 3 , costals, peripheral (see Pl. XIX, fig. 3), and numerous other fragmentary bones of the carapace. It was collected 8 miles N. $60^{\circ} \mathrm{E}$. of Kimbetoh, in sec. 17, T. 23 N., R. 8 W., San Juan County, N. Mex., at a horizon 840 feet above the base of the Puerco, in the Torrejon formation. This specimen is an individual slightly larger than the type of $C$. parva, and the plastral bones appear to be a little thicker than the Puereo specimen (No. 8528) above described. I have carefully compared this specimen with both the type and No. 8528 and fail to detect characters that would serve to distinguish it from them. I therefore propose to refer it provisionally to the present species until such time as the discovery of new material shall definitely determine its exact affinities. The anterior lobe is 37 millimeters long and 67 millimeters wide at the base. The entoplastron is 27 millimeters wide and 23 millimeters fore and aft. It is overlapped by the intergulars in front and the pectorals behind. The hyoplastrals meet on the midline for 117 millimeters. The mesoplastron of the left side is 24 millimeters wide, on the right side only 14 millimeters wide. The bridge is 58 millimeters wide. The posterior lobe is about 60 millimeters wide at the base. The intergulars meet on the midline for 19 millimeters, the humerals for 6 millimeters, the pectorals for 34 millimeters, and the abdominals for about 33 millimeters. The second neural is 14 millimeters long and 16 millimeters wide; the third about 15 millimeters long and 14 millimeters wide. The second vertebral scute has a greatest width of 42 millimeters.

The characters that now appear to definitely distinguish Compsemys parva Hay from the other species of the genus may be briefly stated as follows:

Specific characters: Small size; costo-marginal sulcus crossing peripherals of posterior half of carapace, on their upper fourths, whereas in all other species it crosses them midway or below; posterior lobe of plastron with a median $V$-shaped notch; eighth neural relatively large.

\section{Compsemys vafer Hay.}

Plate II, figures 1 and 2.

Compsemys vafer Hay, U. S. Nat. Mus. Proc., vol. 38, pp. 311-313, text. figs. $2-5$, pl. 10, figs. 4 and 5; pl. 11, figs. 1 and 2, 1910.

This species was founded on a fragmentary specimen (No. 6551, U. S. N. M.) consisting of "about nine peripherals, three neurals, a few fragments of costal plates, and some fragments of the plastron." It was collected from the Puerco formation near Ojo Alamo, San Juan County, N. Mex.

The present collection contains three specimens (Nos. 8529, 8530, and 8600, U. S. N. M.) that are identified as belonging to this species. The best specimen (No. 8529) consists of the greater part of the plastron and a considerable portion of the carapace. It is by far the most perfect specimen of this species yet found and adds materially to our knowledge of this little known form.

This specimen is an individual of approximately the same size as the type of the species. The carapace as now preserved consists largely of the median portion of the shell from which all parts posterior to the eighth neural and the distal thirds of many of the costals are missing. On the left side the third, fourth, and fifth costals and the seventh and eighth peripherals are present. The nuchal is missing, but the bones bounding it give its approximate shape and size as shown in figure 2, A, nu. A little more than one-half of the anterior border of the shell is intact and shows it to be broadly concave when viewed from above as contrasted with the straight, truncated border of Compsemys torrejonensis. Hay, in discussing the type of the species, estimated that "the carapace had originally a length of about 1 foot." No. 8529 , which is of about the same size as the type specimen, would be somewhat under a foot in length. 


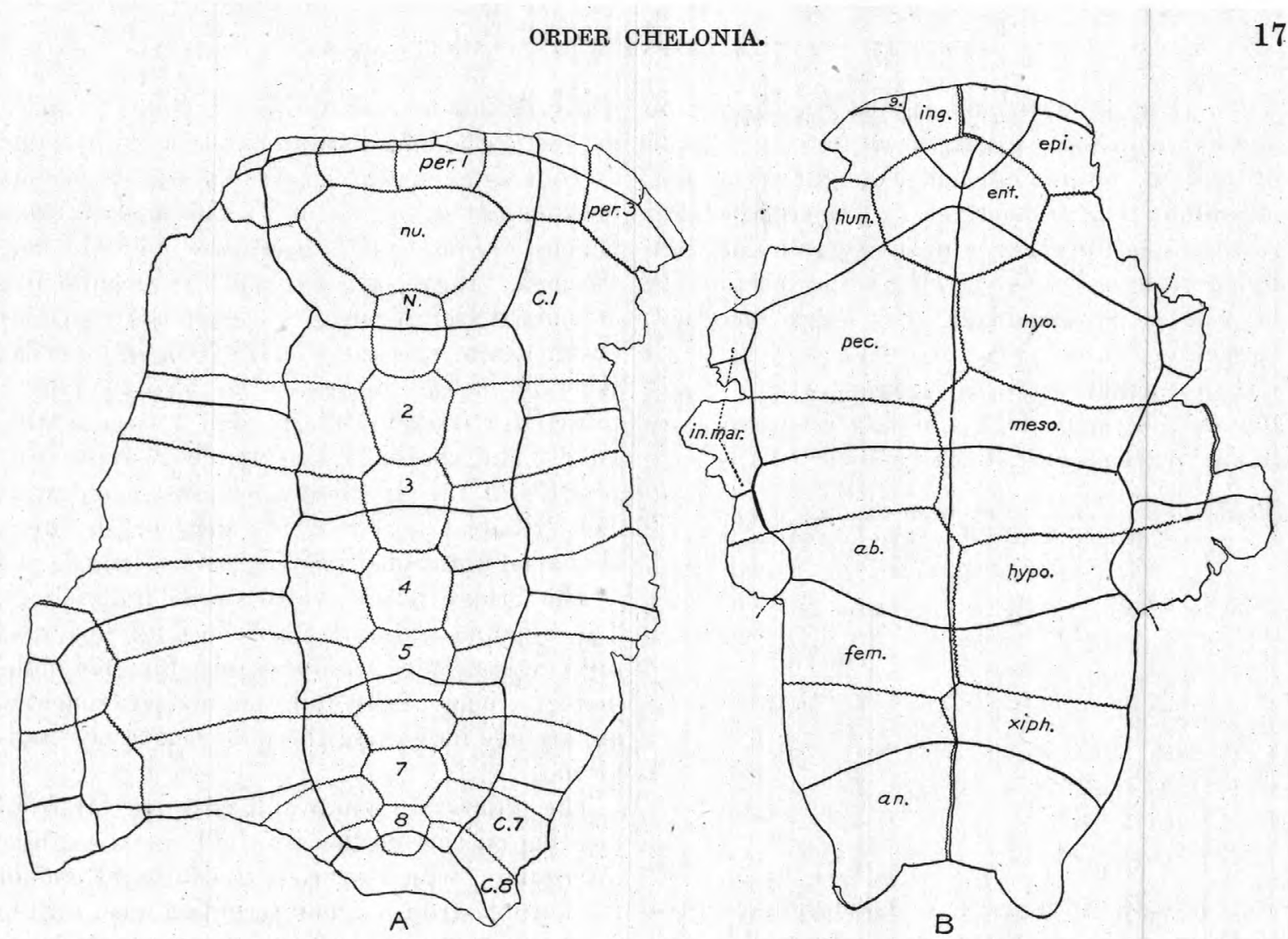

Figure 2.-Compsemys vafer Hay (No. 8529, U. S. N. M.). A, Carapace: $C$ 1, $C \gamma, C$, Costal bones 1,7, and $8 ; N 1,2,3,4,5,6,7,8$, neural bones 1 to 8 ; nu, nuchal; per 1, per 3, peripherals 1 and 3. B, Plastron: $a b$, Abdominal scute; an, anal scute; ent, entoplastron; epi, epiplastron; fem, femoral scute; $g$, gular scute; hum, humeral scute; hyo, hyoplastron; hypo, hypoplastron; ing, intergular scute; in. mar, inframarginal scutes; meso, mesoplastron; pec, pectoral scute; xiph, xiphiplastron. One-half natural size.

The neurals are all perfectly preserved except the eighth, which lacks its posterior extremity. The first is oval; those following are hexagonal, with the broader end forward. All except the first are broader than long. Their form is well shown in figure 2, and their dimensions as compared with those of the type are given in the following table:

Measurements of neurals in Compsemys vafer, in millimeters.

\begin{tabular}{|c|c|c|c|c|}
\hline \multirow{2}{*}{ No. } & \multicolumn{2}{|c|}{ Length } & \multicolumn{2}{|c|}{ Width. } \\
\hline & $\begin{array}{l}\text { No. } 6551 \\
\text { (type). }\end{array}$ & No. 8529 . & $\begin{array}{l}\text { No. } 6551 \\
\text { (type). }\end{array}$ & No. 8529. \\
\hline $\begin{array}{l}1 \\
2 \ldots \\
2 \ldots \ldots \\
4 \ldots \ldots \\
4 \ldots \ldots \\
5 \ldots \ldots \\
7 \ldots \ldots \\
8 \ldots \ldots \\
\ldots \ldots\end{array}$ & 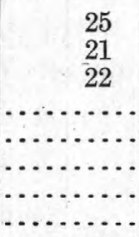 & $\begin{array}{r}23 \\
22 \\
22 \\
20 \\
18 \\
11 \\
15 \\
\ldots .\end{array}$ & 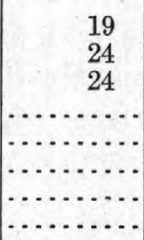 & $\begin{array}{l}19 \\
23 \\
23 \\
25 \\
26 \\
26.5 \\
22 \\
15\end{array}$ \\
\hline
\end{tabular}

The costals fore and aft grow progressively narrower from the first to the seventh. The seventh is relatively very much smaller in all dimensions than the corresponding element in the type of Compsemys torrejonensis (see fig. 4), which measures 21 millimeters in width and has a greatest length of 50 millimeters. $\mathrm{Hay}{ }^{1}$ figured a peripheral which he identified as the first, but a comparison with the present articulated specimen shows this bone to be the right second peripheral.

The first peripherals meet on the median line and thus exclude the nuchal plate from reaching the front margin. The first peripheral has a width on the free margin of 21 millimeters, the second 33 millimeters, and the third 39 millimeters; the height of the third is 33 millimeters. The anterior border is obtusely rounded. On the lower side the sculptured surface extends backward from the edge 9 millimeters at the center where the first peripherals join, but this surface gradually widens away from the center, and at the outer end of the third peripheral it is 18 millimeters

${ }_{1}$ Hay, O. P., Descriptions of eight new species of fossil turtles from west of the one hundredth meridian: U. S. Nat. Mus. Proc., vol. 38, p. 311, pl. 10, fig. 5, 1910. 
wide. The seventh and eighth peripherals of the left side have a length on free borders of 36 and 38 millimeters and a height of 38 and 43 millimeters, respectively. The free borders of these peripherals are obtusely rounded, but more posteriorly, as shown by the peripherals of the type specimen, the edge becomes subacute.

The nuchal scute is very short (3 millimeters) fore and aft, but wide transversely, as in the other species of the genus.

Measurements of vertebral scutes in Compsemys vafer (No. 8529, U.S. N. M.), in millimeters.

\begin{tabular}{|r|r|r|}
\hline No. & Length. & $\begin{array}{r}\text { Great- } \\
\text { est } \\
\text { width. }\end{array}$ \\
\hline $1 \ldots .$. & 57 & 75 \\
$2 \ldots \ldots$ & 46 & 61 \\
$3 . \ldots$. & 42 & 64 \\
$5 \ldots \ldots$ & 43 & 50 \\
\hline
\end{tabular}

As is shown in figure 2, A, the marginal scutes run low down on the peripherals, well below the costo-peripheral suture, as in Compsemys torrejonensis.

The external surfaces of all the bones are ornamented by flat-topped pustules without definite pattern or arrangement. As Hay has already pointed out, there are usually seven of these pustules in a line 5 millimeters long.

The plastron has a length at the center of 203 millimeters. The anterior lobe is about 59 millimeters long; its width at the base is 105 millimeters. The edges are slightly thickened and rounded. In shape the entoplastron is roughly hexagonal, 45 millimeters wide and 35 millimeters long. The hyoplastra meet on the midline for 24 millimeters. The mesoplastra, as in Compsemys parva and C. torrejonensis, differ in their fore and aft width at the midline, where the right element is 24 millimeters wide and the left 45 millimeters. The latter narrows toward its outer end, which is only 30 millimeters in this diameter. The median end meets in succession the hyoplastral, mesoplastral, and hypoplastral bones.

The posterior lobe has a greatest length of 68 millimeters; at the center its length is 56 millimeters. The difference between these measurements (12 millimeters) represents the depth of the very wide posterior notch. The width of this lobe at its base is about 92 millimeters. The edges are thickened and rounded as contrasted with the acutely edged borders in Compsemys parva or with the obtusely beveled borders in $C$. puercensis and $C$. torrejonensis. Between the tips of the prominently developed xiphiplastral processes the posterior notch has a greatest width of 40 millimeters. Between these processes the median border presents a straight, sharp edge 22 millimeters long. The shape of this notch is quite distinctive of this species, when contrasted with the V-shaped notch of $C$. parva or the deep U-shaped notch of C.torrejonensis. (See fig. 4.)

The bridge has a width of 86 millimeters. The hypoplastrals meet on the midline for 38 millimeters; the xiphiplastrals for $41 \mathrm{milli}$ meters. The plastron is somewhat concave, apparently indicating the male sex of the individual.

The gulars are small and crowded far from meeting on the midline by the large triangular intergulars, which overlap the forward end of the entoplastron. The intergulars meet on the midline for 30 millimeters, the humerals for 6 millimeters, the pectorals for 62 millimeters, the abdominals for 44 millimeters, the femorals for 30 millimeters, and the anals for 30 millimeters.

There are four inframarginal scutes on the bridge.

Compsemys vafer can now be distinguished from $C$. torrejonensis by the different form of the posterior notch of the plastron, by the rounded margins of the posterior lobe as contrasted with the beveled lobe of $C$. torrejonensis, by the broadly concave contour of the anterior border of the carapace, by the relatively smaller seventh costal, and by differences in the ornamentation of the carapace and plastron.

In the sculpture Compsemys vafer also differs from both $C$. parva and $C$. victa. From $C$. parva it is also to be distinguished by the larger size and differences in the hinder lobe, especially in the form of the notch and the more rounded free edges, as contrasted with the $U$-shaped notch and acutely beveled edges of that species.

The distinguishing characters of Compsemys vafer may be summed up as follows:

Specific characters: Medium size; costo-marginal sulci crossing posterior peripherals at 
middle of their height or below; sulcus between third and fourth vertebrals crossing fifth neural; posterior lobe of plastron with a wide median notch and prominently developed xiphiplastral processes.

Compsemys puercensis Gilmore, n. sp.

Plate III, figures 1 and 2.

Type: No. 8544, U. S. N. M. ; consists of posterior two-thirds of plastron, first six neurals, with portions of attached costals, and various fragments. Collected by J. B. Reeside, jr., 1916.
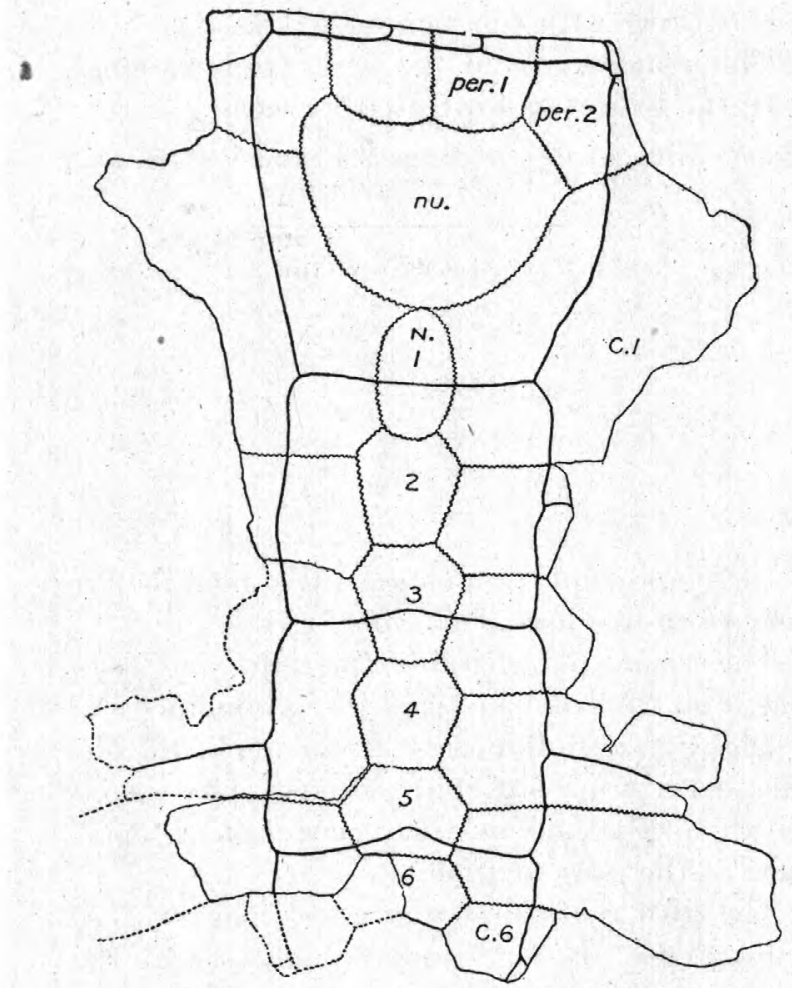

A species, and I therefore propose the name $C$. puercensis for this specimen in reference to the geologic formation in which it was discovered.

The characters which at present distinguish this species are found in the posterior lobe of the plastron, especially those relating to its contour, the form of the posterior notch, and the absence of xiphiplastral processes. Other minor differences will be referred to in the descriptions.

The ornamentation of both carapace and plastron is composed of flat-topped pustules as in Compsemys vafer and $C$. torrejonensis and

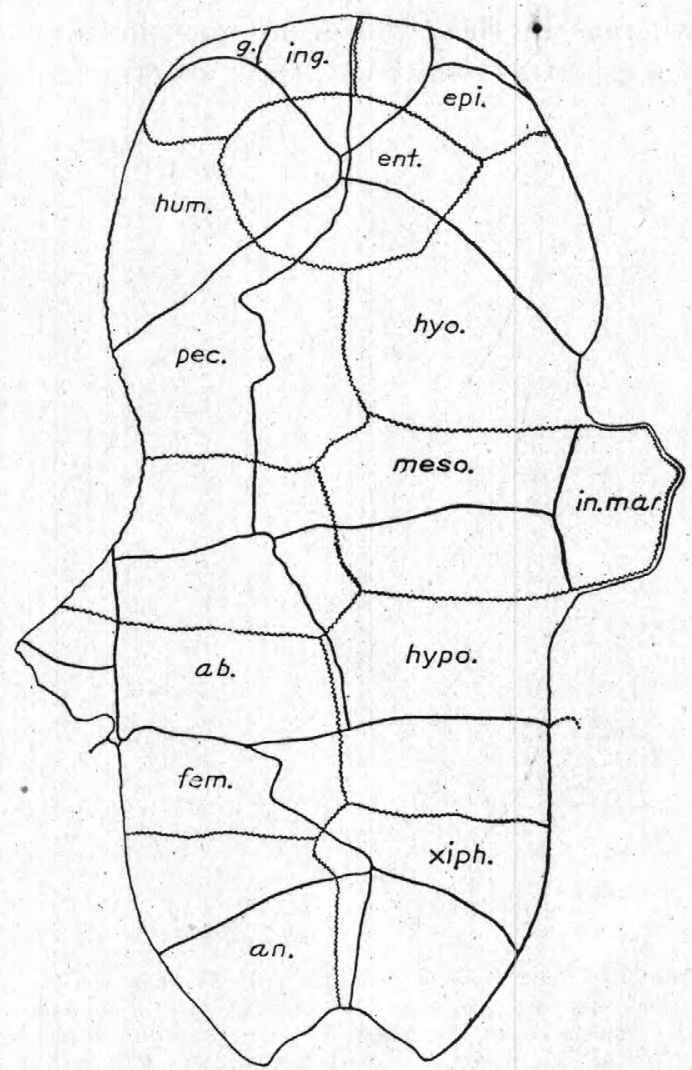

$B$

Figure 3.-Compsemys puercensis Gilmore, n. sp: (No. 8544, U. S. N. M.). A, Carapace: $C 1, C 6$, Costal bones 1 and $6 ; N 1,2,3,4,5,6$, neural bones 1 to 6 ; $n u$, nuchal; per 1, per 2, peripherals 1 and 2. B, Plastron: $a b, \Lambda$ bdominal scute; an, anal scute; ent, entoplastron; epi, epiplastron; fem, femoral scute; $g$, gular scute; hum, humeral scute; hyo, hyoplastron; hypo', hypoplastron; in mar, inframarginal scute; ing, intergular scute; meso, mesoplastron; pec, pectoral scute; xiph, xiphiplastron. One-half natural size.

Type locality: Four miles northwest of Kimbetoh, on the north line of sec. 27, T. 23 N., R. 9 W., San Juan County, N. Mex.

Horizon: Puerco formation (50 feet above the base), basal Eocene.

The specimen selected as, the type of Compsemys puercensis, although rather fragmentary, shows characters in the plastron which appear to distinguish it fully from the other described apparently C. puercensis is indistinguishable from those species in the general composition of this sculpture.

The individual is smaller than specimen No. 8529 , U. S. N. M., referred to C. vafer, the length of the plastron having probably not exceeded 195 millimeters, whereas that of No. 8529 measures 218 millimeters. Both xiphiplastra, the right hypoplastron, portions of 
both mesoplastra, and a part each of the right and left hyoplastron and of the epiplastral bones are present. (See fig. 3, B.)

The posterior lobe has a length at the center of 50 millimeters and a greatest length of 60 millimeters; the difference represents the depth of the wide median notch. From the inguinal notch backward the free borders present subrounded edges that in cross section are about intermediate in form between the acute edges of $C$. torrejonensis and the rounded edges of C. vafer. The lobe is widest (86 millimeters) at its base, the sides of which gradually round in toward the notch on the posterior end, whereas in the two species mentioned above the greatest width of the posterior lobe is

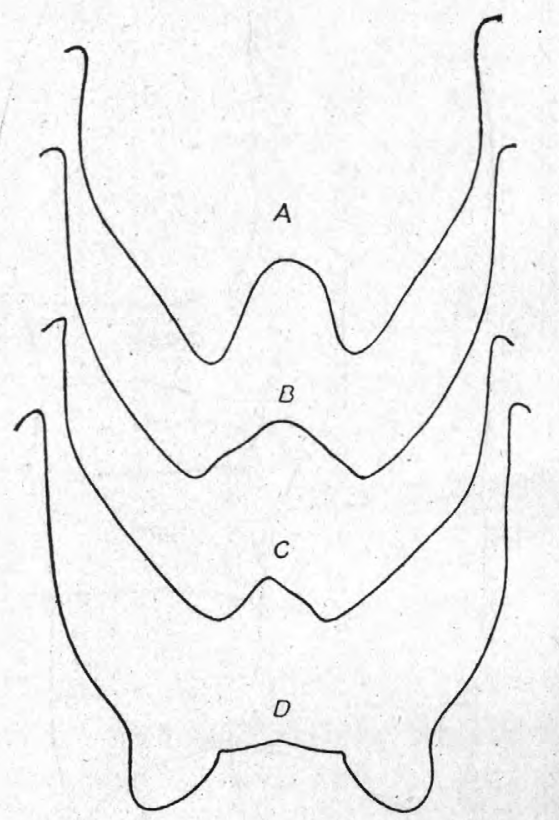

Frgure 4.-Comparative view of the posterior lobes of the plastra of four species of Compsemys. A, Compsemys torrejonensis Gilmore, $\mathrm{n}$. sp. (type; No. 8549 U. S. N. M.); B, C.puercensis Gilmore,n. sp. (type; No. 8544 , U. S. N. M.); C, C. parva Hay (No. 8528 , U. S. N. M.); D, C. vafer Hay (No. 8529 , U. S. N. M.).

posterior to the inguinal notch. The broad posterior notch is 10 millimeters deep and 33 millimeters wide between the tips of the xiphiplastral processes. The shape of this notch is also of assistance in distinguishing $C$. puercensis from the other species of the genus, as is shown in figure 4.

The right mesoplastron has a greatest length on the midline of 32 millimeters and a thickness at the center of 7.5 millimeters; the right hypoplastron is 33 millimeters long on the midline; the xiphiplastrals vary in their length at the center, the left one measuring 38 millimeters and the right only 33 millimeters.

The median sulcus, as is usual in this genus, runs a very irregular course. The femorals meet on the midline for a distance of 28 millimeters; the anals for 25 millimeters.

The parts of the carapace preserved with this specimen are so fragmentary as to be of comparatively little value in furnishing any distinctive features of the species.

The largest articulated portion consists of neurals 1 to 6 , with portions of attached costals, of which only the fifth of the right side is complete. This costal shows, however, that the main attachment with the inguinal buttress was entirely with this bone.

The neurals, except the first, are hexagonal, with the widest end directed forward.

Measurements of neurals in Compsemys puercensis (No. 8544 , U.S. N. M.), in millimeters.

\begin{tabular}{|c|c|c|}
\hline No. & Length. & Width. \\
\hline $\begin{array}{l}1 \ldots \\
2 \ldots \\
3 \ldots \\
4 \ldots \\
5 \ldots \\
6 \ldots\end{array}$ & $\begin{array}{l}20 \\
23 \\
20 \\
17.5 \\
13\end{array}$ & $\begin{array}{l}16 \\
22 \\
22 \\
23.5 \\
25 \\
26\end{array}$ \\
\hline
\end{tabular}

In shape and proportions the neurals are very close to those of $C$. vafer.

The second peripheral of the right side has a width on the free border of 27 millimeters and a height of 27 millimeters; a portion of the left peripheral is present, and these two pieces constitute all that is known of the rim of the carapace at the present time.

The fifth costal has a greatest length of 70 millimeters. It is 19 millimeters wide at the proximal end and 27 millimeters wide at the distal end.

The dimensions of the vertebral scutes, so far as they can be determined, are as follows:

Measurements of vertebrals in Compsemys puercensis (No. 8544, U.S. N. M.), in millimeters.

\begin{tabular}{|c|r|r|}
\hline No. & Length. & Width. \\
\cline { 1 - 2 } & & \\
\hline $3 \ldots$ & 45 & 54 \\
$4 \ldots$. & 42 & 48 \\
& $51 . \ldots$ & 51 \\
\hline
\end{tabular}

These scutes are relatively narrower than in C. vafer. 
Specific characters: Medium size; sulcus between third and fourth vertebrals crosses fifth neural, as in $C$.vafer; posterior lobe of plastron with wide median $V$-shaped notch, and without prominent xiphiplastral processes.

\section{Compsemys torrejonensis Gilmore, n. sp.}

Plate IV, figures 1 and 2.

Type: No. 8549, U. S. N. M.; consists of a nearly complete carapace and plastron. The principal parts missing are the posterior neurals and the median peripherals of both sides. Collected by J. B. Reeside, jr., 1916.

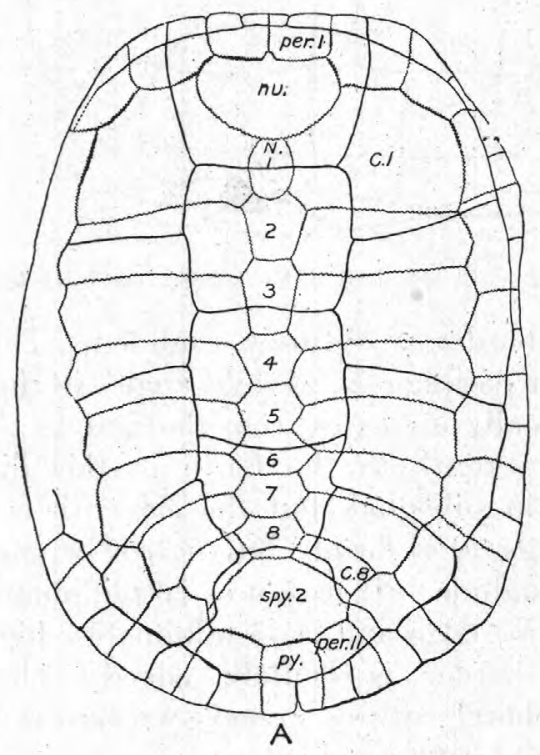

representative of this genus to be found in the Torrejon formation. The specific name given to it refers to the geologic occurrence of the type.

In form the shell is an elongated oval, broadest behind the middle, truncated in front, broadly rounded behind. (See Pl. IV, figs. 1 and 2, and text fig. 5.) From side to side the carapace is flattened, with a long slope from the top to the posterior margin. In front the forward slope of the carapace is much shorter and the downward inclination much less. Viewed from the side the shell is high in front and low behind (see fig. 6), with a strongly arched an-

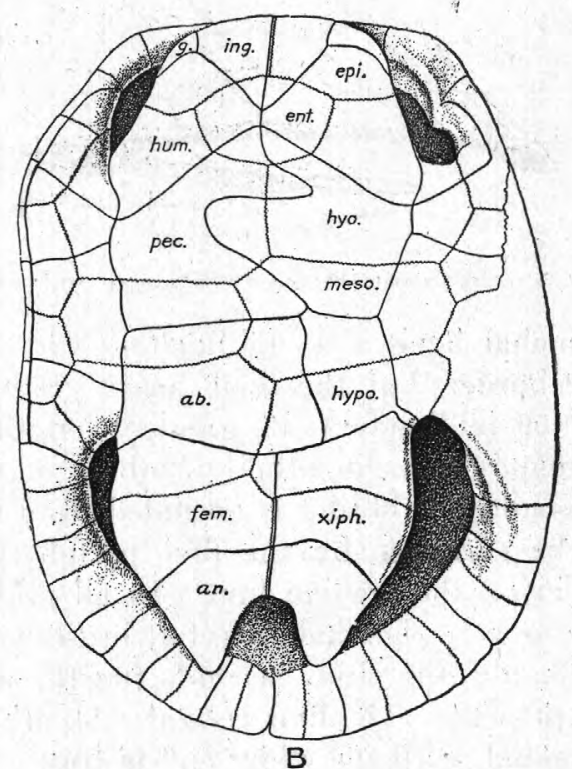

FiguRe 5.-Compsemys torrejonensis Gilmore, n. sp. (No. 8549, U. S. N. M.). Type. A, Carapace: $C 1, C 8$, Costal bones 1 and $8 ; N 1,2,3,4,5,6,7$, 8 , neural bones 1 to 8 ; $n u$, nuchal; per 1, per 11, peripherals 1 and $11 ; p y$, pygal; spy 2, suprapygal 2. B, Plastron: ab, Abdominal scute; an, anal scute; ent, entoplastron; epi, epiplastron; fem, femoral seute; g, gular scute; hum, humeral scute; hyo, hyoplastron; hypo, hypoplastron; ing, intergular seute; meso, mesoplastron; pec, pectoral scute; xiph, xiphiplastron. One-fourth natural size.

Type locality: Eight miles N. $60^{\circ}$ E. of Kimbetoh, in sec. 17, T. 23 N., R. 8 W., San Juan County, N. Mex.

Horizon: Torrejon formation " " 840 feet above base of the Puerco, in Torrejon"), basal Eocene.

The speeimen selected as the type of Compsemys torrejonensis is the most perfect example of the genus Compsemys yet discovered. When found, the shell was broken into many small fragments, but in the skillful hands of Mr. N. H. Boss, preparator in the section of vertebrate paleontology, these pieces were fitted together so as to restore the nearly complete shell with all its contours and proportions but little altered from their original condition. In addition to being the most perfect specimen of the genus known at this time it is also the first terior border, thus forming a very large opening for the head and fore legs as contrasted with the comparatively small openings for the hind legs.

As in Compsemys vafer the external surfaces of all the bones forming the carapace and plastron are covered with an ornamentation of pustules. These pustules are flat topped and are separated by narrow intervening valleys. On many of the bones, especially the peripherals and costals, these pustules form two, three, or even four parallel rows around the borders of the bones. This feature is best shown in a'second specimen (No. 8591, U. S. N. M.) collected at the same time and in the same locality as the type. On the plastron the pustules are to a great extent arranged in rows running longitudinally to the long axis of the shell. This 
arrangement of the pustules will serve to distinguish the plastron of this species from that of $C$. vafer Hay and C. puercensis in which the pustules have no definite arrangement.

The greatest length of the carapace in a straight line is 280 millimeters; the greatest width, which is posterior to the middle, is 208 millimeters; the greatest height is about 82 millimeters.
Posterior to the first their distal ends are pointed and unite closely with the peripherals by jagged sutures. There are, as in most turtles, 11 peripheral bones. Peripheral 1 is entirely in front of the nuchal. It meets its fellow of the opposite side on the midline and is entirely excluded from contact with the first costal. In form it is square, measuring 23 millimeters long and 23 millimeters wide. The

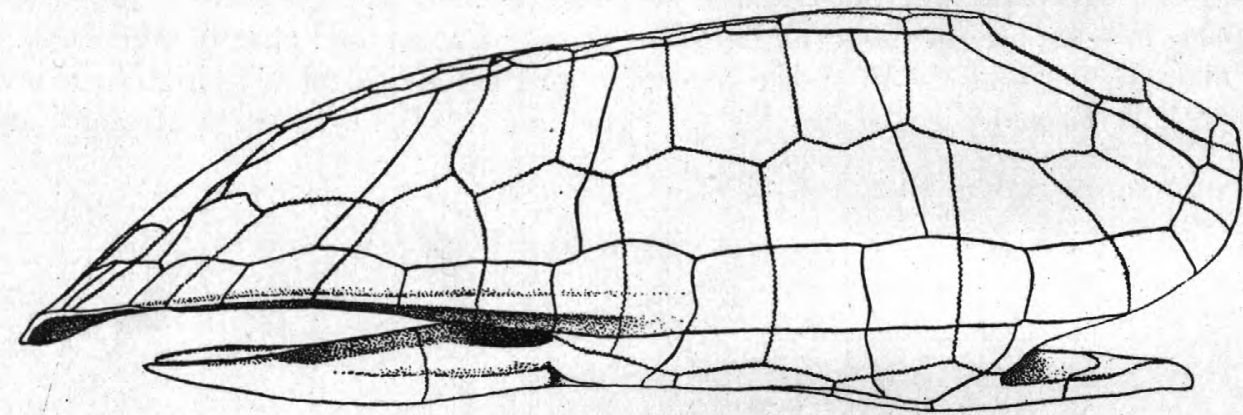

FIGURE 6.-Lateral view of the shell of Compsemys torrejonensis Gilmore, n. sp. (No. 8549, U. S. N. M.). Type. One-half natural size.

The nuchal bone is 45 millimeters wide on the front border; but the bone has a greatest width of 59 millimeters; its greatest length is 37 millimeters. As in other members of the genus, its anterior border is excluded from the rim of the carapace by the first peripherals, which join on the median line. In all probability there were eight neurals, but in the type specimen only the first, second, fourth, and fifth are present. The first is oval; the others are hexagonal, with the wider end in front.

Measurements of neurals in Compsemys torrejonensis (No. - 8549, U.S. N. M.), in millimeters.

\begin{tabular}{|c|c|c|}
\hline No. & Length. & $\begin{array}{c}\text { Great- } \\
\text { est } \\
\text { width. }\end{array}$ \\
\hline $\begin{array}{l}1 \ldots . . \\
2 \ldots . \\
3 \ldots . \\
4 \ldots \\
5 \ldots .\end{array}$ & $\begin{array}{r}25 \\
23 \\
a 26 \\
20 \\
18\end{array}$ & $\begin{array}{r}18 \\
24 \\
a 22 \\
24 \\
26\end{array}$ \\
\hline
\end{tabular}

Apparently there was but a single suprapygal (probably suprapygal 2), and only a small portion of the right side of this element is preserved. It had a greatest width of about 58 millimeters; its length can not be determined.

Antero-posteriorly the costals become successively narrowed from the first to the eighth. free border is obtusely rounded. The height of the peripherals, at right angles to the border, gradually increases from the first to the sixth. The seventh to the tenth in this dimension remain subequal, but the eleventh is shorter. The pygal is deeply but narrowly notched on the midline. It measures 26 millimeters along the free edge and is 35 millimeters high. The free border is acutely edged. The costoperipheral sutures are everywhere well above the costo-marginal sulcus.

The sulci are narrow and shallowly impressed, but nearly all are clearly defined. The nuchal scute is small and rectangular; the longer diameter is transverse. Its length, antero-posteriorly is 6 millimeters; its width 19 millimeters. There are slight indentations of the border at either end of this scute where the sulci come to the margin.

The vertical scutes are broad.

Measurements of vertebral scutes in Compsemys torrejonensis (No. 8549, U.S. N. M.), in millimeters.

\begin{tabular}{|c|c|c|}
\hline No. & Length. & $\begin{array}{l}\text { Greatest } \\
\text { width. }\end{array}$ \\
\hline $\begin{array}{l}1 \ldots \\
2 \ldots \\
3 \ldots \\
4 \ldots \\
5 \ldots\end{array}$ & $\begin{array}{r}66 \\
54 \\
54 \\
\ldots .6 . \\
\ldots .6\end{array}$ & $\begin{array}{l}82 \\
63 \\
61 \\
49 \\
73\end{array}$ \\
\hline
\end{tabular}


The marginal scutes are relatively narrow throughout the series, and none come anywhere near reaching the costo-peripheral suture, which is above. There appear to be 11 marginal scutes. The costal scutes, on account of the shortness of the marginals, are of good size.

The plastron posterior to the center is slightly concave and suggests that this specimen is a male. It has a greatest length at the center of 220 millimeters and a greatest length over all of 246 millimeters. The difference between these measurements, 26 millimeters, represents the depth of the notch on the posterior lobe. The front lobe is comparatively short, is broadly rounded, and extends forward even with the anterior border of the carapace. (See Pl. IV, fig. 2.) The anterior lobe is 57 millimeters long; its width at the base is 117 millimeters. The edges are obtusely rounded, being beveled off from the upper surface downward. The entoplastron is about 34 millimeters long, 52 millimeters wide, and angularly rounded behind. The hyoplastrals meet at the midline for about 32 millimeters; the right element is much longer antero-posteriorly and thus is in contact with the mesoplastron of the left side for a distance of 20 millimeters. The mesoplastra also differ in width antero-posteriorly, the right measuring 27 millimeters and the left 46 millimeters. Both narrow away from the center, but more especially the left, which at the edge of the plastron is only 34 millimeters fore and aft. In the shape and relative proportions of these elements they approach those of Glyptops depressus Hay, from the Denver formation. The hypoplastrals meet on the midline for 41 millimeters. The right element also meets the left mesoplastron. The xiphiplastrals have a contact at the center of 96 millimeters.

The posterior lobe at the center is 65 milli. meters long and 112 millimeters wide at the base. The free borders are acutely edged, but the bone thickens from the borders inward, reaching its maximum thickness (9 millimeters) about 15 millimeters in from the border. The lateral borders swell outward slightly from the inguinal notch posteriorly, but back of the hypo-xiphiplastral suture curve inward and still more rapidly at the femoro-anal sulcus. The posterior end of the plastron is deeply indented by a large $U$-shaped notch, 26 millimeters deep and 40 millimeters wide. The posterior extremities of the plastron end about 28 millimeters anterior to the posterior margin of the carapace. The bridge has a width of 113 millimeters on the right side but measures only 96 millimeters on the left, and there is no apparent distortion or injury. The plastron at the center of the bridge measures 144 millimeters in width.

Strong buttresses rise to the costals; the axillary buttress unites with the underside of the first costal, the inguinal entirely with the fifth costal. Both are attached low down.

Nearly all the sulci bounding the epidermal scutes can be clearly determined. As in the other members of the genus, the median sulcus, so far as it can be traced, runs a very irregular course. The gulars are very small and are excluded by the interposition of the large intergulars from meeting on the midline. (See fig. 5, B.) The intergulars overlap the anterior end of the entoplastron and meet on the middle for 35 millimeters. The humeropectoral sulcus extends diagonally forward from a point posterior to the axillary notch and meets its fellow of the opposite side well forward on the entoplastron. The humerals are thus made very narrow where they meet on the midline, in this specimen only 7 millimeters. The pectorals meet on the midline for a distance of 72 millimeters; the abdominals for 52 millimeters; the femorals for 35 millimeters; the anals for 18 millimeters. The area of the left abdominal is not more than half that of the right. There are four large inframarginal scutes on the bridge, which are remarkable for their inward extension toward the center of the shell. Their inner borders are mesiad of a line drawn connecting the lateral borders of the base of the anterior and posterior lobes. This condition is approached in Glyptops, but in all members of the Baenidae the inner borders are far outside of such a line. In the family Pleurosternidae the mesiad encroachment of the inframarginals on the pectorals and abdominals appears to be peculiar to the genus Compsemys, and in $C$. torrejonensis the inframarginals appear to have reached their maximum development.

Compsemys torrejonensis appears to have its closest affinities with $C$. vafer Hay from the underlying Puerco formation. It may be distinguished from that species by the relatively 
wider posterior lobe, the deeper U-shaped notch of the plastron (see fig. 4, p. 20), and the acuteness of the free borders of the posterior lobe. The squarely truncated end of the carapace will also serve to distinguish these species, as in $C$. vafer this border is broadly concave. The differences in the character of the ornamentation, as has previously been pointed out, will also help in their differentiation. This sculpture also differs from that of both $C$. victa Leidy and $C$. parva Hay. The much smaller size of $C$. parva would at once distinguish it from $C$. torrejonensis.

Specific characters: Typically largest known species; costo-marginal sulcus crossing all peripherals at middle of their height or below; sulcus between vertebrals 3 and 4 crossing sixth neural; posterior lobe of plastron with a deep U-shaped median notch; xiphiplastral processes prominently developed; eighth costal plate relatively small.

Family BAENIDAE Cope.

The family Baenidae is represented in the present collection by specimens pertaining to the genus Baena. The geologio occurrence of the family is here extended into the Puerco formation.

Genus BAENA Leidy, 1870.

Baena nodosa Gilmore.

Baena nodosa Gilmore, U. S. Geol. Survey Prof. Paper 98, pp. 293-295, p. 76, text figures 34, 35, 1916.

Since Baena nodosa was first described, in December, 1916, four additional specimens pertaining to it have been recognized. These somewhat extended the known geologic range and the geographic distribution of the species. All are fragmentary. The better-preserved specimens (Nos. 8603 and 8622 , U. S. N. M.), consisting of portions of the median part of the carapace, were collected in 1916, by J. B. Reeside, jr., No. 8603, U. S. N. M., about 2 miles south of west of Kimbetoh, in sec. 3 , T. 22 N., R. 10 W., San Juan County, N. Mex., 300 feet above the base of the Kirtland formation, and No. 8622 , U. S. N. M., about 5 miles south of Kimbetoh, in sec. $26, \mathrm{~T} .22$ N., R. 10 W., 50 feet above the base of the Fruitland formation. The type is from the Kirtland formution.

A third specimen is recognized among a few fragments collected by Messrs. Gardner and Gidley during the summer of 1909 in the vicinity of Ojo Alamo, San Juan County, N. Mex. These fragments of the carapace show the characteristic nodelike ornamentation of the shell, which is so distinctive of this species. A fourth specimen, collected by Mr. Reeside, $3 \frac{3}{4}$ miles south of west of Kimbetoh, in sec. 4 , T. 22 N., R. 10 W., 55 feet above the base of the Kirtland formation, consists of a great number of fragments, but these show the characteristic nodelike ornamentation of the shell, and it doubtless pertains to the present species.

Baena sp. undet.

In this collection are parts of five individuals which are referable to the genus Baiena but none of which are sufficiently well preserved to be identified specifically. Two of these, consisting of the anterior portions of the plastra, probably represent undescribed species, but the material is so scanty that I do not feel justified in naming them. Both come from the same locality ( $3 \frac{1}{2}$ miles south of west of Kimbetoh, N. Mex., near the south side of sec. 4 , T. 22 N., R. 10 W.) and from the same horizon (75 feet above the base of the Kirtland). The better-preserved specimen (No. 8614, U. S. N. M.) is distinguished from Baena nodosa Gilmore, which it most nearly resembles by the broader, more evenly rounded anterior end of the anterior lobe; gulars meeting broadly on the median line; and on the upper side a broad, shallow depression near the anterior border. The borders of the lobe are also more acute than in Baena nodosa Gilmore.

The second specimen (No. 8623, U. S. N. M.) has an anterior lobe resembling somewhat that of Baena escavada Hay, of the Torrejon, though the inflation of this lobe in front of the humero-gular sulcus is not so pronounced as in the type. It differs from No. 8614 , U.S. N. M., in having a smooth ventral surface, as contrasted with the lumpy irregular surface of the other specimen. A third specimen (No. 8624 , U. S. N. M.) from the same locality and horizon, consisting of the left half of the plastron, may belong to the same species.

Two other specimens, though exceedingly fragmentary, are recognizable as representing baenid turtles. Both were collected by Messrs. Reeside and Clark-one at a horizon " 50 feet above the base of the Puerco," 4 miles west of Kimbetoh, in sec. 35 , T. 23 N., R. 9 W.; the other, 4 miles northwest of Kimbetoh, on the north line of sec. 27, T. 23 N., R. 9 W. These 
two specimens are of interest at this time only as recording the occurrence of the genus Baena in the Puerco formation-a not unexpected discovery, for the genus has a range, shown by many species, from the Judith River up to the top of the Uinta (Eocene).

\section{Family DERMATEMYDIDAE Gray.}

The family Dermatemydidae is represented in the present collection by several species each of the two genera Adocus and Hoplochelys. The name Alamosemys, formerly applied to a member of this family, is here made a synonym of Adocus. This study of most excellent materials, which fully sets forth the detailed skeletal structure of these genera, shows the necessity of a slight modification in the definition of the family as previously given by Hay. ${ }^{1}$ That part of the definition which reads "Neural bones reduced in number except in Baptemys" should now also include Hoplochelys, here shown to possess a full complement of these bones.

\section{Genus ADOCUS Cope, 1868.}

The genus Adocus, established by Cope ${ }^{2}$ in 1868, was based on Leidy's type of Emys beatus, a very fragmentary specimen from the Cretaceous greensand of Monmouth County, N. J. Since 1868 seven other species of the genus have been described by different authors. Six of these eight species were founded on specimens from the Cretaceous of New Jersey, and two (A. Tineolatus Cope and $A$. vigoratus Hay) on very fragmentary specimens from the Rocky Mountain region-A. lineolatus, from the Arapahoe formation of northeastern Colorado, and $A$. vigoratus, from the Ojo Alamo formation of northern New Mexico. An adequate comparison of the species found in the East with these two western forms could never be made. In the present collection there are six fairly complete shells and a considerable number of fragmentary specimens which have come from the Fruitland, Kirtland, Puerco, and Torrejon formations. The discovery of representatives of this genus in basal Eocene deposits gives the first record of its occurrence in rocks younger than Upper Cretaceous.

Five new species are here described, thus making the western species more numerous than those from the East. The discovery and

1 Hay, O. P., The fossil turtles of North America: Carnegie Inst. Washington Pub. 75, p. 223, 1908.

2 Cope, E. D., Acad. Nat. Sci. Philadelphia Proc., p. 235, 1868. collection of this well-preserved material forms a most important contribution to our knowledge of the genus Adocus. The specimens are the first that are-sufficiently complete to give an adequate idea of the bony structure of the western forms and thus make a comparison of eastern and western species of this genus possible.

The species come from successive geologic formations, and certain modifications in structural development appear to be indicated in the later species, notably a reduction in size of the marginal scutes. In all the Upper Cretaceous forms these scutes extend well above the costoperipheral suture, whereas in the Puerco species, Adocus hesperius, the costal scutes are enlarged and there is a corresponding diminution in the size of the marginals. Unfortunately, the two species here described, $A$. onerosus and $A$. annexus, from the Torrejon formation, are based on specimens in which the sulci defining the posterior marginals can not be made out. A closely related form, however, from the same formation (Alamosemys substricta $\mathrm{Hay}^{3}$ ) has the marginals entirely below the costo-peripheral suture. In all other respects Alamosemys substricta is essentially an Adocus, and in the absence of other distinguishing characters that could be considered of generic value I propose to regard Alamosemys as a synonym of Adocus. Thus the two species now become Adocus substrictus (Hay) and A. annexus (Hay). That this is the proper disposition of Alamosemys annexa is further indicated by a comparison of the type, a well-preserved plastron, with the plastra of undoubted specimens of Adocus, for it is found that they agree quite as closely in their general proportions and in the proportions of their constituent parts as the type of A. annexus does with the genotype of $A 7 a-$ mosemys, with which, in describing the species $A$. annexa, Hay ${ }^{4}$ has made the closest comparisons.

A study of this material also shows the utter futility of attempting to identify species of Adocus from the character of the ornamentation of fragmentary specimens. It is now known that specimens having the same sculpture of the carapace and plastron show important

${ }^{3}$ Hay, O. P., The fossil turtles of North America: Carnegie Inst. Washington Pub. 75, pp. 260-263, 1908.

4 Hay, O. P., Description of eight new species of fossil turtles from west of the one hundredth meridian: U. S. Nat. Mus. Proc., vol. 38, pp. 318-321, 1910. 
specific differences when a study is made of their bony structures.

The accompanying table shows the geologic range of the genus Adocus and the position of the several species.
Species of the Rocky Mountain region-Continued.

Torrejon species-Continued.

Entoplastron broad behind, pointed in front:

Anterior lobe rounded; the length of lobe 47 per cent of the width at the base.

Adocus substrictus.

Geologic distribution of the species of Adocus.

\begin{tabular}{|c|c|c|c|}
\hline Age. & & Western region. & Eastern region. \\
\hline \multirow{2}{*}{ Basal Eocene. } & Torrejon. & $\begin{array}{l}\text { Adocus onerosus Gilmore, n. sp. } \\
\text { Adocus annexus (Hay). } \\
\text { Adocus substrictus (Hay). }\end{array}$ & \\
\hline & Puerco. & Adocus hesperius Gilmore, n. sp. & \\
\hline \multirow{4}{*}{ Upper Cretaceous. } & Arapahoe. & Adocus lineolatus Cope. & \\
\hline & Ojo Alamo. & Adocus vigoratus Hay. & \multirow{3}{*}{$\begin{array}{l}\text { Adocus beatus (Leidy). } \\
\text { Adocus punctatus Marsh. } \\
\text { Adocus lacer Hay. } \\
\text { Adocus syntheticus Cope. } \\
\text { Adocus agilis Cope. } \\
\text { Adocus pravus Leidy. }\end{array}$} \\
\hline & Kirtland. & $\begin{array}{l}\text { Adocus bossi Gilmore, n. sp. } \\
\text { Adocus kirtlandius Gilmore, n. sp. }\end{array}$ & \\
\hline & Fruitland. & Adocus sp. & \\
\hline
\end{tabular}

The following key, which is an expansion of the one given by Hay, ${ }^{1}$ may assist in distinguishing the species:

Species of the Rocky Mountain region:

Kirtland species:

Posterior lobe truncated behind; the length about 74 per cent of the width at the base.

Adocus kirtlandius.

Posterior lobe rounded behind; the length about 80 per cent of the width at the base.

Arapahoe and Ojo Alamo species:

Adocus bossi.

Sculpture fine, four or five pits in a line 5 millimeters long..................Adocus lineolatus.

Sculpture coarse, three pits in a line 5 millimeters long.................Adocus vigoratus.

Puerco species:

Costal scutes higher than wide; posterior marginals reduced in height but overlapping costal bones.

Torrejon species:

Entoplastron rhombic:

Anterior lobe rounded with slight median notch, the length of lobe 43 per cent of the width at the base..........Adocus annexus.

Anterior lobe truncated; the length of lobe 33 per cent of the width at the base.

Adocus onerosus.

${ }^{1}$ Hay, O. P., The fossil turtles of North America: Carnegie Inst. Washington Pub. 75, p. 236, 1908.
Species of eastern United States:

Hinder lobe of plastron narrowed behind:

Entoplastron wide; nearly equal to length of the suture between the hyoplastrals.

Adocus beatus.

Entoplastron narrow; width nearly twice in the hyoplastral suture...............Adocus pravus.

Hinder lobe broad behind; rounded or truncated:

Gulo-humeral sulcus close to or crossing the entoplastron:

Hinder lobe truncated behind; the length between three-fifths and four-fifths the wid th at the base..........Adocus punctatus.

Hinder lobe broadly rounded; its length three-fifths the width at the base; gulohumeral sulcus just in contact with the entoplastron............ Adocus syntheticus.

Hinder lobe broadly rounded; its length fourfifths the wid th at base; gulo-humeral sulcus well forward on entoplastron.. Adocus lacer.

Gulo-humeral sulcus faliing considerably behind the entoplastron................. Adocus agilis.

Adocus kirtlandius Gilmore, n. sp.

Plates V and VI.

Type: No. 8593, U. S. N. M. Consists of the carapace, which lacks the front margin and the greater parts of all peripherals anterior to the inguinal notches, and the plastron, from which a considerable portion of the anterior 
lobe is missing. Collected by J. B. Reeside, jr., and F. R. Clark, 1916.

Type locality: About $3 \frac{1}{2}$ miles south of west of Kimbetoh, near the south side of sec. 4, T. 22 N., R. 10 W., San Juan County, N. Mex.

Horizon: Kirtland formation (" 75 feet above the base"), Upper Cretaceous.

In addition to Adocus bossi, described below, the Kirtland formation contains a smaller species which I here designate $A$. kirtlandius, in reference to the geologic occurrence of the type specimen.

Both the carapace and the plastron are ornamented with rows of shallow pits. These pits are fairly uniform in size and are arranged mostly in rows that run obliquely across the neurals, costals, and peripheral bones. On the plastron these rows appear to have a general longitudinal direction. So far as can be judged from descriptions and illustrations, the present specimen is indistinguishable in sculpturing from the type and other specimens which have from time to time been referred to Adocus lineolatus Cope, a species founded on scanty materials thought to have come from beds of Arapahoe age. I have shown in a previous paper" that "turtles having a similar surface ornamentation of the shell lived in the Judith River, Ojo Alamo, Belly River, Arapahoe, and Lance epochs," to which we may add the Kirtland and Fruitland epochs. It is now apparent that more than one species is represented by these specimens that have a similar surface sculpture of the shell, and as ornamentation of this kind can no longer be relied on as distinguishing $A$. lineolatus, I shall henceforth regard $A$. lineolatus as an indeterminate species.

It is estimated that the carapace of the type specimen of Adocus kirtlandius (No. 8593 , U.S. N.M.) had a greatest length at the center of about 500 millimeters and a greatest width of about 350 millimeters. The shape of the shell can not be determined from the materials now available. The posterior end, as shown by the type (see Pl. V), is evenly but

1 Gilmore, C. W., Vertebrate faunas of the Ojo Alamo, Kirtland, and Fruitland formations: U. S. Geol. Survey Prof. Paper 98, p. 298, 1916. broadly rounded. All the bones of the carapace are relatively thin. The peripherals posterior to the inguinal notches are thin and reduced to an acute free edge. They are also flared somewhat upward.

The nuchal region is missing. There are seven neurals present, and, with the exception of the sixth, which is reduced in size, they closely resemble those of Adocus punctatus Marsh, from the Cretaceous of New Jersey. As

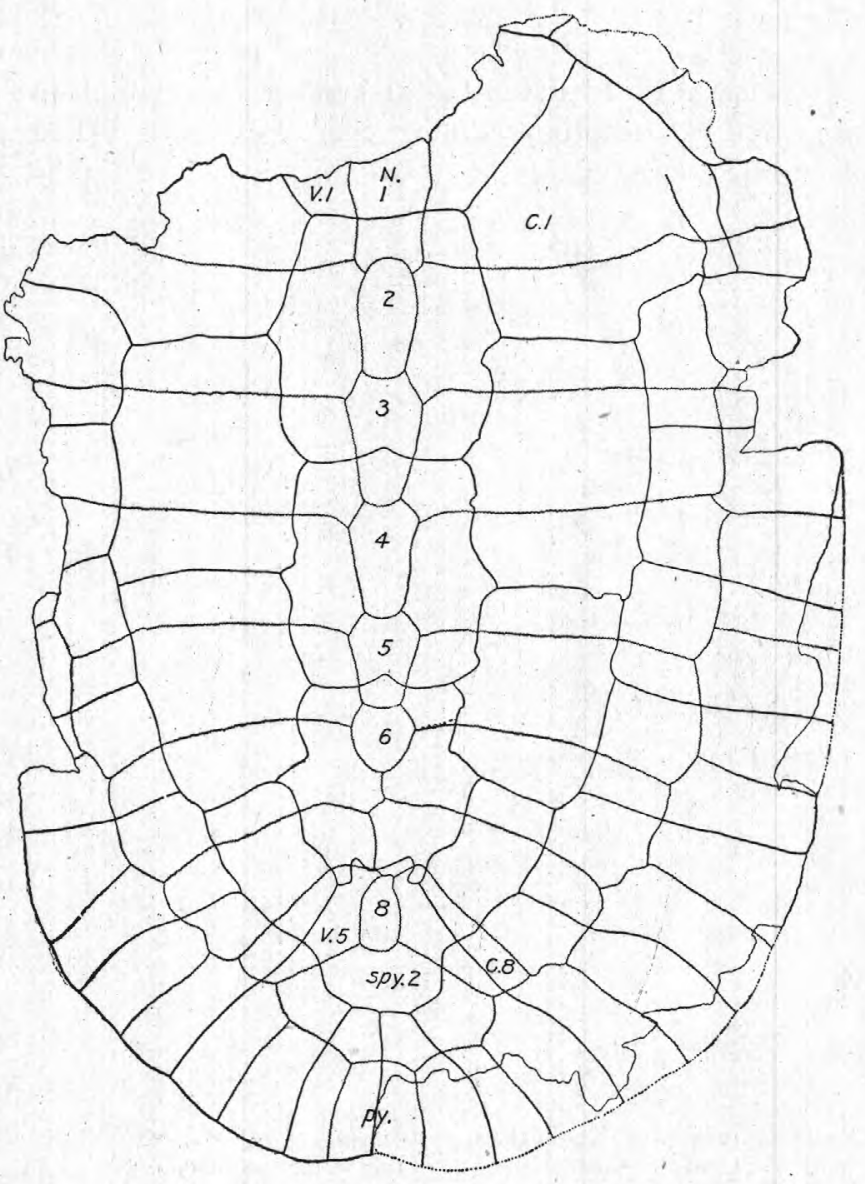

Figure 7.-Carapace of Adocus kirtlandius Gilmore, n. sp. (No. 8593, U.S.N.M.) Type. $C 1, C 8$, Costal bones 1 and $8 ; N 1,2,3,4,5,6,8$, neural bones 1 to 6 and 8; py, pygal; spy 2, suprapygal $2 ; V 1, V 5$, vertebral scutes 1 and 5 . One-fourth natural size. in that species, the seventh neural has disappeared, the second and eighth are suboval in form, and all others are hexagonal.

The reduction in size of the sixth neural and the loss of the seventh permit the sixth and seventh pairs of costals to meet on the midline. In Adocus bossi the eighth neural has disappeared and the eighth pair of costals also meet on the median line. 
Measurements of neurals of Adocus kirtlandius (No. 8593, U.S. N. M.), in millimeters.

\begin{tabular}{|c|c|c|}
\hline No. & Length. & Width. \\
\cline { 1 - 1 } & & \\
\cline { 1 - 2 }$\ldots \ldots$ & $\ldots \ldots$. & $32 \pm$ \\
$3 \ldots \ldots$ & 49 & 23 \\
$4 \ldots \ldots$ & 41 & 30 \\
$5 \ldots \ldots$ & 34 & 27 \\
$6 \ldots \ldots$ & 25.5 & 25 \\
$7 \ldots \ldots$ & $\ldots \ldots .$. & 25 \\
$8 . \ldots$. & 30.5 & 15 \\
\hline
\end{tabular}

Suprapygal 2 is octagonal and has a greatest length of 60 millimeters and a greatestwidth of 90 millimeters.

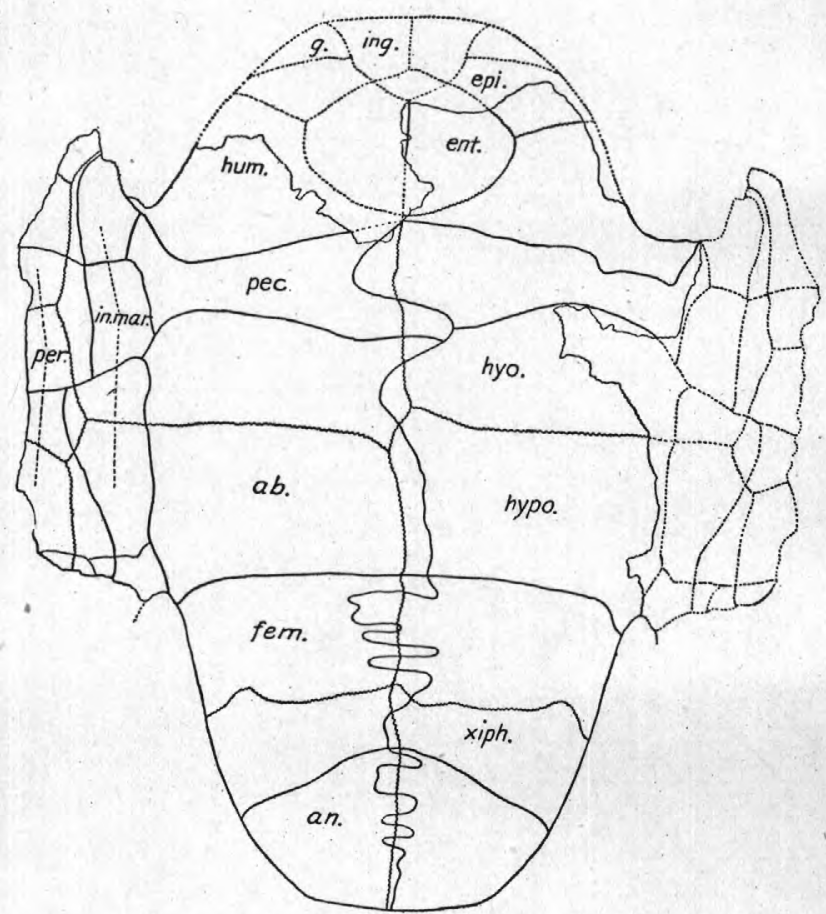

FIGURE 8.-Plastron of Adocus kirtlandius Gilmore, n. sp. (No. 8593, U.S. N. M.). Type. $a b$, Abdominal scute; an, anal scute; ent, entoplastron; epi, epiplastron; fem, femoral scute; $g$, gular scute; hum, humeral scute; hyo, epiplastron; fem, femoral scute; $g$, gular scute; hum, humeral scute; hyo, scute; per, median peripherals; pec, pectoral scute; $x i p h$, xiphiplastron. Onefourth natural size.

The peripherals anterior to the eighth are so poorly preserved as to give but little information regarding them. The eighth has a.width along the free border of 65 millimeters and a greatest height of 84 millimeters; the ninth is 57 millimeters wide on the free border and has a greatest height of 87 millimeters; the tenth is 52 millimeters wide on the free border and has a greatest height of 78 millimeters; the eleventh is 45 millimeters wide on the border and has a greatest height of 63 millimeters.
Only a small portion of the pygal remains, but its upper end has a width of 26 millimeters. It is estimated that the height of this bone was about 54 millimeters.

The costals have the usual shape and proportions for this genus, except that the eighth pair narrow much more rapidly from the median line outward than in any other known species. On the under side of the costals the rib heads are greatly reduced.

The sulci are narrow and very shallowly impressed. The vertebral scutes are large in front but diminish rapidly toward the back. The sides are strongly bracket shaped. The peripheral dimensions of these scutes are given in the subjoined table. Their shape is well shown in figure 7 (p. 27).

Measurements of vertebral scutes of Adocus kirtlandius (No. 8593, U. S. N. M.), in millimeters.

\begin{tabular}{|c|c|c|}
\hline No. & Length. & Width. \\
\cline { 1 - 1 } & & \\
\cline { 1 - 2 } $2 \ldots .$. & 89 & 90 \\
$3 \ldots .$. & 87 & 83 \\
$5 \ldots .$. & 71 & 75 \\
& 63 & 59 \\
\hline
\end{tabular}

The costal and marginal scutes appear to have the usual conformation. The anterior marginals are small and the lateral and posterior are large; there is a corresponding reduction in the area of the costals from the first to the last. The ninth marginal, the longest of the series, measures 124 millimeters in height. The supracaudal scutes meet along the midline for a distance of about 88 millimeters. The first costal scute has a greatest measurement fore and aft of 120 millimeters and a height of 98 millimeters. The last costal scute measures 55 millimeters fore and aft and only 34 millimeters in height.

The plastron lacks the forward half of the anterior lobe, but it is estimated that the total length of the plastron would be about 350 millimeters. The anterior lobe has a width at the base of 182 millimeters. The bridge is 160 millimeters wide. The posterior lobe is $\mathbf{1 2 5}$ millimeters long and 166 millimeters wide at the base. The posterior end is truncated. The free edges of this lobe are subacute, as contrasted with the rounded edges in A.bossi. At 
the center of the bridge the plastron has a greatest transverse width of 242 millimeters.

The plastron is strongly joined to the peripherals by close sutures. The upper sides of the xiphiplastral bones have elongate curved depressions for the pubic bones, as in $A$. punctatus Cope.

The hyoplastrals meet on the midline for a distance of about 72 millimeters; the hypoplastrals for 94 millimeters, the left element being longer than the right in this dimension. The xiphiplastrals meet for 85 millimeters.

The median longitudinal sulci pursue a very irregular course, passing first to one side and then to the other of the median line, as is shown in figure 8. There are four inframarginal scutes on the bridge, the largest one of which extends outward over the median bridge peripheral, whereas in $A$. punctatus these scutes are confined entirely to the plastron.

The pecto-humeral sulcus apparently does not cross the entoplastron, just barely reaching its posterior border. The pectorals measure 42 millimeters along the midline, the abdominals 91 millimeters, the femorals 66 millimeters, and the anals 62 millimeters.

The truncated posterior end of the hinder lobe of the plastron in Adocus kirtlandius distinguishes it at once from all the eastern members of this genus except $A$. punctatus Marsh, and in fact from all other western species in which this portion of the plastron is known. Adocus kirtlandius also resembles A. punctatus in having a broad anterior lobe and the eighth neural. It differs from that species in having the pectoral scutes excluded from the entoplastron, in the greater relative width of the bridge, and in having the vertebral scutes except the third wider than long. From A. vigoratus it is distinguished by the finer ornamentation and the relatively thinner posterior peripheral bones.

The characters that now distinguish Adocus kirtlandius may be summed up as follows:

Specific characters: Posterior lobe with truncated posterior end; eighth neural present, seventh absent, sixth reduced; all vertebral scutes except third wider than long; eighth pair of costals with relatively narrow (fore and aft) proximal ends.
Adocus bossi Gilmore, n. sp.

Plates VII and VIII.

Type: No. 8613, U. S. N. M. Consists of a carapace and plastron, the former lacking the greater part of the costals, all the peripherals of the right side, and peripherals $4,5,9$, and 10 of the left side. The plastron is nearly complete. Collected by J. B. Reeside, jr., 1916.

Type locality: About $2 \frac{3}{4}$ miles south of west of Kimbetoh, in sec. 3, T. 22 N., R. 10 W., San Juan County, N. Mex.

Horizon: Kirtland formation ("75 feet above the base"), Upper Cretaceous.

The specimen selected as the type of the present species is the largest known member of the genus. In a straight line the carapace measures 670 millimeters in length, and in front of the middle it is about 520 millimeters wide. The species is named for Mr. N. H. Boss, preparator in the section of vertebrate paleontology, whose patience and skill in preparing this specimen and in fitting together the great number of broken fragments have made it possible to recognize and describe the species. Although much of the right side of the carapace is missing, enough remains to indicate clearly all the essential characters of the shell (fig. 9).

In form the shell is elongate, being broadly rounded in front and probably also behind. It appears to be widest in front of the middle instead of behind it, as in A. punctatus Marsh, although there is a possibility that these proportions are due to the incompleteness of the individual, especially of the posterior peripherals. The shell is high through the center but slopes off toward either end, so that except for being slightly flattened on the middle portions it is convex in all directions but more steeply inclined in transverse diameter. The posterior peripherals are largely missing. Peripheral 8 has an acute edge with an inclination to flare upward, but those in front of the axillary notches are thickened and rounded on the edges, the upper borders rising above the general level of the upper surface and thus forming a shallow gutter which gradually fades out posterior to the center.

The ornamentation of the carapace and the bones of the plastron consist of shallow pits arranged in more or less regular rows, which 
usually run oblique to the sutural borders of the bones. This ornamentation is of the coarse style, as in $A$. vigoratus Hay, there being usually three pits in a 5-millimeter line. The ridges between the pits are rounded, and the cross ridges are rather indistinct. This coarser sculpture distinguishes this species from $A$. kirtlandius, found in the same formation, which has four or five pits in a 5-millimeter line. The nuchal bone is shallowly notched on the

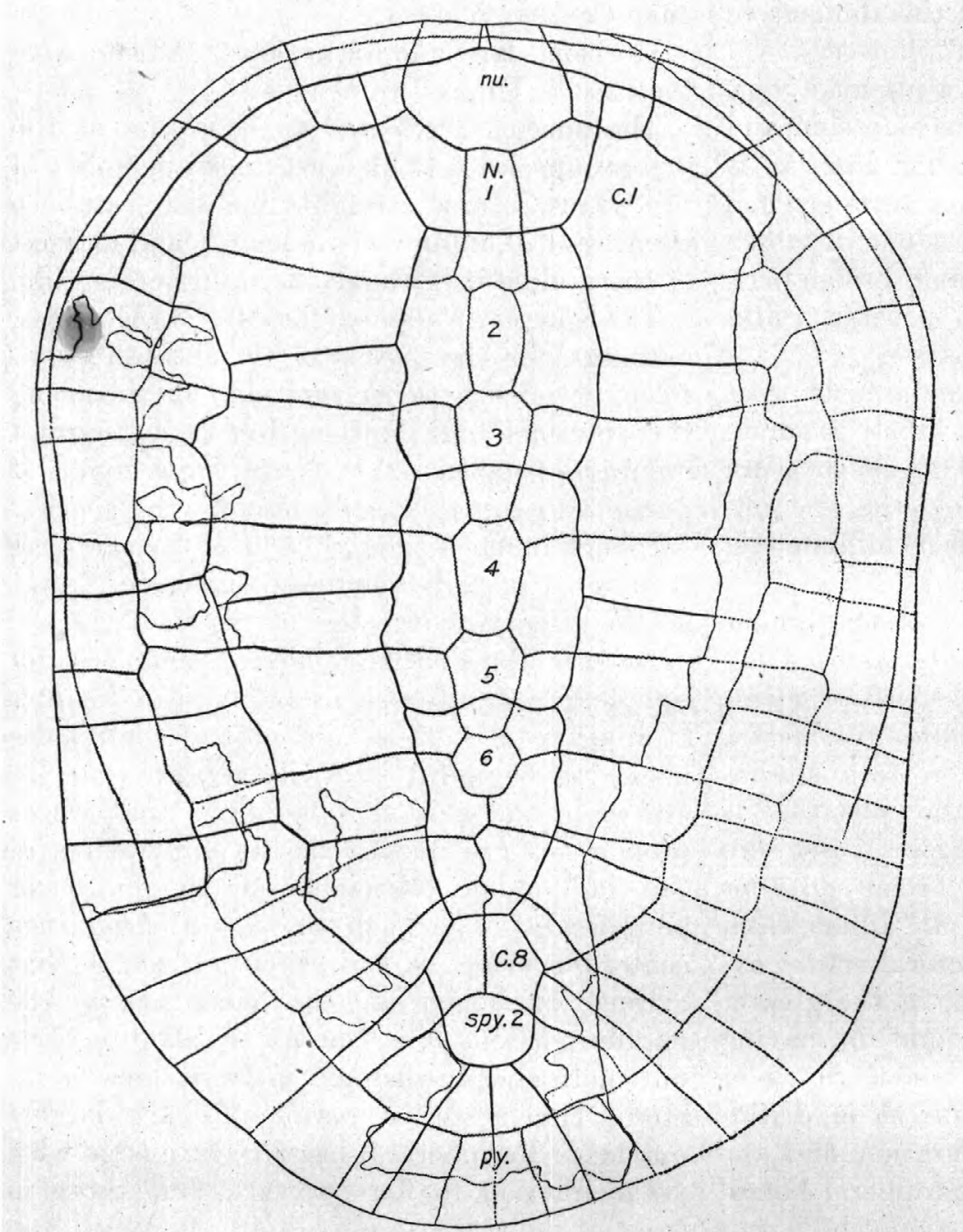

Figure 9.-Carapące of $A$ docus bossi Gilmore, n. sp. (No. 8613,U.S.N.M.). Type. $C 1, C 8$, Costal bones 1 and $8 ; N 1,2,3,4,5,6$, neural bones 1 to 6 ; $n u$, nuchal; $p y$, pygal; spy 2 , second suprapygal. One-fifth natural size.

midline of the free border. It is 87 millimeters long, 90 millimeters in maximum width, and 69 millimeters wide on the free border. There are six neurals. Those posterior to the sixth have disappeared, and the costals meet on the median line.
Measurements of neurals of Adocus bossi (No. 861s, U. S. N. M.), in millimeters.

\begin{tabular}{|c|c|c|}
\hline No, & Length. & Width. \\
\hline $\begin{array}{l}1 \ldots \ldots \\
2 \ldots \\
3 \ldots \\
4 \ldots \\
5 \ldots \\
6 \ldots\end{array}$ & $\begin{array}{l}88 \\
59 \\
65 \\
57 \\
51 \\
32\end{array}$ & $\begin{array}{l}38+ \\
29 \pm \\
39 \\
37 \\
39 \\
36\end{array}$ \\
\hline
\end{tabular}

The second neural is elliptical; the others are hexagonal. The first has the broader end behind, the others in front. The sixth neural interposes itself only part way between the sixth pair of costals, so that behind this neural these costals join on the midline, as do the seventh and eighth pairs. The single suprapygal is large, but its exact contour can not be determined from this specimen, though it is probably octagonal. Fore and aft its greatest length is 90 millimeters.

The peripherals; as in the other species of the genus, are large.

Measurements of peripherals of Adocus bossi (No.8613, U. S. N. M.), in millimeters.

\begin{tabular}{|r|r|r|}
\hline No. & Height. & $\begin{array}{r}\text { Length } \\
\text { of free } \\
\text { border. }\end{array}$ \\
\hline & & \\
$1 \ldots .$. & 80 & 75 \\
$3 \ldots .$. & 80 & 78 \\
$4 \ldots \ldots$ & 109 & 73 \\
$5 \ldots .$. & 80 \\
$6 \ldots .$. & 119 & 69 \\
$7 \ldots .$. & 110 & 73 \\
$8 \ldots$. & 120 & 75 \\
\hline
\end{tabular}

The pygal, which lacks its posterior extremity, is estimated to measure about 65 millimeters in height; at the upper end it is 31 millimeters wide.

The sulci on both carapace and plastron are narrow and shallowly impressed. 
Measurements of vertebrals of Adocus bossi (No. 8613, U.S. N. M.), in millimeters.

\begin{tabular}{|r|r|r|}
\hline No. & Length. & $\begin{array}{r}\text { Width. } \\
.\end{array}$ \\
\cline { 1 - 3 } $1 \ldots .$. & 123 & 136 \\
$2 \ldots .$. & 124 & 104 \\
$3 \ldots .$. & 117 & 100 \\
$4 \ldots .$. & 113 & 80 \\
$5 \ldots .$. & 89 & 65 \\
\hline
\end{tabular}

The four anterior marginals are small and below the costo-peripheral suture, but the fifth rises high above the costo-peripheral suture. The fourth marginal has a greatest height at right angles to the border of 48 millimeters; the fifth is at least three times as high. This great height of the marginals decreases correspondingly the area of the costal scutes. The eighth is 180 millimeters in height and the next two are but little lower. The supracaudal scutes meet along the midline for a distance of about 110 millimeters. The costal scutes diminish in size from the first to the last, as in all the other species of this genus.

The nuchal scute is wedge-shaped, with the point directed forward and barely reaching the free margin. It is 20 millimeters long and its posterior end is 7 millimeters wide.

The posterior pair of costals, the widest of the series, meet on the midline for a distance of 57 millimeters.

The plastron (see fig. 10) is large. The anterior lobe, as in the other species of the genus, is short and broad, with a truncated end, but the posterior lobe is elongated, with a sharply rounded end. The total length of the plastron is 510 millimeters. The anterior lobe is 103 millimeters long, and 255 millimeters wide at the base.

The large entoplastron is subhexagonal in outline and measures 105 millimeters in width and 70 millimeters antero-posteriorly. The bridge is 235 millimeters wide. The length of the posterior lobe is 175 millimeters, and its width at the base 220 millimeters. The free borders of the posterior lobe are subacute, being sharply beveled off from the upper side. This beveled surface rises above the level of the surface so as to form a decided ridge along the posterior half of this lobe, which subsides before reaching the midline. On the dorsal surface on the midline 28 'millimeters forward of the posterior border is a subconical projec- tion that stands well above the surrounding surfaces. At either side and somewhat forward are well-defined pubic scars. The posterior end of this lobe turns decidedly upward from the horizontal. The truncated end of the anterior lobe is 80 millimeters wide. On either side the free border is thickened (14 millimeters) and rounded, but more posteriorly it thins (7 millimeters) to a narrow rounded border. The plastron articulates with the carapace by means of buttresses and sutures.

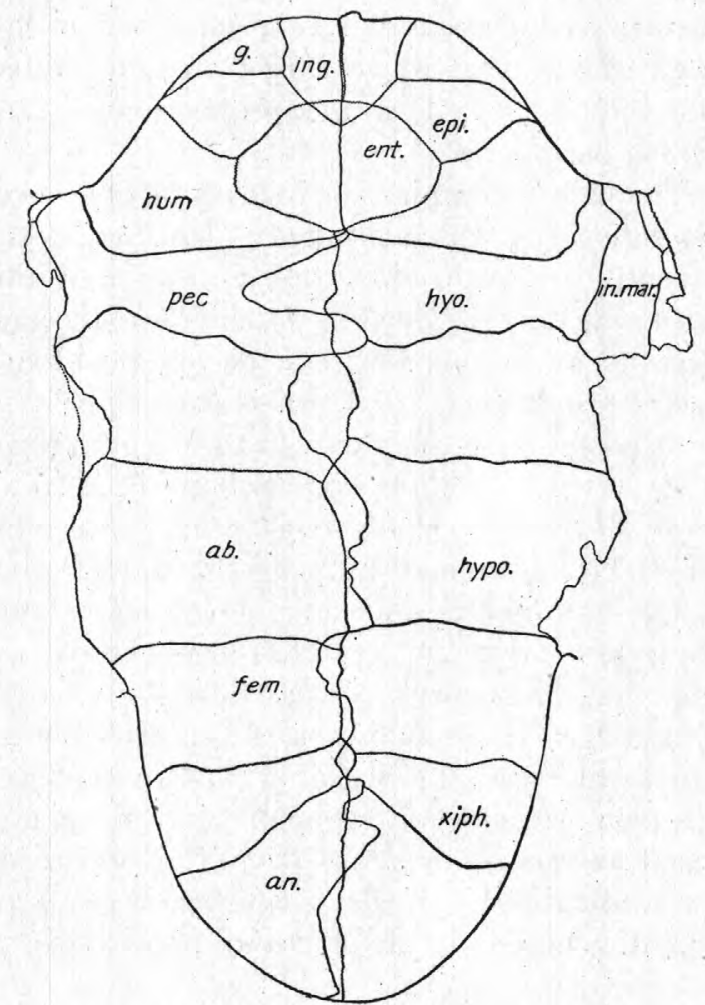

Figure 10.-Plastron of Adocus bossi Gilmore, n. sp. (No. 8613, U. S. N. M.). Type. ab, Abdominal scute; $a n$, anal scute; ent, entoplastron; epi, epiplastron; fem, femoral scute; $g$, gular scute; hum, humeral scute; hyo, hyoplastron; hypo, hypoplastron; ing, intergular scute; in mar, inframarginal scute; $p e c$, pectoral scute; $x i p h$, xiphiplastron. One-fifth natural size.

The epiplastra meet on the midline for a distance of 43 millimeters. The right hyoplastron is wider than the left, but they meet for a distance of 109 millimeters on the midline; the hypoplastron for 137 millimeters; and the xiphiplastron for 124 millimeters.

The sulci are moderately impressed, and the longitudinal sulcus runs a very irregular course, crossing first to one side and then to the other of the median longitudinal suture. The gulars are excluded from meeting on the midline by the interposition of the intergulars. The 
intergulars overlap slightly the forward end of the entoplastron. They meet on the midline for 57 millimeters, the humerals for 53 millimeters, the pectorals for 65 millimeters, the abdominals for 140 millimeters, the femorals for 74 millimeters, and the anals for $\mathbf{1 1 0}$ millimeters.

The species has inframarginal scutes, but their number can not be determined from this specimen.

Adocus bossi closely resembles $A$. vigoratus Hay in the character and coarseness of the surface sculpture, but it is to be distinguished from that species by its larger size and differences to be found in the proportions of the eighth peripheral.

The eighth peripheral of the type of Adocus vigoratus Hay was mistakenly identified as the seventh in the original description, and this error was unrecognized in my subsequent comparison of this bone with a peripheral identified $^{1}$ as belonging to $A$. lineolatus Cope.

A comparison of the eighth peripheral of $A$. bossi with the homologous bone in $A$. vigoratus shows that while both are of the same length (73 millimeters), the height of the former is 120 millimeters and that of the latter only 96 millimeters. Other differences noted are that the free border of $A$. bossi presents a more acute edge; the shoulder on the anterior border which receives the inguinal buttress of the plastron is relatively thinner, and the sculptured surface extends in from the border on the ventral side of the peripheral to half its height, whereas in $A$. vigoratus it is considerably less.

Typically Adocus bossi is the largest species of the genus. From A. kirtlandius, of the same geologic horizon, it is distinguished by the rounded hinder end of the plastron, the greater length of the anal scutes, the absence of neural 8, the very wide proximal ends of the eighth pair of costals, and the vertebral scutes longer than wide. From $A$. hesperius it is distinguished by the coarser character of the sculpturing of the shell and in having the costal scutes longer than high, whereas in that species they are higher than long.

From the Torrejon forms Adocus annexus and A. substrictus the present species is at once distinguished by the truncated anterior end of

1 Gilmore, C. W., Vertebrate faunas of the Ojo Alamo, Kirtland, and Fruitland formations: U. S. Geol. Survey Prof. Paper 98, pp. 297-298, 1916. the plastron as contrasted with the rounded lobes in $A$. annexus and $A$. substrictus. Adocus onerosus, found in the same formation, has a truncated anterior lobe, but the relative proportions are quite unlike in the two species. In $A$. bossi the length of the anterior lobe is 40 per cent of the width, whereas in $A$. onerosus it is 33 per cent of the width. The rhomboid shape of the entoplastron of $A$. onerosus will also assist in distinguishing these forms.

The characters which now appear to distinguish Adocus bossi are as follows:

Specific characters: Typically of large size; anterior lobe truncated, length 40 per cent of width at base; posterior lobe rounded; seventh and eighth neurals suppressed, sixth reduced; all vertebrals except first longer than wide; eighth pair of costals meeting wide on midline; anterior border of carapace but slightly excavated for the neck, entoplastron broad behind, pecto-humeral sulcus falling somewhat behind the entoplastron; sculpture coarse, three pits in 5-millimeter line.

A second specimen (No. 8577, U. S. N. M.) from the same locality and the same geologic horizon as the type of Adocus bossi is here provisionally identified as pertaining to that species. It consists of a complete plastron firmly joined by the bridge peripherals to the damaged central part of the carapace, as shown in Plate VIII. The carapace lacks much of the forward end as well as suprapygal 2 and the peripherals of the posterior end. The specimen is a considerably smaller individual than the type, and while in the main features these specimens closely agree, there are other minor differences, as will be shown later.

The carapace of this specimen, though badly damaged by crushing and the loss of important parts, shows that there were six neurals in the same state of reduction as in the type. The sixth neural being much reduced in size and the seventh and eighth entirely gone, the corresponding costals of opposite sides meet on the midline. As in the type, the eighth pair are especially wide at the center.

The plastron is in a beautiful state of preservation and clearly shows all the suitures between the different bones and all the sulci defining the dermal scutes. The greatest length of the plastron at the center is 380 millimeters. As in the type of $A$. bossi, the 
anterior lobe is short and broad and has a truncated anterior end. The anterior lobe is 88 millimeters long and 205 millimeters wide at the base. The entoplastron is broad behind, pointed in front, and overlapped by the intergular scutes; the pectoral-humeral sulcus barely reaches its posterior border.

The posterior lobe is relatively shorter than in the type, the posterior end is more broadly rounded, and the areas of the anal scutes are somewhat reduced. None of these differences, however, could be considered as representing more than individual peculiarities.

This specimen shows that Adocus bossi has three inframarginal scutes. The middle one is 93 millimeters long and 21 millimeters wide, and in the proportions of this scute $A$. bossi closely resembles $A$. Zacer Hay, from the New Jersey Cretaceous. The bridge region in the type of $A$. bossi is so damaged that it is impossible to determine either the number or the shape of these scutes.

The principal dimensions of the bones forming the plastron along the center line in specimen No. 8577 are as follows: The epiplastrals meet for 29 millimeters; the hyoplastrals differ in this measurement, the left being 77 millimeters and the right 92 millimeters fore and aft; the hypoplastrals likewise differ on the two sides, the left measuring 105 millimeters and the right 96 millimeters; the xiphiplastrals meet for 99 millimeters.

The intergulars meet on the median line for 25 millimeters, the pectorals for 44 millimeters, the humerals for 47 millimeters, the abdominals for 102 millimeters, the femorals for 68 millimeters, and the anals for 71 millimeters. The area of the anals is considerably less than in the type specimen.

\section{Adocus hesperius Gilmore, n. sp.}

Plate IX.

Type: No. 8596 , U. S. N. M. Consists of the carapace, lacking the anterior border and the peripherals and distal parts of the costals of the left side. (See fig. 11.) Collected by J. B. Reeside, jr., 1916.

Type locality: Four miles northwest of Kimbetoh, in secs. 27 and 22, T. 23 N., R. 9 W., San Juan County, N. Mex.

Horizon: Puerco formation (" 50 feet above the base"), basal Eocene.

$$
115836^{\circ}-19-3
$$

The specimen selected as the type of the new species Adocus hesperius has additional interest in being the first representative of the genus to be found in the Puerco formation.

In the type specimen the carapace is crushed flat, which makes it impossible to determine anything of the transverse contours of the shell. By a comparison with other specimens it is estimated that the carapace when complete had a total length at the center of about 480 millimeters. The greatest width at the center, as now flattened out, is 440 millimeters; in life it probably measured somewhat less. Viewed from above the posterior end of the shell is regularly rounded. Behind the inguinal notch the free borders of the peripherals present acute edges, and, as in $A$. kirtlandius, these bones have a tendency to flare upward.

The first neural and the anterior half of the second neural are missing. The series in this species, as in $A$. bossi, consists of six neurals, and the sixth one is reduced in size. The dimensions of those preserved are given in the table:

Measurements of neurals of Adocus hesperius (No. 8596, U.S. N.M.), in millimeters.

\begin{tabular}{|c|c|c|}
\hline No. & Length. & Width. \\
\cline { 1 - 1 } $3 \ldots \ldots$ & 45 & 27 \\
$4 \ldots .$. & 37 & 23 \\
$6 \ldots .$. & 34 & 24 \\
& 28 & 21 \\
\hline
\end{tabular}

On account of the suppression of the seventh and eighth neurals and the reduction in size of the sixth neural, the sixth, serenth, and eighth pairs of costals meet on the median line. The eighth pair measure 38 millimeters fore and aft where they join at the middle but taper down to a width of only 13 millimeters at their outer extremities.

There is a single large pentagonal second suprapygal. It is 73 millimeters in length along the midline and has a greatest width of 111 millimetters.

The pygal bone is 57 millimeters high and 56 millimeters in transverse diameter.

The eleventh peripheral bone is 58 millimeters wide on the free border and 64 millimeters high, the tenth 53 millimeters wide and 79 millimeters high, the ninth 54 millimeters wide and 81 millimeters high, the eighth 56 
millimeters wide and 81 millimeters high, the outward beyond the costo-peripheral suture. seventh 60 millimeters wide and 77 millimeters The second costal has a length of 85 millihigh, and the sixth 58 millimeters wide and 79 meters and a height of 96 millimeters; the millimeters high.

third is 81 millimeters long and 91 millimeters

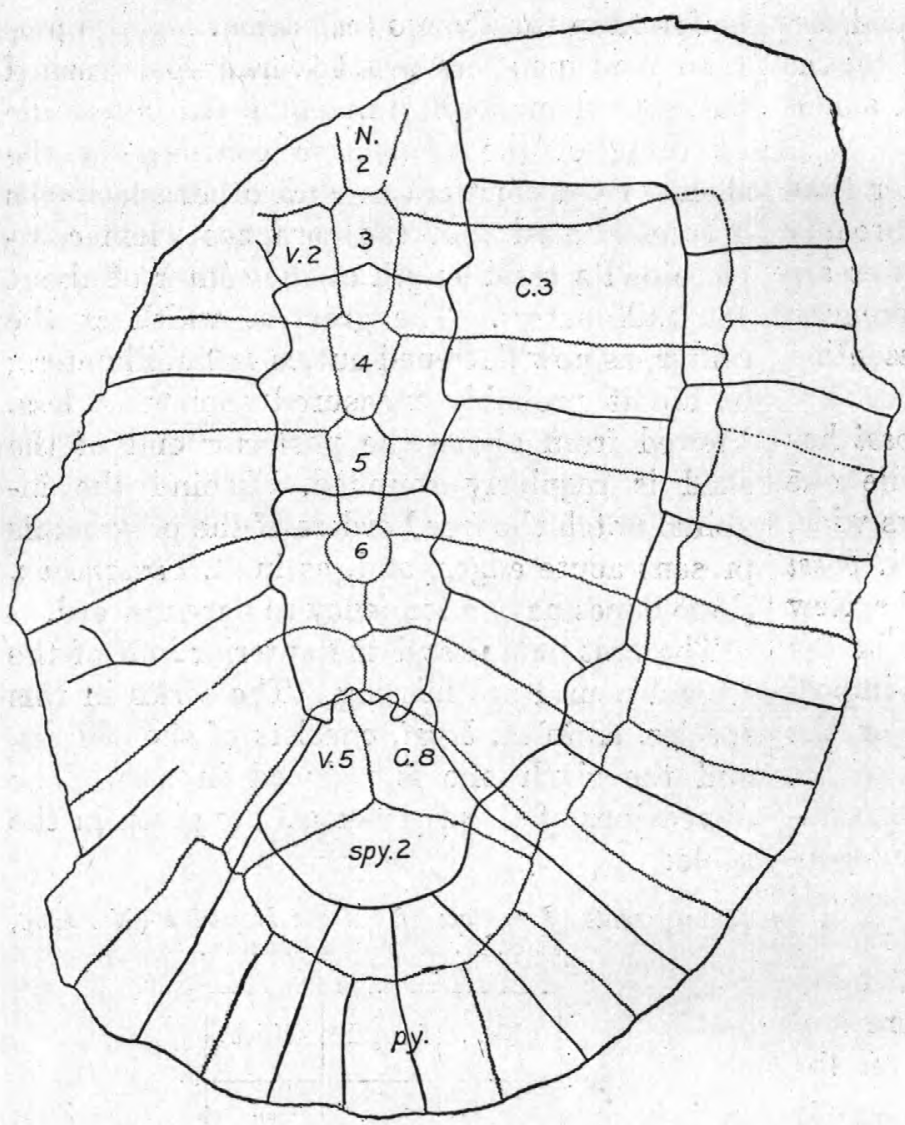

FigURE 11.-Carapace of Adocus hesperius Gilmore, n. sp. (No. 8596, U. s. N. M.) Type. $C s, C 8$, Costal bones 3 and $8 ; N 2,3,4,5,6$, neural bones 2 to $6 ; p y$, pygal; spy 2 , second suprapygal; $V \&, V 5$, vertebral scutes 2 and 5 . One-fourth natural size.

The vertebral scutes are relatively large, especially the fifth.

Measurements of vertebrals of Adocus hesperius (No. 8596, U.S. N. M.), in millimeters.

\begin{tabular}{|c|c|c|}
\hline No. & Length. & Width. \\
\hline 2. & & 80 \\
\hline 3. & 85 & 75 \\
\hline 4. & 77 & 67 \\
\hline 5. & 87 & 83 \\
\hline
\end{tabular}

The supracaudal scutes meet along the midline for a distance of 83 millimeters.

The costal scutes are higher than long, whereas in all other species the length exceeds the width. In this respect this species shows a development in the direction of $A$. substrictus, of the Torrejon, in which the costals extend in height; the fourth is 56 millimeters long and 62 millimeters in height.

The marginal scutes of $A$. hesperius are reduced in height as compared with those of the Cretaceous species of Adocus.

The type specimen shows that all marginals posterior to the fifth extend above the costo-peripheralsuture. On the assumption that the complete series consists of eleven marginals, the dimensions of those posterior to the fifth are given in the table below.

\section{Measurements of the marginals of Adocus hesperius (No. 8596, U. S. N. M.), in} millimeters.

\begin{tabular}{|c|c|c|}
\hline No. & Height. & $\begin{array}{l}\text { Width } \\
\text { on free } \\
\text { border. }\end{array}$ \\
\hline $\begin{array}{c}6 \ldots \\
7 \ldots \\
8 \ldots \\
9 \ldots \\
10 \ldots \\
11 \ldots\end{array}$ & $\begin{array}{c}93 \pm \\
94 \pm \\
85 \\
104 \\
104 \\
104\end{array}$ & $\begin{array}{l}60 \\
60 \\
59 \\
62 \\
56 \\
51\end{array}$ \\
\hline
\end{tabular}

The whole surface of the carapace is ornamented with small shallow pits. On the peripherals these pits are arranged in rows that assume an oblique direction to the longer axes of the bones. On the surface of the costals, and especially within the area of the vertebral scutes, the pits are not so well defined, being hardly more than longitudinal valleys between rounded ridges that are narrower than the depressions; the cross ridges are commonly absent or, if present, are low and barely discernible.

The finer sculpture of $A$. hesperius, which has four pits in a line 5 millimeters long, distinguishes this species at once from both $A$. vigoratus Hay and $A$. bossi, which have only three pits in a 5-millimeter line.

The absence of the plastron in the type of Adocus hesperius makes it difficult to contrast this species with the eastern members of the genus. It is distinguished, however, from all known species in which the carapace is pre- 
served, except the Torrejon forms, by the proportions of the costal scutes, which are higher than long. The finer sculpture and more rounded form of the pits forming the surface ornamentation will separate the present species from $A$. vigoratus Hay, from the Ojo Alamo formation. The posterior marginal scutes, extending slightly above the costo-peripheral suture, distinguish $A$. hesperius from $A . s u b-$ strictus, in which these marginals are confined exclusively to the peripheral bones. From $A$. onerosus and $A$. annexus the present species is to be separated by the better-defined pattern of the sculpture, and from A. onerosus by having the vertebral scutes longer than wide instead of wider than long.

The following combination of characters appears to be diagnostic of this species:

Specific characters: Seventh and eighth neurals suppressed, sixth reduced; vertebral scutes longer than wide; fifth vertebral unusually large; eighth pair of costals meeting wide on the midline; costal scutes higher than long; posterior marginals reduced in height; sculpture made up of rounded pits; three pits in 5-millimeter line.

\section{Adocus onerosus Gilmore, n. sp.}

Plate $\mathrm{X}$, figures 1 and 2.

Type: No. 8594 , U. S. N. M. Consists of a considerable part of a poorly preserved carapace, which lacks most of the peripherals, except those of the median anterior border, and the plastron, which lacks the posterior ends of the xiphiplastral bones.

Type locality: Eight miles N. $60^{\circ}$ E. of Kimbetoh, in sec. 17, T. 23 N., R. 8 W., San Juan County, N. Mex.

Horizon: Torrejon formation (" 840 feet above the base of Puerco, in Torrejon"), basal Eocene.

The specimen here designated as the type of the new species Adocus onerosus is, like many other fossil specimens from the Torrejon formation, in so poor a state of preservation as to leave many points in the structure of its anatomy undetermined. Not only has the carapace suffered much from crushing and the loss of important parts, but the coalescence of many of the sutures and the obscureness of the sulci render the study of the individual bones and dermal scutes difficult.
The few posterior peripherals present in specimen No. 8594 show no marginal sulci crossing them at right angles, and their absence leads to the conclusion that the scutes extended above the costo-peripheral suture overlapping the costal bones, as in all known specimens of Adocus. This genus has not before been recognized in the Torrejon formation, and the discovery of the type of $A$. onerosus and another specimen, described below, thus materially extends its previously known geologic range.

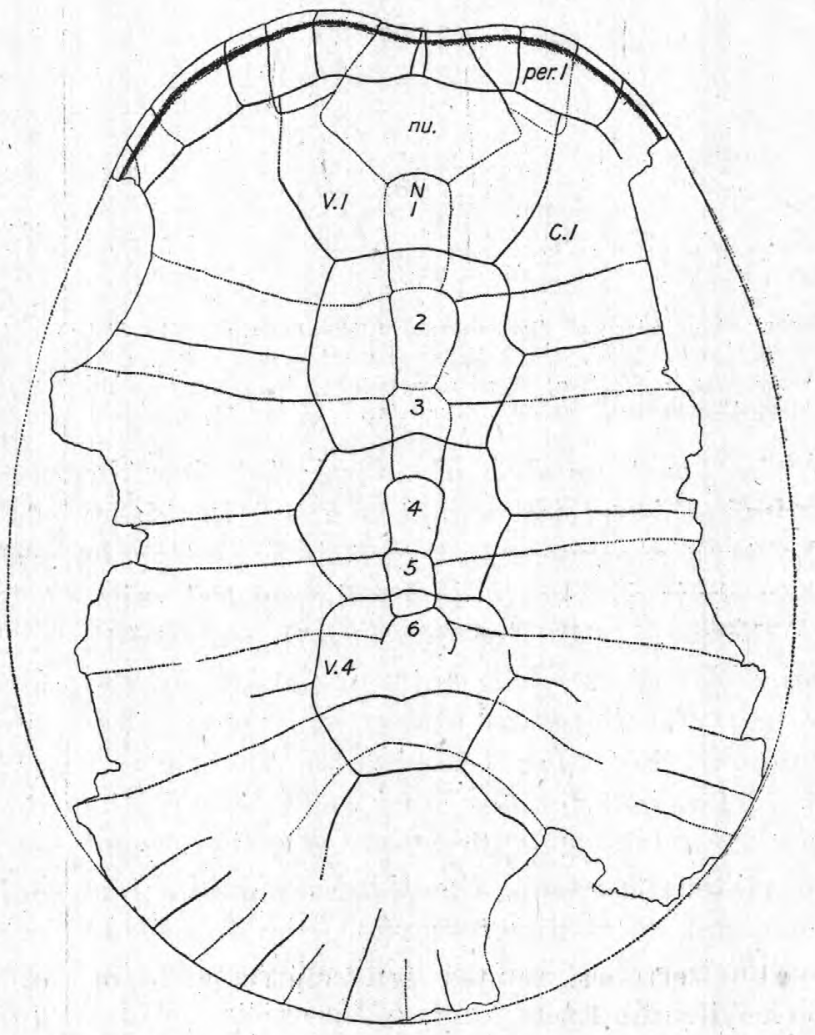

FIGURE 12-Carapace of Adocus onerosus Gilmore, n. sp. (No. 8594, U. s. N. M.). Type. $C 1$, First costal bone; $N 1,2,3,4,5,6$, neural bones 1 to 6; $n u$, nuchal; per 1, peripheral 1; V1,V4, vertebral scutes 1 and 4. Onefifth natural size.

The type specimen is a large individual, the carapace of which is estimated to have had in life a total length at the center of about 600 millimeters. The contours of the front border, both horizontal and vertical, have been preserved, though elsewhere the carapace is crushed out flat. It shows this end to have been broadly rounded, with a pronounced emargination for the neck at the middle. (See fig. 12.)

The nuchal, one of the few bones in this specimen to be clearly differentiated, is hexagonal. It has a greatest length of 76 milli- 
meters and a greatest width of 102 millimeters, and its free border is only 43 millimeters wide. Near the anterior rim and on the bordering peripherals the nuchal flares upward.

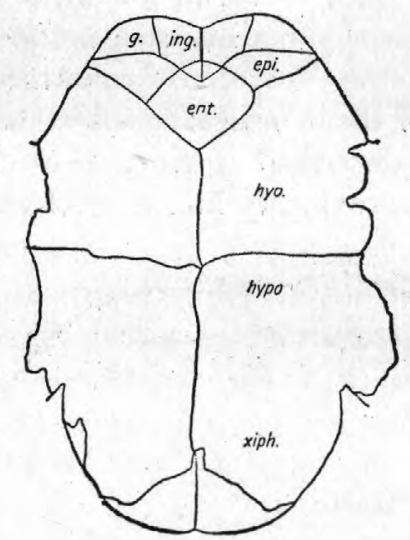

Figure 13.-Plastron of Adocus onerosus Gilmore, n. sp. (No. 8594, U.S. N. M.). Type. ent, Entoplastron; epi, epiplastron; $g$, gular scute; hyo, hyoplastron; hypo, hypoplastron; ing, intergular scute; xiph, xiphiplastron. One-fifth natural size.

The exact number of neurals forming the series in this species can not be determined from the type specimen, but that it is not more than six is clearly shown by the sutural union on the median line of the seventh and eighth pairs of costals. The anterior neurals appear to have the shape and proportions indicated in figure 12 , but some uncertainty still exists as to their exact limits. As identified here the first neural is 62 millimeters long, the second 54 millimeters long, the third 48 millimeters long and 35 millimeters wide, the fourth 43 millimeters long and 33 millimeters wide, the fifth 36 millimeters long. The existence of a sixth neural can not certainly be determined.

As in $A$. bossi, the eighth pair of costals meet for a considerable distance (48 millimeters) on the median line.

Of the bones forming the borders of the shell only peripherals 1,2 , and 3 of the anterior end and a few badly preserved ones posterior to the inguinal notches are preserved. The first peripheral has a width on the free border of 67 millimeters and a height of 65 millimeters; the second is 56 millimeters wide and 64 millimeters high; the third is 52 millimeters wide.

The costal sutures are nearly all plainly discernible, as shown in figure 12 .

The nuchal scute is small and $V$-shaped with the point forward. It is 24 millimeters long and 9 millimeters wide at the posterior end. The first marginal has a width of 58 millimeters and a height of 36 millimeters; the second is 57 millimeters wide and 46 millimeters high; the third is 54 millimeters wide.

The vertebrals are exceptionally short and wide.

Measurements of vertebrals in Adocus onerosus (No. 8594, U. S. N. M.), in millimeters.

\begin{tabular}{|r|r|l|}
\hline No. & Length. & Width. \\
\cline { 1 - 2 } & & \\
\cline { 1 - 2 } & 90 & 180 \\
$2 \ldots$ & 101 & 116 \\
$4 \ldots$. & 85 & 119 \\
& 102 & $103 \pm$ \\
\hline
\end{tabular}

The posterior peripherals are all badly preserved. Their free edges are acute and they show the same tendency to flare upward as in other species.

The whole surface of the carapace is ornamented with pittings that on the peripherals appear to be arranged diagonally to the longer axis of the bones. Toward the center of the shell there appears to be no pattern or at least nothing more than rather obscure longitudinal groovings.

The plastron is complete except for the greater portion of the bridges and the posterior end of the xiphiplastrals.

The anterior lobe is broadly truncated, and the truncated end is broadly and angularly concave. The length of the anterior lobe is 72 millimeters and its greatest width at the base is 215 millimeters. The anterior border presents a blunt edge which at the center is only 5 millimeters in thickness.

The entoplastron is subrhombic, 65 millimeters long and 87 millimeters wide. The length of the posterior lobe can not be determined; its width at the base is 183 millimeters. The free edge is acute up to the inguinal buttress. Near the edge this part of the plastron is only 5 millimeters thick, but 20 millimeters toward the center from the edge the bones increase to 13 millimeters in thickness. The posterior lobe near the position of the femoral sulcus shows a marked contraction, and the whole border of the lobe appears to have rounded in rapidly toward the center, as restored in figure 13 .

The epiplastrals meet on the median line for a distance of 23 millimeters, the hyoplastrals for 70 millimeters, and the hypoplastrals for 107 millimeters. It is estimated that the bridge 
had a width of 148 millimeters. Of the sulci only those bounding the gular and intergular scutes can now be recognized. The intergulars lap over the forward end of the entoplastron. They meet on the midline for a distance of 35 millimeters, and their combined width is 64 millimeters.

The whole surface of the plastron appears to have been covered with some obscure pitting, the exact character of which can not be made out in this specimen.

Additional and corroborative information relating to the plastron of this species is furnished by two other specimens.

Specimen No. 8650, U. S. N. M., is from the same locality and geologic horizon as the type and consists of the articulated epiplastra and a portion of the entoplastron. It shows the same truncated end with abrupt border. This specimen is the only member of the species known at this time which shows an accurate outline of the anterior half of the entoplastron. The two sides meet at the center, forming an obtuse angle of about $135^{\circ}$.

Specimen No. 8649 , U. S. N. M., consists of the greater portion of a plastron, of about the same proportions as the type specimen. Unfortunately the precise locality and geologic horizon where this specimen was obtained are unknown, though in all probability about the same as those of the type. Its chief importance at this time is in being the first specimen to show the extent of the plastral scutes posterior to the intergulars. The intergulars overlap the forward end of the entoplastron, which is missing in this specimen. The pectorals reach the posterior border of the entoplastron but do not overlap; they measure 40 millimeters along the median line. The pecto-humeral sulcus curves forward very little at the center; the pecto-abdominal sulcus swings backward with a considerable sweep. In all other species this condition is reversed. The abdominals meet on the midline for 87 millimeters, the femorals for 69 millimeters.

Adocus onerosus resembles $A$. bossi in having a truncated anterior lobe, but the length of this lobe is only 33 per cent of the width at the base, a proportion that is considerably less than in any other known species of the genus.

It resembles $A$. annexus (Hay) in the rhombic form of the entoplastron, in the obscure character of the ornamentation, and in the well-defined median excavation of the anterior boarder of the carapace for the reception of the neck. It can be distinguished from that species, however, by difference found in the shape and proportions of the anterior lobe, so plainly seen by a comparison of figures 13 and 14.

The specific characters of Adocus onerosus may be enumerated as follows:

Specific characters: Anterior lobe of plastron truncated; length 33 per cent of width at base; epiplastrals meeting for a relatively short distance on midline; entoplastron rhombic; overlapped in front by intergulars; anterior border of carapace with pronounced median excavation for reception of neck. Sculpture having obscure pattern.

\section{Adocus annexus (Hay) Gilmore.}

Plate XI, figures 1 and 2; Plate XII.

Alamosemys annexa Hay, U. S. Nat. Mus. Proc., vol. 38, pp. 318-321, fig. 19, 1911.

This species was established by Hay on a well-preserved plastron (No. 6539, U. S. N. M.) found by J. H. Gardner, of the United States Geological Survey, in sec. 1, T. 34 N., R. 8 W., in the Ignacio quadrangle, La Plata County, Colo.

A comparison of this plastron with that of the genotype of Alamosemys (A. substricta Hay) showed such close similarities as to bring about its reference to that genus.

Alamosemys was distinguished from Ad́ocus by a single character, the restriction of the marginal scutes to the peripheral bones. In all other respects the specimens referred to Alamosemys are essentially like Adocus. In the present collection the species Adocus hesperius, found in the Puerco formation, shows an enlargement of the costal scutes and a corresponding reduction in the height of the marginals, which still, however, rise above the costo-peripheral suture. It would appear, therefore, that Adocus substrictus (Hay), of the Torrejon formation, might well represent the next stage in the progressive reduction of the marginal scutes. In the absence of other distinguishing characters which might be considered of generic value, I now regard Alamosemys as a synonym of Adocus, and thus the two species become Adocus substrictus (Hay) and $A$. annexus (Hay). 
The soundness of the above conclusion appears to be further strengthened by a study. of two specimens from the Torrejon formation in the present collection, which in their main features clearly belong to the genus Adocus. Unfortunately the sulci defining the posterior marginals can not be traced in these specimens, so that the extent of the marginal scutes can not be determined. One is described in the present paper as the type of the new species A. onerosus, the other (No. 8606, U. S. N. M.) plastron of specimen No. 8606 confines the contrasting of the specimens to the general proportions of the plastra and of the individual bones which make up that part of the shell.

In the accompanying table are presented various comparative measurements of the plastra of the type specimens on which Adocus annexus (Hay) and Adocus substrictus (Hay) were founded and specimen No. 8606. The first three columns give actual measurements; the fourth column contains the measurements

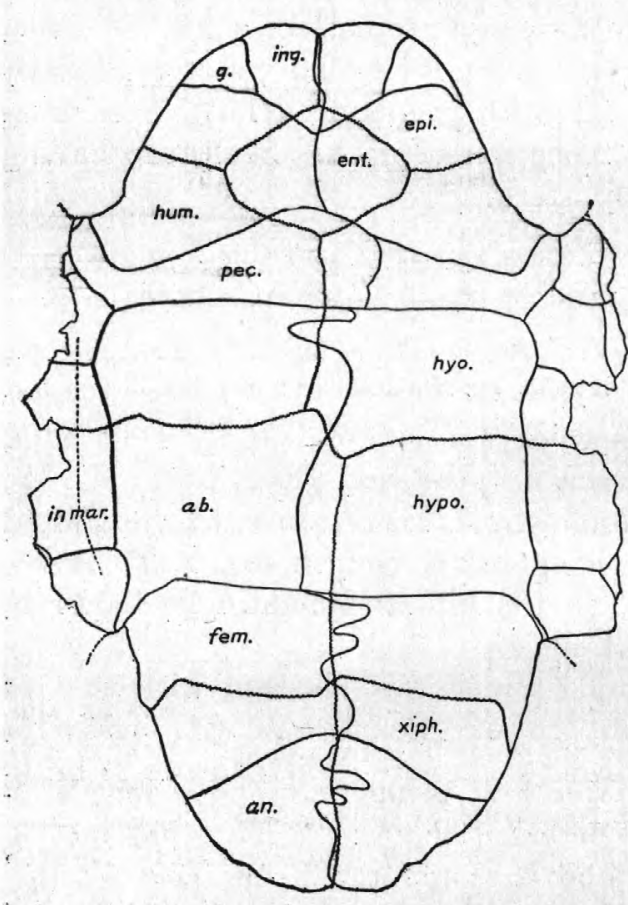

Figure 14.-Plastron of Adocus annexus (Hay) (No. 6539, U. S. N. M.). Type. $a b$, Abdominal scute; $a n$, anal scute; ent, entoplastron; epi, epiplastron; $g$, gular scute; hum, humeral scute; hyo, hyoplastron; pec, pectoral scute; fem, femoral scute; hypo, hypoplastron; ing, intergular; in mar, inframarginals; xiph, xiphiplastron. One-fourth natural size.

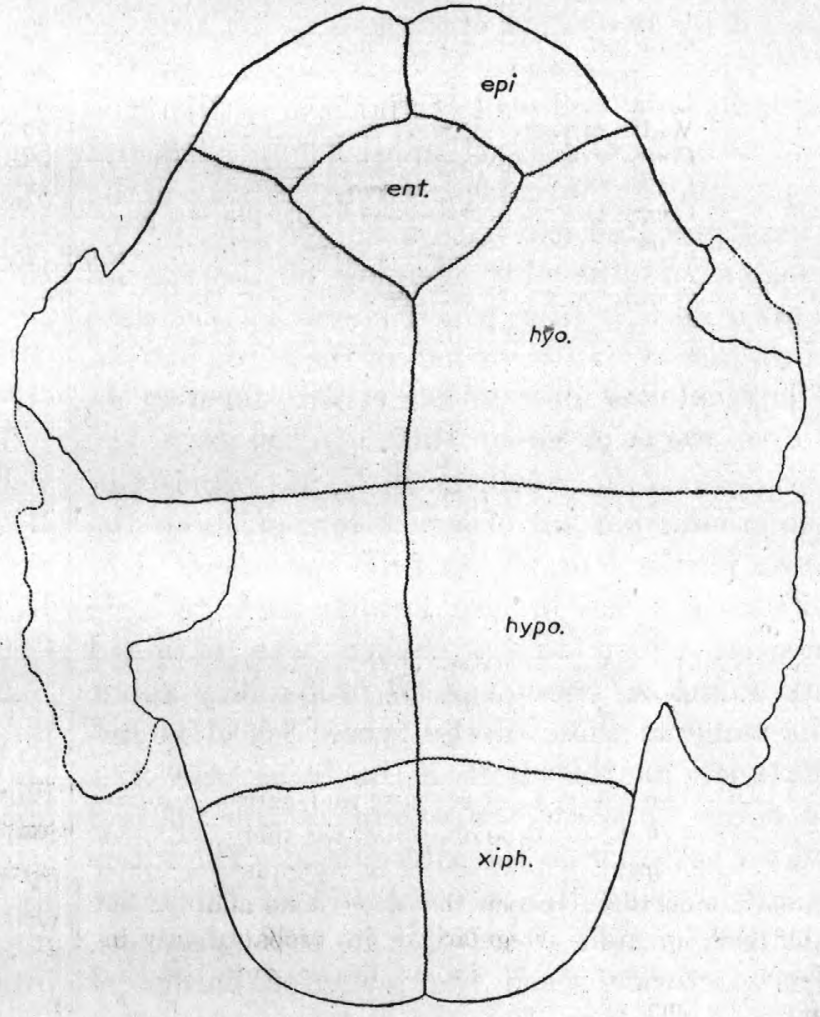

Figure 15.-Plastron of Adocus annexus (Hay) (No. 8606, U. S. N. M.); ent, Entoplastron; epi, epiplastron; hyo, hyoplastron; hypo, hypoplastron; xiph, xiphiplastron. One-fourth natural size. is here provisionally referred to $A$. annexus. This specimen consists of the damaged carapace (see Pl. XII) and the complete plastron. It was collected by J. B. Reeside, jr., 8 miles N. $60^{\circ}$ E. of Kimbetoh, in sec. 17 , T. 23 N., R. 8 W., San Juan County, N. Mex., in the Torrejon formation (" 840 feet above base of Puerco, in Torrejon") basal Eocene.

The specific identity of this specimen with the type of Adocus annexus (Hay) appears to be established by a comparison of the plastra of the two specimens. (See figs. 14 and 15.) The obliteration of nearly all the sulci on the of the first column reduced 16 per cent, and the fifth column contains the measurements of the second column reduced 15 per cent, the length of the anterior lobe of the type of $A$. annexus, 84 millimeters, being made the standard. A comparison of the measurements in the third column with those in the fourth and fifth columns shows at once the differences between No. 8606 and $A$. substrictus, and the close resemblance of No. 8606 to A. annexus.

The rhombic shape of the entoplastron in specimen No. 8606 is further evidence of its specific identity with $A$. annexus. 
Comparative measurements of plastra of Adocus, in millimeters.

\begin{tabular}{|c|c|c|c|c|c|}
\hline & \multicolumn{3}{|c|}{ True measurements. } & \multicolumn{2}{|c|}{$\begin{array}{l}\text { Reduced measure- } \\
\text { ments. }\end{array}$} \\
\hline & \multirow{2}{*}{$\begin{array}{l}\text { A. sub- } \\
\text { strictus } \\
\text { (type). }\end{array}$} & \multicolumn{2}{|c|}{ A. annexus. } & \multirow{2}{*}{$\begin{array}{l}\text { A. sub- } \\
\text { strictus } \\
\text { (type). }\end{array}$} & \multirow{2}{*}{$\begin{array}{c}\text { A. an- } \\
\text { nexus } \\
(\text { No. 8606) }\end{array}$} \\
\hline & & No. 8606. & $\begin{array}{l}\text { No. } 6539 \\
\text { (type). }\end{array}$ & & \\
\hline Length of anterior lobe.... & 100 & 99 & 84 & 84 & 84 \\
\hline Width of anterior lobe....... & 209 & 230 & 177 & 175 & 195 \\
\hline Thickness of edge near front.......... & 9 & 8 & 8 & 7.5 & 7.8 \\
\hline Length of entoplastron.............. & 55 & 65 & 51 & 46 & 55 \\
\hline Width of entoplastron......... & 90 & 87 & 71 & 76 & 74 \\
\hline Width of bridge........... & 180 & 185 & 160 & 151 & 157 \\
\hline Length of posterior lobe........ & 132 & 120 & 100 & 110 & 102 \\
\hline Width of posterior lobe......... & 190 & 182 & 163 & 160 & 155 \\
\hline Contact of hyoplastral bones..... & 100 & 78 & $72 \pm$ & 84 & 66 \\
\hline Contact of hypoplastral bones............. & 135 & 107 & $100 \pm$ & 113 & 91 \\
\hline 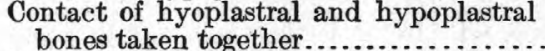 & 235 & 185 & 173 & 197 & 158 \\
\hline 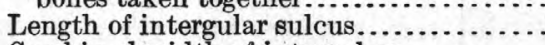 & 50 & & 43 & 42 & ......... \\
\hline Combined width of intergulars............ & 75 & 78 & 65 & 63 & 66 \\
\hline
\end{tabular}

The detailed description of the plastron of A. annexus as given by Hay is as follows:

The anterior lobe is rounded in front, without appearance of epiplastral lip. Its free borders are subacute. Seen from above, the bones thicken from this edge, until at about 15 millimeters from the edge they have a thickness of from 7 to 9 millimeters. The upper surface of the lobe is nearly flat. The buttresses, anterior and posterior, are little developed. The entoplastron differs from that of A. substricta in being somewhat pointed behind, instead of rounded or subtruncated. It is longer than that of A. substricta in the ratio of 51 to 46 and narrower in the ratio of 71 to 76 . It will be observed that there is a union of the left hyoplastron with the right hypoplastron and a similar connection between the latter bone and the left xiphiplastron. Such irregularities are probably only individual peculiarities, but similar ones are quite common among the ancient turtles.

It is seen that the hyoplastra and the hypoplastra are shorter than in $A$. substricta, relatively to the length of the anterior lobe. The bridge, too, is shorter. The free border of hinder lobe is somewhat less acute than that of the anterior lobe. At the hypo-xiphiplastral suture the bones are 9 millimeters thick. On the midline, 30 millimeters behind the suture just mentioned, the thickness is only 7 millimeters. The free borders of the xiphiplastrals posteriorly are acute. On the upper surface of each xiphiplastral there is a crescentric elevation for attachment of the pubic bone.

The lower surface of the plastron is very indistinctly sculptured. The appearance is as if there were rows of small pits as in Adocus, but they are so faintly impressed that they are hardly to be detected.

It will be seen that many of the horny scutes had very irregular boundaries. Especially the median sulcus runs a very tortuous course. The gular and intergular scutes differ little from those of $A$. substricta. The humeropectoral sulcus crosses the hinder border of the entoplas- tron. In $A$. substricta the sulcus is only tangent to the bone. The line of contact between the right and the left humerals is thus shorter than in A. substricta in the ratio of 28 to 40 . * * * The pectorals of the two species have the same relative length as also the abdominals have. The hinder lobe of $A$. annexa is more narrowed posteriorly than that of $A$. substricta. On exch bridge there are four inframarginal scutes, which resemble closely those of the type of the genus.

The plastron of specimen No. 8606 at the center measures 395 millimeters in length. The anterior lobe is 99 millimeters long and 230 millimeters wide at the base. The length of this lobe is therefore 43 per cent of the width, whereas in Adocus onerosus it is only 33 per cent. The anterior lobe is rounded, as in the type of $A$. annexus, but the hinder lobe has a relatively broader posterior extremity, which resembles that of $A$. substrictus more nearly than it does that of the type of $A$. annexus.

Only the gular-intergular sulcus can be made out, and it shows that the forward end of the entoplastron was overlapped somewhat by the intergular scutes.

The surfaces of both carapace and plastron are ornamented with pittings, but this specimen is so poorly preserved that the pattern is obscure. A considerable portion of the anterior and median part of the carapace is preserved with this specimen, and although only a few of the sutures and none of the sulci can be traced, it is important as giving us the first information regarding the upper shell of this 
species. It shows the anterior end of the carapace to have been broadly rounded, with a pronounced median excavation for the neck of the animal. In the contour of this end of the carapace it shows a striking resemblance to Adocus onerosus, described above, and also to $A$. substrictus.

The nuchal plate is 89 millimeters long and has a greatest width of 94 millimeters and a width on the free border of 58 millimeters. The upper surface of this bone as it approaches the free border flares upward, like the bordering peripherals.

The first peripheral is 62 millimeters wide and 63 millimeters high; the second 55 millimeters wide. None of the other bones have been differentiated.

Adocus annexus may now be characterized as follows:

Specific characters: Anterior lobe rounded, with slight median notch; length 43 per cent of width at base; posterior lobe rounded; seventh and eighth neurals suppressed; vertebrals wider than long; eighth pair of costals meeting for a considerable distance on midline; entoplastron rhombic overlapped by both intergular and pectoral scutes.

\section{Genus HOPLOCHELYS Hay, 1905.}

The study of the excellent collection of Hoplochelys material now enables me to define the genus as follows:

A genus of the Dermatemydidae. External surfaces of the shell finely shagreened. Carapace flattened on top and having three dorsal carina. Eight neurals. Eleven peripherals, which unite with the plastral bones by means of digitations and dentated sutures; with the costals by gomphosis, and in young by simple apposition with pits for distal prolongations of costals, in adults by close sutures. Plastron cruciform, with anterior and posterior lobes immovable, and with the posterior narrow end pointed. A row of inframarginal scutes on each bridge. Pectoral and femoral scutes meeting and crowding the abdominals from mutual contact at the midline. Intergulars and gulars wanting or consolidated with the humerals.

All the known specimens of this genus, with the exception of the type of Hoplochelys coelata Hay, from the Fort Union of Montana, have come from the basal Eocene deposits of New Mexico. Seven species are now recognized, two of which are described as new in the present paper.

The type of the genus is Hoplochelys crassa (Cope), a fragmentary specimen, which is now thought to be an immature individual, so that some of the characters formerly used for distinguishing the species can no longer be regarded as valid specific differences. Fortunately an articulated specimen (No. 8525, U. S. N. M.), consisting of the greater part of the carapace and the median portion of the plastron, appears to be referable to this species and for the first time gives a comprehensive idea of the chief characteristics of the species.

With the exception of $H$. paludosa Hay, based on a single peripheral, the other Torrejon species of the genus Hoplochelys may at once be distinguished from the Puerco representatives by their relatively wider vertebrals and neurals.

Of the seven described species five have been recognized in the present collection, all represented by well-preserved specimens. These show that there was a full complement of eight neural bones, a feature in which this genus differs from all other members of the family Dermatemydidae, except Baptemys, thereby requiring a slight modification in the definition of that family.

The accompanying table shows the geologic distribution of the species.

Hay ${ }^{1}$ regards Hoplochelys as being doubtfully related to Staurotypus, now living in southern Mexico and Guatemala, of which Sumichrast ${ }^{2}$ says:

It lives in muddy pools. Its food consists of small aquatic animals, especially of mollusks belonging to the genus Ampullaria. Its disposition is voracious and irritable. Its gait on land is free, and it runs with some swiftness, a fact due to the form of the plastron, which leaves to the limbs freedom of motion.

Hay ${ }^{3}$ observes: "The small posterior lobe of the plastron of Hoplochelys indicates that the hinder limbs were strong and endowed with freedom of movement. Its habits and disposition may have been not greatly different from those of Staurotypus."

1 Hay, O. P., The fossil turtles of North America: Carnegie Inst. Washington Pub. 75, p. 263, 1908.

2 Soc. zool. France Bull., 1880, p. 169.

3 Op. cit., p. 266 
Geologic distribution of the species of the genus Hoplochelys.

\begin{tabular}{l|l|l}
\hline Fort Union. & Hoplochelys coelata Hay. \\
\cline { 2 - 2 } & $\begin{array}{l}\text { Hoplochelys saliens Hay. } \\
\text { Hoplochelys paludosa Hay. } \\
\text { Hoplochelys elongata Gilmore, } \\
\text { n. sp. }\end{array}$ \\
\hline $\begin{array}{l}\text { Torrejon. } \\
\text { \% }\end{array}$ & $\begin{array}{l}\text { Hoplochelys crassa (Cope). } \\
\text { Hoplochelys bicarinata Hay. } \\
\text { Hoplochelys laqueata Gilmore, } \\
\text { n. sp. }\end{array}$ \\
\hline
\end{tabular}

Hoplochelys crassa (Cope) Hay.

Plate XIII.

Dermatemys sp. Cope, Am. Philos. Soc. Proc., vol. 20, p. 461 (no description), 1882.

Chelydra crassa Cope, Science, vol. 11, p. 198 (no description), 1888; Am. Philos. Soc. Trans., $2 \mathrm{~d}$ ser., vol. 16, p. 306, 1888.

Hay, Bibliography and catalogue of the fossil Vertebrata of North America: U. S. Geol. Survey Bull. 179, p. 446, 1902.

Hoplochelys crassa (Cope) Hay, Am. Geologist, vol. 35, p. 339, 1905; The fossil turtles of North America: Carnegie Inst. Washington Pub. 75, pp. 263-265, text fig. 325 , pl. 38, figs. 4-9, 1908.

Matthew, W. D., Geol. Soc. America Bull., vol. 25, p. $383,1914$.

Hoplochelys crassa was established by Cope on the remains of two individuals. Hay, ${ }^{1}$ in discussing this species, says of these:

Of the first there were present two vertebral bones, nine peripherals, and three plastrals; of the second, three vertebrals. The bones of the first-mentioned individual are now in the American Museum of Natural History and bear the catalogue number 6091; where the remains of the second specimen are is not at present known.

Through the kindness of Dr. W. D. Matthew, specimen No. 6091 was lent to me for study with the present collection, and by comparison with it I have identified three individuals as pertaining to this species. These bear the catalogue Nos. 8525,8641 , and 8643 , U. S. N. M. No. 8525 has a considerable part of the carapace preserved and is the first specimen to give adequate information as to the shape and general proportions of the shell. (See Pl. XIII.)

The principal characters for distinguishing the species Hoplochelys crassa, as pointed out by Hay, are in "having the bones of the plastron less firmly sutured with the latter bones, at least those of the bridge region, without close

1. The fossil turtles of North America: Carnegie Inst. Washington Pub. 75, p. 236, 1908. suture with the costals." This is precisely the condition noted in both Nos. 8641 and 8643, a condition which I will attempt to demonstrate is due to the immaturity of the individuals. In the type of $H$. crassa (Cope), now before me, the few peripherals present have the upper borders smooth - that is, without sutural edgesand the upward extension of these bones above the costo-marginal sulcus is exceedingly short. In all other respects, including the deep pits on the inner side for the costal rib extensions, these bones are identical with those which have a higher development of the bone above the costo-marginal sulcus and which are suturally united with the ends of the costals. It is also significant that all three of the specimens showing this peculiarity of the peripherals are much smaller individuals than any of those in which the sutural union of the peripherals and costals has been perfected. Additional evidence of the immaturity of specimen No. 8643 is furnished by the unfinished character of the sutural surface on the hyoplastron for union with the epiplastron, which in all larger individuals is strongly and clearly defined.

It would thus appear that the species $H$. crassa (Cope) was founded on a juvenile specimen and that the characters heretofore used for distinguishing the species are largely due to the immaturity of the individuals and can not be relied upon as being constant specific differences. However, specimen No. 8525, which agrees in all other respects with the type of $H$. crassa, such as having sharp lateral keels and well-defined carinae crossing the bridge peripherals, now shows other characters that clearly distinguish the species, and on that account I now give a detailed description of this specimen.

Specimen No. 8525 , U. S. N. M., consists of the greater part of the carapace and median portion of the plastron. (See fig. 16.) Several of the neurals and portions of the costals and peripherals are missing. The specimen was collected by J. B. Reeside, jr., in 1916, 4 miles east of Kimbetoh, in sec. 35, T. 33 N., R. 9 W., San Juan County, N. Mex., 50 feet above the base of the Puerco formation. Although lacking many important parts, this specimen is nevertheless perfect enough to give a very good idea of the shape and proportions of the shell of this species. 
The carapace is moderately elongate oval, slightly truncated in front by the very narrow excavation for the neck, and pointed behind, as in $H$. laqueata. The posterior end of the carapace has a moderate slope to the peripherals. The shell presents the usual shagreened surface, which is apparent only under the glass. The carapace on the midline measures 235 millimeters in length. The width in life is estimated to be about 160 millimeters, which is 68 per cent of the length.

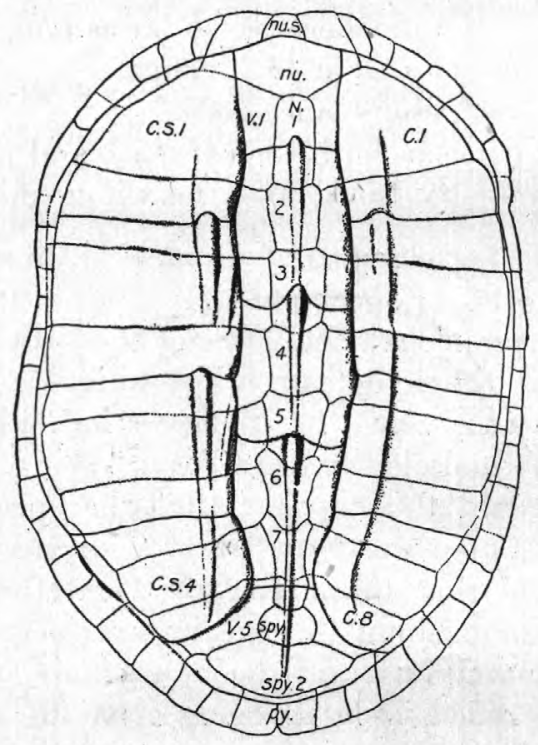

FIGURE 16.-Carapace of Hoplochelys crassa (Cope) (No. 8525, U. S. N. M.). $C 1, C 8$, Costal bones 1 and $8 ; C S 1, C S 4$, costal scutes 1 and $4 ; N 1,2, s, 4, \mid 5,6,7$, neural bones 1 to $7 ; n u$, nuchal; $n u s$, nuchal scute; $p y$, pygal; $s p y$, suprapygal; $s p y$ 2, second suprapygal; $V 1, V \bar{b}$ vertebral scutes 1 and 5 . One-third natural size.

There are three dorsal carinae. The lateral keels are sharply defined, as in the type, and have acute crests, not obtuse, as in H. bicarinata, or broadly rounded, as in H. laqueata.

The second neural is hexagonal, with the broader end forward. It is 18 millimeters long and 14 millimeters wide. With the exception of portions of the first and third, all the other neurals are missing.

The nuchal is narrowly excavated for the neck. Its width in front is 34 millimeters; its greatest width 55 millimeters; its length 37 millimeters.

The first peripheral is 26 millimeters high; the second 25 millimeters long and 28 millimeters high. The acute edge of the anterior peripherals continues across the bridge peripherals as a sharp, well-defined ridge or keel that eventually becomes the acute edge of the pos- terior peripherals. Above this lateral keel on the bridge the peripherals abruptly thicken to form a sort of roll along the shell. Above this thickening the peripherals send a plane portion upward to unite suturally with the costals. At the base of this upward prolongation of the peripherals runs the costo-marginal sulcus, which is throughout the shell well below the costo-peripheral suture.

The pygal is 22 millimeters wide and 23 millimeters high. Its free border is acutely edged and shallowly notched at the center.

The sulci are narrow but well defined on account of recurring in shallow depressions in the bone. Where these cross the lateral keels they loop forward, as in the other species.

The vertebrals were narrow. The first measures 40 millimeters in length and has a greatest width at the anterior end of only 33 millimeters; the posterior end is 37 millimeters wide. The second vertebral is about 45 millimeters long and 36 millimeters wide; the third about 42 millimeters long and 35 millimeters wide.

The nuchal is small and trapezoidal, with the widest end posterior. Its width on the free border is 6.5 millimeters; its greatest width 11 millimeters; its length 9 millimeters. The costo-marginal sulci are well below the costoperipheral suture. The intermarginal sulci are toward the anterior ends of the peripherals.

Of the plastron only portions of the hyoplastra and hypoplastron remain. These elements, on the right side at the hyo-hypoplastral sulture, measure 58 millimeters in width. It is estimated that the bridge had a width of about 30 millimeters. The usual intermarginals are present on the bridge. The abdominals are distant 17 millimeters from the center of the plastron.

In the shape and proportions of the carapace this specimen most nearly approaches the type of $H$. laqueata, but it is distinguished from that species by the much narrower excavation of the nuchal for the neck, by the sharpness of the lateral keels as contrasted with their rounded crests in $H$. laqueata by the presence on the bridge peripheral of a sharp and welldefined longitudinal keel, and by a greater thickening of these bones ventral to the costomarginal sulcus. The unusual narrowness of the first vertebral will also help to distinguish this species. It is quite possible that some of 
the differences pointed out may be sexual characters, but at this time I know of no way of determining the sex in this extinct genus of turtles.

Specific characters: Carapace oval, pointed behind; breadth of carapace 68 per cent of length; lateral carina well defined, sharp; carina crossing bridge peripherals well defined, sharp; excavation for neck narrow.

Hoplochelys bicarinata Hay.

Plate XIV, figures 1 and 2.

Hoplochelys bicarinata Hay, U. S. Nat. Mus. Proc., vol. 38, pp. 321-324, pl. 12, text figs. 20-23, 1910.

The species Hoplochelys bicarinata Hay was founded on a somewhat fragmentary specimen (No. 6549, U. S. N. M.) consisting of two

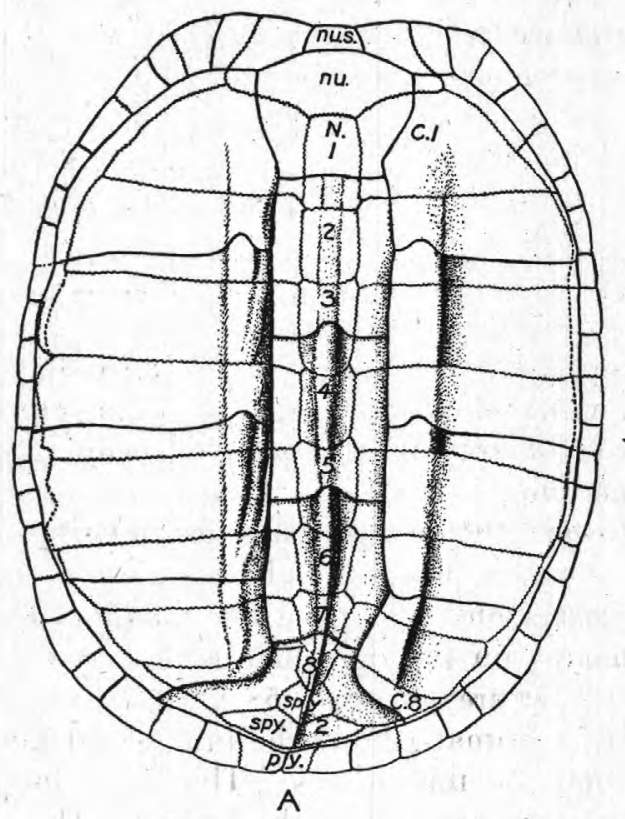

this specimen in considerable detail as being the first individual to portray fully the skeletal structure of this genus.

This specimen was collected by J. B. Reeside, jr., 4 miles east of Kimbetoh, in sec. 35, T. 23 N., R. 9 W., in the San Juan Basin, N. Mex., 50 feet above the base of the Puerco formation. This would appear to be about the same geologic horizon as that of the type specimen found in the vicinity of Ojo Alamo, N. Mex.

Specimen No. 8524, U. S. N. M., is an individual of slightly larger size than the type of the species but otherwise, so far as homologous parts are available for comparison, showing the closest resemblance to it.

The bones of both the carapace and plastron are relatively thick, and the whole shell is of

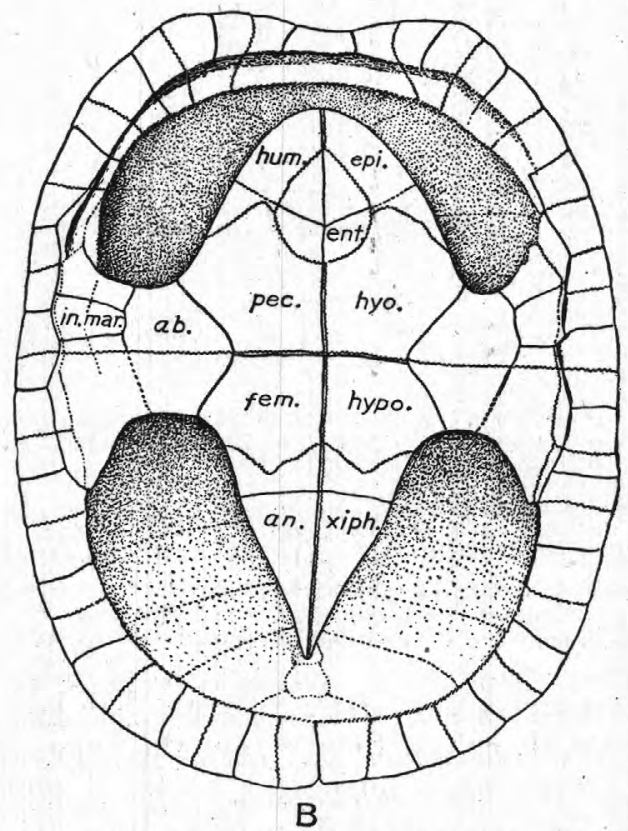

Frgure 17.-Hoplochelys bicarinata Hay (No. 8524, U. S. N. M.). A, Carapace: $C 1, C 8$, Costal bones 1 and 8; $N 1,2,3,4,5,6,7,8$, neural bones 1 to 8 ; $n u$, nuchal; $n u s$, nuchal scute; $p y$, pygal; $s p y$, first suprapygal; $s p y$ 2, second suprapygal. B, Plastral view: $a b$, Ab. dominal scute; an, anal scute; ent, entoplastron; epi, epiplastron: hum, humeral scute; fem, femoral scute; hyo, hyoplastron; hypo, hypoplastron; in mar, inframarginal scutes; pec, pectoral scute; xiph, xiphiplastron. One-third natural size.

neurals, the complete fourth costal of the left side, parts of several other costals, 11 peripherals, and the greater part of the plastron. In the present collection a nearly perfect shell (No. 8524, U. S. N. M.; see Pl. XIV, figs. 1 and 2 ) is identified as belonging to this species. This specimen is noteworthy not only as being the most nearly perfect example of this species known but also in being by far the most complete individual of the genus Hoplochelys yet discovered. On that account I shall describe compact and solid construction. The outer surfaces of nearly all the bones are undulating, finely shagreened but without other ornamentation.

Viewed from above (see fig. 17, A) the carapace is oval, the front border is shallowly concave, and the back border is broadly but evenly rounded. The shell is highly arched transversely, dropping off almost vertically at the seventh neural to the slightly flaring posterior peripherals, but in front the slope is 
gradual to the widely excavated border for the neck. (See fig. 18.)

The carapace in a straight line through the center has a greatest length of 228 millimeters and a greatest width of 180 millimeters. At the center the shell has a height of 100 millimeters.

Along the center of the back, within the area of the vertebral scutes, the carapace is somewhat flattened and depressed below the surface level of the adjoining costal bones. There is a feeble median keel which begins on the first neural and whose crest rises but little above the surface of the bone; but immediately behind the sulcus that separates the second and third vertebrals there is a sudden

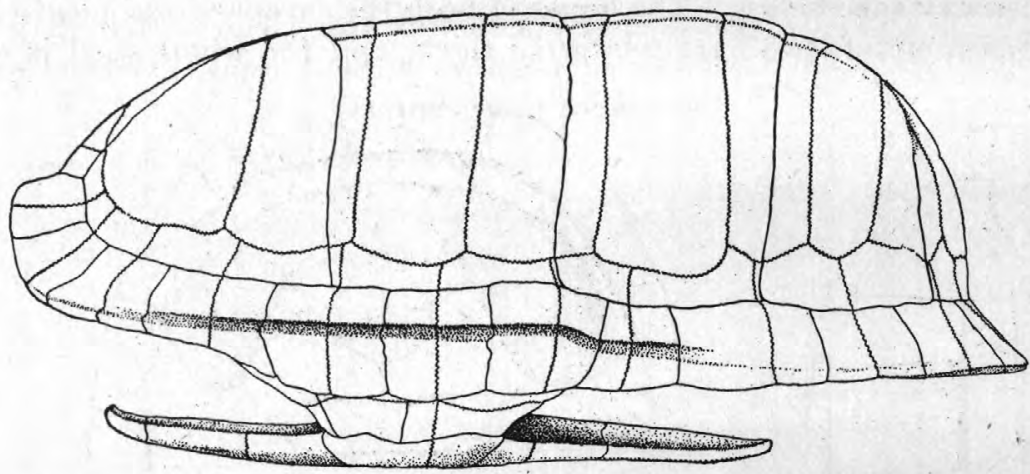

FIGURE 18.-Carapace of Hoplochelys bicarinata Hay (No. 8524, U. S. N. M.). Viewed from the left side. One-half natural size.

depression of the bone, so that the keel stands up very prominently. Proceeding backward this keel gradually subsides, but it is again revived in the same manner where the sulcus separating the third and fourth vertebrals crosses the fifth neural. In a somewhat lesser degree this subsidence and subsequent elevation are repeated posterior to the division between the fourth and fifth vertebrals, where the ridge is much reduced, and it fades out altogether on the anterior end of the second suprapygal.

This median keel is paralleled on either side by strong lateral keels that are not so acute as those of $H$. crassa but have rounded summits. On the side toward the midline the base of each lateral keel is bounded by the deep and sharply impressed sulcus that limits the vertebral scutes laterally. Just in front of the sulcus that descends between contiguous costal scutes the keel rises abruptly from the costovertebral sulcus and then rounds off into the general level of the costal bone. On the slope of the keel toward the median line a well-defined groove begins at the crossing of the descending sulcus and runs backward, gradually disappearing before reaching the next descending sulcus.

The nuchal bone is broadly excavated in front for the neck. The upper surface near the border has a tendency to flare upward. On the free border this bone is 45 millimeters wide. Its greatest transverse diameter is 67 millimeters and its greatest length at the center is 35 millimeters. There are eight neurals in the complete series, though in the present specimen neurals 1,5 , and 8 are missing. With the exception of Baptemys, Hoplochelys is the only other genus of the family Dermatemydidae to have a full neural series.

Although the first neural is missing in the present specimen, the sutural boundaries show its exact shape and dimensions. As in $A d o-$ cus and Basilemys, it is the longest one of the series and is hexagonal, with the wider end directed posteriorly. The second neural is suboval. The remaining neurals, except the eighth, are hexagonal, with the broadest end forward. The eighth is much reduced.

Measurements of neurals in Hoplochelys bicarinata, in millimeters.

\begin{tabular}{|c|c|c|c|c|}
\hline \multirow[b]{2}{*}{ No. } & \multicolumn{2}{|c|}{ Length. } & \multicolumn{2}{|c|}{ Width. } \\
\hline & $\begin{array}{l}\text { No. } \\
8524 \text {, } \\
\text { U. S. } \\
\text { N. M. }\end{array}$ & $\begin{array}{l}\text { No. } \\
6549 \text {, } \\
\text { U. S. } \\
\text { N. M. } \\
\text { (type). }\end{array}$ & $\begin{array}{l}\text { No. } \\
8524 \text {, } \\
\text { U. S. } \\
\text { N. M. }\end{array}$ & $\begin{array}{l}\text { No. } \\
6549 \\
\text { U. S. } \\
\text { N. M. } \\
\text { (type). }\end{array}$ \\
\hline & 32 & & 20 & \\
\hline & 22 & 25 & 15 & 14 \\
\hline 3. & 26 & $\cdots$ & 17 & $\cdots$ \\
\hline & 21 & & 17 & \\
\hline & $\begin{array}{l}25 \\
18\end{array}$ & $a_{21}$ & $\begin{array}{l}20 \\
18\end{array}$ & 18 \\
\hline & $\begin{array}{l}18.5 \\
22\end{array}$ & $\cdots$ & $\begin{array}{l}18 \\
18\end{array}$ & \\
\hline & $a 10$ & & 10 & \\
\hline
\end{tabular}

The suprapygal is small and subtriangular, with the widest end posterior. It is 15 millimeters long and has a greatest width of 16 millimeters. The second suprapygal is large and hexagonal. It measures 27 millimeters antero-posteriorly along the midline and has 
a greatest width of 51 millimeters. The pygal is largely missing in this specimen, but in all specimens in which it is present it shows a slight notch on the midline. In the present specimen this element has a height of about 23 millimeters and a width of about 25 millimeters.

There are eight pairs of costals. All except the third and fifth have the distal exceeding the proximal end in width.

Measurements of costals in Hoplochelys bicarinata (No. 8524, U. S. N. M.), in millimeters.

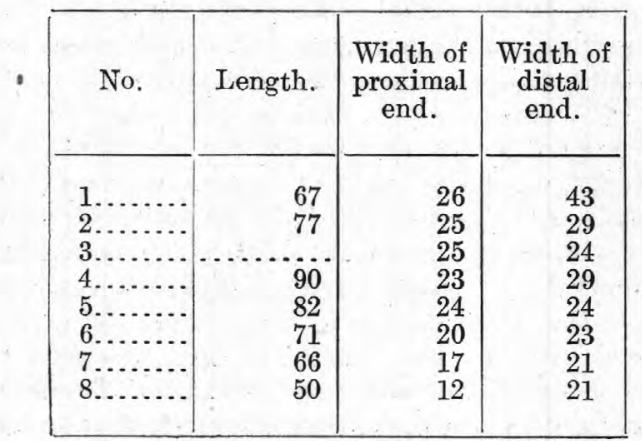

The costals are much thickened near their proximal ends where crossed by the lateral keel. They are closely and strongly joined with the peripherals by jagged sutures, but this union is further strengthened by the development on the distal end of strong median rib projections of the costal which extend down on the inside and are received in deep pits on the inner side of the peripherals.

There are 11 pairs of peripherals. The first is 29 millimeters long and 29 millimeters wide on the free border, the second 28 millimeters long, the third 30 millimeters, the fourth 25 millimeters, the fifth and sixth 24 millimeters each; the seventh 27 millimeters, the eighth 28 millimeters, the ninth 30 millimeters, the tenth 29 millimeters, and the eleventh 27 millimeters. The third, fourth, and fifth peripherals articulate with the hyoplastron; the third only with its anterior process, which is received in a diagonal groove on the inner side. Likewise the sixth, seventh, and eighth peripherals unite with the hypoplastron. The eighth has a pit on the inner face of its anterior end for a process of the hypoplastron. All the peripherals except the first, second, and eleventh have pits or deep grooves on the upper and inner surfaces for the reception of the rib processes of the costals. Each peripheral has a thin extension rising above the costo-marginal sulcus, the absence of which in the few peripherals present in the type specimen of $H$. crassa is now considered a juvenile feature.

From the slightly upturned free border of the third peripheral a low keel, bounded above by a shallow groove, continues backward across the bridge peripherals, merging into the free border on the eighth and succeeding peripherals. The free borders of the posterior peripherals present an acute edge, the whole bone having a tendency to flare upward.

The sulci of the carapace are narrow but deeply impressed. Those bounding the vertebral scutes laterally run in deep grooves on the median side of the lateral keels. At the center of each transverse sulcus between vertebral scutes where the sulcus crosses the median keel it forms a loop forward. The vertebrals are long and narrow, without especial lateral expansion of their centers.

Measurement of vertebrals of Hoplochelys bicarinata (No. 8524, U.S. N. M), in millimeters.

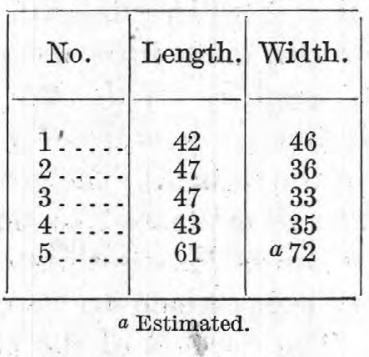

The length of the vertebral scutes as given in the table is taken at the side, as the absence of neurals 5 and 8 made it impractical to get this measurement at the center of the scute, as is the usual custom. Hay gives the following information regarding the dimensions of the vertebral scutes in the type: "The second vertebral scute was evidently 34 millimeters wide. The third was 36 millimeters wide and about 45 millimeters long."

The nuchal scute is small and trapezoidal, with the wider end posterior. On the midline it is 8 millimeters long, and on the free border it is 11 millimeters wide.

The sulci descending on the second, fourth, and sixth costals are near the posterior borders of those bones. They also loop forward in crossing the lateral keels. The costo-marginal sulci run along well below the upper borders of the costo-peripheral suture, being on the posterior members at about the middle of their height. The intermarginal sulci descend a little in front of the middle of the length of the peripherals. 
The plastron is narrow and cruciform. It has a pointed posterior lobe, and both lobes are fixed. The plastron of specimen No. 8524, U. S. N. M., is but little more complete than that of the type specimen (No.6549, U. S. N. M.), and the description here given will be supplemented by reference to the type specimen. From the plastron of No. 8524 there are missing the right epiplastron, portions of both the hyoplastron and hypoplastron of the right side, and the posterior ends of both xiphiplastra.

The form of the plastron and its various bones are well shown in figure 17, B. The missing xiphiplastral processes were restored from the complete right xiphiplastron of No. 8528 , U. S. N. M., the only known specimen of the genus Hoplochelys in which this bone is perfectly preserved.

The plastron articulates strongly with the peripherals by dentated sutures and by slender posterior and anterior processes, that are received in grooves and pits on the inner side of the peripherals. The hyoplastron unites with the third, fourth, and fifth peripherals; the hypoplastron slightly with the fifth and entirely with the sixth and seventh and the anterior end of the eighth. The greatest length of the plastron is estimated to be about 152 millimeters, whereas Hay estimated the plastron of the type specimen to be close to 130 millimeters. The borders of the anterior lobe are obtuse, having a thickness of 7 millimeters.

Some of the principal measurements of this specimen as compared with the type are given in the accompanying table:

Measurements of plastra of Hoplochelys bicarinata Hay, in millimeters.

\begin{tabular}{l|r|r}
\hline & $\begin{array}{r}\text { No. } 6549 \\
\text { U.S. N. M. } \\
\text { (type) }\end{array}$ & $\begin{array}{r}\text { No. } 8524, \\
\text { U. S. N. M. }\end{array}$ \\
\hline Length of anterior lobe......... & 40 & 52 \\
Width of anterior lobe at base... & 70 & 87 \\
Length of entoplastron........... & 26 & 32 \\
Width of entoplastron........... & 26 & 29 \\
Width of bridge.............. & 41 & 40 \\
Width of posterior lobe at base... & 55 & 64 \\
\hline
\end{tabular}

The entoplastron is about as broad as long and is pointed in front and broadly rounded behind. The epiplastra are long, narrow bones that join by a median suture in front of the entoplastron for 13 millimeters. Their posterior ends join the hyoplastra by strong digitating sutures for 25 millimeters, the hypoplastra for 25 millimeters, and the xiphiplastrals for about 58 millimeters.
The width of the bridge is 40 millimeters, evenly divided between the hyoplastra and hypoplastra.

The scutes of the plastron are described by Hay ${ }^{1}$ as follows:

The scutes of the plastron have a remarkable arrangement. On each bridge are two inframarginals, the posterior being considerably larger than the anterior, and in addition a small axillary scute and apparently a small inguinal scute. The anals and the femorals can be identified without doubt. The femorals extend forward to the hyo-hypoplastral suture [slightly posterior to the suture in both specimens]. In front of the femorals is a pair of large scutes that reach nearly to the middle of the entoplastron and overlap the hinder ends of the epiplastron. On each side, lying between the scutes just described and the inframarginals, is another large scute that extends from the axillary to the inguinal notch and inwardly to within about 18 millimeters of the midline. It seems that these last-mentioned scutes must be the abdominals which, as in Chelydra, have been crowded from the midline by the expansion of the pectorals and the femorals. There are no traces of intergulars. Gulars and humerals remain to be accounted for, and only a single pair remains. It seems probable that the gulars have been suppressed or have coalesced with the humerals. The arrangement of the plastral scutes of this genus resembles that of Batemys tricarinata, ${ }^{2}$ except that the abdominals of Hoplochelys have been excluded from the midline.

Comparative measurements of the plastral bones and scutes in Hoplochelys bicarinata, in millimeters.

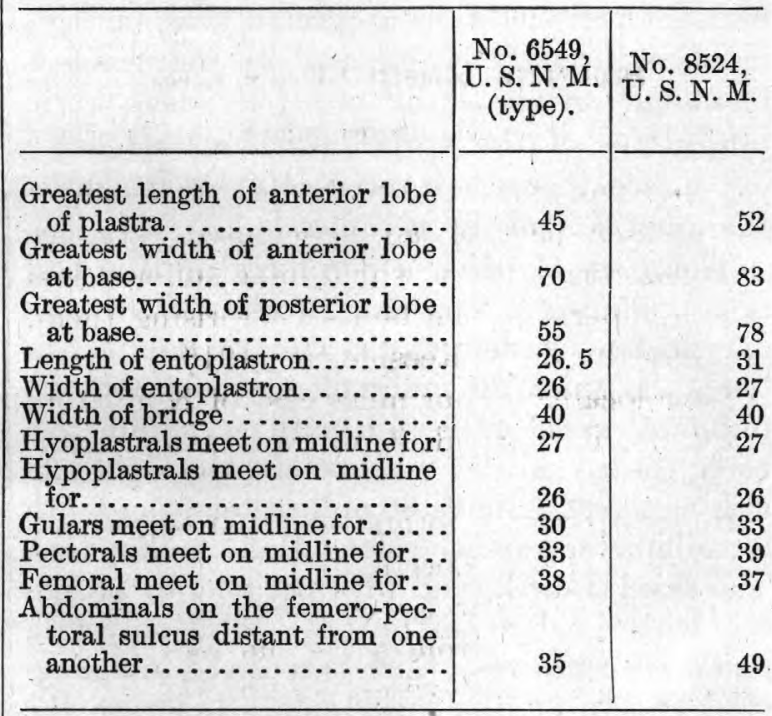

In the paper cited above Hay, in discussing the relationships of the species, says:

This species differs from $H$. crassa (Cope) in having the lateral keels of the carapace broader and more obtuse. H. crassa also evidently had the abdominal scutes pushed

1 Hay, O. P., Descriptions of eight new species of fossil turtles from west of the one hundredth meridian: U. S. Nat. Mus. Proc., vol. 38, p. 324, 1910.

2 Hay, O. P., The fossil turtles of North America: Carnegie Inst. Washington Pub. 75, p. 276, figs. 347, 348, 1908. 
away from the midline. The width of these at the inguinal notch was about 13 millimeters, whereas in H. bicarinata, a larger individual, these scutes are only 5 millimeters wide.

From $H$. caelata the present species differs in not having the bones sculptured with oblique ridges. The outer faces of the hinder peripherals are not flat, as they are in $H$. caelata, but more or less concave, with the free borders somewhat upturned. In H. caelata the hypoplastron did not enter the eighth peripheral. The hinder end of the seventh is thin, as is also the whole of the eighth. In $H$. bicarinata the anterior end of the eighth is much thickened and receives a process from the hypoplastron. The hypoplastron of $H$. crassa (Cope) does not pass behind the seventh peripheral, resembling in this respect $H$. caelata.

An examination of specimen No. 8524, U. S. N. M., shows that the last statement is incorrect, as the eighth peripheral in $H$. crassa does receive a process of the hypoplastron.

The characters that now appear to distinguish $H$. bicarinata are as follows:

Specificcharacters: Carapacerelativelyshort, broadly rounded behind; posterior end descending abruptly to peripherals; breadth of carapace 69 per cent of length; lateral carina well defined, obtuse; carina crossing bridge peripherals well defined, sharp; excavation for neck wide; first neural hexagonal, wider end directed posteriorly.

\section{Hoplochelys laqueata Gilmore, n. sp.}

Plate XV, figures 1 and 2.

Type: No. 8527, U. S. N. M. Consists of the greater part of an articulated carapace and plastron, both of which have suffered loss of many parts of the bones comprising them. Collected by J. B. Reeside, jr., 1916.

Type locality: Four miles east of Kimbetoh, in sec. 35 , T. 23 N., R. 9 W., San Juan County, N. Mex.

Horizon: Puerco formation (" 50 feet above the base"), basal Eocene.

The specimen selected as the type of Hoplochelys laqueata is from the same locality and the same geologic horizon as No. 8524, U. S. N. M., here identified as pertaining to $H$. bicarinata, but it is at once distinguished from that species by the more elongated and pointed posterior end of the carapace. (See fig. 19.)

The form of the carapace in H. laqueata is an elongated oval, slightly truncated in front and pointed behind. Viewed from the side (see fig. 20) the carapace on the posterior end is seen to have a gradual slope from the top to the peripheral border, as contrasted with the almost vertical descent of this region in both $H$. bicarinata and $H$. elongata. (See figs. 18 and 22.) The shell is highly arched, the sides gradually rounding up to the lateral keels and not steep, as in the two last-mentioned species.

The greatest length on the midline is about 265 millimeters; the width is 185 millimeters; the height at the center is 86 millimeters. The greatest width of the carapace is about 69 per cent of the length, whereas in $H$. bicarinata it is 78 per cent and in the type of $H$. elongata only 62 per cent.

The bones of both the carapace and plastron are smooth, not having the undulating surfaces found in $H$. bicarinata, and the whole shell is of relatively lighter construction.

There are the usual three dorsal carinae along the back. The lateral keels are low and broadly rounded, a feature that will serve to distinguish Hoplochelys laqueata from all other described species of the genus. Between the lateral keels the median surface of the shell appears slightly depressed below the general level of the carapace.

There are eight neurals, of which the posterior part of the first and the sixth and eighth are missing from the type. The second is hexagonal, as in $H$. elongata, whereas in $H$. bicarinata the second neural is oval; otherwise the neurals of these two species are very similar.

Measurements of neurals in Hoplochelys laqueata (No. 852\%, U. S. N. M.), in millimeters.

\begin{tabular}{|c|c|c|}
\hline No. & Length. & Width. \\
\hline 1. & & 16 \\
\hline $2 \ldots$ & 25 & 18 \\
\hline 3. & 22 & 16 \\
\hline $4 \ldots$ & 29 & 16 \\
\hline $5 \ldots$ & 22 & 16 \\
\hline 6. & 25 & \\
\hline $7 \ldots$ & 21 & 18 \\
\hline & 14 & 11 \\
\hline
\end{tabular}

The nuchal is largely missing, but it appears to have been as widely excavated for the neck as in $H$. bicarinata.

The suprapygal and second suprapygal are as in $H$. bicarinata. The pygal is rectangular and has a slight median notch on the midline. It is 27 millimeters wide and 24 millimeters high. 
The peripherals in their main features are very similar to those of $H$. bicarinata, except that the bridge peripherals are smooth and not crossed by the lateral carina, in this respect resembling those of $H$. paludosa. The union of the plastron with the bridge and other peripherals, in so far as can be determined from the type specimen, is almost identical with the relation of these bones in $H$. bicarinata (see p. 45), and it appears unnecessary to repeat their description here.

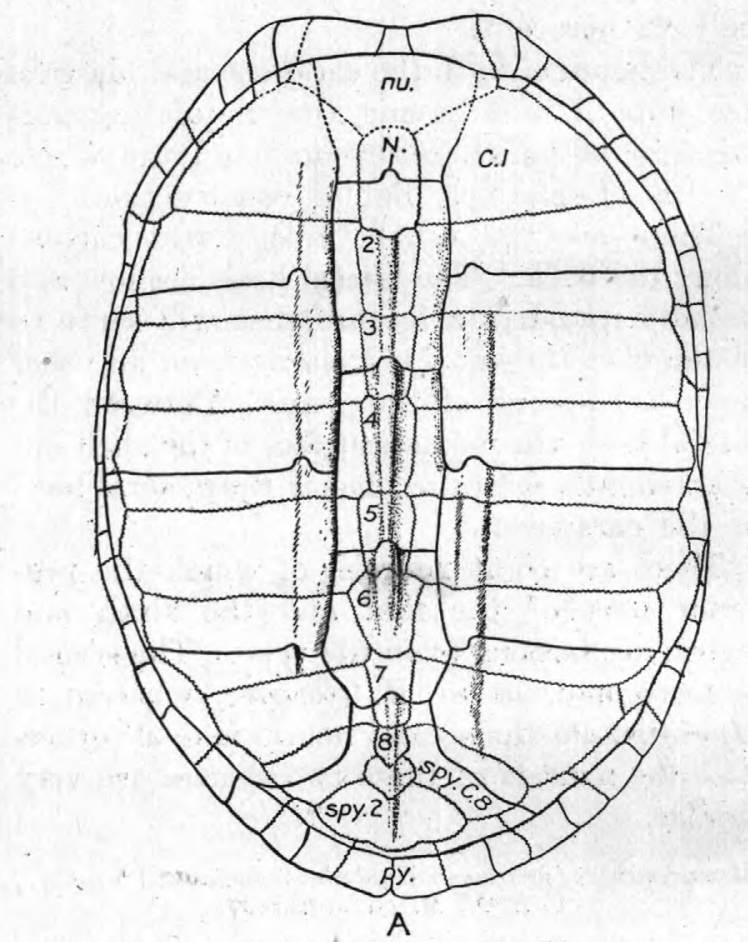

The sulci on the costals can be clearly traced, but they do not follow down well-defined depressions, as in $H$. bicarinata and other species. The costo-marginal sulcus runs well below the costo-peripheral suture, but there again the groove which it follows is very shallow as compared with those in the other known species.

The only important parts of the plastron missing in this specimen are the posterior

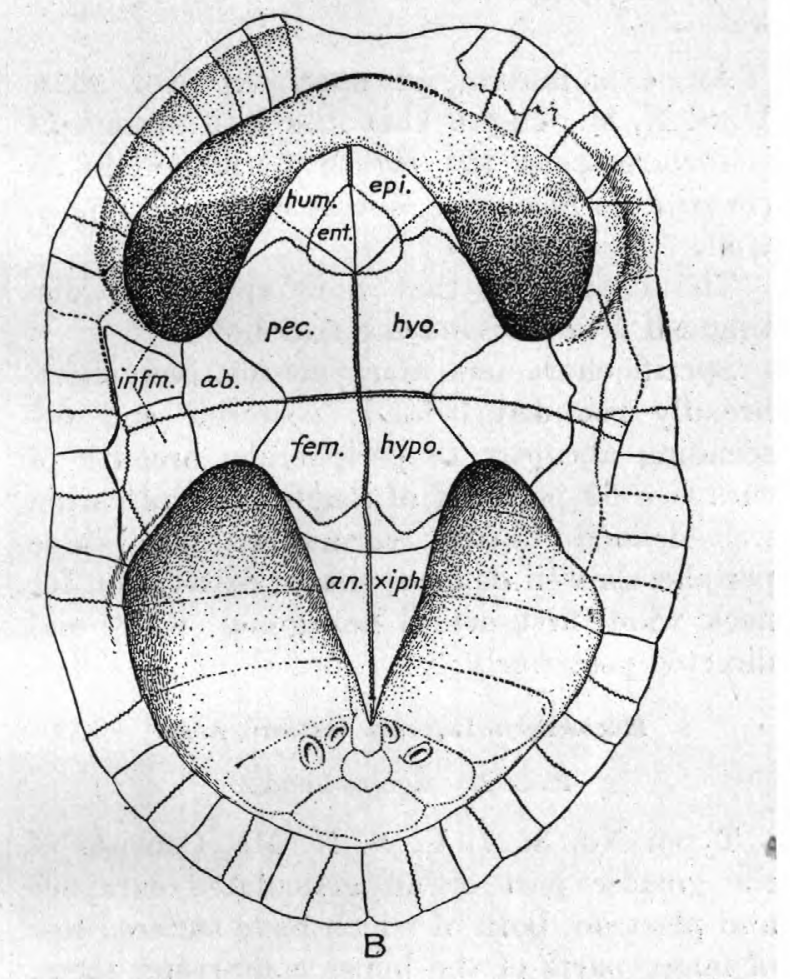

Figure 19.-Hoplochelys laqueata Gilmore, n. sp. (No. 8527, U. S. N. M.). Type. A, Carapace: $C 1, C 8$, Costal bones 1 and 8; $N 1,2,3,4,5,6,7,8$, neurals 1 to 8; $n u$, nuchal; $p y$, pygal; spy, first suprapygal; spy 2, second suprapygal. B, Plastral view: $a b$, Abdominal scute; an, anal scute; ent, entoplastron; epi, epiplastron; fem, femoral scute; hum, humeral scute; hyo, hyoplastron; hypo, hypoplastron; infm, inframarginal scute; pec, pectoral scute; xiph, xiphiplastron. One-third natural size.

The sulci are narrow and much more shallowly impressed than in any other known species of the genus. The transverse sulci between vertebral scutes and those bounding these scutes laterally run in deepened grooves. Where these sulci cross the median and lateral keels there is the usual forward loop. As in all the other known Puerco species of this genus, the vertebrals are long and narrow.

Measurements of vertebrals of Hoplochelys laqueata (No. 852\%, U. S. N. M.), in millimeters.

\begin{tabular}{|c|c|c|}
\hline No. & Length. & Width. \\
\cline { 1 - 3 } $1 \ldots . . . \ldots$ & $\ldots \ldots .$. \\
$2 \ldots \ldots$ & 52 & 34 \\
$3 \ldots \ldots$ & 51 & 31 \\
$4 \ldots .$. & 51 & 35 \\
$5 \ldots .$. & 73 & 84 \\
\hline
\end{tabular}

tips of the xiphiplastra and portions of both epiplastra.

The plastron has the usual narrow cruciform shape, with pointed posterior lobe. The form of this part of the shell is well shown in figure $19, \mathrm{~B}$. The greatest length of the plastron is estimated to be about 170 millimeters, the length of the anterior lobe 57 millimeters, the width of the anterior lobe at the base 87 millimeters, and the width of the posterior lobe at the base 60 millimeters. The entoplastron is 26 millimeters long and 24 millimeters wide and is pointed in front and broadly rounded behind.

The epiplastra join on the median line in front of the entoplastron for 12 millimeters. The hyoplastra meet on the midline for 32 
millimeters; the hypoplastra for 32 millimeters; the xiphiplastra for about 68 millimeters. The bridge has a width of 36 millimeters, of which the hyoplastron contributes slightly more than one-half.

The plastral scutes have approximately the same arrangement as in $H$. bicarinata, though, as will be pointed out, their proportions are somewhat different. The femorals meet on the midline for 48 millimeters, the pectorals for 32 millimeters, and the combined gulars and humerals for 37 millimeters. The abdominals of opposite sides are separated by the interposed femorals and pectorals for a distance of posed femorals
41 millimeters. The pectorals are relatively longer fore and aft than in $H$. bicarinata. The combined humeral-gular scute in $H$. laqueata on the median line extends posteriorly to the posterior border of

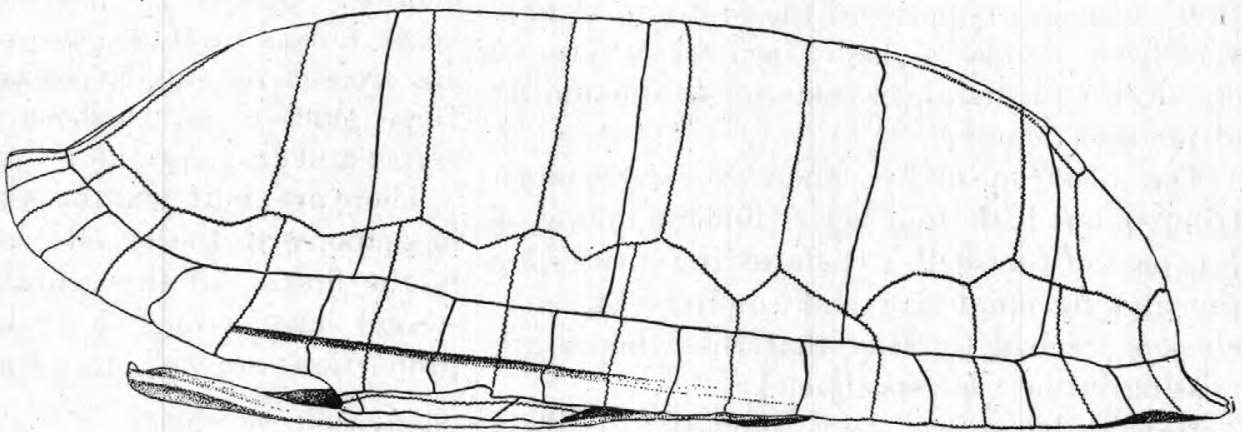

FIGURE 20.-Carapace of Hoplochelys laqueata Gilmore, n. sp. (No. 8527, U. S. N. M.). Type. Viewed from the left

the entoplastron, whereas in $H$. bicarinata it reaches a point only slightly posterior to the middle of that bone.

Hoplochelys Taqueata, like all the other Puerco species of this genus, can be distinguished at once from the Torrejon forms by the relatively narrower neurals and vertebrals.

Specific characters: Carapace elongated oval, pointed behind; posterior end $45^{\circ}$ slope to peripherals; breadth of carapace 78 per cent of length; lateral carina not well defined, broadly rounded; carina crossing bridge peripherals faintly indicated; excavation for neok wide; humeral scute reaching posterior border of entoplastron.

\section{Hoplochelys saliens Hay.}

Hoplochelys saliens Hay, The fossil turtles of North America: Carnegie Inst. Washington Pub. 75, pp. 265-266, text figs. 326-327, 1908.

Matthew, Geol. Soc. America Bull., vol. 25, p. 383, 1914.

Hoplochelys saliens was established by Hay on the greater portion of a crushed shell covered by a refractory matrix that so obscured certain parts of the shell as to make a study of the detailed structure of the bones very difficult. side. One-half natural size.

The discovery of two specimens in the Reeside collection that are referable to this species clears up some of these details and extends the known geographic distribution of the species.

The better-preserved specimen (No. 8605, U. S. N. M.) consists of the median and lateral parts of the carapace, with the greater portion of the plastron. The value of this specimen, like that of the type, is largely destroyed because of a closely adhering matrix.

The second specimen (No. 8646, U. S. N. M.) consists of four peripherals, four neurals, numerous pieces of the costals, and fragments of the plastron. These bones are all free of

the matrix and in an excellent state of preservation. Both of these specimens were collected in the same locality, 8 miles N. $60^{\circ} \mathrm{E}$. of Kimbetoh, in sec. 17, T. 23 N., R. 8 W., San Juan County, N. Mex., in the Torrejon formation.

A comparison of the neurals of No. 8646 with those of the type shows that these elements were incorrectly figured in the original description of the type specimen. The first neural is shown by specimen No. 8646, U. S. N. M., to be oval instead of quadrangular, as tentatively outlined by Hay. The succeeding neurals are relatively broad and hexagonal, with the wider end forward, and the posterior end much narrowed and convex on end, not wide and with straight posterior end, as Hay indicated.

Measurements of neurals of Hoplochelys saliens (No. 8646, U. S. N. M.), in millimeters.

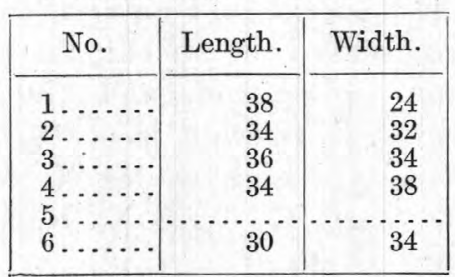


It appears quite probable that, as in the other species of the genus, there was a complete set of eight neurals, not a reduced number, as indicated in the original figure of the type specimen.

The lateral keels present features that appear to be distinctive of the species. On the external side the heavy keels drop off vertically to the general surface level, and, as in the type, along none of these keels is the bone especially sunken in for the passage of the intercostal sulcus. This specimen shows the second vertebral scute to have had a length of about 69 millimeters and a width of 62 millimeters. The transverse sulcus between the first and second vertebrals sends a loop forward where it crosses the median keel posterior to the middle of the first neural.

The plastron of specimen No. 8606 contributes but little to a better understanding of this part of the shell. It shows the sutures for the missing epiplastra and confirms the conclusion reached by Hay that these bones are missing in the type specimen.

Hoplochelys saliens Hay resembles $H$. elongata in having relatively wide neurals and vertebrals, as compared with any of the Puerco species described. It is to be distinguished from $H$. elongata by its larger size, the wider excavation of the nuchal region, and the stronger development of the median and lateral keels.

The characters that now appear to distinguish this species may be briefly summed up as follows:

Specific characters: Largest species of the genus; lateral carina broad, external sides dropping perpendicularly to general surface level, not sunken where crossed by sulci; vertebrals and neurals relatively broad; excavation for neck broad.

\section{Hoplochelys elongata Gilmore, n. sp.}

Plate XVI, figures 1 and 2.

Type: No. 8553, U. S. N. M. Consists of the greater part of an articulated carapace and plastron. The former lacks the proximal portions of the posterior and anterior costals and the posterior end of the nuchal; the latter, the entoplastron, epiplastron, and xiphiplastron. Collected by J. B. Reeside, jr., 1916.

Type locality: Eight miles N. $60^{\circ} \mathrm{E}$. of Kimbetoh, in sec. 17, T. 23 N., R. 8 W., San Juan County, N. Mex.
Horizon: Torrejon formation, basal Eocene.

In form the carapace of Hoplochelys elongata is an elongated oval, rounded in front and more broadly rounded behind. The sides are steeply arched; the top flattened. The greatest length on the midline is 275 millimeters; the width 170 millimeters; the height at the center about 92 millimeters. In size, therefore, this species is intermediate between $H$. bicarinata, from the Puerco, and $H$. saliens, from the Torrejon.

There are the usual three dorsal carinae. The median keel presents a sharper and higher ridge posteriorly than in $H$. crassa, but as in. that species it fades out on the anterior neurals. On either side are the heary rounded keels, but as in $H$. saliens none of these keels are crossed by sunken areas where the transverse sulci cross, such as are found in $H$. crassa and $H$. bicarinata.

There are eight neurals, which are hexagonal in shape, with the broader end forward except in the first. All the neurals posterior to the second have a median keel. The shape and proportions are well shown in figure 21.

Measurements of neurals in Hoplochelys elongata (No. 8553, U.S. N. M.), in millimeters.

\begin{tabular}{|c|c|c|}
\hline No. & Length. & Width. \\
\hline $\begin{array}{l}1 \ldots \\
2 \ldots \\
3 \ldots \\
4 \ldots \\
5 \ldots \\
6 \ldots \\
7 \ldots \\
8 \ldots\end{array}$ & $\begin{array}{l}26 \\
27 \\
26 \\
23 \\
23.5 \\
17 \\
19\end{array}$ & $\begin{array}{l}17 \\
22.5 \\
26 \\
26 \\
26 \\
25 \\
20 \\
18\end{array}$ \\
\hline
\end{tabular}

The nuchal, as compared with those in other species of the genus, is narrowly excavated for the neck. In front its free border is 34 millimeters wide. This bone in conjunction with 11 peripherals and a pygal forms the rim of the carapace. The peripherals behind the bridge have a tendency to flare slightly upward and are acutely edged. Those in front have more obtuse borders. The bridge peripherals are crossed low down by a lateral keel, which fore and aft merges into the rim of the carapace. Above this keel the peripherals suddenly thicken to form "a sort of roll along the shell." The first peripheral is 29 millimeters long on the free border; the second, 31 millimeters; the fourth, 29 millimeters; the seventh, 32 millimeters long and 32 millimeters high; the eighth, 32.5 millimeters long and 36 millimeters 
high; the ninth, 31 millimeters long; the tenth, 30 millimeters long and 36 millimeters high; the eleventh, 30 millimeters long. The pygal is 30 millimeters wide on the free border and 28 millimeters high.

The anterior costal plate has a greatest width of about 75 millimeters; the next five pairs, a width of 30 millimeters or more.

The surfaces of the bones of the carapace are smooth, but under the glass present a shagreened texture, a feature typical of the other species of the genus.

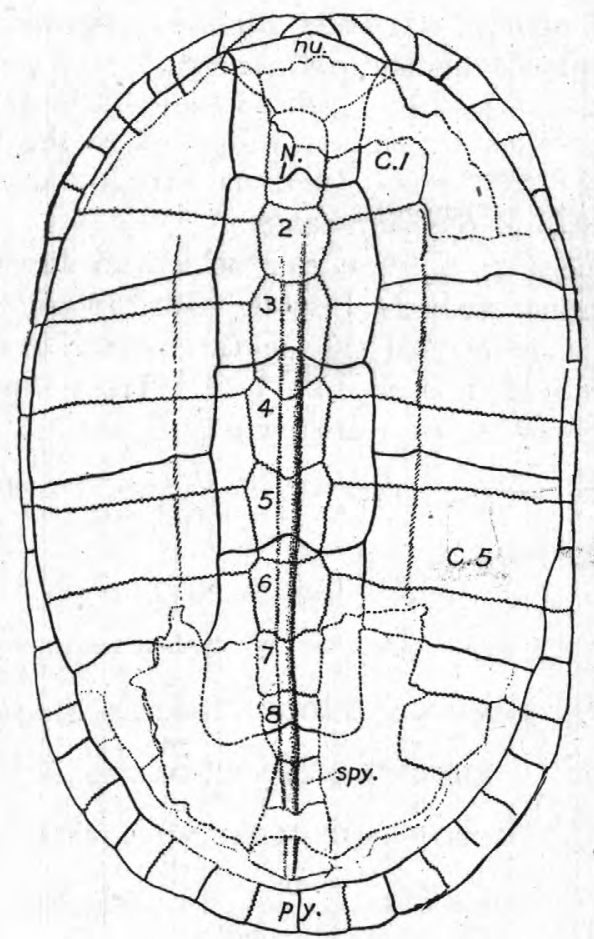

A
The transverse sulcus between the fourth and fifth vertebrals crosses the eighth neural, as in H. Zaqueata. The costo-marginal sulcus runs below the costo-peripheral suture at about the middle of their height. The nuchal scute is subtriangular in form, with the narrow end forward. On the free border it measures 7 millimeters wide; on the posterior border, 12 millimeters. The entoplastron, epiplastron, and xiphiplastron are missing from the plastron of this specimen. At the center the plastron has a greatest breadth of 120 millimeters. It

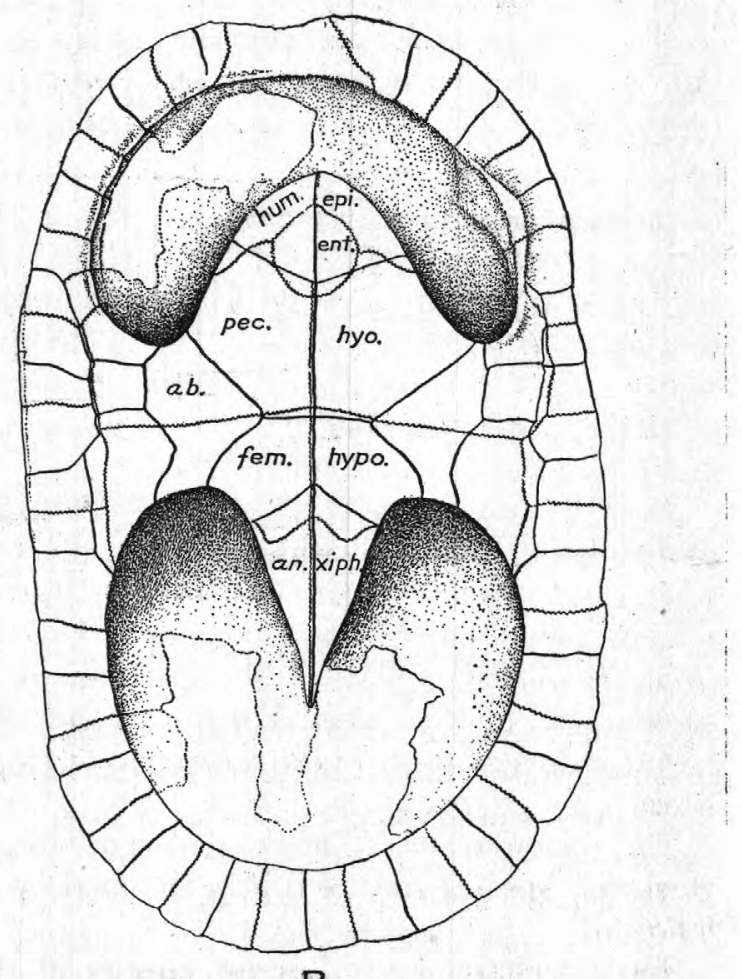

B

Figure 21.-Hoplochelys elongata Gilmore, n. sp. (No. 8553, U. S. N. M. ). Type. A, Carapace: $C 1, C 5$, Costal bones 1 and $5 ; N 1,2,3,4,5,6,7,8$, neural bones 1 to 8 ; $n u$, nuchal; $p y$, pygal; spy, first suprapygal. B, Plastral view: ab, Abdominal scute; an, anal scute; ent, entoplastron; epi, epiplastron; fem, femoral scute; hum, humeral scute; hyo, hyoplastron; hypo, hypoplastron; pec, pectoral seute; xiph, xiphiplastron. One-third natural size.

The sulci are narrow, as in $H$. crassa and $H$. bicarinata, and about as deeply impressed. The vertebral scutes are broad, as in $H$. saliens, a feature that at once distinguishes the Torrejon from the known Puerco species of the genus. (Compare figs. 17, 19, and 21.)

Measurements of vertebrals in Hoplochelys elongata (No. 8553, U.S. N. M.), in millimeters.

\begin{tabular}{|c|c|c|}
\hline No. & Length. & Width. \\
\cline { 1 - 2 } & & \\
\hline $1 \ldots .$. & 58 & 44 \\
$2 \ldots$. & 55 & 49 \\
$3 \ldots .$. & 56 & 47 \\
$4 \ldots$. & 53 & $\ldots . .$. \\
$5 \ldots$ & 73 & 94 \\
\hline
\end{tabular}

is strongly sutured to peripherals $4,5,6$, and 7 , and a long tapering process extends forward in a groove to further strengthen this union on the inside of peripheral 3 and into a pit on peripheral 8. The form of the bones preserved is well shown in figure $21, \mathrm{~B}$. The anterior lobe is 76 millimeters wide at the base; the posterior lobe, 55 millimeters. The entoplastron had a greatest width of about 27 millimeters. The hyoplastra joined on the midline for a distance of 33 millimeters; the hypoplastra for 34 millimeters. The greatest thickness of the hypoplastra is 16 millimeters. The least width of the bridge is 41 millimeters. The scutes of the plastron, so far as they can be observed, have 
the same arrangement as in $H$. bicarinata, except that the anal scutes extend anterior to the hypo-xiphiplastral suture. There are three inframarginal scutes on the bridge; each of the anterior two is considerably smaller than the posterior one. The femorals extend forward nearly to the hyo-hypoplastral suture. The triangular abdominals are excluded from meeting on the midline by the expanded femorals and pectorals, which join transversely between the abdominals for a distance of 28 millimeters. The pecto-humeral sulcus crosses the posterior end of the entoplastron, as in $H$. bicarinata.

The present collection contains, in addition to the type, two other specimens (Nos. 8608 and 8609 , U. S. N. M.) that are sufficiently rounded lateral keels along the top of the carapace. From H. paludosa Hay it differs by having, like most other species of Hoplochelys, a keel crossing the bridge peripherals well below the costo-marginal sulcus.

The characters which at this time will serve to distinguish $H$. elongata may be briefly summed up as follows:

Specific characters: Carapace elliptical; shell narrow, elongated, width being 62 per cent of the length; lateral carinae broadly rounded; carinae crossing bridge peripherals well defined, sharp; excavation for neck narrow; vertebrals and neurals relatively broad; posterior end of carapace descending abruptly to peripheral border. (See fig. 22.)

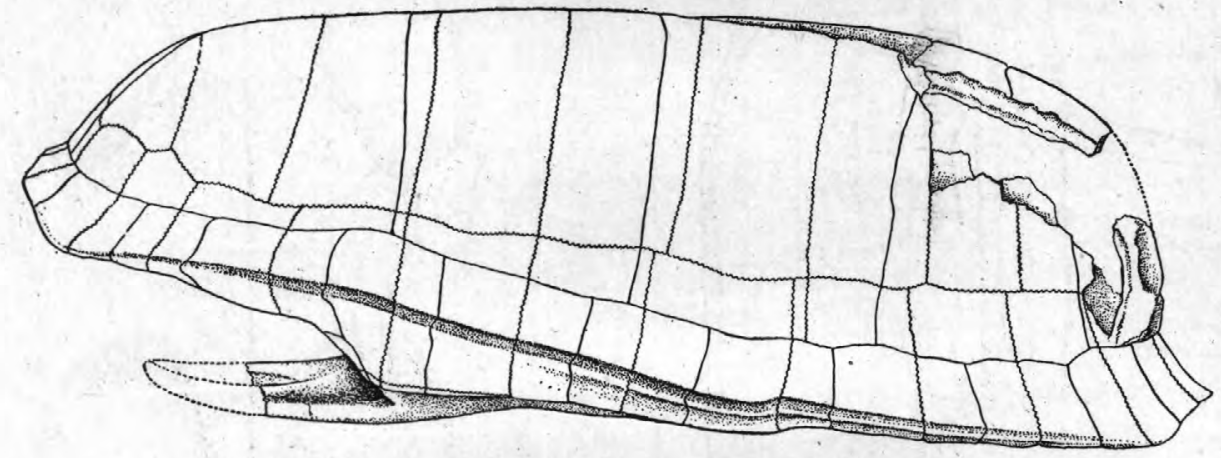

FigURE 22.-Carapace of Hoplochelys elongata Gilmore, n. sp. (No. 8553, U, S. N. M.). Type. Viewed from the left side. One-half natural size.

well preserved to be identified as pertaining to this species. Both are from the same locality and the same geologic horizon as the type specimen.

In No. 8609 the first neural, a bone part of which is missing in the type, is preserved intact. This bone is oval, as contrasted with the hexagonal first neural of $H$. bicarinata Hay. It is 34 millimeters long and has a greatest width of 22 millimeters. In text figure $21, A$, the missing part of this element has been restored after this bone.

Hoplochelys elongata differs from $H$. bicarinata Hay in the more elongate form of the carapace, the narrower notch in the nuchal for the neck, the wider vertebrals, the more pronounced median keel, and the less pronounced depressions where the transverse sulci cross the lateral keels. From H. saliens Hay it is distinguished by its somewhat smaller size, the relatively narrower bridges and nuchal notch for the neck, and the less prominent median and more

\section{Superfamily TRIONYCHOIDEA Hay.}

Family PLASTOMENIDAE Hay.

Genus PLASTOMENUS Cope, 1873.

The genus Plastomenus is represented in the present collection by two specimens, both of which appear to be true members of the genus.

As the principal characters that define this genus are found in the plastron-that is, the hyoplastra, hypoplastra, and xiphiplastra are closely united, usually by suture-the assignment of a species based on the carapace is always problematic. This remark applies especially to the type of Plastomenus perplexus.

Fifteen species have been assigned to this genus prior to the study of the present collection, but Hay remarks that "when more complete remains shall have been discovered some of these species will have to be placed in other genera." A single Torrejon species, P. acupictus Hay, was known previously. 
A second specimen (No. 8553), consisting of parts of the hyoplastra and hypoplastra, from the same formation and locality as $P$. perplexus, certainly belongs to Plastomenus and apparently represents an undescribed species, which I defer naming on account of its incomplete state of preservation. (See Pl. XXIII, fig. 2.)

Plastomenus robustus, from the Kirtland, is the first member of this genus to be recognized. specifically from that formation.

\section{Plastomenus robustus Gilmore, n. sp.}

Plate XVII; Plate XVIII, figure 1.

Type: No. 8538, U.S. N. M. Consists of the nearly perfect carapace, and the hyoplastron and hypoplastron of the right side. Collected by J. B. Reeside, jr., 1916.

Type locality: About $3 \frac{1}{2}$ miles southwest of Kimbetoh, near the south side of sec. 4, T. 22 N., R. 10 W., San Juan County, N. Mex.

Horizon: Kirtland formation (75 feet above the base). Upper Cretaceous.

The carapace of Plastomenus robustus is subquadrangular in outline and is broader than long, the length being 400 millimeters and the width 430 milimeters. It is convex transversely, being shallowly depressed along the middle. The front of the shell is very slightly concave along the nuchal, and the back is widely excavated, as in Aspideretes beecheri Hay. The abruptly rounded lateral borders are somewhat sinuous; the front and back borders are abruptly cut off at right angles to the upper surface. (See fig. 23.)

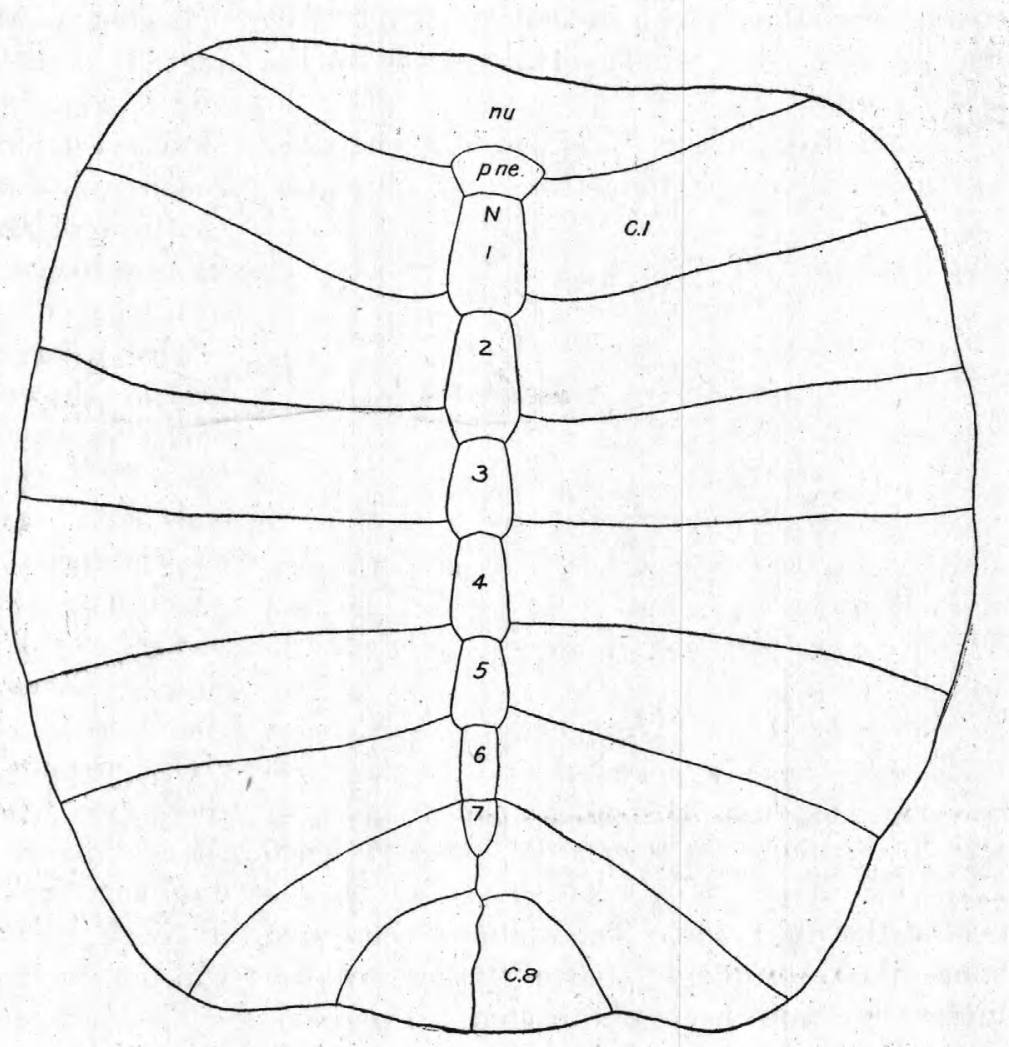

Figure 23.-Carapace of Plastomenus robustus Gilmore, n. sp. (No. 8538, U. S. N. M.). Type. $C 1, C 8$, Costal bones 1 and $8 ; N 1,2,3,4,5,6,7$, neural bones 1 to $7 ; n u$, nuchal; $p$ ne, preneural. One-fourth natural size.
Measurements of neurals in Plastomenus robustus (No. 8538 , U. S. N. M.), in millimeters.

\begin{tabular}{|c|r|r|}
\hline No. & Length. & Width. \\
\hline & & \\
\hline$\ldots .$. & 32 & 32 \\
$3 \ldots$ & 45 & 29 \\
$4 \ldots$. & 40 & 28 \\
$5 \ldots .$. & 41 & 26 \\
$6 \ldots$ & 36 & 23 \\
$7 \ldots$. & 29 & 15 \\
& 21 & 14 \\
\hline
\end{tabular}

The costals display nothing particularly characteristic. The ribs extend little if at all beyond the borders of the carapace. There are the usual eight costals. The eighth pair meet on the midline for their full width, a
The nuchal bone from side to side measures 270 millimeters in length. At the center, where it is notched for the preneural, it is 47 millimeters wide. There is a shallow sinus running along the middle of its anterior border. The preneural is as broad as long, measuring 37 millimeters in both diameters. There are seven neurals. 
The sculpture of the carapace consists of a network of flat-topped ridges, inclosing pits that are usually circular in shape. There are usually three of these pits in a 10-millimeter line, though toward the center of the shell, where the ridges appear to be washed off, the pits are shallower and smaller and have concave bottoms and in many places there are four pits in a 10-millimeter line. On the outer half of the costals, where the pits are largest, they are arranged in rows transverse to the longer diameter of the costals. On the outer ends of these bones the summits of the ridges become acute and the pits smaller and more irregular in shape and size. As in $A$. beecheri, the upper two-thirds of the sutures between the costals resemble seams in leather sewed with fine stitches. The whole surface of the nuchal is sculptured.

The plastron of this specimen is represented by the complete hyoplastron and hypoplas-

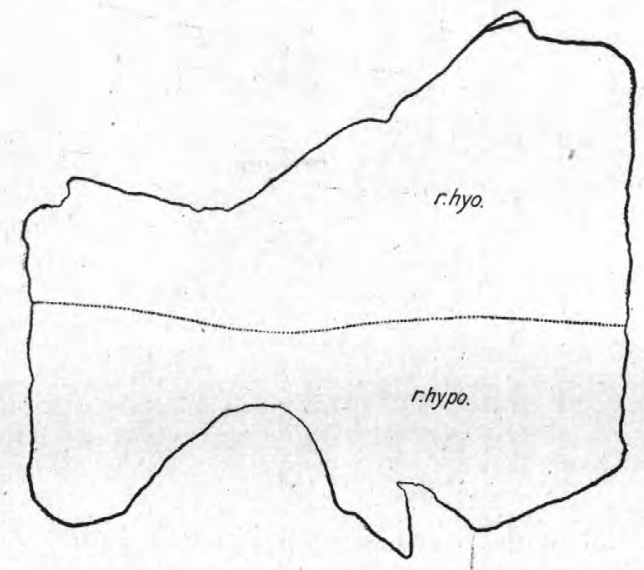

Figure 24.-Plastral bones of Plastomenus robustus Gilmore, n. sp. (No. 8538, U. S. N. M.). Type. $r$ hyo, Right hyoplastron; $r$ hypo, right hypoplastron. One-fourth natural size.

tron of the right side. The union of these two bones is so thorough that all traces of the suture has now been obliterated. The combined length of these elements at the midline is 158 millimeters. Their greatest width anteroposteriorly at the center is 237 millimeters; the width of the entire plastron across the bridges would be about 474 millimeters. Along the median suture these bones have an average thickness of 15 millimeters. For 120 millimeters on either side of the midline the ventral surfaces of these bones are flat, but farther away they slope upward and outward. Where this upward slope begins the bone becomes thinner and continues so to their outer edges. The bridge is 79 millimeters wide. The posterior border of the hypoplastron between the deep notch and the median line shows an oblique thickened sutural edge for the xiphiplastron. The hinder lobe has a width at the base of about 250 millimeters. The outwardly directed processes are missing from both the hyoplastra and hypoplastra.

The whole lower surfaces of these bones are sculptured into a network of ridges inclosing pits of varying shapes and sizes, nowhere having any regular arrangement. In a 10millimeter line there may be either four or five pits. This sculpture is well shown in Plate XVIII, figure 1.

A hypoplastron (No. 8350, U. S. N. M.) collected by Mr. Bauer in 1915 from the Farmington sandstone member of the Kirtland, which was figured by me, ${ }^{1}$ represents a very closely related if not identical species. It is considerably smaller than the hypoplastron of the type of Plastomenus robustus (fig. 24), and the sculpture differs somewhat, as may be seen by a comparison of the two figures.

The closely united hyoplastra and hypoplastra, as shown in this specimen, indicate at once its generic assignment to Plastomenus. Its very large size, truncated front and back ends, and carapace without welts crossing the costals form a combination of characters in which it is quite unlike any of the other known species of this genus. Without the plastron I should have unhesitatingly assigned it to Aspideretes, and it serves to illustrate the great uncertainty in assigning to either of these two genera specimens consisting only of the carapace. It now appears that only the discovery of plastra of the several species in each genus founded on the upper shell will render their generic assignment certain.

The combination of characters which at this time will distinguish Plastomenus robustus may be stated as follows:

Specific characters: Typically of large size; disk of carapace broader than long; anterior end truncated, posterior end broadly excavated; costals without welts; eighth pair of costals reduced; sculpture of carapace moderately coarse, there being three or four pits in 10-millimeter line; sculpture of plastron somewhat vermiculate.

1 Gilmore, C. W., Vertebrate faunas of the Ojo Alamo, Kirtland, and Fruitland formations: U. S. Geol. Survey Prof. Paper 98, p. 299, pl. 78, fig. 1, 1916. 
Plastomenus torrejonensis Gilmore, n. sp.

Plate XIX, figure 2.

Type: No. 8543 , U. S. N. M. Consists of six costals of the right and three of the left side, neurals 2 and 4, and a small fragment of the plastron. Collected by J. B. Reeside, jr., 1916.

Type locality: Eight miles N. $60^{\circ}$ E. of Kimbetoh, in sec. 17, T. 23 N., R. 8 W., San Juan County, N. Mex.

Horizon: Torrejon formation (" 840 feet above base of the Puerco, in Torrejon"), basal Eocene.

It is estimated that the carapace of the type specimen of Plastomenus torrejonensis had a greatest length of about 106 millimeters and a width across the fourth pair of costals of 67 millimeters. The rib ends extended beyond the ends of the costals, but all are missing in this specimen. The second neural is 15 millimeters long; the fourth 12 millimeters long and 9 millimeters wide. The two halves of the fourth neural are divided by a longitudinal flat-topped keel. The costals have the following dimensions, the length being taken from the free end of the costal to the border of the neural and the width taken at the neural border: First, 22 millimeters long, 15 millimeters wide; second, 29 millimeters long, 14 millimeters wide; third, 31 millimeters long, 13 millimeters wide; fourth, 31 millimeters long, 13 millimeters wide; fifth, 28 millimeters long, 13 millimeters wide; seventh, 22 millimeters long, 14 millimeters wide.

The anterior border of the first costal is smooth, indicating that it was not suturally united with the nuchal. The oblique cutting off of the anterior proximal corner of the first costal; which has a sutural edge, apparently indicates the presence originally of a small preneural bone. The surfaces of the costals are crossed fore and aft by four to five subparallel ridges or welts, which run from one end of the carapace to the other. (See Pl. XIX, fig. 2.) The surface is pitted everywhere except on the outer ends of the costals. The pits are usually in rows parallel with the more conspicuous ridges. There are from six to seven of these shallow pits in a line 10 millimeters long.

Originally there were eight pairs of costal bones, though the last pair were small. (See fig. 25, $C$ 8.) The seventh pair appear to have been in contact on the median line for one-half their width. It would seem that there were seven neurals; the seventh was greatly redused.

It appears quite possible that the nuchal of this individual may have had no sutural connection with the anterior costals, being in sutural contact with the disk only through a small preneural that is now missing.

In its small size, the character of the surface ornamentation, the presence of a number of

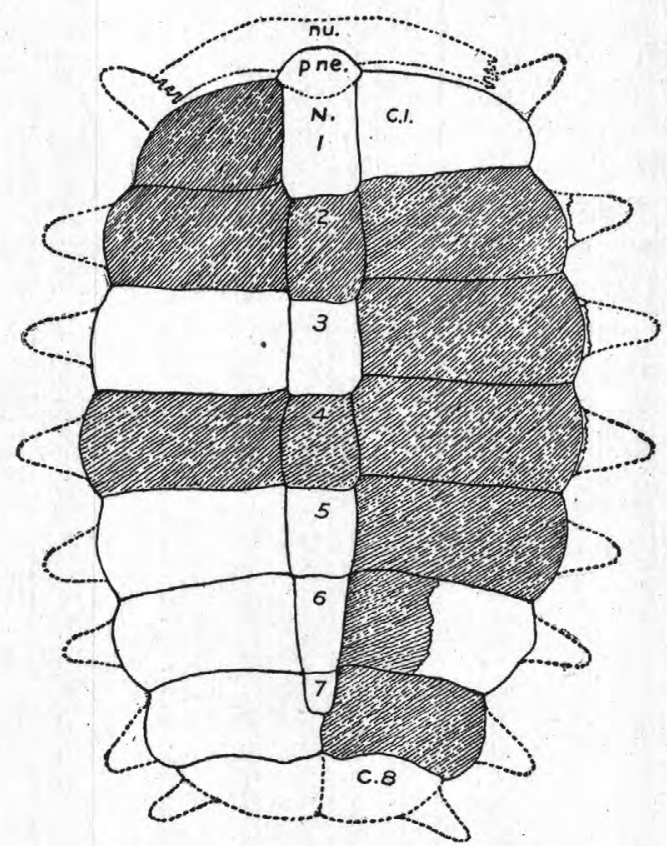

FIGURE 25.-Carapace of Plastomenus torrejonensis Gilmore, n. sp. (No. 8543 , U. S. N. M.). Type. $C 1, C 8$, Costal bones 1 and $8 ; N 1,2,3,4$, $5,6,7$, neural bones 1 to 7 ; $n u$, nuchal; $p$ ne, preneural. Three-fourths natural size.

parallel welts crossing the costal bones, and the wide rib ends this specimen closely resembles Platypeltis seriatis (Cope), Platypeltis trepida Hay, and Plastomenus acupictus Hay.

The presence in specimen No. 8543 of a full complement of costals and evidenee indicating the former presence of a pr=neural bone shows that its generic affinities are with either Aspideretes or Plastomenus. Provisionally it is referred to Plastomenus until the discovery of more complete materials, especially of the plastron, shall definitely decide its proper disposition.

A review of the materials on which Platypeltis trepida Hay and Platypeltis antiqua Hay were founded shows that the generic assignment of these species is not altogether certain. More complete materials may show that one or both should be transferred to the genus Plastomenus. 
Specimen No. 8543 is distinguished from Platypeltis trepida Hay by its narrower shell and the nonsutural union of the nuchal with the first costals. It resembles Platypeltis antiqua in the proportions of the carapace and the lack of the sutural articulation of the nuchal with the first costal, but its wider neurals and the lack of longitudinal welts crossing the costals appear to indicate specific distinctness.

Plastomenus torrejonensis is distinguished from Plastomenus acupictus, also from the Torrejon formation, by the larger pits forming the sculpture, the smaller number of longitudinal welts crossing the costals, and the very much smaller seventh costal.

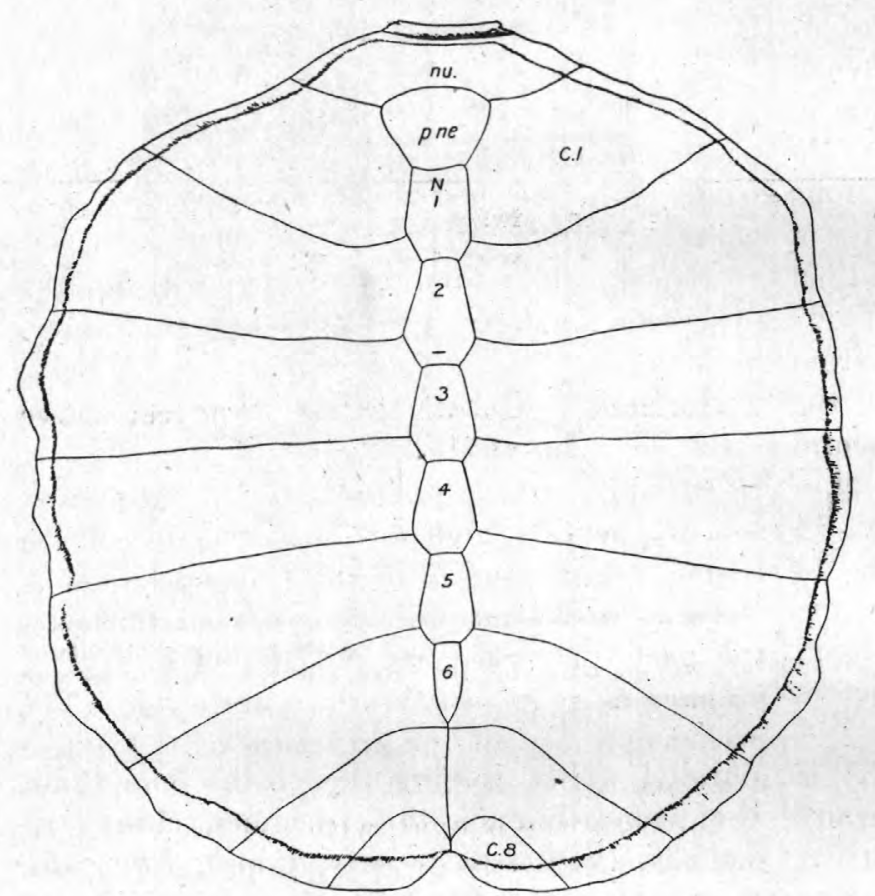

Figure 26.-Carapace of Aspideretes reesidei Gilmore, n. sp. (No. 8537, U. S. N. M.) Type. $C 1, C 8$, Costal bones 1 and $8 ; N 1,2,3,4,5,6$, neural bones 1 to 6 ; $n u$, nuchal; $p$ ne, preneural. One-third natural size.

Specific characters: Disk of carapace elongated oval; nuchal not suturally united to first costals; longitudinal welts crossing costals; some of neurals keeled; six or seven pits in a line 10 millimeters long.

\section{Family TRIONYCHIDAE.}

Genus ASPIDERETES Hay, 1904.

Five new species are here assigned to the genus Aspideretes, four of which are from the Puerco, thus doubling the number of known forms from that formation.
Aspideretes reesidei Gilmore, n. sp.

Plate XX.

Type: No. 8537, U. S. N..M. Consists of an almost complete carapace. Collected by J. B. Reeside, jr., 1916.

Type locality: About 4 miles east of Kimbetoh, in secs. 22 and 27 , T. 23 N., R. 9 W., San Juan Basin, San Juan County, N. Mex.

Horizon: Puerco formation ("50 feet above the base"), basal Eocene.

The carapace of Aspideretes reesidei is subcircular (fig. 26). The shell measures 260 millimeters in length on the midline, and 255 millimeters in width across the third costals at the widest part. The latter measurement does not include the rib projections, which are largely missing in this specimen. The carapace is flattened out, but in life it was moderately convex transversely and in all probability less so longitudinally. The margins of the shell are scalloped, with a smooth beveled band that is very slightly concave and extends around the entire shell. In this respect it resembles $A$. puercensis Hay. The front margin of the small nuchal plate in the midline is shallowly concave transversely. The outline of the shell is broadly rounded behind, with a decided notch on the midline, much as in Aspideretes guttatus (Leidy). The sculpture consists of a network of flattopped ridges, which on the neurals and upper third of the costals inclose small pits of irregular shapes and sizes. On the distal two-thirds of most of the costals the ridges have more acute tops and assume a fore and aft direction with deep valleys between. These valleys are divided by low transverse ridges, the summits of which are for the most part rounded and rise but little above the level of the valley floor. Here and there these transverse ridges rise to the height of the longitudinal ridges, thus inclosing pits of various shapes and sizes. This feature becomes more apparent on the front and back portions of the shell. There are usually five of these longitudinal ridges in a line 10 millimeters long. The median half of the sutural borders of the costals presents a band almost devoid of pits and is finely striated at right angles to the sutures, as in Aspideretes puercensis Hay. 
The nuchal is firmly joined by its whole posterior border to the preneural and first costals. Some of its outer extremities appear to be missing; but the lateral extent is estimated to be about 134 millimeters and the antero-posterior extent is 30 millimeters. On the upper side the nuchal is smooth except on a patch in the central portion, 75 millimeters wide and 17 millimeters long, which has the sculptured surface found elsewhere on the carapace. Around this area the bone is beveled off in continuation of the beveled border of the rest of the carapace. The outer extremities of the nuchal are slightly damaged, so that their full extent can not be determined.

There are six neural bones preceded by a preneural of good size. There are the usual number of eight costals.

The preneural is a trapezoid, whose longest side, measuring 34 millimeters, articulates with the nuchal, while its shortest side, $16 \mathrm{mil}-$ limeters, joins, the first neural. The first five neurals are elongated hexagonal, with the broader end directed posteriorly. The sixth is narrow and tapers off to a point on the posterior end.

Measurements of preneural and neurals in Aspideretes reesidei (No. 8537, U. S. N. M.), in millimeters.

\begin{tabular}{|c|r|r|}
\hline Element. & Length. & Width. \\
\cline { 1 - 3 } Preneural...... & 25 & 33 \\
Neural 1...... & 26 & 20 \\
Neural $2 \ldots . .$. & 31 & 21 \\
Neural $3 \ldots . .$. & 28 & 19 \\
Neural 4...... & 26 & 19 \\
Neural 5...... & 26 & 15 \\
Neural 6....... & 24 & 8 \\
\hline
\end{tabular}

Of the costal bones the first is broadest, at its midlength measuring 43 millimeters fore and aft. The second and fifth have a greater distal breadth than any of the others. The eighth pair meet on the midline for a distance of only 4 millimeters. The sixth pair barely meet at the center, posterior to the pointed sixth neural. In the form of the carapace, the shape of the preneural, and the scalloped border with beveled edges this specimen resembles A. sagatus Hay, also from the Puerco deposits of New Mexico. The decided notch on the posterior median border, the shape of the nuchal, and the character of the sculpturing form an assemblage of characters not found in any other described species of the genus. I take pleasure in naming this beautiful specimen Aspideretes reesidei in honor of Mr. J. B. Reeside, jr., who was responsible for bringing together this fine collection of chelonian materials.

Specific characters: Disk of carapace slightly longer than wide; nuchal relatively narrow transversely, joined by its whole length to preneural and first costals, and extending forward beyond the general outline of the disk; free ends of first costals looking strongly forward; notch on posterior median border of disk. Outer two-thirds of costals crossed by longitudinal ridges; five ridges or four valleys in a line 10 millimeters long.

\section{Aspideretes vegetus Gilmore, n. sp.}

Plate XVIII, figure 2; Plate XXI.

Type: No. 8539 , U. S. N. M. Consists of considerable portions of the carapace and plastron. Collected by J. B. Reeside, jr., and party, 1916.

Type locality: Four miles east of Kimbetoh, in sec. 35, T. 23 N., R. 9 W., San Juan County, N. Mex.

Horizon: Puerco formation (" 50 feet above the base"), basal Eocene.

Although the preneural, first, fifth, and seventh neurals, and portions of many of the costals are missing from the type specimen of Aspideretes vegetus, for all practical purposes the parts preserved are distributed in such a manner as to give a very accurate and comprehensive idea of the structure of the entire carapace. (See fig. 27.)

The carapace is oval, with the broader portion somewhat in front of the middle. It has a greatest length in a straight line of 215 millimeters; a width of 193 millimeters. The nuchal is relatively short (84 millimeters) transversely, reaching only to the rib of the first costal. At the center it measures 21 millimeters antero-posteriorly. The front margin of this plate on the midline is slightly convex both longitudinally and transversely. Around the margin the carapace is abruptly beveled except on the first costals, which are perpendicularly truncated.

The preneural is missing, but the sutural edges on the first costal and median posterior border of the nuchal plate clearly show that it was present, and also that it projected forward 
into the body of the nuchal plate, the specimen in this respect resembling Plastomenus oedemius Cope. All the described species of Aspideretes based on sufficient material show the union between preneural and nuchal as being straight, without indentation of the nuchal by the preneural.

There were seven neurals, but the first, fifth, and seventh are missing in this specimen. Their principal dimensions are given in the accompanying table and their other characteristics are clearly shown in figure 27.

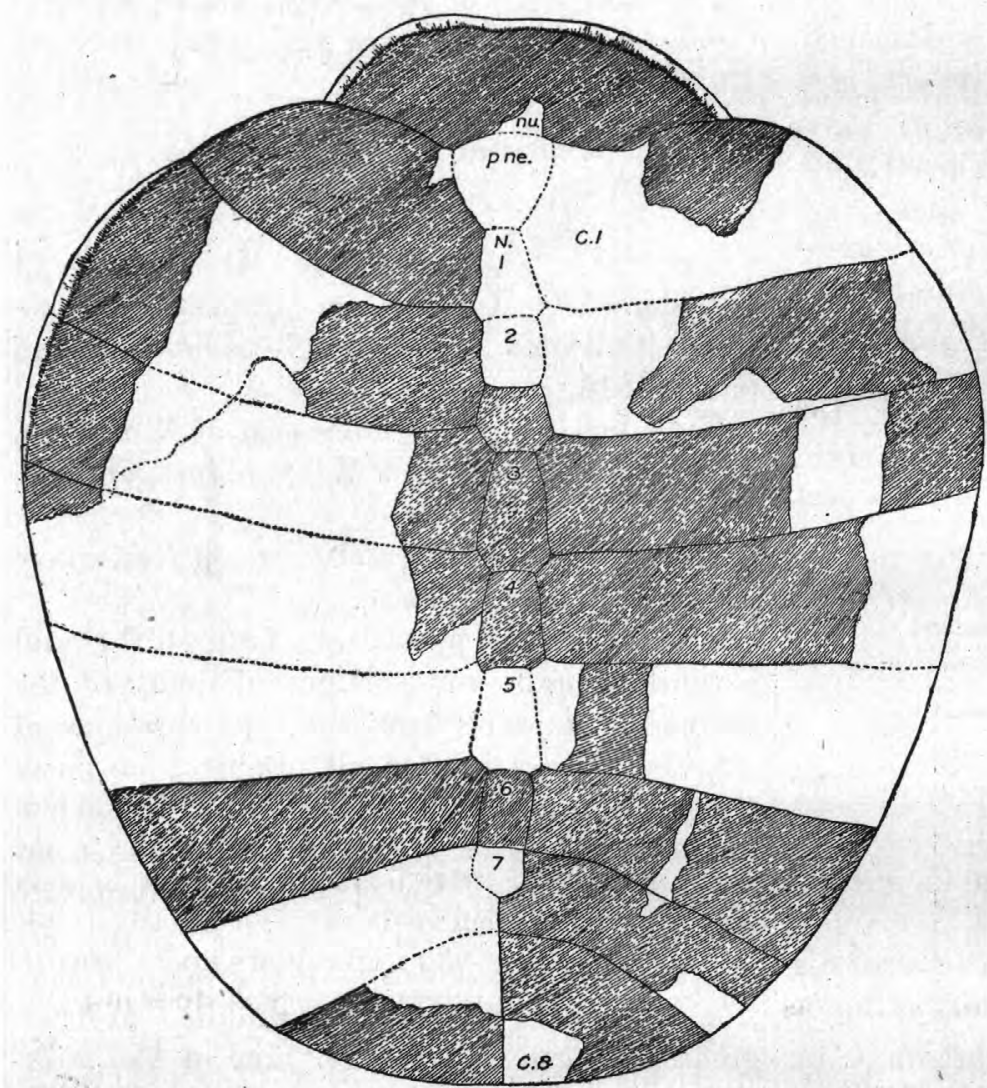

Figure 27,-Carapace of Aspideretes vegetus Gilmore,n. sp. (No. 8539, U.S.N.M.). Type. C1, $C 8$, Costal bones 1 and $8 ; x+2,3,4,5,6,7$, neural bones 1 to 7 ; $n u$, nuchal; $p$ ne, preneural. One-half natural size.

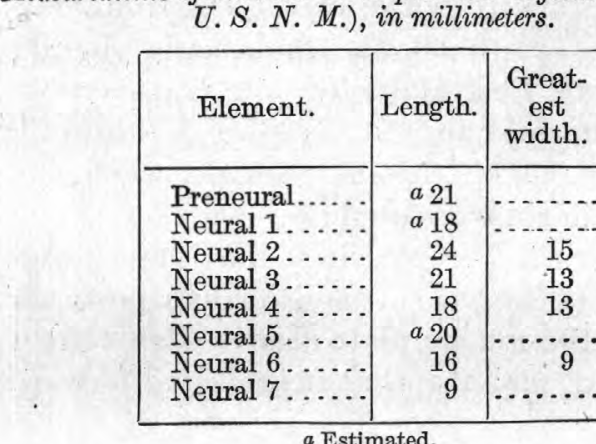

\begin{tabular}{|c|c|c|}
\hline Element. & Length. & $\begin{array}{c}\text { Great- } \\
\text { est } \\
\text { width. }\end{array}$ \\
\hline Preneural. & $a_{21}$ & \\
\hline Neural $1 .$. & $a 18$ & \\
\hline Neural 2.. & 24 & 15 \\
\hline Neural 3.. & 21 & 13 \\
\hline Neural 5. . & $a_{20}$ & \\
\hline Neural 6. & 16 & 9 \\
\hline Neural $7 .$. & 9 & ........ \\
\hline
\end{tabular}

Measurements of neurals in Aspideretes vegetus (No. 8539,

The sculpture of the carapace consists of rather shallow pits, separated by ridges whose summits are either flat topped or rounded. Of these pits there are usually four in a line 10 millimeters in length. They show only a slight tendency toward arrangement in rows. Along the middle of the carapace are a considerable number of parallel longitudinal ridges or welts. These appear most prominent on the posterior end of the disk, where they extend to the rim. (See Pl. XXI.) These ridges forward of the seventh costal are flat topped, and their summits are punctured with minute pits. These ridges or welts extend outward from the center well down on the costals; and many of them assume a diagonal course in relation to the longer axis of the shell. The ribs projected well beyond the borders of the carapace, though all of these ends are missing on this specimen. The free border of the seventh costal is especially narrow, as in $A$. sagatus Hay, measuring only 20 millimeters; the eighth pair of costals contribute 91 millimeters to the posterior border of the carapace. They meet on the midline for a distance of 43 millimeters.

Ot the plastron there are preserved the greater portion of the right hyoplastron, a fragment of the left, and nearly all of both the hypoplastra. The xiphiplastron is represented by two or more fragments. (See fig. 28.)

The hyoplastron and hypoplastron join by a straight suture for a distance of 90 millimeters. Along this suture the bone ranges from 5 to 7 millimeters in thickness. The narrowest part of the bridge is estimated to have been about 45 millimeters in width, of which the hyoplastron contributes 15 millimeters, the hypoplastron making up the difference. The lower surfaces of the plastral bones are covered by an ornamentation different from that of the carapace, consisting of a series of short bent ridges, few of which inclose distinct pits. The character of this sculpture is well shown in Plate XXI. 
In the oval form of the carapace with the widest part in front of the middle and the presence of longitudinal welts this specimen, it would seem, should be referred to the genus Plastomenus, but because of the distinct median separation of the two halves of the plastron and the presence of a preneural it should according to the accepted definition be referred to the genus Aspideretes. This species most closely resembles $A$. ellipticus Hay, also from the Puerco of New Mexico, but it is readily distinguished from that species by differences in the shape of the carapace, and the nuchal and preneural bones. The ornamentation will serve to separate the species, and the presence of welts in the present speci-
Type locality: Four miles northwest of Kimbetoh, in secs. 22 and 27, T. 23 N., R. 9 W., San Juan County, N. Mex.

Horizon: Puerco formation ("50 feet above base"), basal Eocene.

The damaged condition of the anterior portion of the carapace of the type specimen of Aspideretes quadratus makes the determination of the bones of this part of the shell somewhat uncertain. There appears to be a preneural bone present, and on that account I refer the species to the genus Aspideretes, but the acquisition of better preserved material may later show the absence of the preneural bone, in which event the genus $A m y d a$ would probably be its proper assignment.
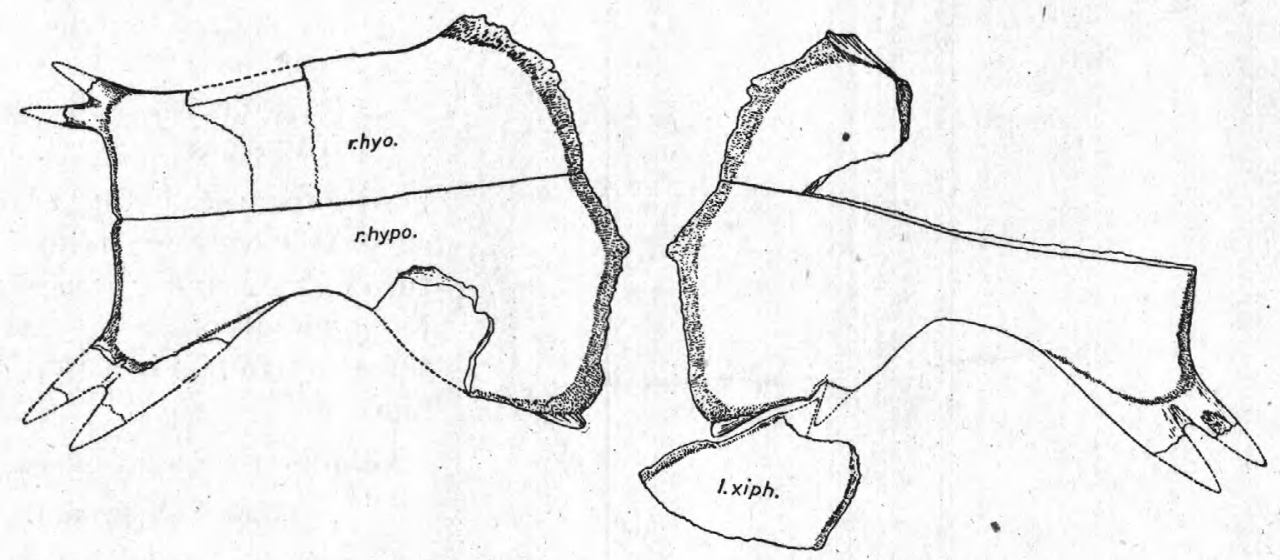

Figure 28.-Plastron o Aspideretes vegetus Gilmore, n. sp. (No. 8539, U. S. N. M.). Type. $r$ hyo, Right hyoplastron; $r$ hypo, right hypoplastron; $l x i p h$, anterior portion of left xiphiplastron. One-half natural size.

men will also be of assistance in identifying subsequently discovered specimens.

The characters relied on at this time to distinguish this species may be summed up as follows:

Specific characters: Disk of carapace oval in outline; entire upper surface of nuchal sculptured; joined by whole length to preneural and first costals; notched on median posterior border for preneural; costals crossed by numerous longitudinal welts; sculpture consisting of shallow rounded pits, usually four in a 10-millimeter line; plastron with twisted ridges.

Aspideretes quadratus Gilmore, n. sp.

\section{Plate XXII.}

Type: No. 8545. U. S. N. M. Consists of the carapace, lacking the nuchal and distal portions of the costals of the left side. Collected by J. B. Reeside, jr., 1916.
The quadrangular form of the carapace has suggested its specific name. Originally it had a length of about 330 millimeters and a breadth of at least 370 millimeters, which does not take into account the extension of the ribs beyond the ends of the costal plates. The shell proper is therefore wider than long. The right half of the carapace is nearly perfect (see Pl. XXIII), lacking only the anterior border of the first costal and the rib ends. The nuchal and preneural bones are not recognizable, even though portions of both are probably present.

Measurements of neurals in Aspideretes quadratus (No. 8545, U.S. N. M.), in millimeters.

\begin{tabular}{|c|c|c|}
\hline No. & Length. & Width. \\
\cline { 1 - 2 } $1 \ldots . . \ldots$ & $\ldots . .$. & 34 \\
$2 \ldots .$. & 41 & $\ldots \ldots .$. \\
$3 \ldots .$. & 38 & 26 \\
$4 \ldots .$. & 34.5 & 24 \\
$5 \ldots .$. & 31 & 23.5 \\
$6 \ldots .$. & 28 & 17 \\
$7 \ldots .$. & 18.5 & 17 \\
\hline
\end{tabular}


There are sèven neurals of the usual hexagonal shape. The most posterior one is considerably reduced. (See Fig. 29).

There are eight costals, all of which increase greatly in width toward their distal ends. The fifth is the widest of the series. It measures 80 millimeters fore and aft at the outer extremity. The seventh and eighth pairs of costals join on the median line. The eighth

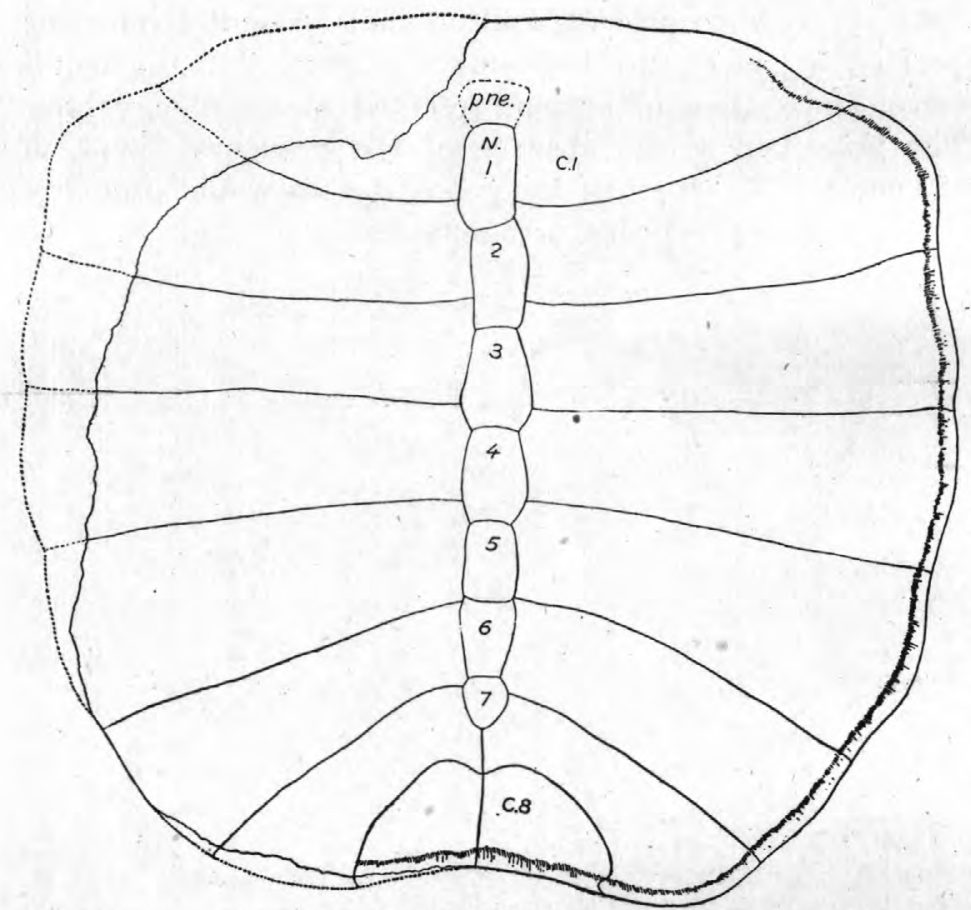

Frgure 29.-Carapace of Aspideretes quadratus Gilmore, n. sp. (No. 8545, U. S. N. M.). Type. $C 1, C 8$, Costal bones 1 and $8 ; N 1,2,8,4,5,6,7$, neural bones 1 to $7 ; p$ ne, preneural. One-fourth natural size.

pair contributes 95 millimeters to the median part of the posterior border and meet on the median line for a distance of 38 millimeters. All the costal borders are smooth and beveled off rather gradually along the sides but become more abrupt on the posterior end.

The hinder end of the carapace is slightly concave transversely. The sculpture of Aspideretes quadratus consists of pits surrounded by sharp ridges that are narrower than the pits. The pits are of all shapes and sizes, though angularly rounded pits predominate. They are small on the central part of the disk, there being from four to five pits in a 10-millimeter line. The pits increase in size toward the distal ends of the costals, where there are usually three pits in a 10-millimeter line. There is only a slight tendency on some of the median costals for the pits to arrange themselves in rows more or less parallel to the margins of the carapace. The chief features of the sculpture are well shown in Plate XXII. Aspideretes quadratus is at once distinguished from all the other Puerco representatives of this genus, including $A$. nassau Hay, in having the disk of the carapace wider than long. It appears to resemble most nearly $A$. subquadratus Lambe, ${ }^{1}$ from the Belly River formation of Alberta, but the much greatersize of the present specimen, the change in contour of the anterior end beginning with the second costal, and a much less pronounced tendency of the sculpture to form continuous grooves or channels indicate its distinction from that species. It may be diagnosed as follows:

Specific characters: Disk of carapace broader than long; posterior border truncated and broadly concave transversely; lateral border turning in abruptly toward the center on middle of second costal; from three to five pits in a 10-millimeter line.

\section{Aspideretes perplexus Gilmore, n, sp.} Plate XIX, figure 1.

Type: No. 8532 , U. S. N. M. Consists of the carapace lacking the nuchal, the seventh neural, and portions of the first costals. Collected by J. B. Reeside, jr., 1916. Type locality: Four miles east of Kimbetoh, in sec. 35 , T. 23 N., R. 9 W., San Juan County, N. Mex.

Horizon: Puerco formation (" 50 feet above the base"), basal Eocene.

The specific name perplexus is applied to a specimen that is with doubt referred to the genus Aspideretes, as it could with almost equal propriety be assigned to Plastomenus, and its true generic assignment must await the discovery of the plastral bones. The presence of seven costals appeared at first to indicate its affinities with Platypeltis, but the subsequent recognition of a distinct preneural precludes its assignment to that genus.

1 Lambe, L. M., On new species of Aspideretes from the Belly River formation of Alberta, with further information regarding the structure of the carapace of Boremys pulchra: Royal Soc. Canada Trans., vol. 8, pp. 11-13, 1914. 
The individual is a relatively small one. The greatest length of the carapace is estimated to have been about 180 millimeters; the width of the disk in a straight line is 152 millimeters. In outline the shell is elliptical, with a broad, shallow notch on the median posterior border. The lateral borders of the carapace are undulating, as shown in figure 30. The rib ends project beyond the disk an undetermined distance, as none are perfectly preserved.

The nuchal is missing. The preneural is a small, thin, angularly rounded bone. Following it are six neurals, the posterior one of which is missing. These are relatively narrow.

Measurements of neurals in Aspideretes perplexus (No. 8532, U.S. N. M.), in millimeters.

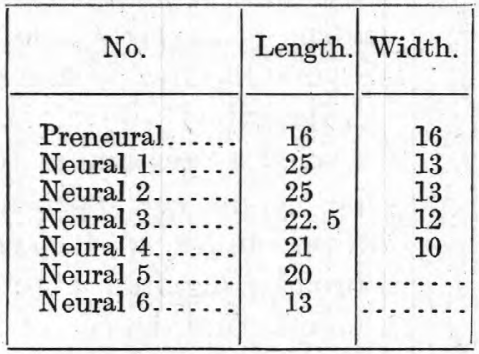

There are seven costals present; the eighth pair seems to have entirely disappeared. The first costal has a width of 31 millimeters. The sixth pair join on the midline for about half their width. The seventh pair join on the midline for their whole width, a distance of 16 millimeters.

The ornamentation of the carapace consists of ridges inclosing pits, all of which are wider than the ridges. There are from five to six pits in a line 10 millimeters long. Many of these pits are angular in shape, but hardly any are arranged in definite rows. The ridges have sharp summits on the outer ends of the costals but become wider and more rounded toward the center of the carapace. On the outer ends of several of the costals many of the ridges run fore and aft, thus inclosing elongate valleys of irregular shapes and sizes. The outer edges of the costals are steeply beveled.

This species is assigned to the genus Aspideretes rather than to Plastomenus, because of the absence of the eighth pair of costals and the reduction of the seventh pair. While all the known species of Aspideretes have a full complement of these bones, the eighth pair are usually much reduced in size, whereas in most species of Plastomenus they are of robust development.

Aspideretes perplexus may be distinguished by the following characters:

Specific characters: Carapace with seven pairs of costals; seventh pair considerably reduced; notch on median posterior end; sculpture of medium coarseness, five or six pits in a 10millimeter line.

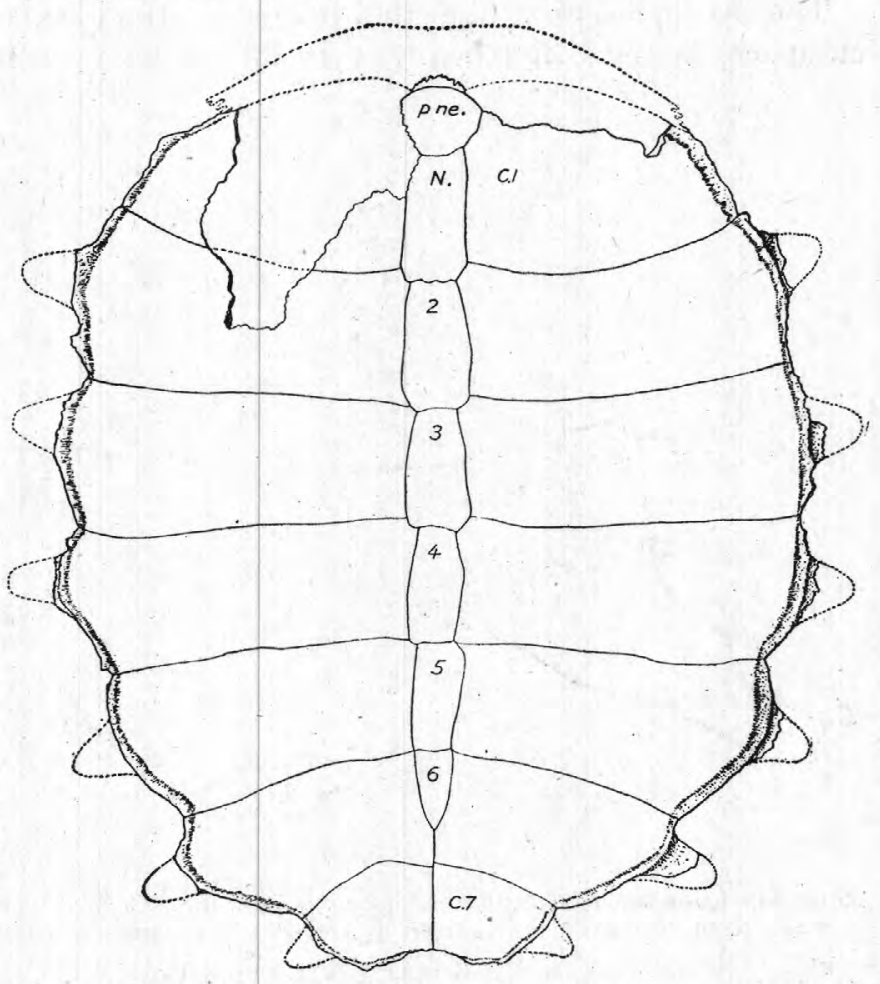

FIGURE 30.-Carapace of Aspideretes perplexus Gilmore, n. sp. (No. 8532, U. S. N.M.). Type. $C 1, C 7$, Costal bones 1 and $7 ; N 1,2,3,4,5,6$, neural bones to $6 ; p$ $e$, preneural. One-half natural size.
Aspideretes sagatus Hay.

Plate XXIII, figure 1.

Aspideretes sagatus Hay, The fossil turtles of North America: Carnegie Inst. Washington Pub. 75, pp. 497, 498, pl. 93, figs. 1-3, text fig. $652,1908$.

Specimen No. 8554, U. S. N. M., collected by J. B. Reeside, jr., 8 miles N. $60^{\circ} \mathrm{E}$. of Kimbetoh, San Juan County, N. Mex., in sec. 17, T. 23 N., R. 8 W., " 840 feet above the base of the Puerco, in the Torrejon formation," is provisionally referred to Aspideretes sagatus Hay. This species was founded on a well- 
preserved carapace from the Puerco deposits of New Mexico.

The present specimen consists of the right half of the carapace, a portion of the nuchal and first costal of the left side, the preneural, and numerous fragments. The plastron is represented by a nearly perfect right hypoplastron and a portion of the end of the right hyoplastron. As these are the first plastral bones of this species to be found it appears important that they should be described and figured.

The hypoplastron, like the bones of the carapace, is thick and heavy. At the center



FIGURE 31.-Right half of the plastron of Aspideretes sagatus Hay (No. 8554, U. S. N. M.). $r$ hyo, Right hyoplastron; $r$ hypo, right hypoplastron. Two-thirds natural size.
The sculpture consists of a network of ridges which inclose pits of irregular size and form. Most of the pits are of somewhat greater diameter than the ridges which inclose them. The pits become more uniform in size on the inner half and at the same time gradually grow fainter and fainter until on the median fourth the surface is without sculpture. The inner end is broadly beveled off.

The inner or median end of the right hyoplastron has a fore and aft width of 59 millimeters. This end, as in the hypoplastron, is beveled off to a subacute edge along the superior border. The form of the end of this bone is well shown in Plate XXIII, figure 1.

A second specimen (No. 8652 , U. S. N. M.), consisting of the almost complete hypoplastron of the right side, from the same locality as the specimen described above, is here identified as pertaining to this same genus and species. It differs from No. 8554 in having a broader inguinal notch and in some other details of form. The carapace of specimen No. 8554 ,U.S.N.M., agrees in most particulars very closely with the type as described by Hay. The sculpture, how e ver, is somewhat different toward the distal ends of the costals, where many of the ridges, instead of breaking up into tubercles;

of the suture with the hyoplastron the thickness is 13 millimeters. One border of the notch for the xiphiplastron remains. (See fig. 31.)

Measured across the narrowest part the hypoplastron is 26 millimeters wide; its transverse measurement is about 122 millimeters. On the outer end anterior to the lateral processes the sculpture on the surface stops about 9 millimeters short of the border and the thickness of the bone is reduced one-half by the abrupt depression of the surface, which beyond the depression is without sculpture and terminates in a subacute border, much as in A. puercensis Hay. The inguinal notch is rather angular as contrasted with the broadly curved notch of most other species of the genus. grow broader than the pits and assume a fore and aft direction. This feature is especially pronounced on costals 2, 3, 4, and 5. More perfect specimens may show that this form belongs to a distinct species, but for the present its close resemblance in all important particulars indicates that its closest affinities are with $A$. sagatus Hay.

\section{Genus AMYDA Oken.}

The genus $A m y d a$ is represented in the present collection by a single specimen from the Puerco formation. This specimen extends slightly the geologic range of this genus in the West, as prior to this time its most ancient known occurrence was in the Wasatch, though on the Atlantic slope specimens referred to Amyda are found in Cretaceous deposits. 
Amyda eloisae Gilmore, n. sp.

Plate XXIV.

Type: No. 8540 , U. S. N. M. Consists of a nearly complete carapace. The more important parts missing are the middle portion of the nuchal and the distal third of the left first cóstal. Collected by J. B. Reeside, jr., and party, 1916.

Type locality: About $2 \frac{3}{4}$ miles east of north of Kimbetoh, in sec. 19, T. 23 N., R. 9 W., San Juan County, N. Mex.

Horizon: Puerco formation (" 50 feet above the base"), basal Eocene.

The specimen here described is of interest as being the first recognizable member of the genus $A m y d a$ to be found in the Puerco formation.

The carapace (Pl. XXIV) is broad and uniformly arched from side to side. The front margin appears to have been broadly rounded, the rear broadly and squarely truncated. The greatest length of the carapace at the center was about 237 millimeters; its greatest width in a straight line 243 millimeters. Measured over the curve of the shell its greatest width is 274 millimeters. The bones are rather thick and heavy at the sutural borders; near the ends of the costals they are from 8 to 10 millimeters thick, and through the ribs the thickness is 12 millimeters. The lateral borders are sinuous. As in Aspideretes grangeri, the upper layer of the carapace overhangs the middle layer, so that a gutter runs around the edge of most of the carapace.

The ornamentation of the carapace is fairly uniform in character and is made up of a network of narrow, sharp ridges that ramify and inosculate so as to inclose small sunken areas of irregular shape and size. Most of the inclosed areas are wider than the ridges which inclose them. Toward the center and front of the shell the pits become smaller and shallower and the apexes of the ridges more rounded. The apexes of many of the ridges are lifted into sharp points, especially at the angles. There are from four to five pits in a line 10 millimeters long. The nuchal joins along its entire posterior margin with the first costals and neural. It is estimated to have had a greatest transverse extent of 142 millimeters and an anteroposterior extent of about 42 millimeters.
The whole top of this bone appears to have been sculptured. There are seven neurals, and these decrease in size from the first to the last. The first is 34 millimeters long and 18 millimeters wide, the second 28 millimeters long and 17.5 millimeters wide; the third 26 millimeters long and 17 millimeters wide; the fourth 15 millimeters long. The seventh is missing, but the surrounding bones show it to have been reduced in size, as shown in figure 32 .

The eight pairs of costals are small and join one another on the midline. Their free ends form about 44 millimeters of the median posterior border.

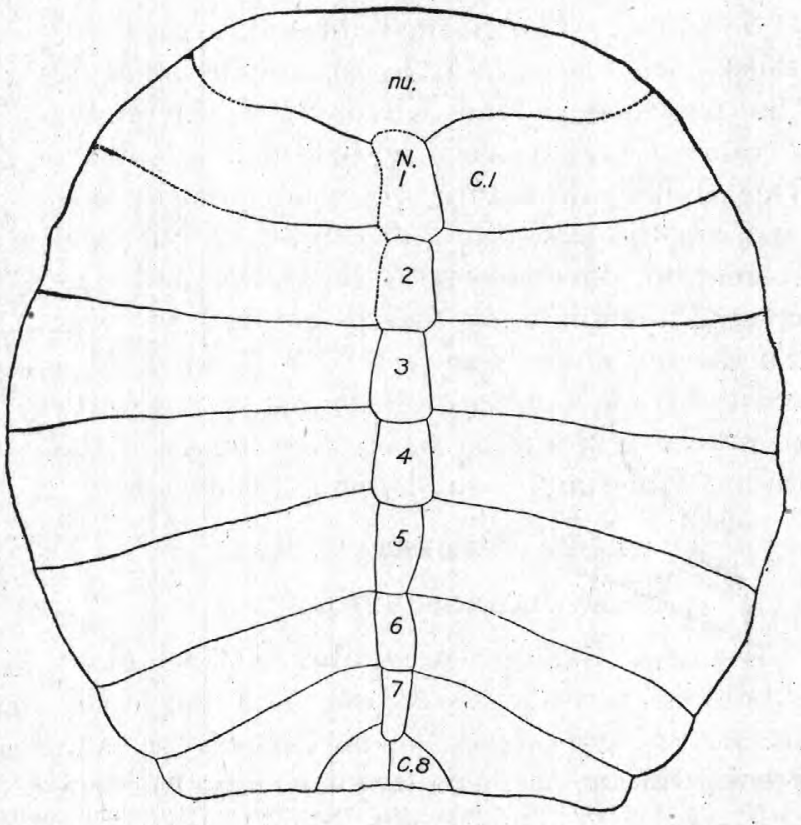

FrGURE 32.-Carapace of A myda eloisae Gilmore, n. sp. (No. 8540, U. S. N. M.). Type. $C 1, C 8$, Costal bones 1 and $8 ; N 1,2,3,4,5,6,7$, neural bones 1 to ; nu, nuchal. One-third natural size.

This species resembles Amyda salebrosa Hay in the general shape of the carapace and in its ornamentation but is distinguished from that species by its much smaller size, by the channeled borders as contrasted with the beveled rim of $A$. salebrosa, and by having the greatest width posterior to the middle.

Amyda eloisae is the most ancient member of the genus yet to be discovered in the Rocky Mountain region, though in the Atlantic region representatives of the genus have been found in the Cretaceous. It is dedicated to my eldest daughter, Miss Eloise Elizabeth Gilmore. Specific characters: Disk of carapace slightly broader than long; sculpture four to five pits in 10-millimeter line, irregular in 
character; greatest width slightly posterior to middle; nuchal more than half the width of the carapace.

\section{Order DINOSAURIA.}

In addition to the notable series of turtle remains described in the preceding pages, the present collection contains a number of incomplete dinosaurian specimens that despite their fragmentary condition contribute important facts to our knowledge of the geographic and geologic distribution of these animals.

The armored dinosaurs are represented by fragmentary remains from the Kirtland and Ojo Alamo formations, and thus I am able to record for the first time their presence in the Ojo Alamo. The horned dinosaurs or Ceratopsia are represented by specimens showing the presence in the Kirtland of the genus Ceratops? or a very closely related form. Duck-billed dinosaurs or trachodont specimens in the collection, also from the Kirtland formation, show that both the crested and noncrested members of this group are present. Furthermore, for the first time remains of a crested trachodont have been discovered south of northern Montana, where they occur in the Judith River and Two Medicine formations.

\section{Suborder PREDENTATA Marsh.}

\section{Family HADROSAURIDAE Cope.}

Because of the great number of trachodont dinosaurs already described, and especially because of the paucity of our knowledge concerning many of them, any attempt to identify species or even genera from fragmentary materials is hazardous. For this reason no attempt has been made to identify generically any of the trachodont specimens in the present collection. Their chief importance is in furnishing strong if not conclusive corroborative evidence as to the Montana age of the Kirtland formation, shown by the presence of a specimen having an ischium with a footed distal extremity and another specimen with an ischium terminated by a blunt rounded end, thus indicating the presence of the crested and noncrested types of trachodonts, which elsewhere are found associated only in formations of the Montana group. On the above differences Brown ${ }^{1}$ has proposed the division

1 Brown, Barnum, Corthyosaurus casuarius, a new crested dinosaur from the Belly River Cretaceous, with provisional classification of the family Trachodontidae: Am. Mus. Nat. Hist. Bull., vol. 33, pp. 564-565, 1914. of the family Trachodontidae into the two subfamilies Trachodontinae, ${ }^{2}$ comprising those having a skull without a crest, and Saurlophinae, comprising those with a crest.

Subfamily HADROSAURINAE Lambe.

The subfamily Hadrosaurinae is represented in the Kirtland and Ojo Alamo formations by specimens recognized by Brown as belonging to the genus Kritosaurus. Reeside collected a specimen that belongs to this subfamily and possibly to Kritosaurus, $2 \frac{3}{4}$ miles south of west of Kimbetoh, San Juan County, N. Mex., in sec. 3 , T. 32 N., R. 10 W., 330 feet above the base of the Kirtland formation.

This specimen (No. 8628, U. S. N. M.) consists of the poorly preserved but articulated sacrum of 10 vertebrae, four dorsals, 2 caudals, the right pubis complete and a portion of the left, the greater part of one ischium, the preacetabular portion of theilium, both humeri, and several ribs. Unfortunately this specimen can not be compared with the type of Kritosaurus, which was based largely on a skull and lower jaws.

\section{Subfamily SAURLOPHINAE Brown.}

The presence of a member of the subfamily Saurlophinae is indicated by the preservation of the greater part of an ischium from the right side, which shows a distal end terminating in a footlike extremity. Isohia of this style are associated only with the skulls having a crest. A single tall spinous process and a phalangial element of the front foot are the other bones of this specimen collected. $\mathrm{Mr}$. Reeside tells me, however, that more of the skeleton remains in the field and that lack of time prevented its colleotion. It was found 4 miles west of Kimbetoh, in sec. 34, T. 23 N., R. 10 W., San Juan County, N. Mex., 380 feet above the base of the Kirtland formation.

\section{Family CERATOPSIDAE Marsh.}

Genus CERATOPS March, 1888.

Ceratops sp.

Plate XXV, figures 1 and 2.

The bone (No. 8604, U. S. N. M.) figured on Plate XXV, figures 1 and 2, is the median bar of

s Lambe has adopted the provisional classification of this group of the Dinosauria proposed by Brown (see Ottawa Naturalist, February, 1918, p. 138) and shows that the family term Hadrosauridae, which has priority by several years over Trachodontidae, must be revived, especially as the validity of the genus Hadrosaurus is recognized. The subfamily designation in turn is therefore changed to Hadrosaurinae. 
the frill of a fenestrated ceratopsian dinosaur. It was collected by Messrs. Reeside and Clark $3 \frac{1}{2}$ miles south of west of Kimbetoh, near the south side of sec. 4 , T. 22 N., R. 10 W., San Juan County, N. Mex., 75 feet above the base of the Kirtland formation. The very close resemblance of this specimen, both in size and in form, to the homologous element from the Belly River formation described and figured by Lambe ${ }^{1}$ as Monoclonius belli ${ }^{2}$ leaves no doubt as to their close relationship. In the complete skull this bar forms the median part of the frill and separates the large fenestrae on either side. On account of the close resemblance of this specimen to the Belly River form, it is provisionally referred to the genus Ceratops, the genotype of which is from the Judith River formation of Montana.

Regardless of the correctness of the present generic identification, it represents a stage of development in the ceratopsian Dinosauria that has been found only in the Judith River and Belly River formations, and its-discovery in the Kirtland substantiates the earlier conclusion $^{3}$ that this formation is not later than Montana in age.

A second specimen, a considerable portion of a right squamosal, was collected $3 \frac{1}{4}$ miles south of west of Kimbetoh, N. Mex., near the southeast corner of sec. 4 , T. 22 N., R. 10 W., 115 feet above the base of the Kirtland formation. The small size and the shortness of this bone make it quite probable that it also pertains to the genus Ceratops.

Ceratopsian, genus and species undetermined.

A very fragmentary skull was collected in Barrel Springs Arroyo, about 1 mile southwest of Ojo Alamo store, San Juan County, N. Mex., 10 to 12 feet above the base of the Ojo Alamo sandstone. From the great number of fragments a considerable part of the posterior end of what appears to be the median or dermosupraoccipital was pieced together. Although this large fragment is not sufficiently characteristic to indicate the generic affinities, it is of

1 Lambe, L. M., On Vertebrata of the Mid-Cretaceous of the Northwest Territory; pt. 2, Contr. Canadian Paleontology, vol. 3, p. 66, pl. 20, figs. 1 and $2,1902$.

2 Lambe in a subsequent article refers this form to the genus Centrosaurus, whereas Brown now regards it as synonymous with the earlier described Ceratops.

3 Gilmore, C. W., Vertebrate faunas of the Ojo Alamo, Kirtland, and Fruitland formations: U. S. Geol. Survey Prof. Paper 98, p. 281, 1916.

$$
115836^{\circ}-19-5
$$

interest as showing the presence here of a ceratopsian which is distinct from either Triceratops, Ceratops, or Monoclonius. This fragment shows a fenestrated frill in which the openings are apparently smaller than in either of the genera mentioned above. In all probability it represents an undescribed form.

\section{Family SCELIDOSAURIDAE Huxley.}

\section{Genus and species undetermined.}

Plate XXVI, figure 2.

A left scapula (No. 8571, U. S. N. M.) was collected by J. B. Reeside, jr., in Barrel Spring Arroyo, about 1 mile southwest of Ojo Alamo store, San Juan County, N. Mex., 10 to 12 feet above the base of the Ojo Alamo sandstone.

This isolated bone belongs to one of the armored dinosaurs and is of special interest at this time in being the first bone of a representative of this group to be found in the Ojo Alamo formation.

The scapula is very short and massive throughout. There is a prominent acromion process, a very wide end contributing to the formation of the glenoid socket, and a thick, heavy blade that is rounded off on its upper extremity. The presence of a well-developed acromion process and the relative shortness of the bone distinguish it from all the known members of the Ankylosauridae, which are without such a process. In order to determine if possible its true affinities, the specimen was sent to Mr. Barnum Brown, of the American Museum of Natural History, New York, and he very kindly compared it with the excellent armored-dinosaur material in that museum. Under date of Januáry 30, 1917, he wrote as follows:

The scapula is that of an armored dinosaur closely related to if not the genus Hoplitosaurus, and I would assign it provisionally to that genus. *** Your specimen differs from a Hoplitosaurus scapula in the American Museum in that it has less dorso-ventral curvature, the blade is thicker, and the distal end is not broadly expanded, although the terminal border is somewhat broken. The large acromion process is similar in both, and the coracoid border is likewise extensively developed.

I have carefully compared the present specimen with the proximal half of the scapula of the genotype of Hoplitosaurus marshi (No. 4752 , U. S. N. M.) and find differences that would indicate they are in all probability generically distinct, though I believe their fam- 
ily attributes will be found to be the same. Provisionally, therefore, I refer it to the family Scelidosauridae until such time as the discovery of additional material shall disclose its true relationships. This bone undoubtedly represents an undescribed form, but on account of the meagerness of the material I defer naming it. plates, with many fragments, was collected by the Reeside party about 1 mile southwest of Ojo Alamo store, in Barrel Spring Arroyo, 10 to 12 feet above the base of the Ojo Alamo sandstone. These bones in all probability pertain to the same kind of an animal as the scapula previously described, which was found a quarter of a mile distant from this locality.

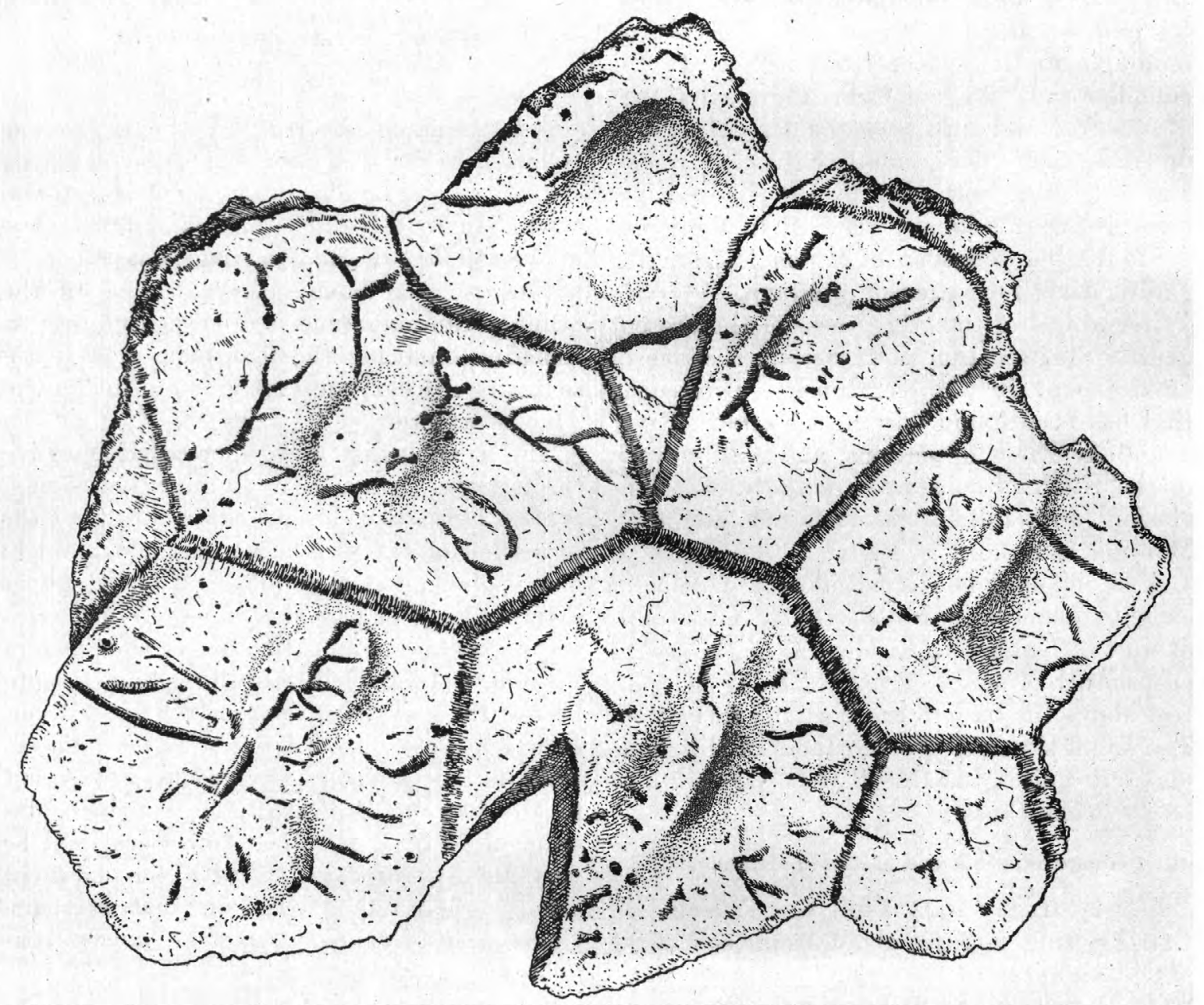

FIGURE 33.-Dermal plates of an armored dinosaur (No, 8610, U, S .N. M.) from the Ojo Alamo formation. Two-thirds natural size.

Some of the mone important dimensions of the scapula under discussion are: Greatest length from posterior border of glenoid cavity to upper end of blade, 320 millimeters; greatest width of blade, 120 millimeters; least width, 95 millimeters; greatest transverse width of proximal end, 120 millimeters; thickness of shaft at center, 48 millimeters; thickness of blade at upper end, 29 millimeters.

A second specimen (No. 8610, U. S. N. M.), consisting of a number of dermal scutes or
The scutes are comparatively thick, flattened plates of various sizes and shapes. Some have low dorsal ridges or carinae asymmetrically placed; others present only a slightly raised rounded center. (See fig. 33.) Several show by their smooth rounded edges that they existed as independent plates, but the greater number have sutural edges, indicating that they were closely united into a carapace-like covering. Scutes of this type are probably from the skin above the pelvic region, where 
they must have formed a pelvic shield much as in Polocanthus and Stegopelta. The close resemblance of the largest plate in this series with those found attached to the ilium in the genotype of Stegopelta is well shown by a comparison of figure 33 with Plate.XXVI, figure 1, which shows the largest scute preserved, measuring 195 millimeters in one diameter and 182 millimeters in the other.

A third specimen in this same collection (No. 8611, U. S. N. M.), consisting of several plates, was found 1 mile south of Ojo Alamo, in Barrel Springs Arroyo, 3 to 8 feet above the base of the Ojo Alamo sandstone. It includes a few fragmentary scutes with sutural edges similar to those found with No. 8610 , but in addition there are several thicker, heavier plates that are without dorsal ridges and have but few vascular markings.

Some of the dermal scutes of these specimens show a marked resemblance to those of Stegopelta, from the Colorado formation, but, unfortunately, the scapula of that genus is unknown, so that a comparison of these bones can not be made at this time. As suggested above, this material may represent an undescribed form, but as there are no less than eight described genera of armored dinosaurs known from North America, all but three of which are based on scanty materials, it seems best not to burden the literature further with names.

These armored dinosaurs have a wide vertical range, and when the several described forms are fully known they should furnish a most interesting chapter in dinosaurian development.

A list of the described American species and the formations in which they occur is given below.

Ankylosaurus magniventris Brown ....Ltance (Hell Creek beds).

Ankylosaurid dinosaur (undescribed).Edmonton.

Europlocephalus tutus Lambe... . . . Belly River.

Palaeoscincus costatus Leidy......... Judith River.

Scelidosaurid dinosaur (undescribed). Ojo Alamo.

Scelidosaurid dinosaur (undescribed). Kirtland.

Hierosaurus sternbergii Wieland. . . . . Niobrara.

Nodosaurus textilis Marsh . . . . . . . . . Benton.

Stegopelta landerensis Williston...... Benton.

Hoplitosaurus marshi (Lucas) ......... Lakota.

Priconodon crassus Marsh. ...........Arundel (Potomac). Scelidosaurid dinosaur (undescribed). Cloverly.

Stegosaurus (several species)..........Morrison.
Suborder THEROPODA.

Family MEGALOSAURIDAE.

Genus and species undetermined.

A few fragmentary vertebrae of a very large carnivorous dinosaur were collected by J. B. Reeside, jr., in Barrel Spring Arroyo, west of the road, 1 mile south of Ojo Alamo, N. Mex., 3 to 8 feet above the base of the Ojo Alamo formation. This specimen is too fragmentary to be identified and is of interest only as showing the occurrence in the Ojo Alamo formation of a large carnivorous dinosaur of the proportions of Tyrannosaurus. During the preceding season carnivorous dinosaur teeth were found by the United States Geological Survey party under C. Max Bauer in the same locality ${ }^{1}$ and practically at the same geologic horizon.

\section{Order CROCODHIA.}

Fossil crocodile remains are present in both the Puerco and Torrejon formations, although to judge from the present collection they are more abundant in the Puerco, there being 15 specimens from that formation, whereas there are only three from the Torrejon.

All these specimens are extremely fragmentary, and in the present state of our knowledge regarding the extinct crocodiles none are identifiable. Cope ${ }^{2}$ in 1885 , on inadequate material, named one species, Crocodilus stavelianus, from the Puerco formation, and it is quite probable that some of the specimens in the present collection may pertain to that species, though I doubt the ability of anyone to identify specimens with a species founded on a single tooth.

The relatively small size of the dermal scutes and vertebral centra preserved indicates that the individuals represented were comparatively small.

Those specimens in the present collection from the Puerco formation were found 4 miles northwest of Kimbetoh, in sec. 27, T. 23 N., R. 9 W., San Juan County, N. Mex., 50 feet above the base of the formation. Those from the Torrejon formation were found near by, in the same section.

1 Gilmore, C. W., Vertebrate faunas of the Ojo Alamo, Kirtland, and Fruitland formations: U. S. Geol. Survey Prof. Paper 98, p. 288, 1916.

2 Cope, E. D., The relations of the Puerco and Laramie deposits: Am. Naturalist, vol. 19, p. 986, 1885. 
Crocodile remains are also found in the Ojo Alamo, Kirtland, and Fruitland formations, ${ }^{1}$ but no new materials were obtained by the expedition of 1916.

Class PISCES.

Genus LEPISOSTEUS Lacépède, 1803.

Lepisosteus sp.

In recent years it has become customary for paleontologists to refer all fossil fish scales to Lepisosteus, a genus founded on living specimens. This procedure has but little significance outside of indicating the ganoid nature of the scales. That more than one genus is represented among the materials thus referred

1 Gilmore, C. W., Vertebrate faunas of the Ojo Alamo, Kirtland, and Fruitland formations: U.S. Geol. Survey Prof. Paper 98, p. 289, 1916. is quite probable, but more perfect specimens are needed before this matter can be decided. It is quite impossible to identify genera or even species from these simple lozenge-shaped scales.

The present collection contains ganoid scales from the Kirtland and Puerco formations which were found 8 miles N. $70^{\circ} \mathrm{E}$. of Kimbetoh, in sec. 21 , T. 23 N., R. 8 W., 820 feet above the base of the Puerco, in the Torrejon; 8 miles N. $60^{\circ} \mathrm{E}$. of Kimbetoh, in sec. $17, \mathrm{~T}$. 23 N., R. 8 W., 840 feet above the base of the Puerco in the Torrejon; and $2 \frac{1}{2}$ miles south of west of Kimbetoh, in sec. 3, T. 22 N., R. 10 W., 200 feet above the base of the Kirtland. ${ }^{2}$

2 Other Upper Cretaceous localities are listed in U. S. Geol. Survey Prof. Paper 98, p. 302,1916. 


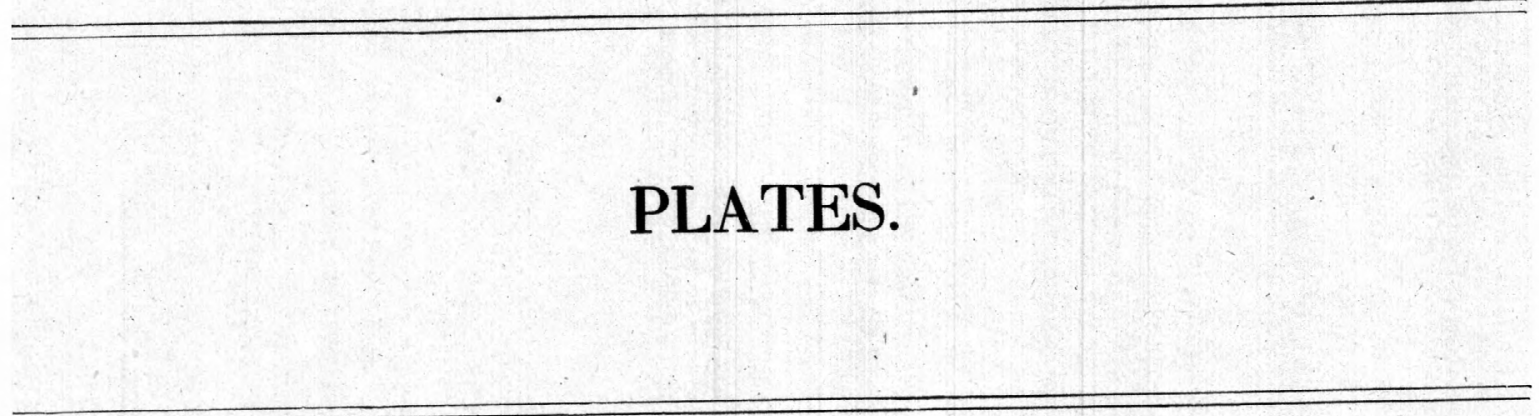







COMPSEMYS PARVA HAY.

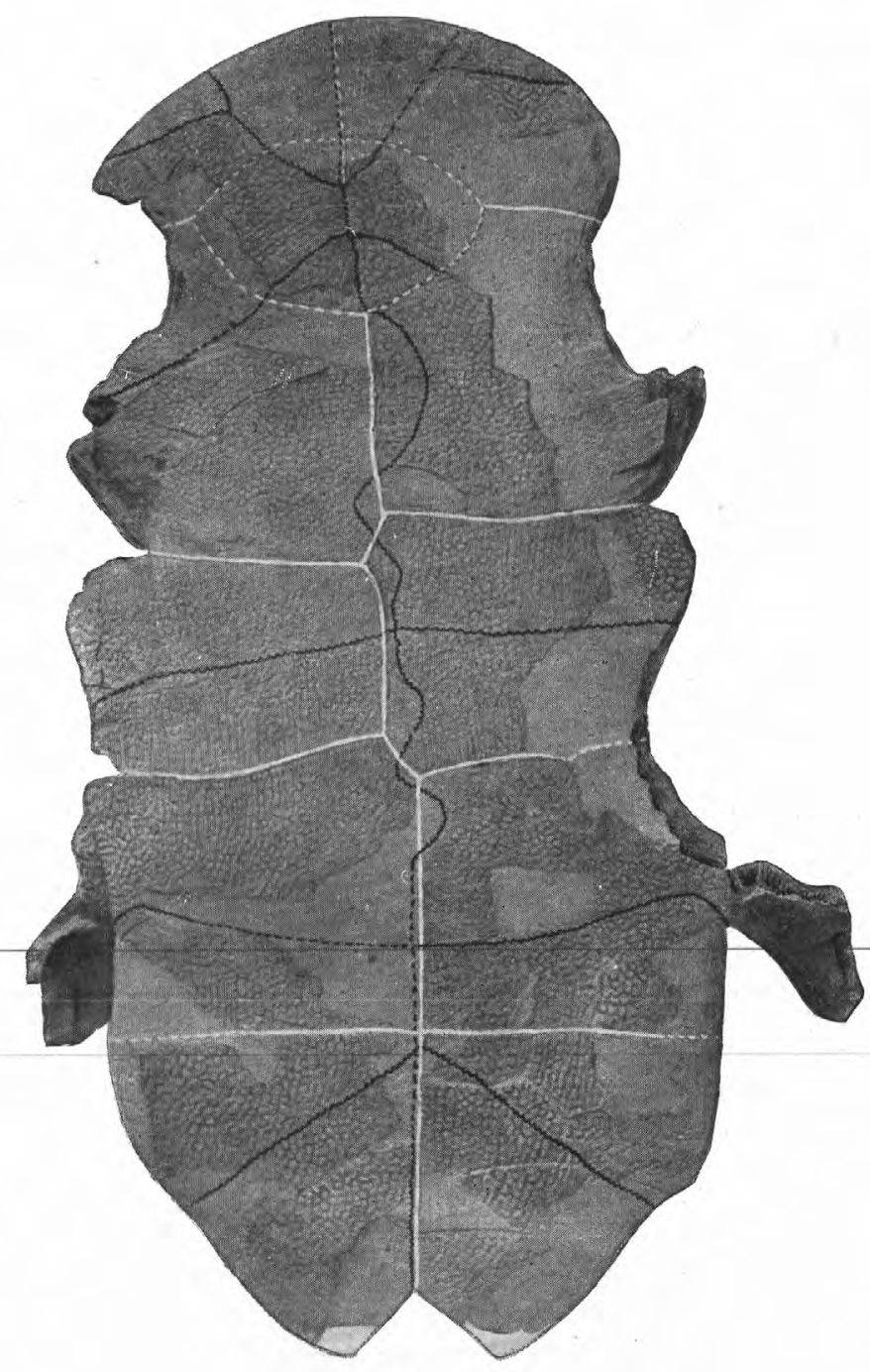

No. 8528 , U. S. N. M. 1, Carapace; 2, plastron. Natural size. See p. 13. 

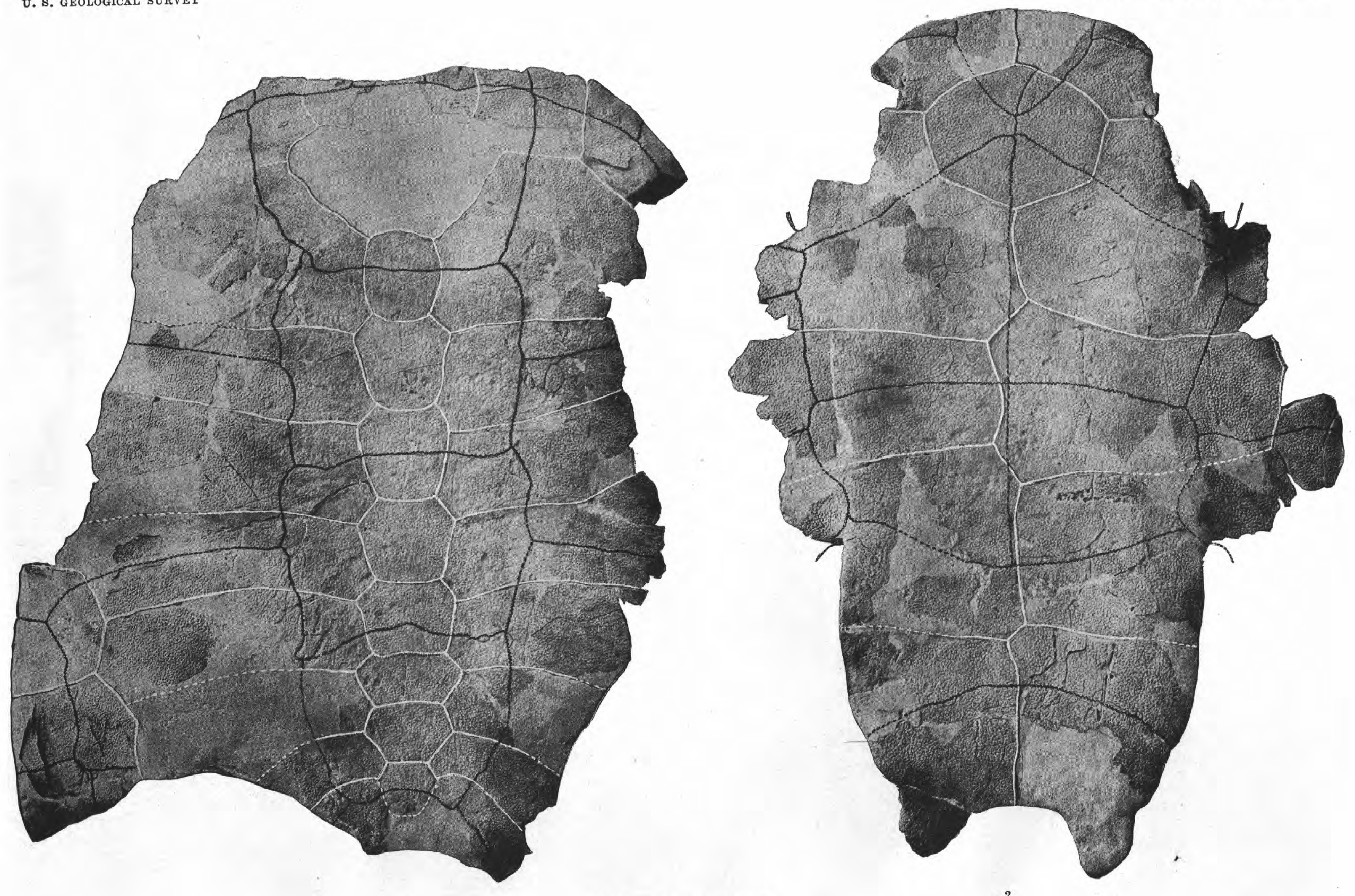

COMPSEMYS VAFER HAY.

2

No. 8529 , U. S. N. M. 1, Carapace; 2, plastron. Three-fourths natural size. See p. 16. 
PROFESSIONAL PAPER 119 PLATE III

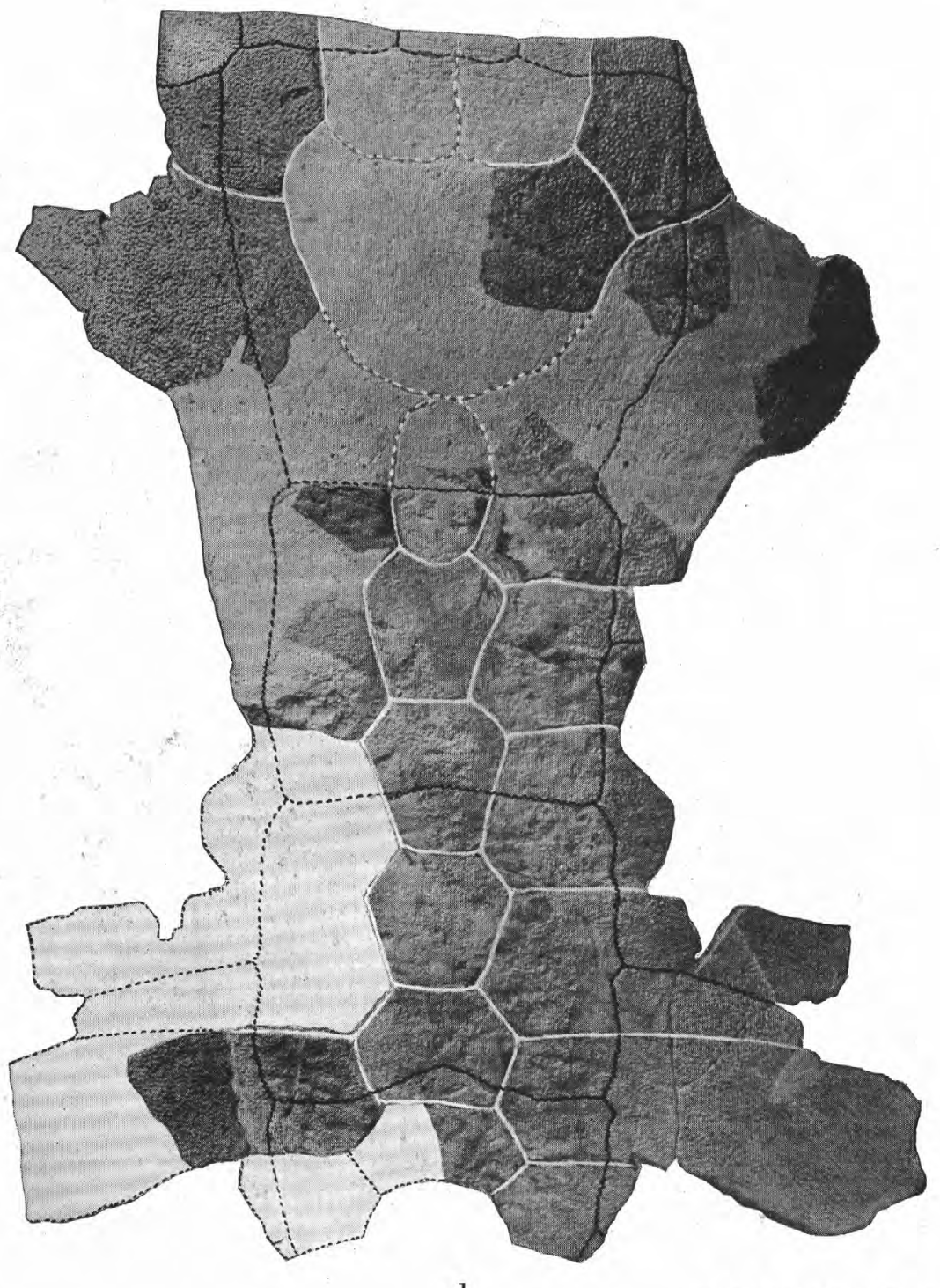

COMPSEMYS PUERCENSIS GILMORE, N. SP.

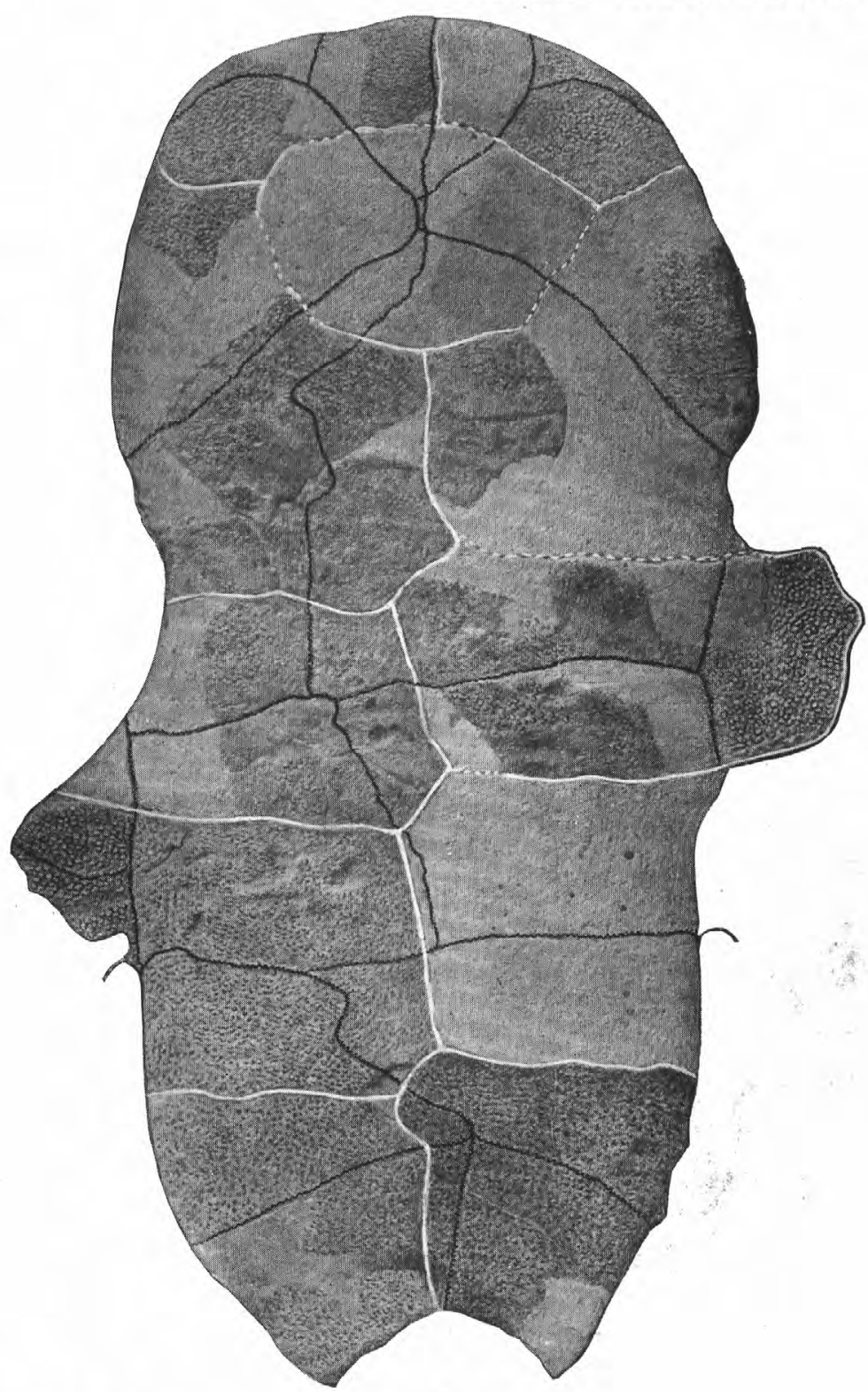

2

Type; No. 8544, U. S. N. M. 1, Carapace; 2, plastron. Three-fourths natural size. See p. 19 
U. S. GEOLOGICAL SURVEY

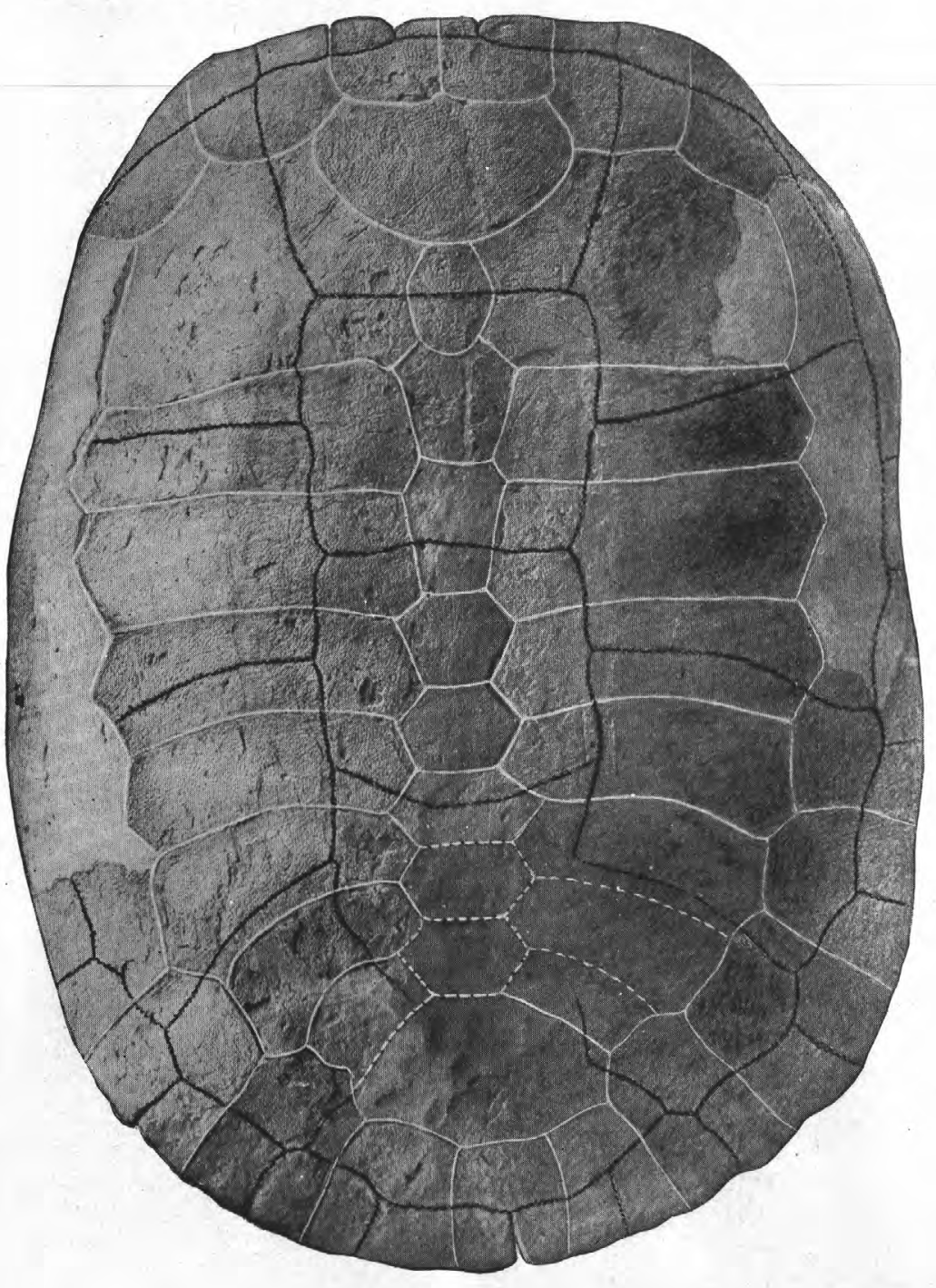

PROFESSIONAL PAPER 119 PLATE IV

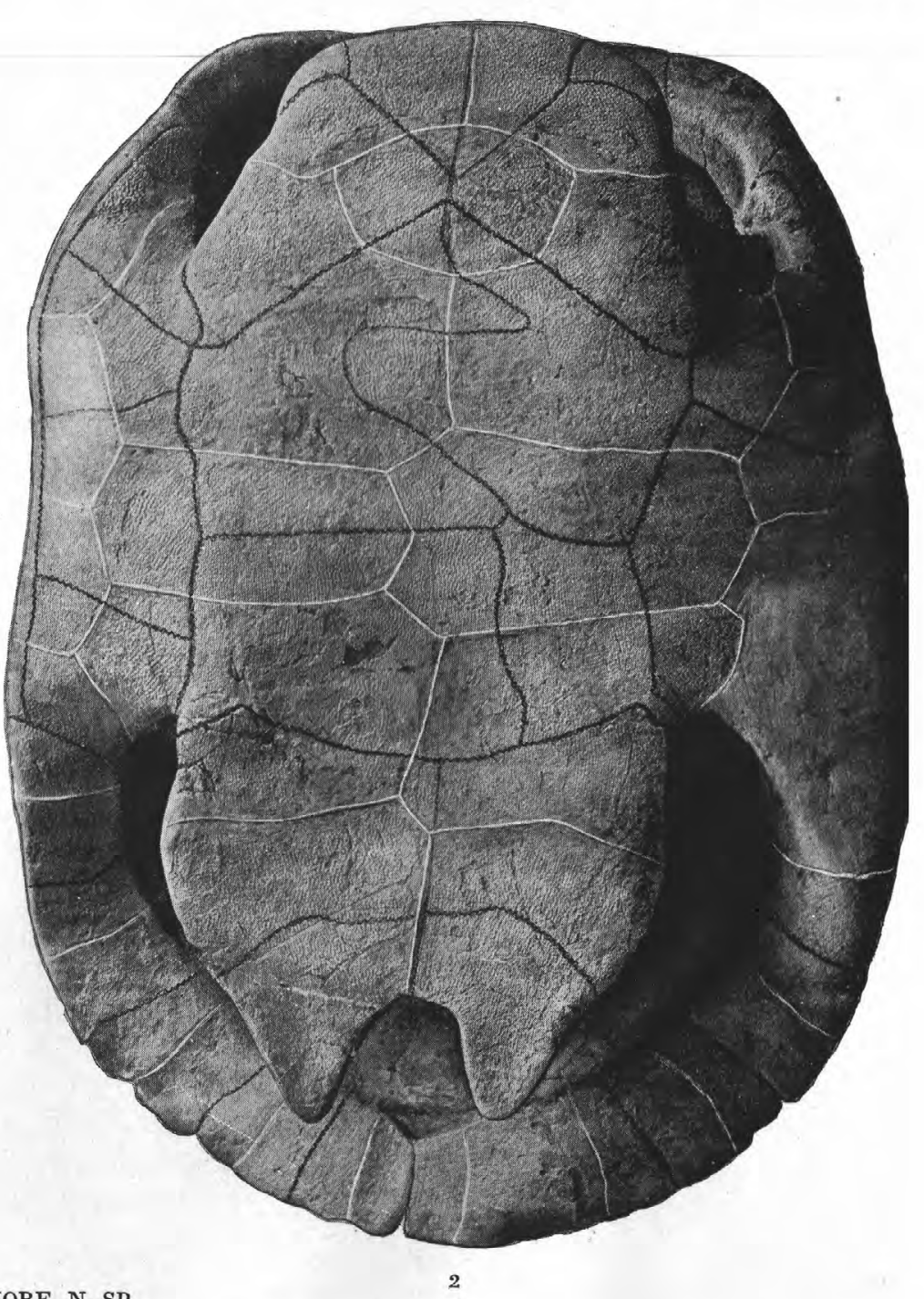

COMPSEMYS TORREJONENSIS GILMORE, N. SP.

Type; No. 8549, U. S. N. M. 1, Carapace; 2, plastron. One-half natural size. See p. 21. 


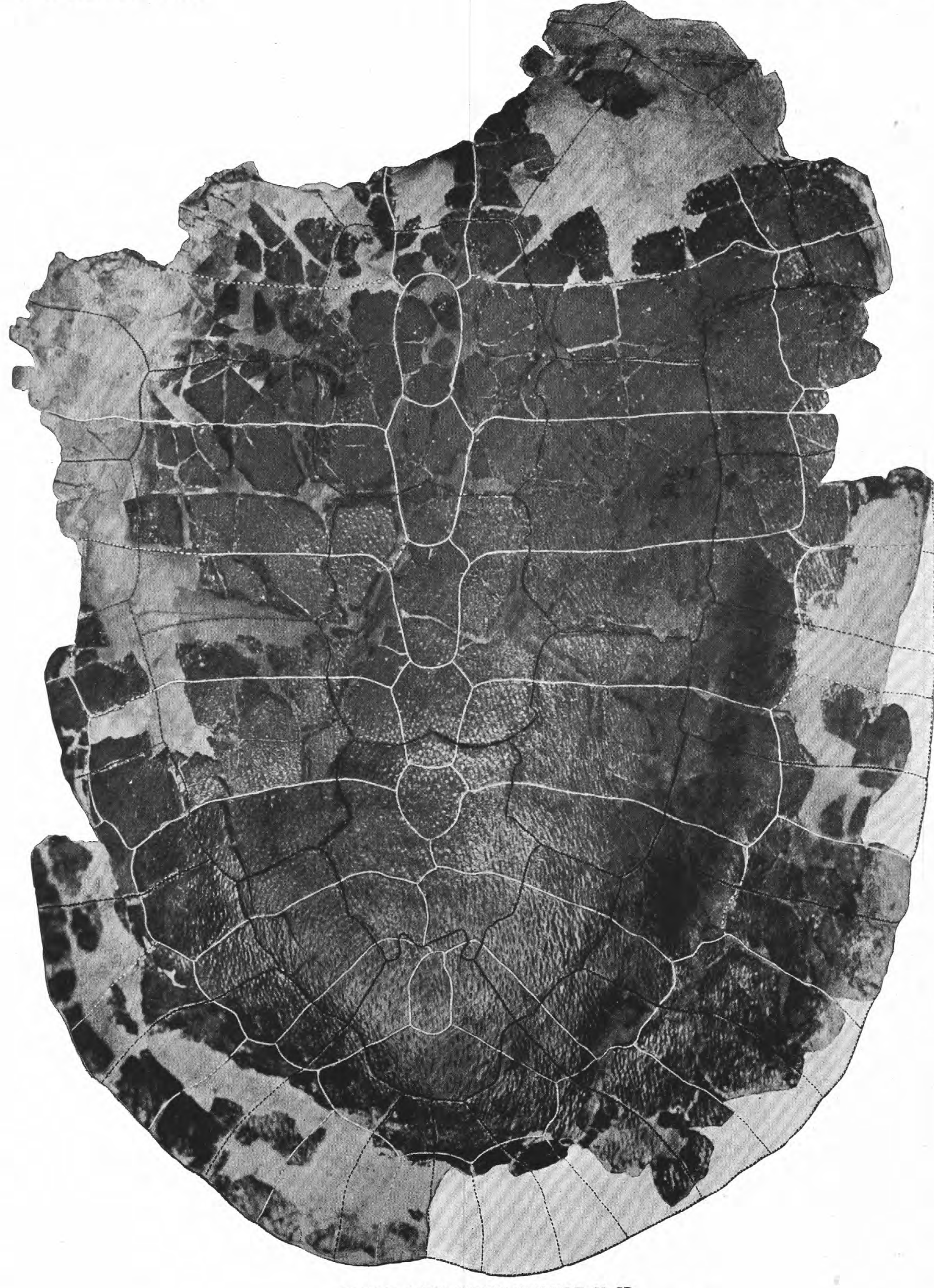

ADOCUS KIRTLANDIUS GILMORE, N. SP.

Type; No. 8593, U. S. N. M. Carapace. One-half natural size. See p. 26. 


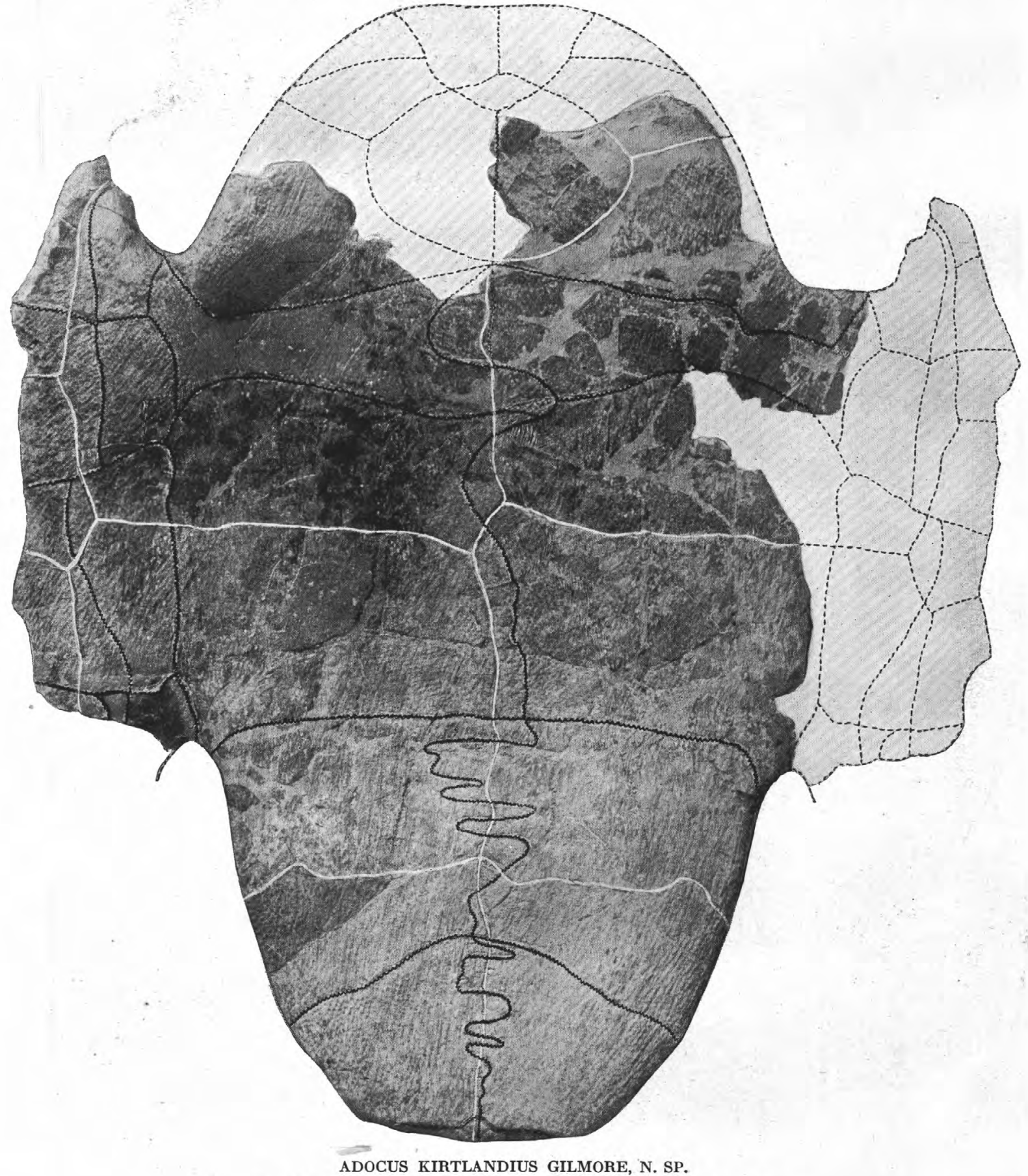

Type; No. 8593, U. S. N. M. Plastron. One-half natural size. See p. 28. 


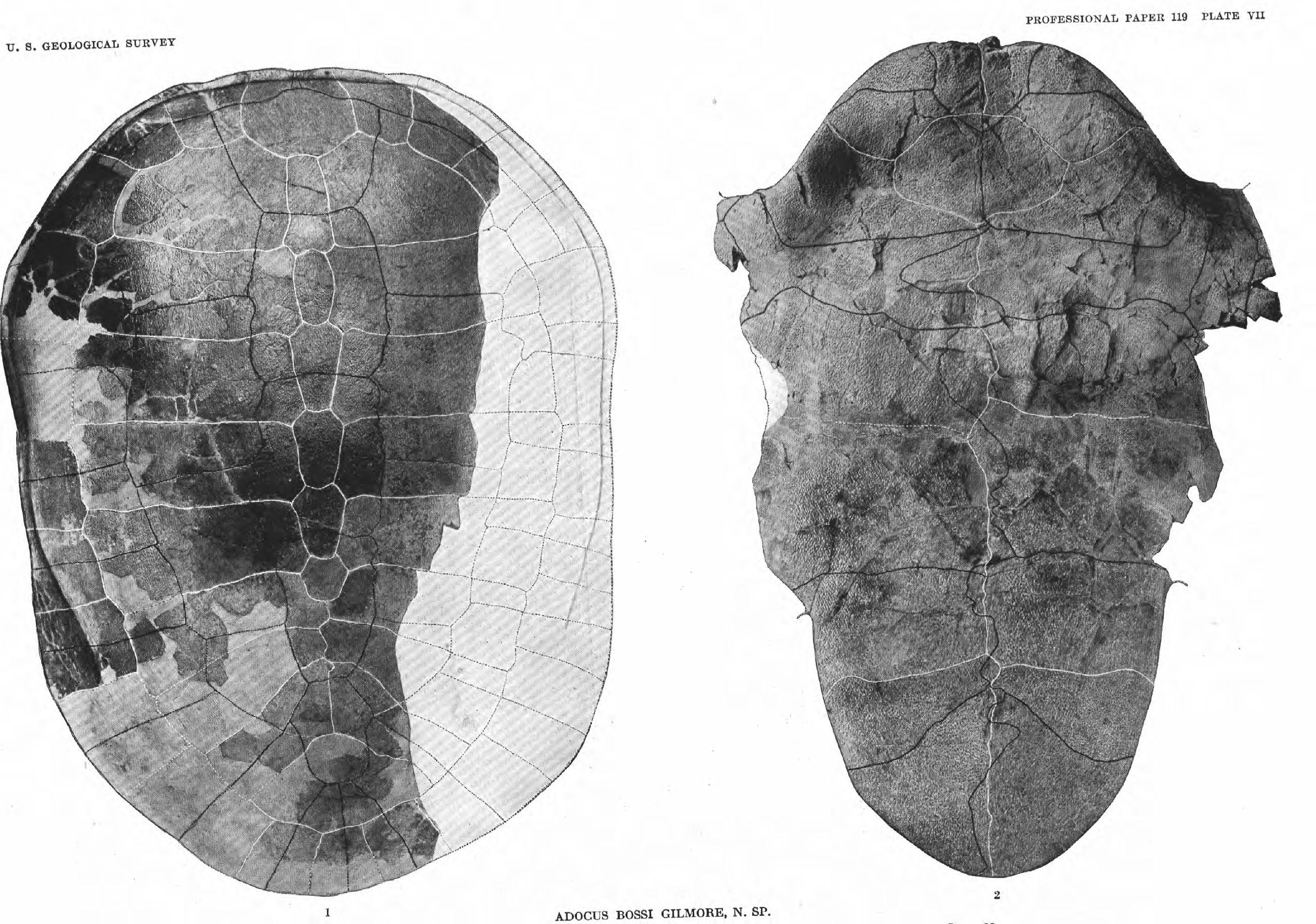

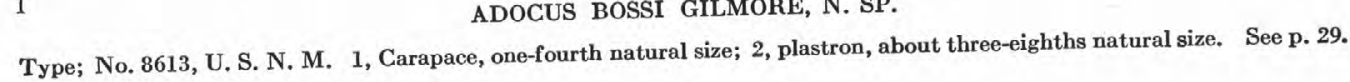




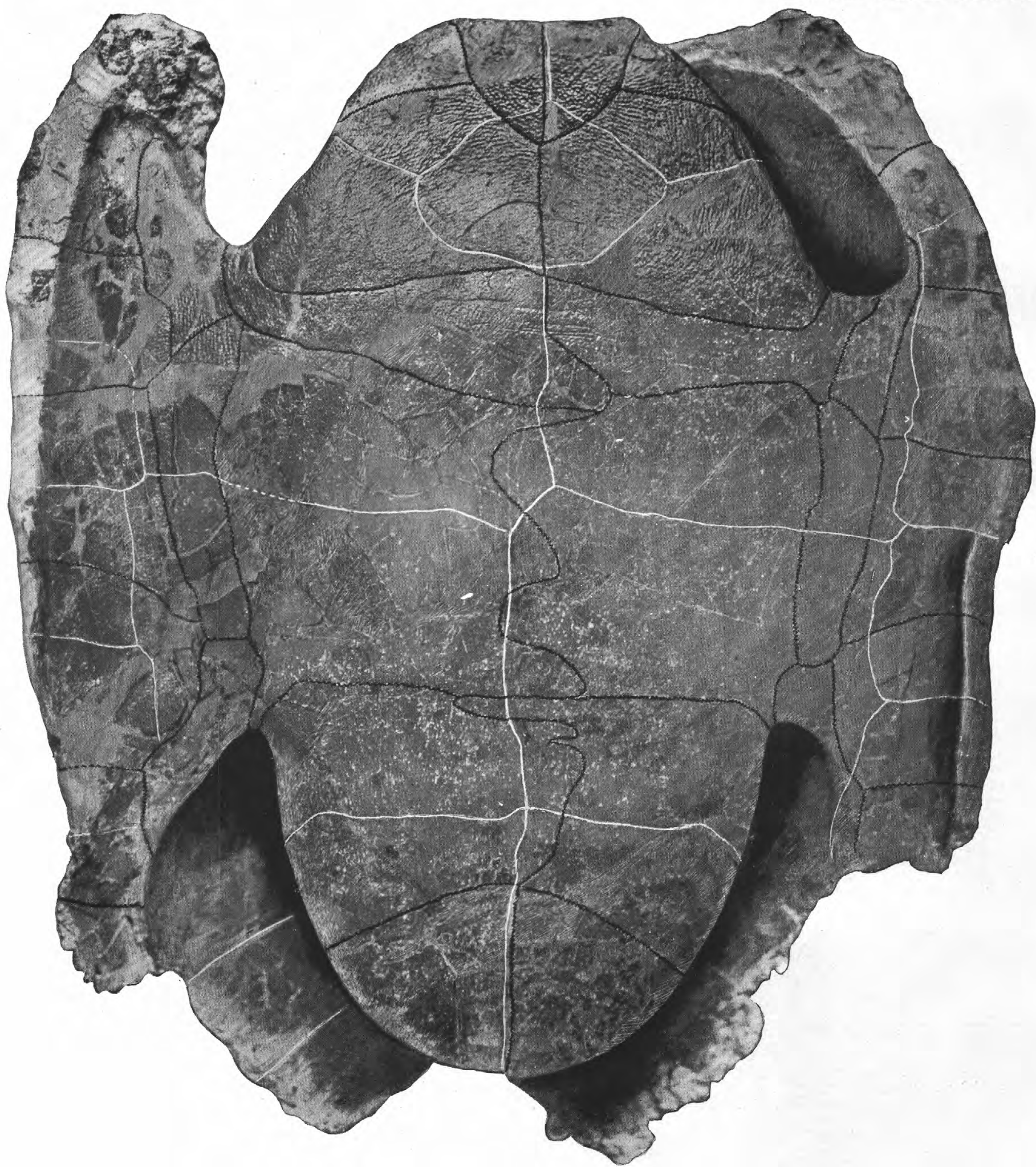

ADOCUS BOSSI GILMORE, N. SP.

No. 8577, U. S. N. M. Plastral view. One-half natural size. See p. 32. 


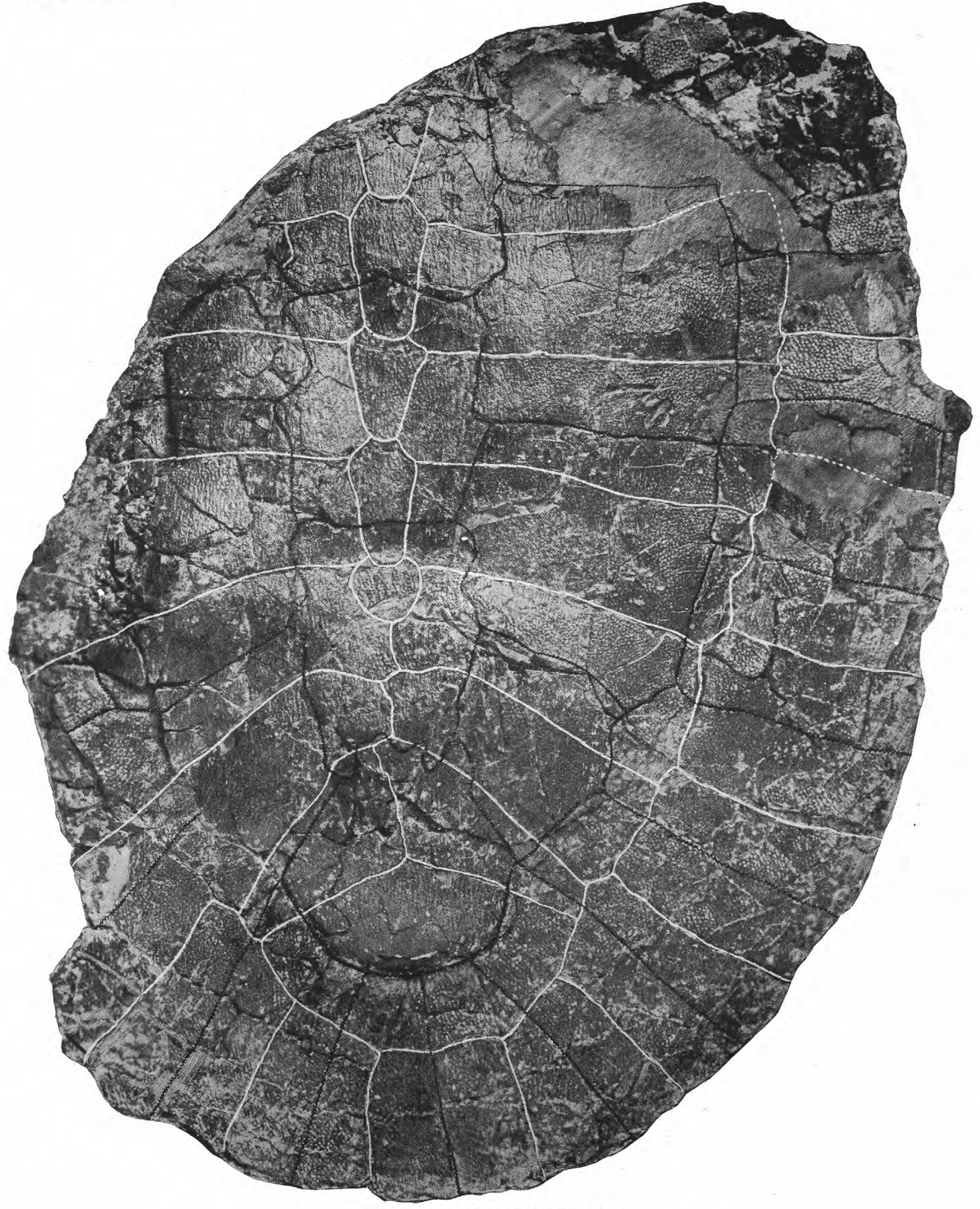

ADOCUS HESPERIUS GILMORE, N. SP.

Type; No. 8596, U. S. N. M. Carapace. One-half natural size. See p. 33. 
U. S. GEOLOGICAI SURVEY

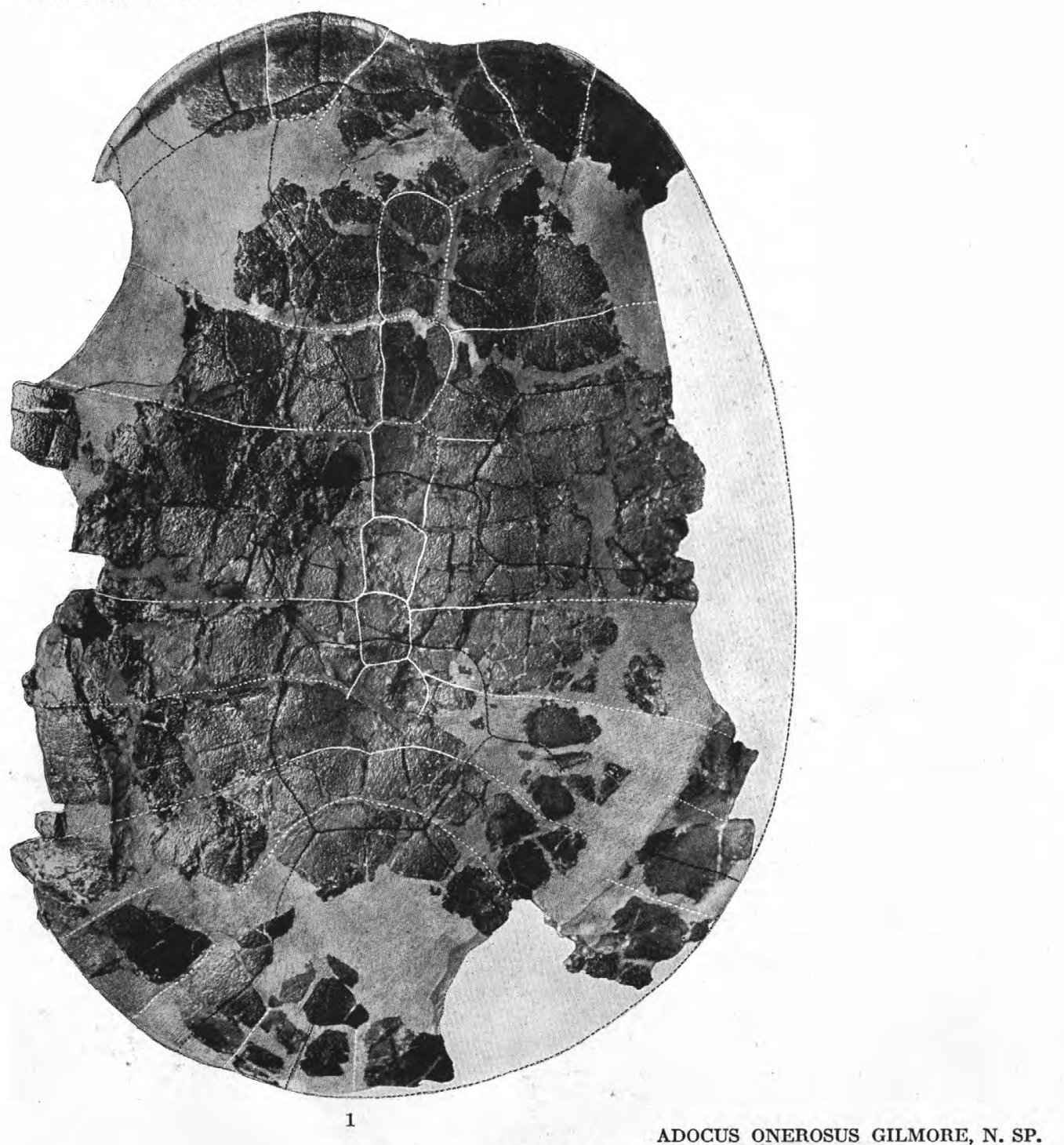

PROFESSIONAL PAPER 119 PIATE $x$

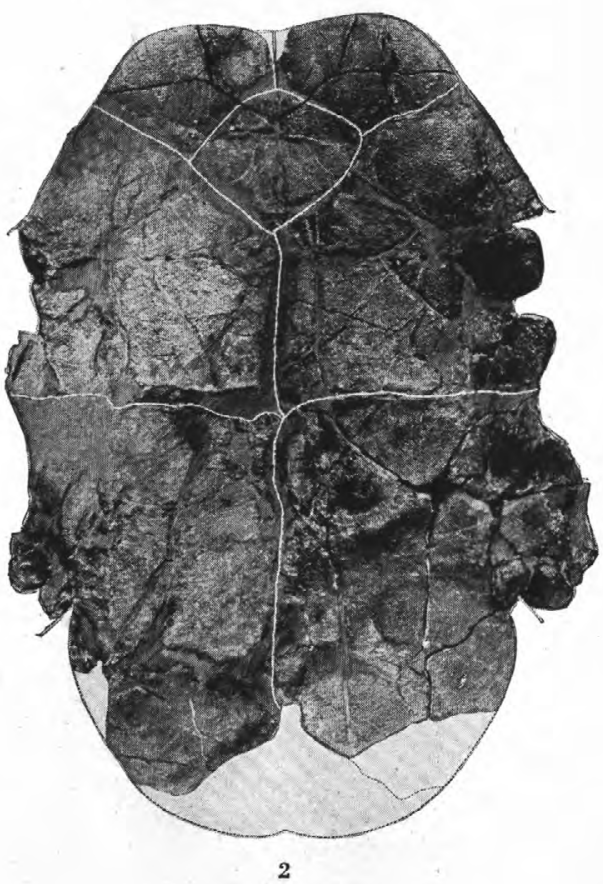

Type; No. 8594, U. S. N. M. 1, Carapace; 2, plastron, One-fourth natural size, See p. 35, 
U. S. GEOLOGICAI, SURVEY

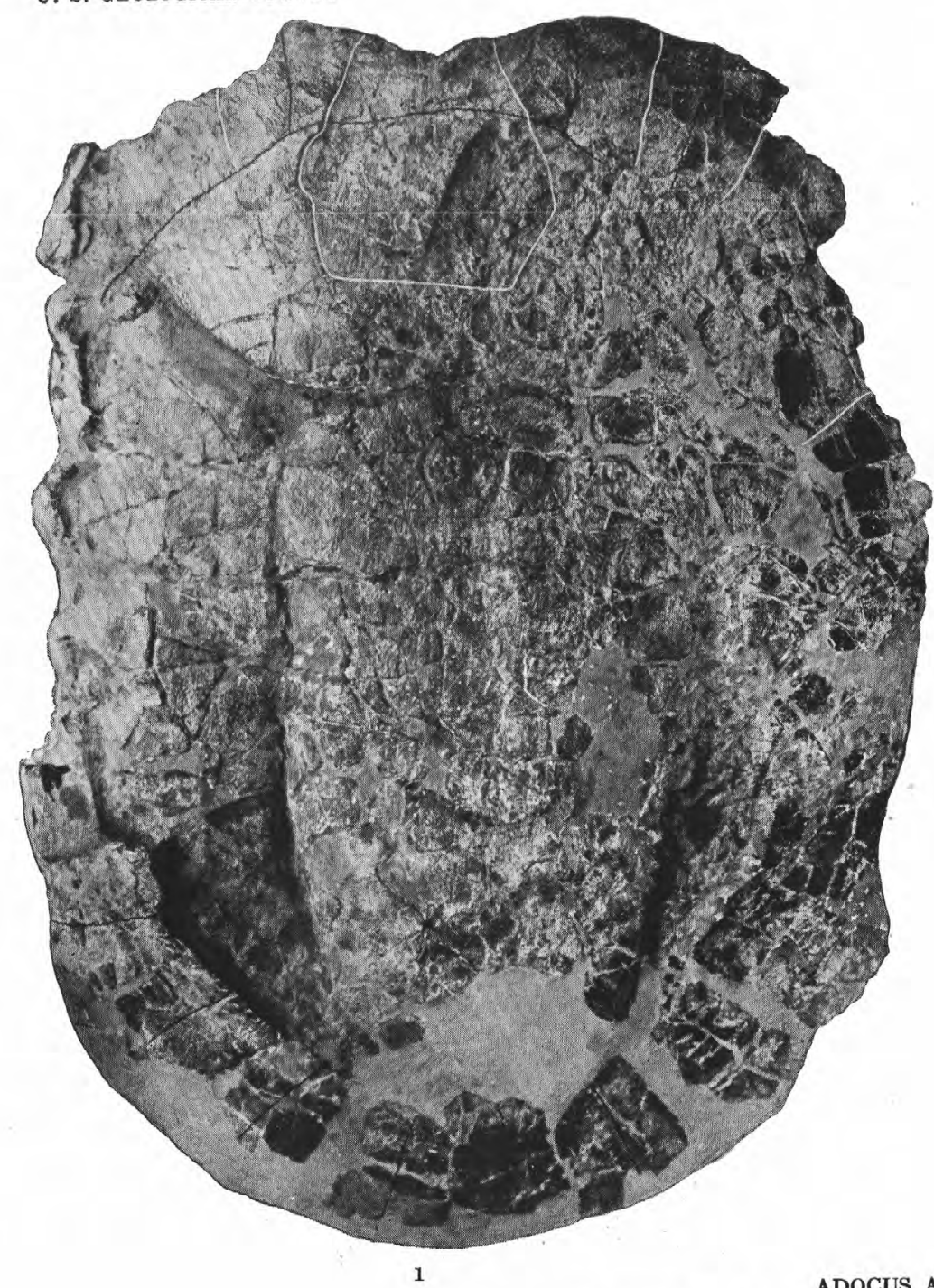

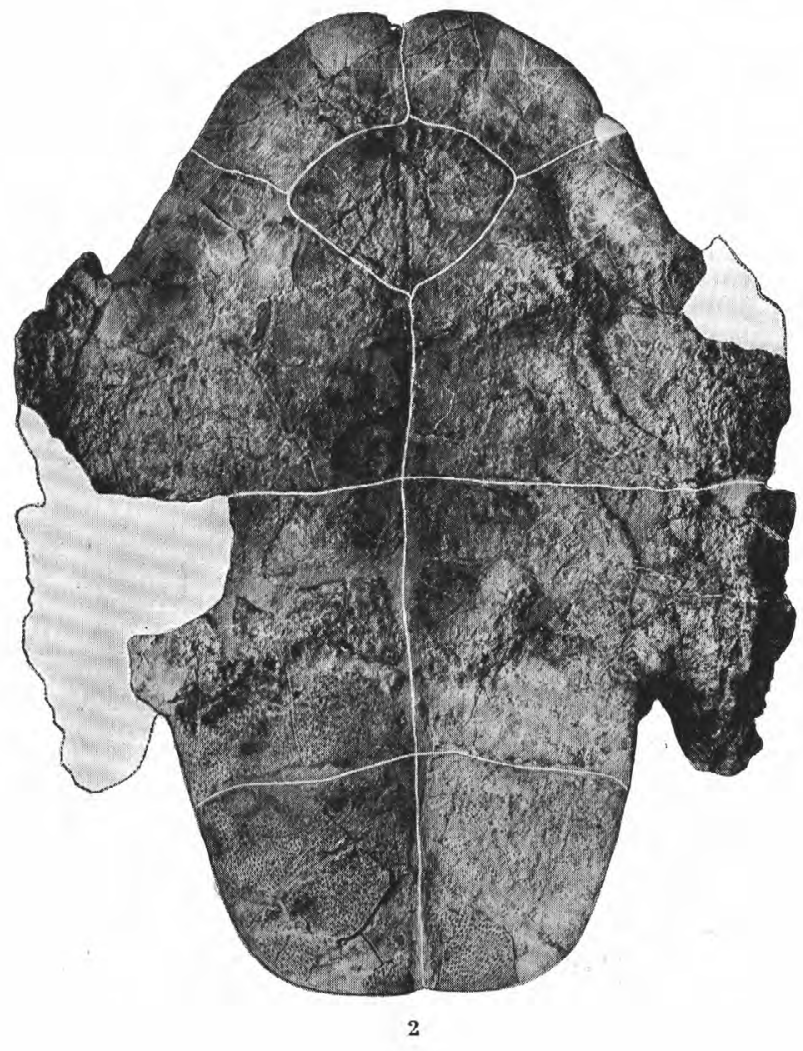

No. 8606 , U. S. N. M. 1, Carapace; 2, plastron. One-fourth natural size. See p. 37. 
U. S. GEOLOGICAL SURVEY

PROFESSIONAL PAPER 119 PLATE XII

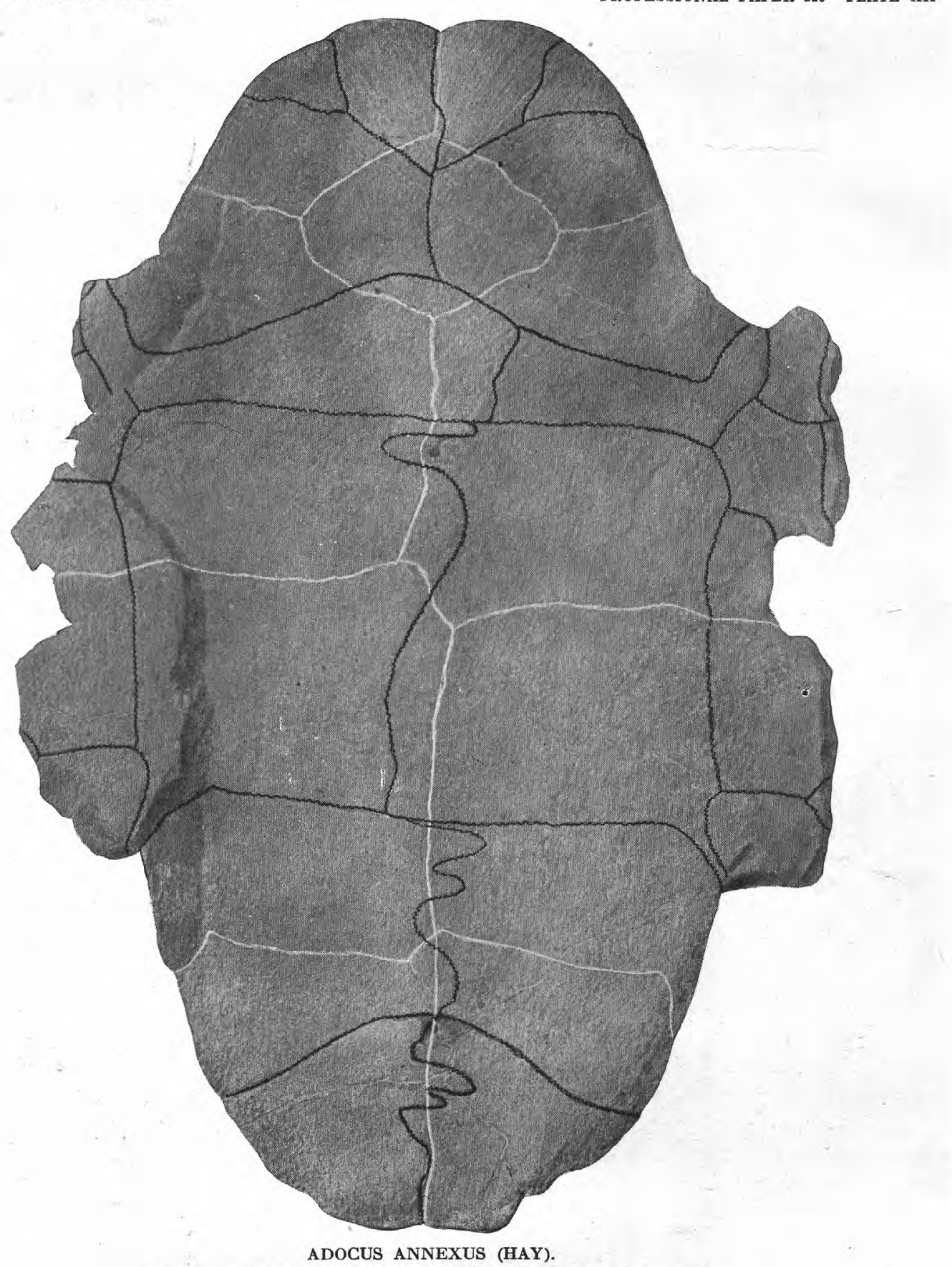

Type; No, 6539, U. S. N. M. Plastron. One-half natural size. See p. 39. 


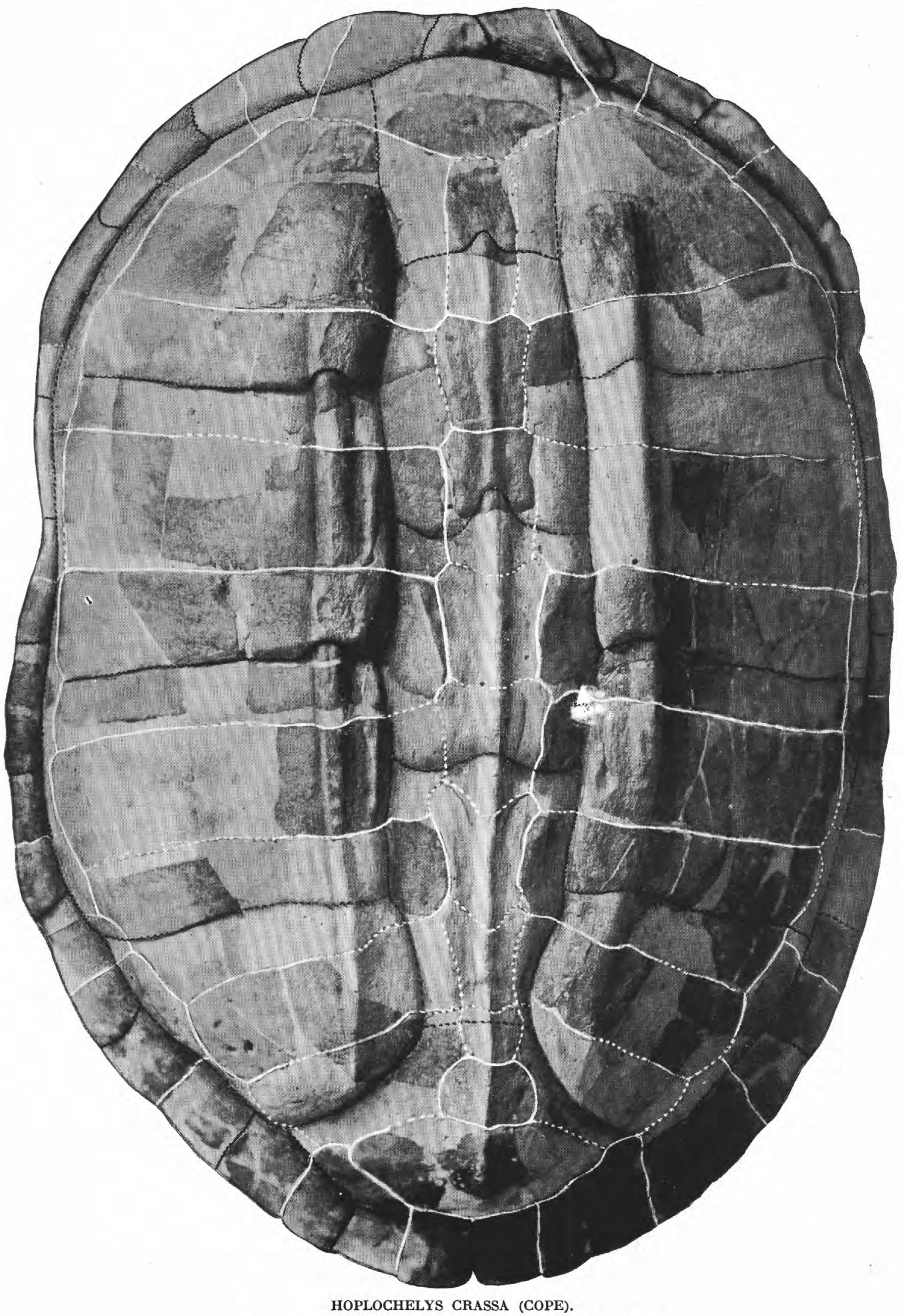

No. 8525 , U. S. N. M. Carapace. About natural size. See p. 41. 
U. S. GEOLOGICAL SURVEY

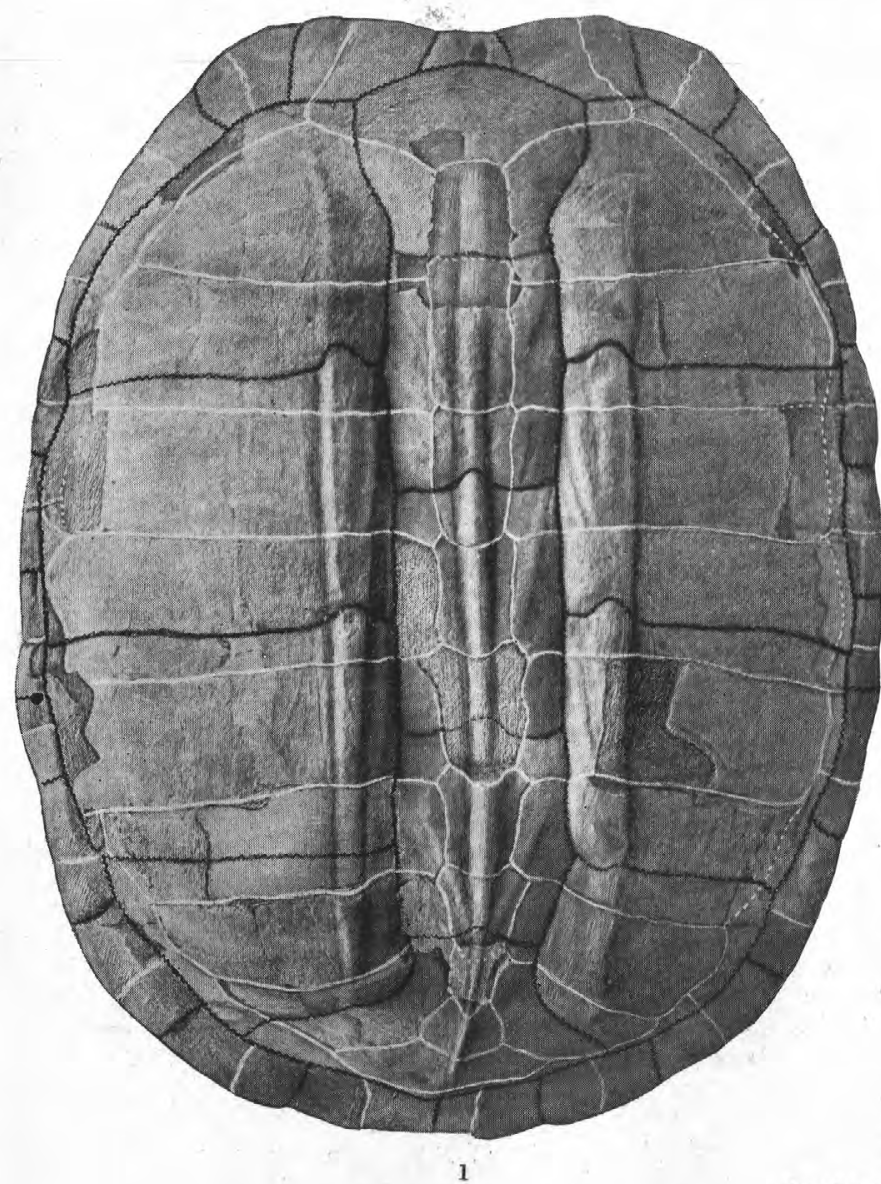

HOPLOCHELYS BICARINATA HAY.

No. 8524 , U. S. N. M. 1, Carapace; 2, plastron. One-half natural size. See p. 43

PROFESSIONAL PAPER 119 PLATE XIV

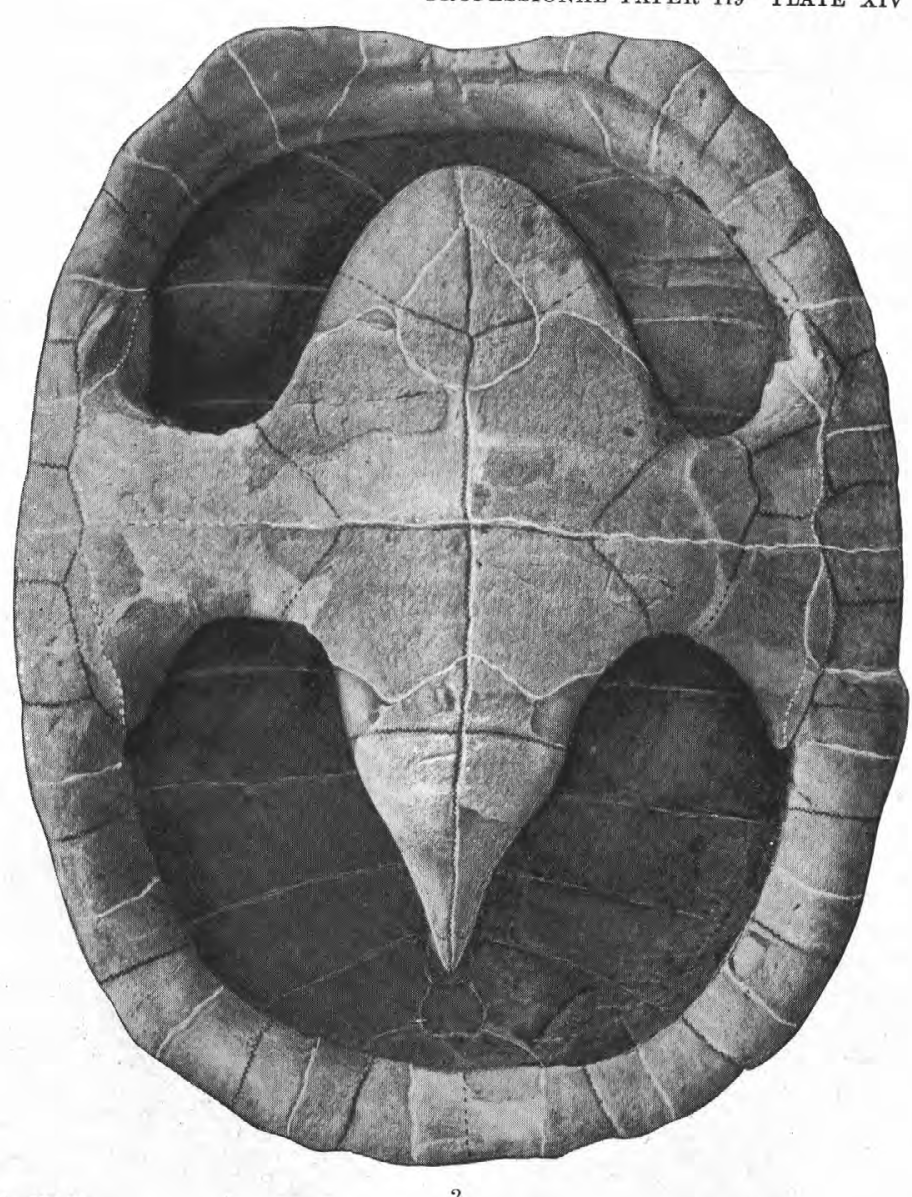


U. S. GEOLOGICAL SURVEY

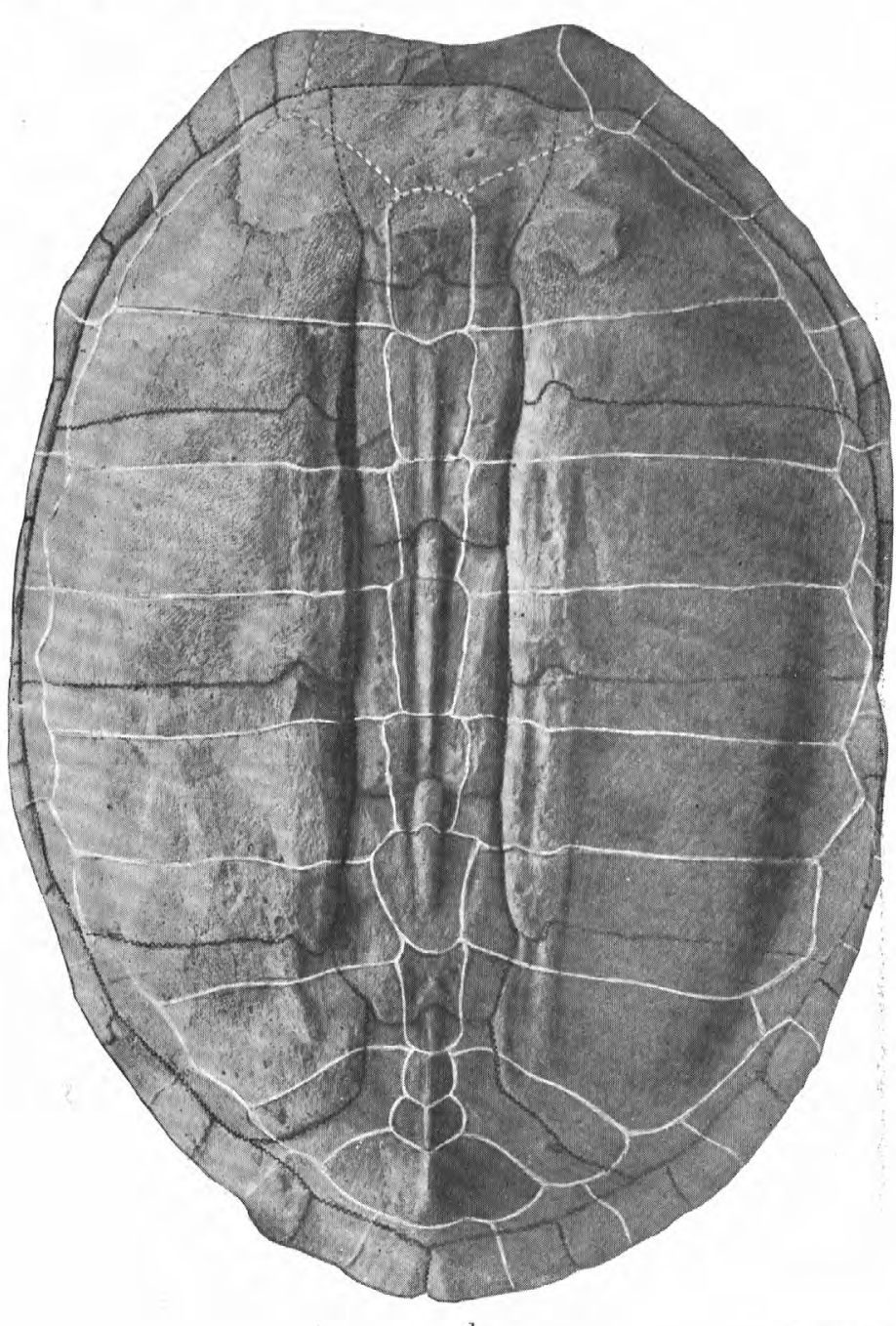

PROFESSIONAL PAPER 119 PLATE XV

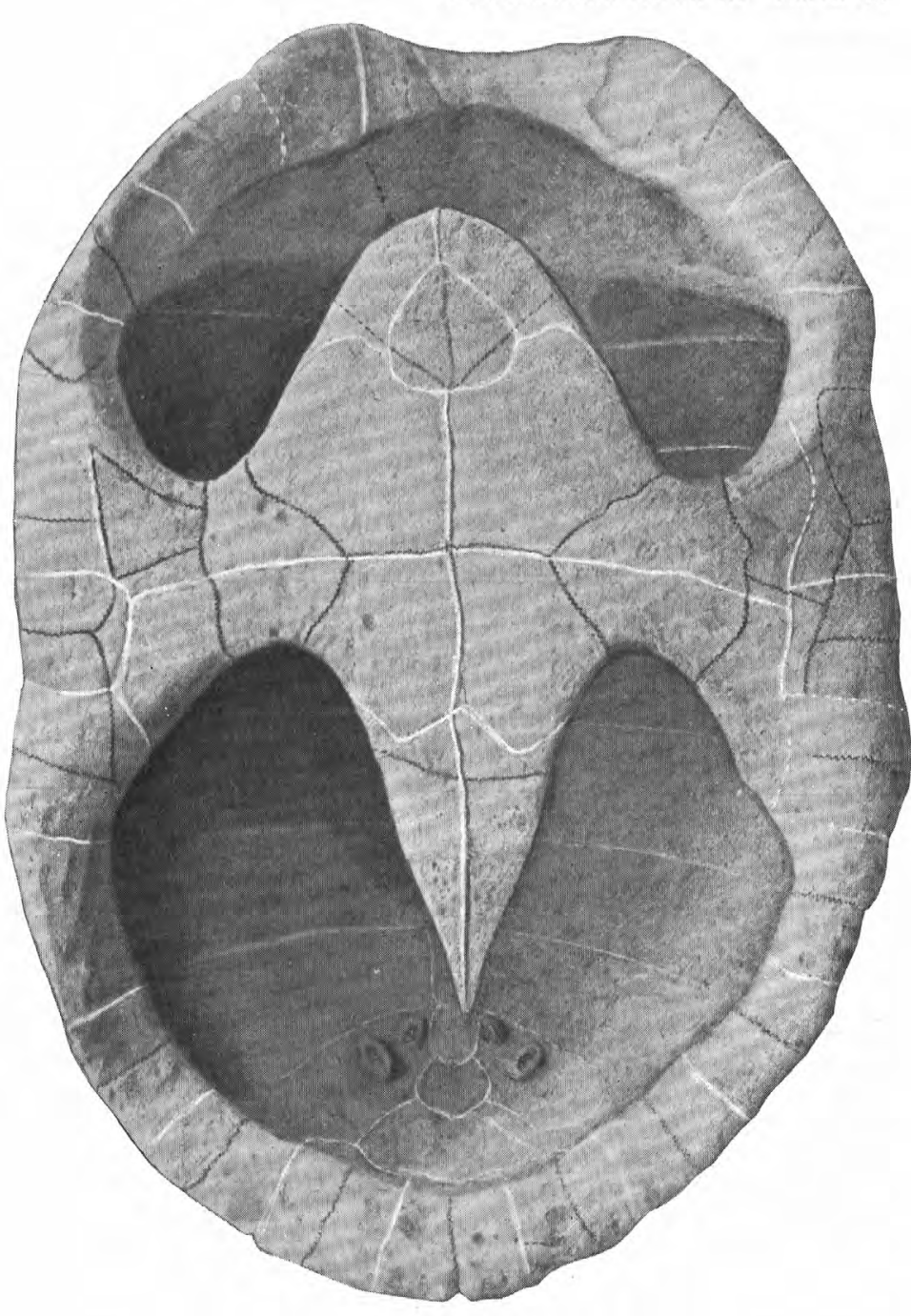

2

HOPLOCHELYS LAOUEATA GILMORE, N. SP.

Type; No. 8527, U. S. N. M. 1, Carapace; 2, plastron. One-half natural size. See p. 47 . 
U, S, GEOLOGICAL SURVEY

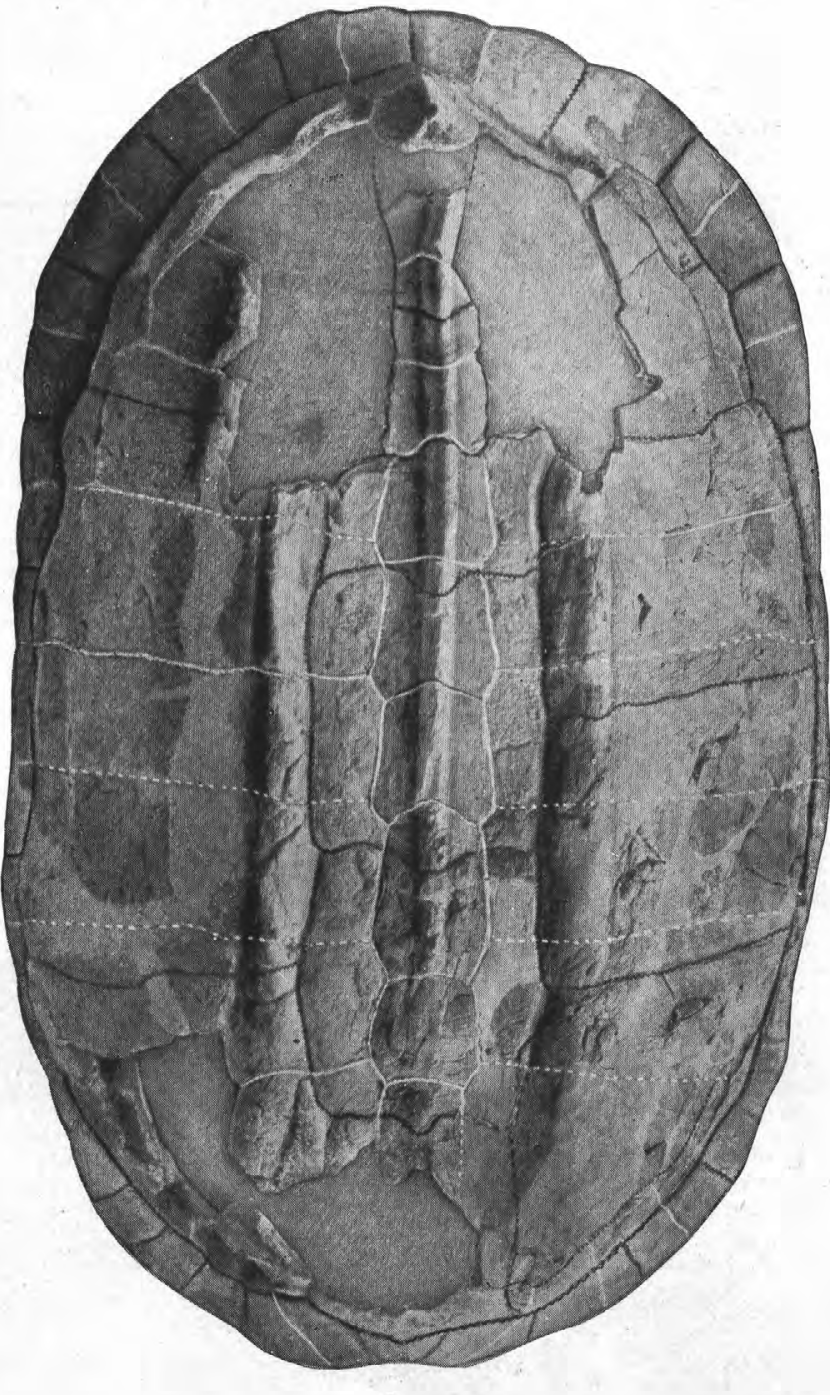

PROFESSIONAL PAPER 119 PIAATE XVI

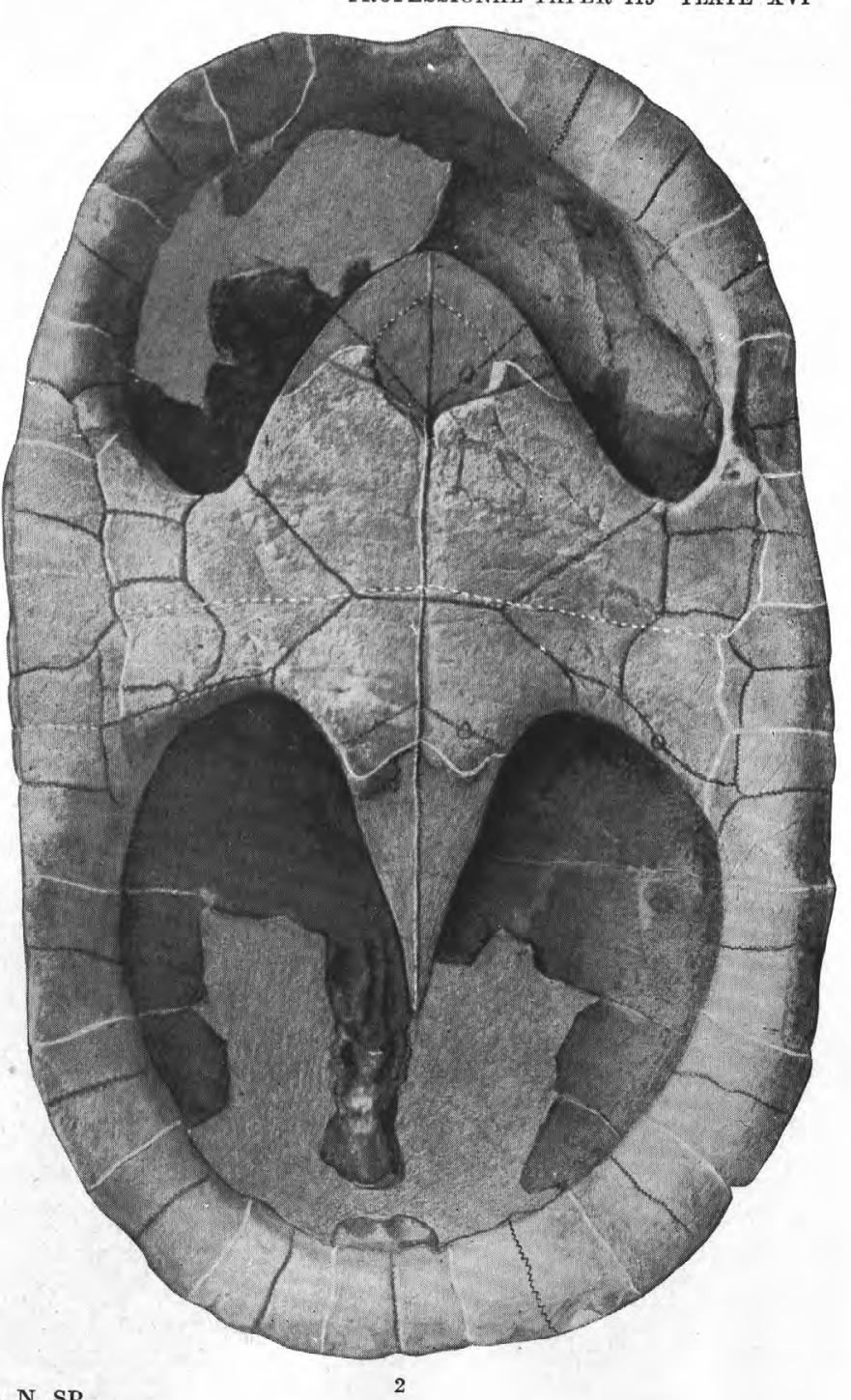

HOPLOCHELYS ELONGATA GILMORE, N. SP.

Type; No. 8553, U. S. N. M. 1, Carapace; 2, plastron. One-half natural size. See p. 50 


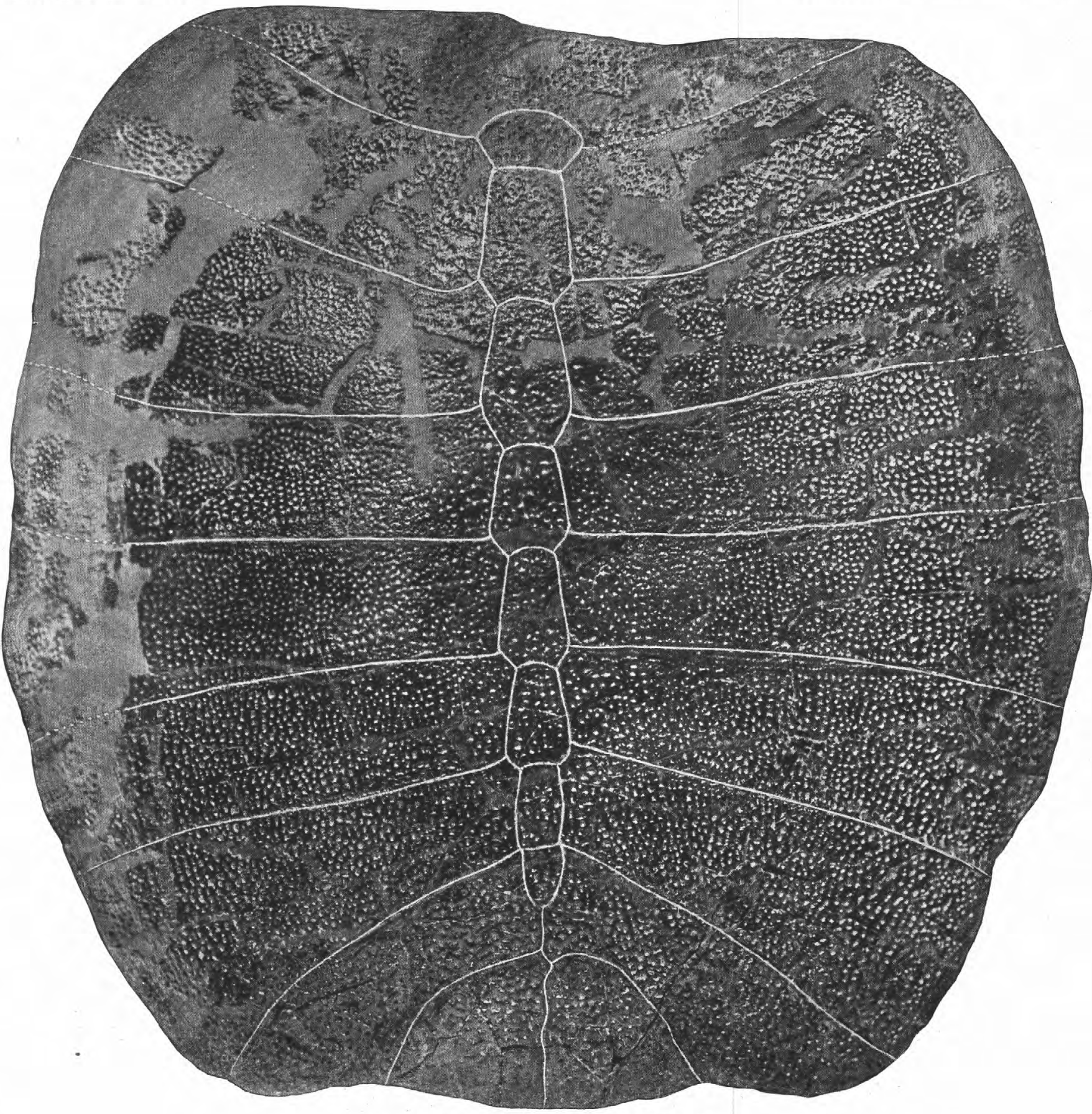

PLASTOMENUS ROBUSTUS GILMORE, N. SP.

Type; No, 8538, U. S. N. M. Carapace. Seven-sixteenths natural size. See p. 53. 


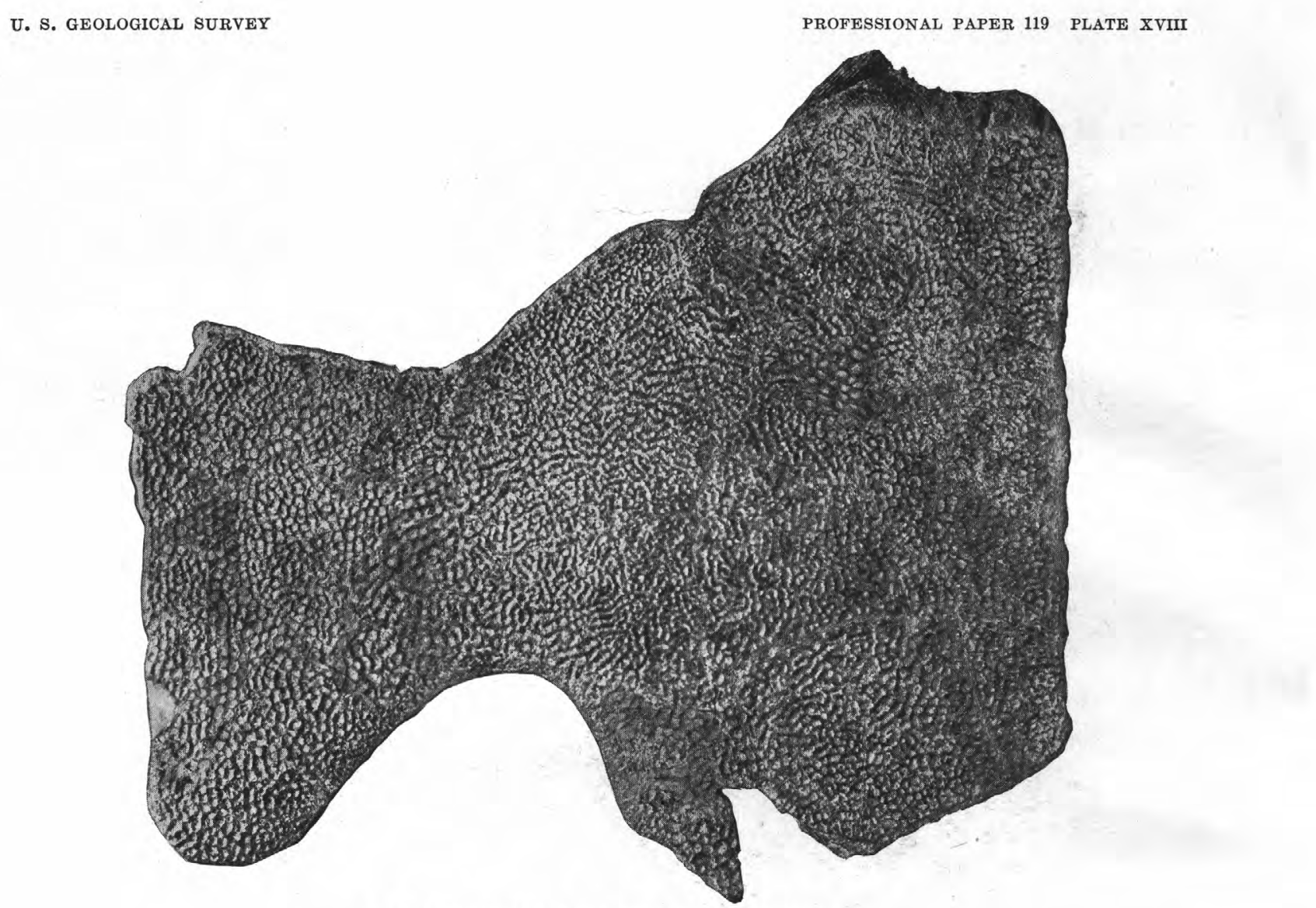

1. PLASTOMENUS ROBUSTUS GILMORE, N. SP.

Type; No. 8538, U. S. N. M. Right half of plastron. One-half natural size. See p. 54.

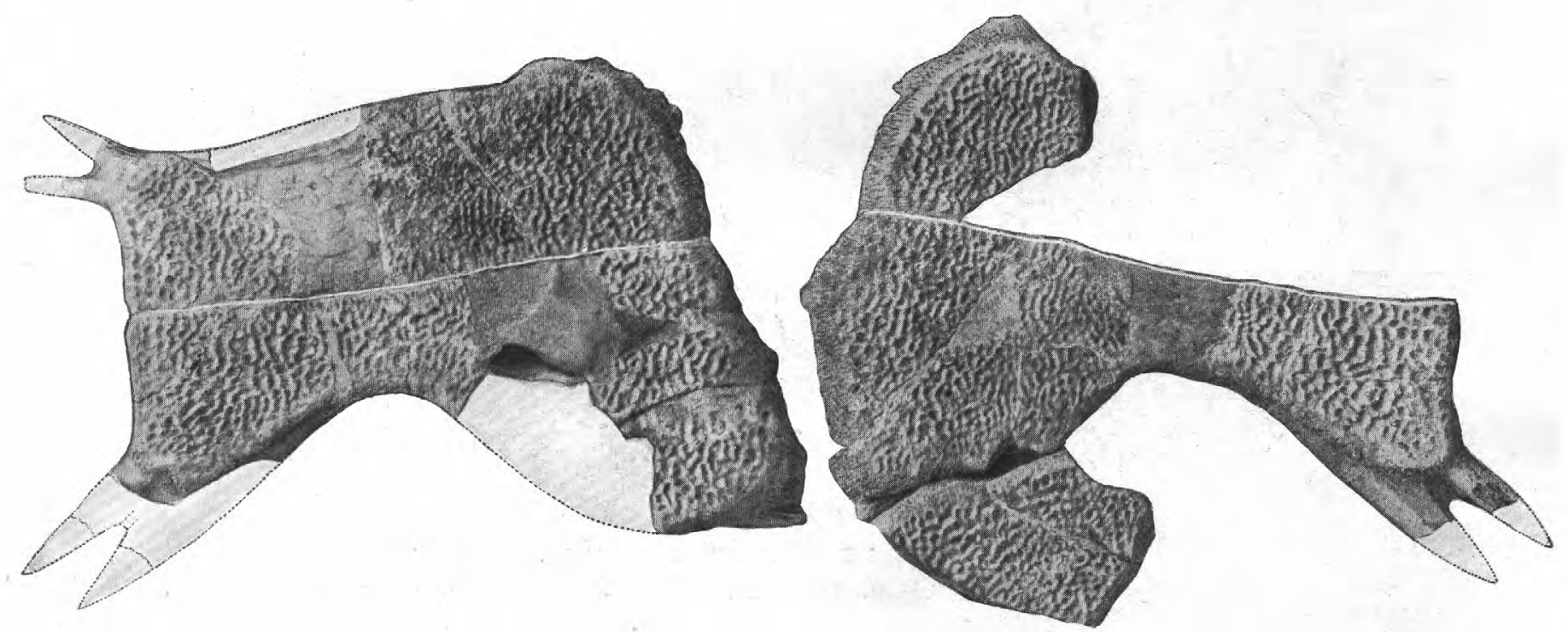

2. ASPIDERETES VEGETUS GILMORE, N. SP.

Type; No. 8539, U. S. N. M. Plastral bones. Three-fourths natural size. See p. 58. 


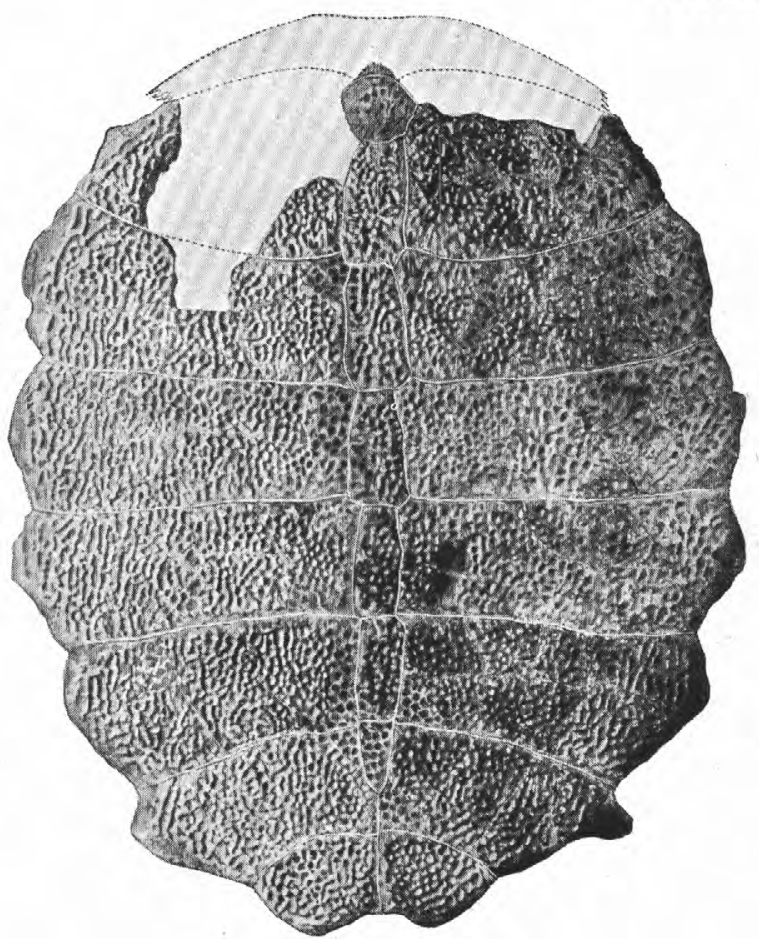

1. ASPIDERETES PERPLEXUS GILMORE, N. SP.

Type; No. 8532, U. S. N. M. Carapace. About one-half natural size. See p. 60.

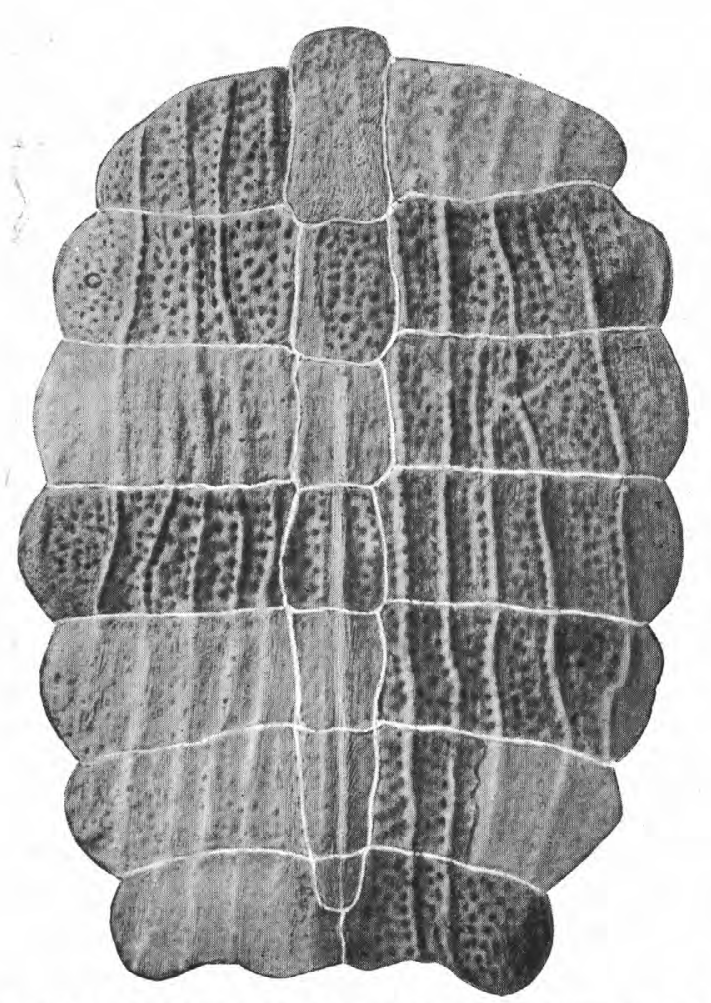

2. PLASTOMENUS TORREJONENSIS GILMORE, N. SP. Type; No. 8543, U. S. N. M. Carapace. Natural size. See p. 55.

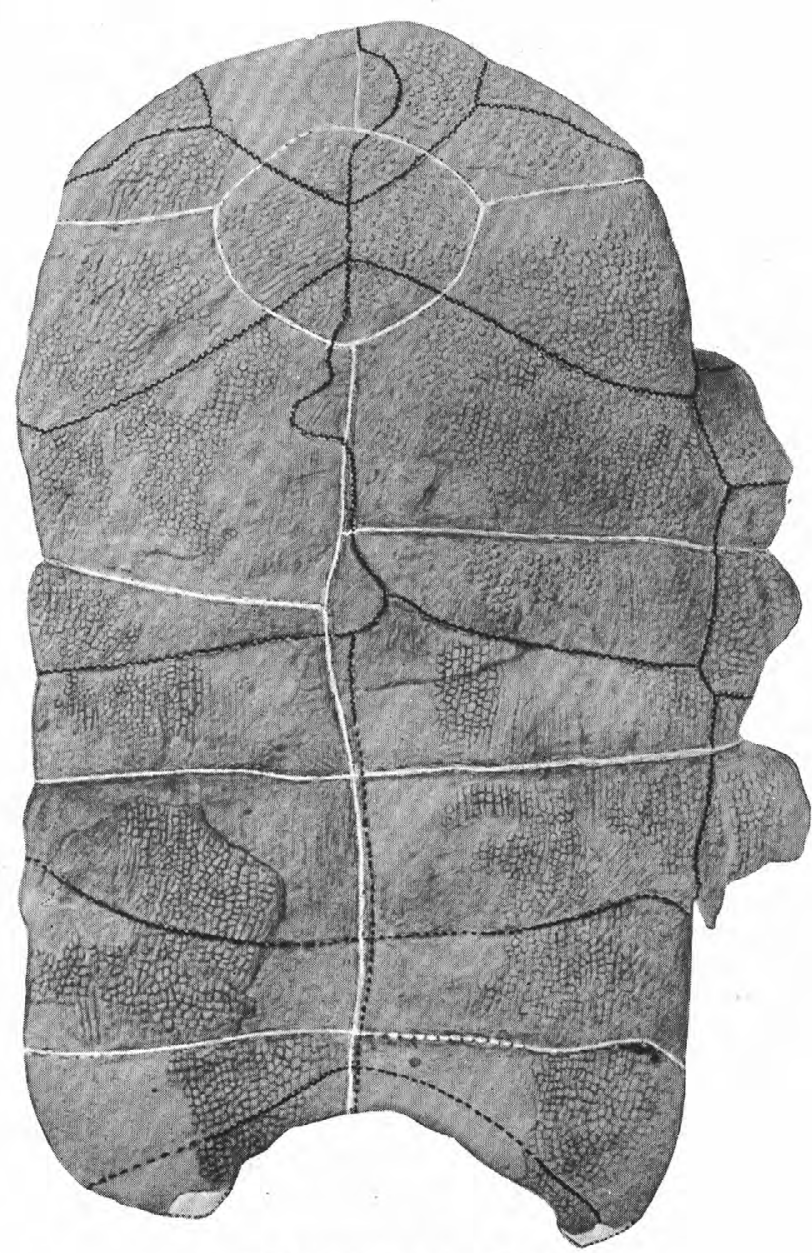

3. COMPSEMYS PARVA? HAY

No. 8598, U. S. N. M. Plastron. Natural size. See p. 16. 




Type; No. 8537, U. S. N. M. Carapace. About three-fourths natural size. See p. 56. 


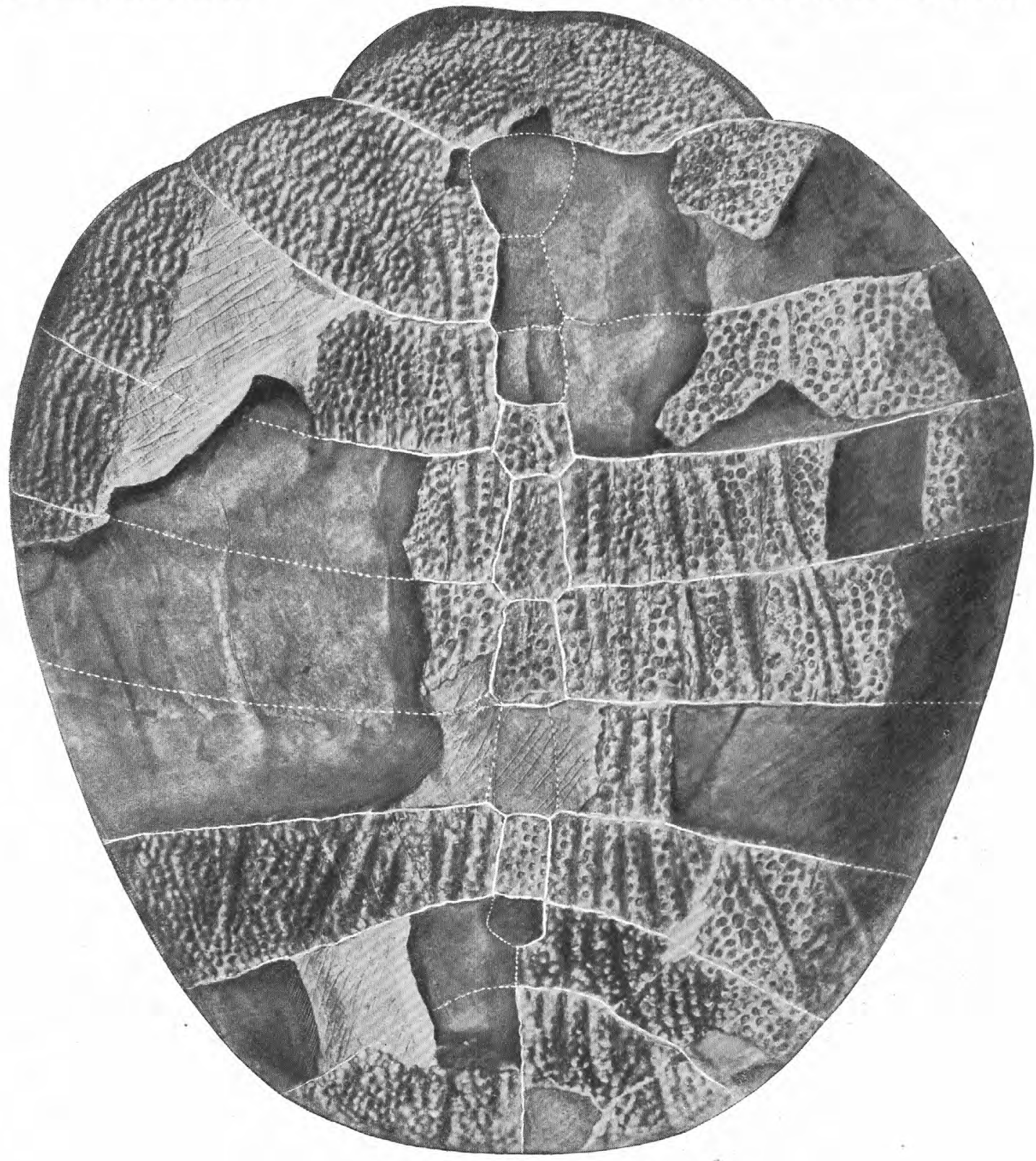

ASPIDERETES VEGETUS GILMORE, N. SP.

Type; No. 8539, U. S. N. M. Carapace. Three-fourths natural size. See p. 57. 




ASPIDERETES QUADRATUS GILMORE, N. SP.

Type; No. 8545, U. S. N. M. Carapace. One-half natural size. See p. 59. 


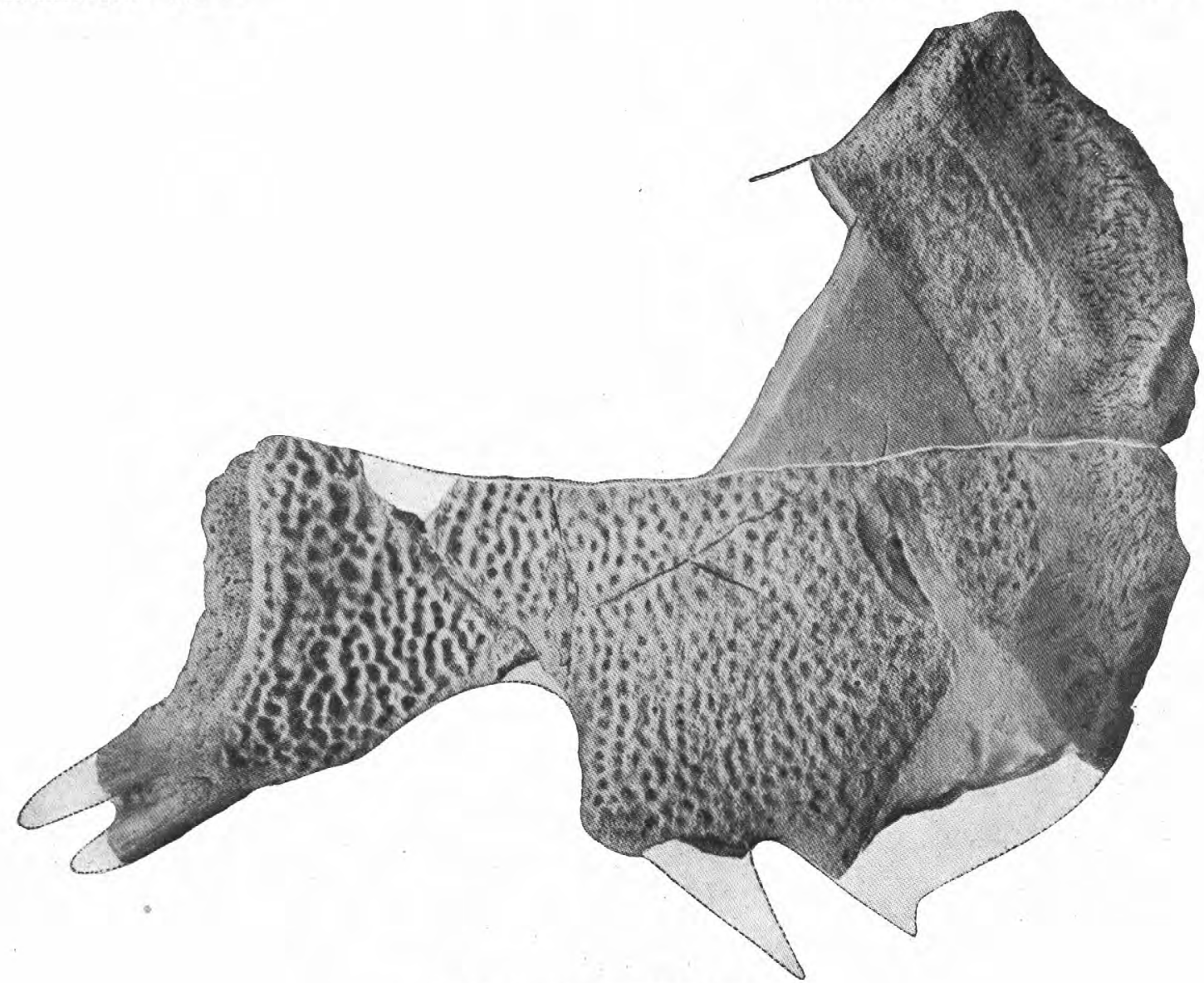

1. ASPIDERETES SAGATUS haY.

No. 8554 , U. S. N. M. Right half of plastron. Natural size. See p. 62 .

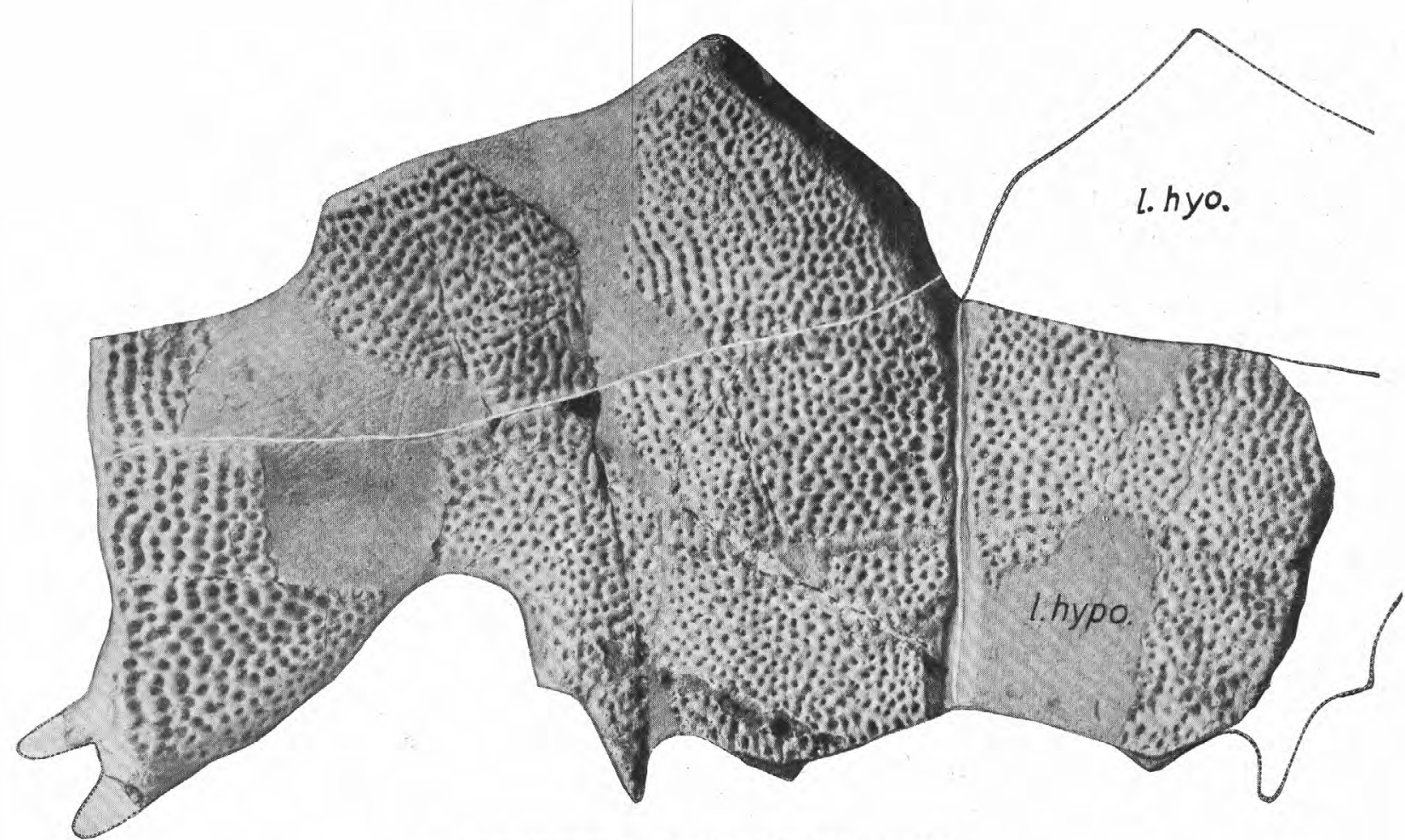

2. UNIDENTIFIED SPECIES OF PLASTOMENUS.

No. 8553, U. S. N. M. Plastral hones. Natural size. 1. hyo., Left hyoplastron; 1. hypo., left hypoplastron. See p. 53. 


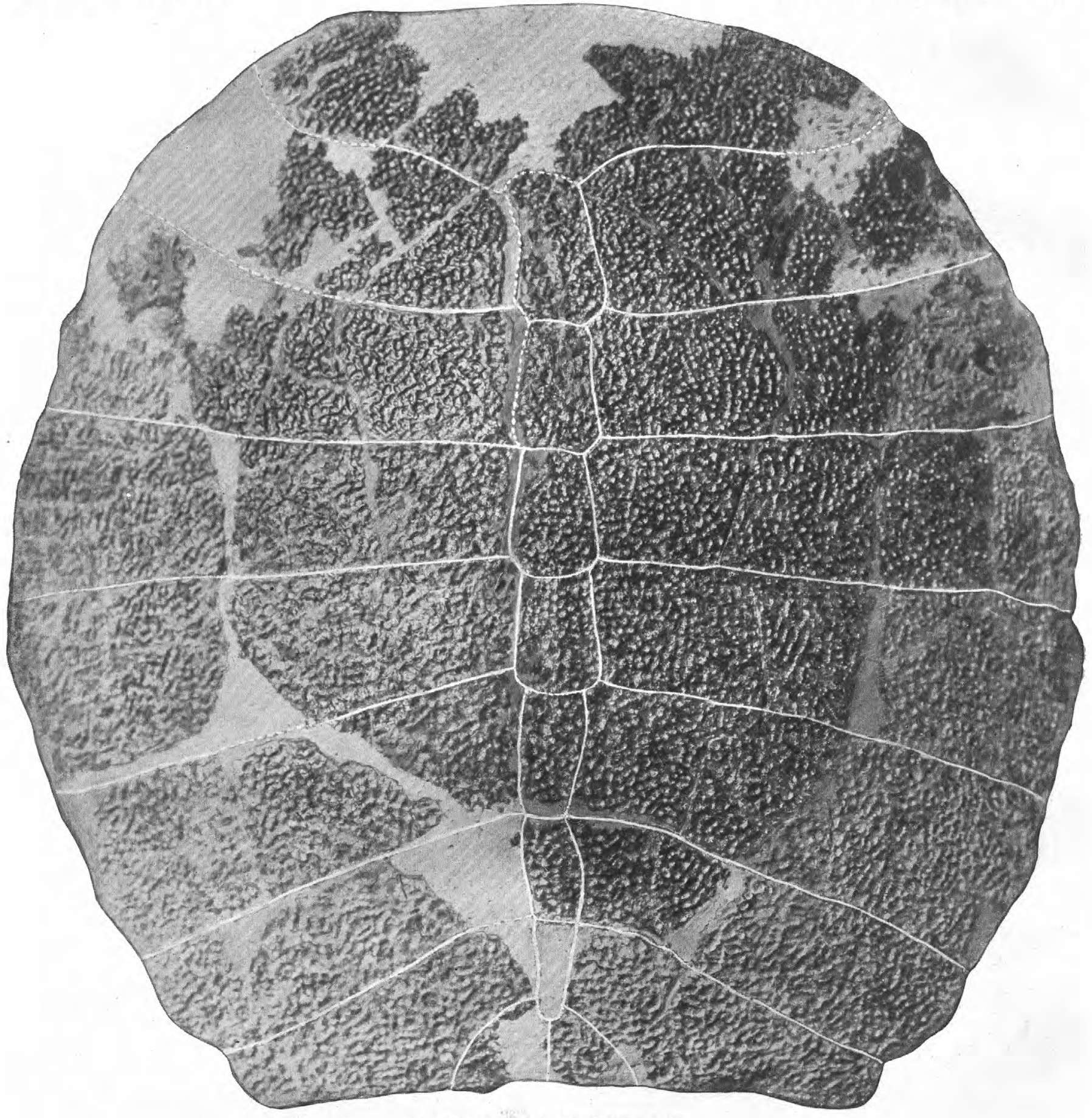

AMYDA ELOISAE GILMORE, N. SP.

Type; No. 8540, U. S. N. M. Carapace. About three-fourths natural size. See p. 63. 
U. S. GEOLOGICAL SURVEY

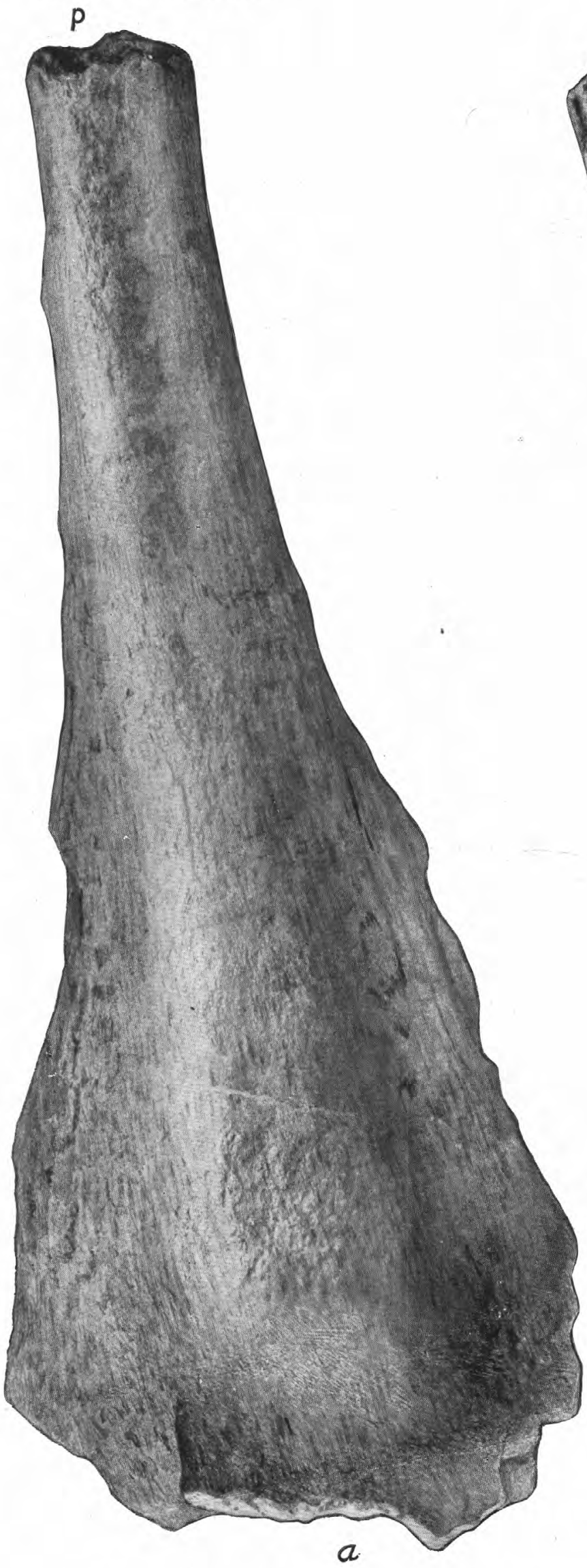

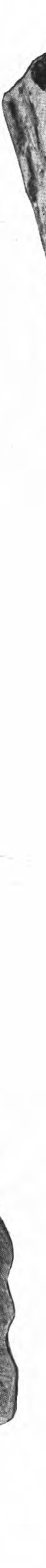

P

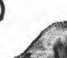

not.

Ixth

1 153

16.9.

1.

6

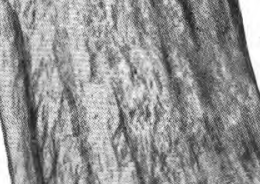

Wrisente

Me $1=0$

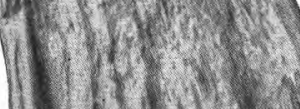

(1)

(1)

y)
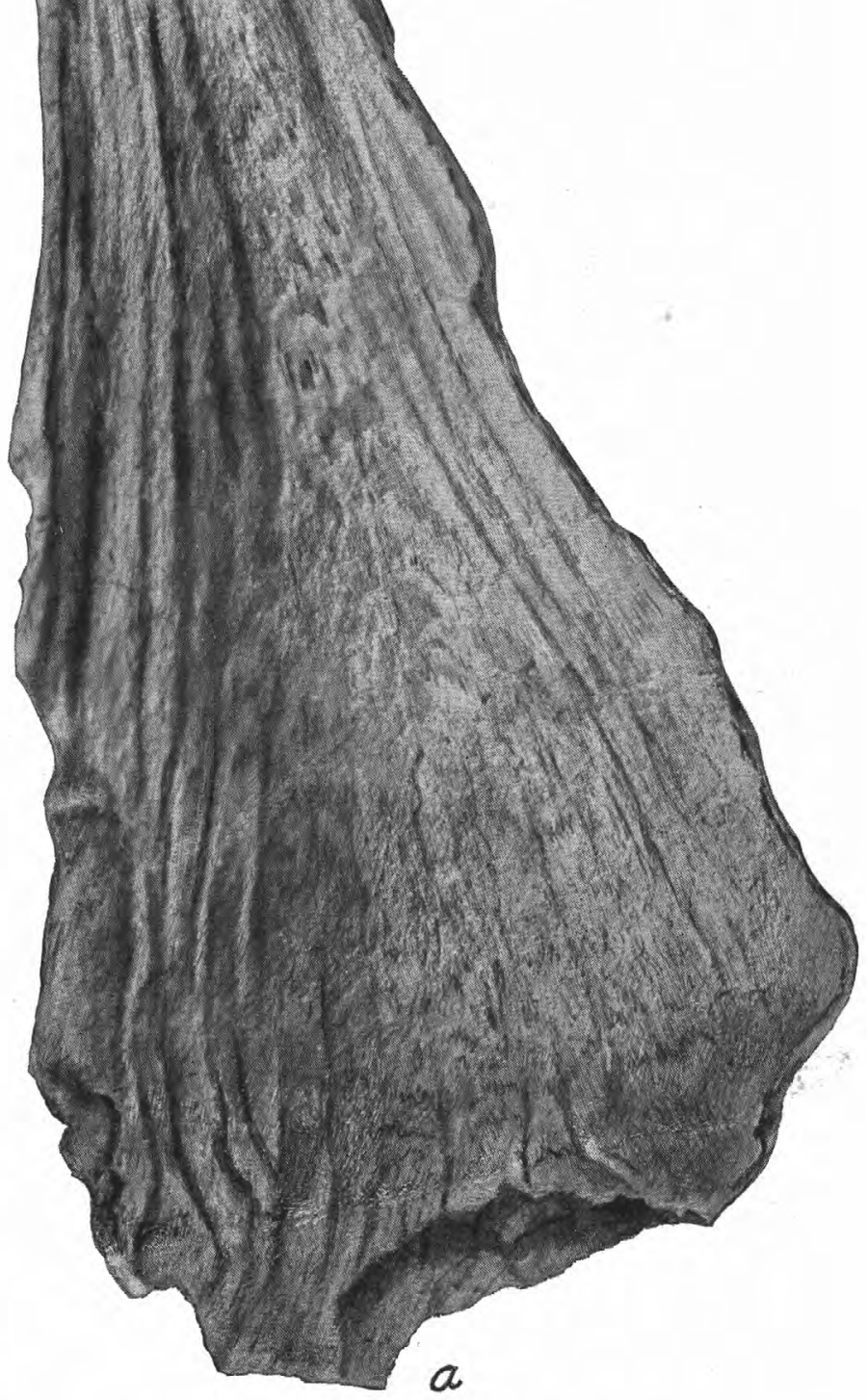

2

MEDIAN PORTION OF THE FRILL OF A CERATOPSIAN DINOSAUR, PROBABLY PERTAINING TO THE GENUS CERATOPS.

No. 8604, U.S. N. M. 1, Dorsal view. $a$, anterior end; $p$, posterior end. 2, Ventral view. $a$, anterior end; $p$, posterior end. One-half natural size. See p. 64 . 


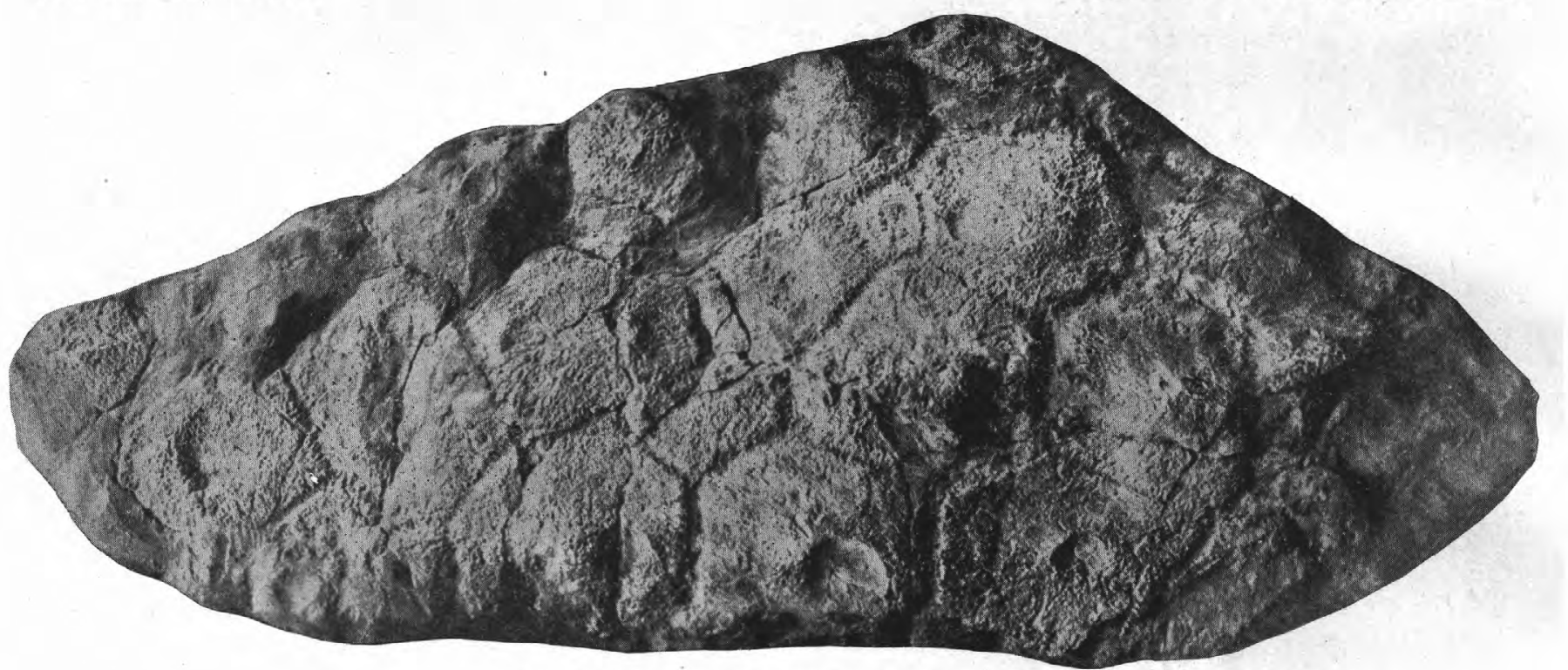

1. STEGOPELTA LANDERENSIS WILLISTON.

Type. Dorsal surface of left ilium. One-fourth natural size. After Moodie. See p. 67 .

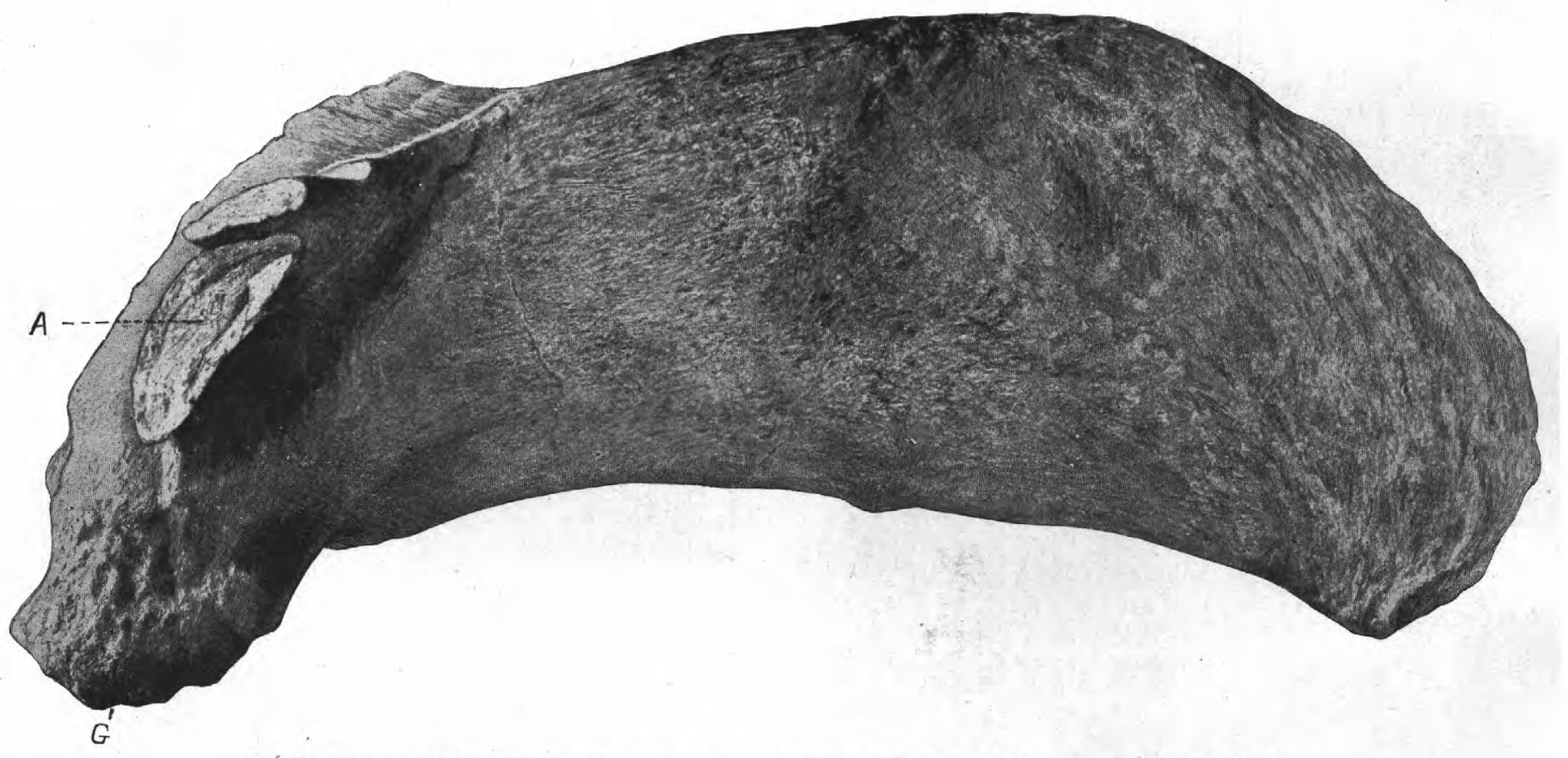

2. UNIDENTIFIED MEMBER OF THE SCELIDOSAURIDAE FROM OJO ALAMO FORMATION.

No. 8571, U. S. N. M. Left scapula. A, Acromion process; G, glenoid cavity. About one-half natural size. See p. 65. 


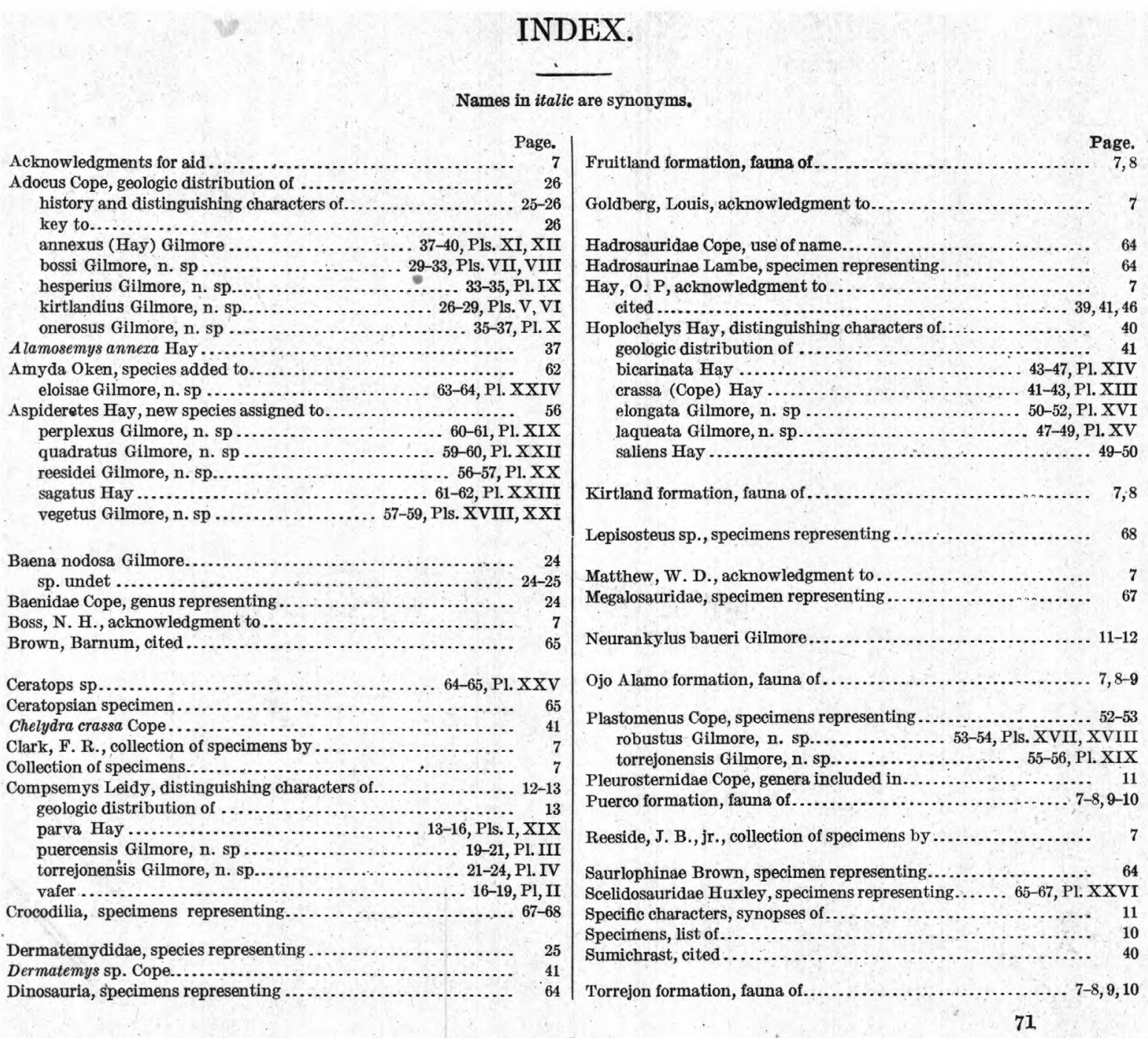



